Universidade de São Paulo

Instituto de Astronomia, Geofísica e Ciências Atmosféricas

Evandro Moimaz Anselmo

\title{
Morfologia das tempestades elétricas na América do Sul
}


Evandro Moimaz Anselmo

\section{Morfologia das tempestades elétricas na América do Sul}

Versão Corrigida. O original encontra-se disponível na Unidade.

Tese ao departamento de Ciências Atmosféricas, realizada como pré-requisito para obtenção do título de Doutor em Ciências.

Orientador:

Prof. Dr. Carlos Augusto Morales Rodriguez

Instituto de Astronomia, Geofísica e Ciências Atmosféricas da

Universidade DE SÃo PAUlo

São Paulo - SP 


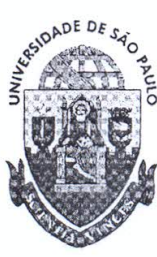

Fanus

\author{
Universidade de São Paulo
}

\title{
RELATÓRIO DE DEFESA
}

Aluno: 14133 - 7285001 - 2 / Página 1 de 1

Relatório de defesa pública de Tese do(a) Senhor(a) Evandro Moimaz Anselmo no Programa: Meteorologia, do(a) Instituto de Astronomia, Geofísica e Ciências Atmosféricas da Universidade de São Paulo.

Aos 24 dias do mês de abril de 2015, no(a) Sala 15, realizou-se a Defesa da Tese do(a) Senhor(a) Evandro Moimaz Anselmo, apresentada para a obtenção do título de Doutor intitulada:

"Morfologia das tempestades elétricas na América do Sul"

Após declarada aberta a sessão, o(a) Sr(a) Presidente passa a palavra ao candidato para exposição e a seguir aos examinadores para as devidas arguições que se desenvolvem nos termos regimentais. Em seguida, a Comissão Julgadora proclama o resultado:

\begin{tabular}{|c|c|c|c|}
\hline Nome dos Participantes da Banca & Função & Sigla da CPG & Resultado \\
\hline Carlos Augusto Morales Rodriguez & Presidente & IAG - USP & \\
\hline Rachel Ifanger Albrecht & Titular & IAG - USP & \\
\hline Paola Veronica Salio & Titular & UBA-Argent - Externo & Aproson \\
\hline Eldo Edgardo Avila & Titular & UNC-ARG - Externo & ADPROVED \\
\hline Stephen William Nesbitt & Titular & Illinois - Externo & Approved \\
\hline
\end{tabular}

Resultado Final: $A p n s / 2 d o$

1. aluno deve REflize Parecer da Comissão Julgagora *

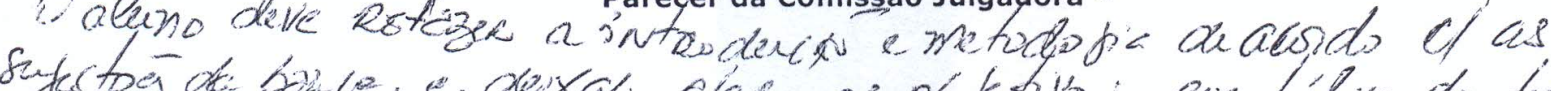

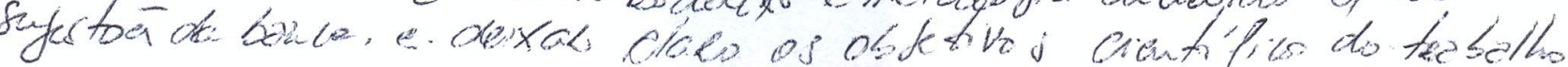
Eu, Marcel Yoshio Kimura mporturl/f , lavrei a presente ata, que assino juntamente com os(as) Senhores(as). São Paulo, aos 24 dias do mês de abril. de 2015.

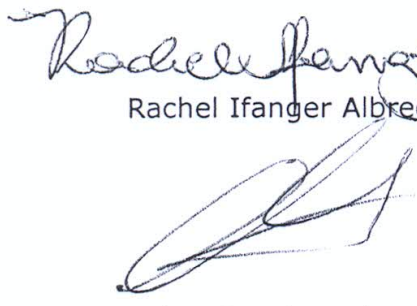

Eldo Edgardo Avila

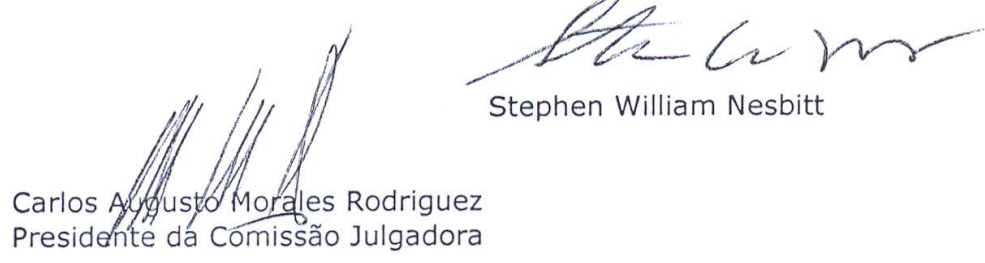

* Obs: Se o candidato for reprovado por algum dos membros, o preenchimento do parecer é obrigatório.

A defesa foi homologada pela Comissão de Pós-Graduação em 06.05206 e, portanto, o(a) aluno(a) faz jus ao título de Doutor em Ciências obtido no Programa Meteorologia.

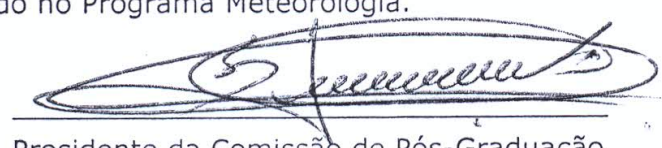

Presidente da Comissão de Pós-Graduação

\section{Prof. Dr Fdmiluon Dias de Freltas}

Prosiciente da CPG - IAG 
In memorian de Darci Priciliano Anselmo, Francisco Anselmo, Julieta Scarpin Moimaz e Dulcílio Moimaz 


\section{AGRADECIMENTOS}

A Coordenação de Aperfeiçoamento de Pessoal de Nível Superior (CAPES) e o seu Programa de Excelência Acadêmica (PROEX), ao Conselho Nacional de Desenvolvimento Científico e Tecnológico (CNPQ) e a Companhia Energética do Estado do Ceará (COELCE) PD-0039-0040/2010 pelo apoio financeiro que tornou possível a realização deste trabalho de pesquisa científica.

Ao professor Dr. Carlos Augusto Morales Rodriguez, por sua dedicação e nível de exigência/confiança com este trabalho de pesquisa.

A professora Rachel Albretch que concedeu os dados do LIS (eventos, grupos e raios), com tempo de visada com resolução de $0,25^{\circ} \times 0,25^{\circ}$ processados na NASA.

Ao professor Dr. Moacir Lacerda da UFMS que foi meu orientador durante o mestrado e me incentivou bastante a fazer o doutorado no IAG.

Ao professor Dr. Colin Price que durante sua visita no IAG, ministrou seminário, debateu a respeito deste trabalho no laboratório STORM-T indicando referencias e contribuindo com sugestões. Também ao professor Dr. Daniel Cecil que durante a sua participação no experimento CHUVA em Santa Maria, dedicou seu tempo para debater a respeito deste trabalho.

Ao João Neves, Eduardo, Vinícius e Diego por auxiliaram na manutenção da infraestrutura de pesquisa do laboratório STORM-T, ambiente aonde esse trabalho de pesquisa foi realizado.

A minha família, minha mãe Aparecida Moimaz, meu pai, Francisco Jairo Anselmo e minha irmã Minéia Moimaz Anselmo.

A todos os meteorologistas que durante o cumprimento dos créditos, me auxiliaram a estudar Meteorologia, foi uma trabalheira com Glauber, Mercel, Juliano, Rafael, Bruna, Camila, Carol, Lívia, Fabiani, Luana, Andreia, Luiz, Maria, etc.

Aos professores, e técnicos do IAG. 


\section{RESUMO}

Com base nas observações do satélite Tropical Rainfall Measuring Mission (TRMM) entre janeiro de 1998 e dezembro de 2011, foi criado um banco de dados de tempestades elétricas sobre a América do Sul $\left(10^{\circ}\right.$ Norte $-40^{\circ}$ Sul e $90^{\circ}-30^{\circ}$ Oeste). As tempestades elétricas foram definidas por regiões de pixeis contíguos com $T_{b} \leq 258 \mathrm{~K}(10,8 \mu \mathrm{m}$ do Visible and InfraRed Scanner (VIRS)) e com ocorrência de pelo menos um raio - flash - do Lightning Imaging Sensor (LIS). Definidas as distribuições espaciais das tempestades elétricas, os perfis verticais do fator de refletividade do radar $\left(Z_{c}\right)$ do Precipitation Radar (PR) foram extraídos sobre as regiões coincidentes às tempestades elétricas. A partir desta metodologia, identifica-se 157592 tempestades elétricas do TRMM, tornando possível determinar o ciclo diurno, ciclo anual, distribuição geográfica: de densidade de raios, de densidade de tempestades elétricas e da densidade de raios por tempestades sobre a América do Sul (AS). Identifica-se que a estação de tempestades elétricas na AS se configura entre outubro e março e possui dois picos: o maior pico em outubro, período de transição entre a estação seca e chuvosa (primavera), e o segundo pico em março, período também de transição, mas entre a estação chuvosa e seca (outono). A hora local de maior ocorrência de tempestades elétricas foi durante às 14h, em que a probabilidade de ocorrência de tempestade elétrica foi 5,4 vezes maior do que no horário de menor ocorrência, às $9 \mathrm{~h}$. Em termos de sazonabilidade temos a primavera com o maior número de tempestades elétricas (57 861) seguidas pelo verão (46 077), outono (36 804) e inverno (16 850). As regiões mais eficientes em termos de densidades de raios por tempestades elétricas, ficam situadas na Foz do Rio Catatumbo (pixel com $772 \mathrm{~km}^{2}$ ) com valor de 11,73 $\times 10^{-2}$ ano $^{-1} \mathrm{~km}^{-2}$, mostrando que 1256 sistemas foram responsáveis por 114333 raios ano $^{-1}$ e em seguida a Bacia do Prata e Serra de Córdoba da Argentina com valores $\simeq 5,5$ $\times 10^{-2}$ ano $^{-1} \mathrm{~km}^{-2}$. Adicionalmente, foi estudada a severidade das tempestades elétricas a partir da taxa de raios no tempo - FT - (raios $\left.\left[\mathrm{min}^{-1}\right]\right)$ e taxa de raios no tempo normalizada pela área do sistema - FTA - (raios $\left.\left[\mathrm{min}^{-1}\right]\left[\mathrm{km}^{-2}\right]\right)$ combinada com o estudo da probabilidade de ocorrência dos perfis de $Z_{c}$ por nível de altitude e nível de temperatura, sendo a altitude das observações do $\mathrm{PR}$ convertidas em níveis de temperatura a partir das reanálises do NCEP-DOE. As tempestades elétricas potencialmente severas estiveram associadas com dois grupos de eventos extremos, os com FTA entre 29,3-1258,7 $\times 10^{-4}$ raios $\mathrm{min}^{-1} \mathrm{~km}^{-2}$ e com FT entre 47,2-1283,6 raios $\mathrm{min}^{-1}$. Os sistemas com valores extremos de FTA, são mais frequentemente observados com área de 3 ordens de grandeza menor do que a área dos extremos de FT, com 70\% de área convectiva e 30\% de área estratiforme, enquanto que para os extremos de FT, $20 \%$ de fração convectiva e $75 \%$ de fração estratiforme. A análise da morfologia da estrutura tridimensional da precipitação mostra maior quantidade de água líquida super-resfriada, portanto, processo de acreção mais vigoroso nas regiões dos núcleos de raios das tempestades elétricas com extremos de FTA do que nos núcleos de raios das tempestades elétricas com extremos de FT.

Palavras-chave: raios, tempestades elétricas, TRMM, precipitação tridimensional, eletrificação de nuvens, tempo severo, rastreamento de tempestades. 


\section{ABSTRACT}

Based on observations of Tropical Rainfall Measuring Mission (TRMM) satellite between January 1998 and December 2011, a thunderstorms database on South America was created $\left(10^{\circ}\right.$ North $-40^{\circ}$ South e $90^{\circ}-30^{\circ}$ West $)$. The thunderstorms were defined by regions of contiguous pixels with $T_{b} \leq 258 \mathrm{~K}(10.8 \mu \mathrm{m}$ of Visible and InfraRed Scanner (VIRS)) with an incidence of at least one flash observed by Lightning Imaging Sensor (LIS). Defined spatial distributions of thunderstorm, the vertical profiles of radar reflectivity factor $\left(Z_{c}\right)$ of Precipitation Radar $(\mathrm{PR})$ were extracted on coincident regions. From this methodology, 157,592 thunderstorms of TRMM were identified making it possible to determine the diurnal cycle, annual cycle, geographic distribution of: flash density, thunderstorms density and flashes by thunderstorms density over America South (AS). We find that the thunderstorms season in the AS is configured between October and March and has a peak in October, the transition period between the dry and rainy season, when the highest activity was observed electrical storms and another in March, transition period between the rainy and dry season. In local time most frequent thunderstorms was during $14 \mathrm{~h}$, where the probability of thunderstorms was 5.4 times higher than in the lower occurrence in time, at $9 \mathrm{~h}$. In terms of seasonality have that spring has the highest activity of thunderstorms $(57,861)$ followed by the summer $(46,077)$, autumn $(36,804)$ and winter $(16,850)$. The most efficient regions in terms of storms by lightning densities, are located at the mouth of the Catatumbo River (pixel with $772 \mathrm{~km}^{2}$ ) in the amount of $11.73 \times 10^{-2}$ year $^{-1} \mathrm{~km}^{-2}$, showing that 1256 systems were responsible for 114,333 flashes year ${ }^{-1}$, and then the La Plata Basin and Sierra of Cordoba in Argentina with values $\simeq 5.5 \times 10^{-2}$ year $^{-1} \mathrm{~km}^{-2}$. In addition, the severity of thunderstorms was studied from flash rate in time $-\mathrm{FT}-\left(\right.$ flash $\left.\left[\mathrm{min}^{-1}\right]\right)$ and flash rate in time normalized by the system area - FTA - (flash $\left.\left[\mathrm{min}^{-1}\right]\left[\mathrm{km}^{-2}\right]\right)$ combined with the study of the probability of occurrence of profiles of $Z_{c}$ per altitude level and temperature level, and the altitude of PR observations was converted to temperature levels from the NCEP-DOE reanalysis. Potentially severe thunderstorms were associated with two groups of extreme events, with the FTA between 29.3-1258.7 $\times 10^{-4}$ flashes $\mathrm{min}^{-1} \mathrm{~km}^{-2}$ and FT between $47.2-1283.6$ flashes $\min ^{-1}$. Systems with FTA extremes values are more commonly observed with an area of 3 orders of magnitude smaller than the area of the extremes of FT with $70 \%$ of convective fraction and $30 \%$ of stratiform fraction, while for the extremes FT, $20 \%$ of convective fraction and $75 \%$ of stratiform fraction. Analysis of the morphology of the three-dimensional structure of rainfall shows greater amount of supercooled liquid water, therefore more vigorous accretion process in areas of lightning cores with FTA extreme thunderstorm than in lightning cores of thunderstorms with extreme of FT.

Key-words: lightning flashes, thunderstorms, TRMM, tree-dimensional precipitation, electrification of clouds, severe weather, storm tracking. 


\section{LISTA DE FIGURAS}

$1 \quad$ Efeitos que influenciam sobre a banda brilhante observada por radar (adap-

tada de Austin e Bemis (1950)). . . . . . . . . . . . . . . . . 28

2 Interpretação dos perfis médios de $Z$ observado pelo PR a bordo do TRMM para uma determinada tempestade elétrica. A barra de cores corresponde a temperatura de brilho em infravermelho observada pelo Visible and Infrared Scanner (VIRS). . . . . . . . . . . . . . . . . . . 30

3 Representação do tripolo eletrostático de uma tempestade elétrica. A medida de campo eletrostático na superfície (parte inferior da figura), corresponde aos centros de cargas $Q_{+}, Q_{-}$e $q_{+}$(adaptada de Ogawa|(1995)). . . 30

$4 \quad$ Estrutura elétrica de uma tempestade elétrica idealizada a partir de sondagens de campo eletrostático realizadas no interior de nuvens de tempestades (adaptada de Stolzenburg et al.[(1998)). . . . . . . . . . . . . . . . . . 30

5 Representação do processo convectivo de eletrização. . . . . . . . . . . . . 31

6 Eletrização dos hidrometeoros por processo indutivo. A ilustração representa a configuração das cargas antes e depois da colisão. . . . . . . . . . . 32

7 Sinal da carga adquirida pelo gelo durante o processo de acreção, conforme diferentes experimentos realizados em laboratório (adaptada de Saunders

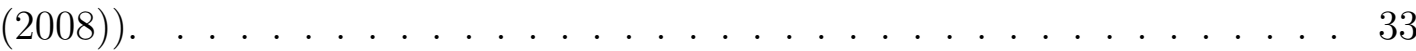

8 Ilustração do satélite TRMM e as principais características de varredura dos sensores (adaptada de Kummerow et al.[(1998)). . . . . . . . . . . . . 38

9 Ilustração do algoritmo de identificação de eventos, grupos e os raios do LIS (CHRISTIAN et al., 2000). . . . . . . . . . . . . . . . . . . . . 40 
10 Nuvem de tempestade elétrica considerada "enorme". Na parte superior e inferior da figura, há informações referentes a data e hora em que o sistema foi observado, número de raios e eventos (FL/EV), fração do sistema observado pelo PR, área do sistema (A), semieixo maior (a), menor (b), distância focal (2c) e excentricidade (e) de uma elipse ajustada às dimensões do sistema, a qual está plotada sobre a região geográfica. A barra de cores corresponde as temperaturas de brilho em infravermelho (VIRS 10,8 $\mu \mathrm{m}$ ) do topo da tempestade elétrica.

11 Número de sobrevoos do VIRS em cada ponto da grade de $0,25^{\circ} \times 0,25^{\circ}$ de latitude e longitude entre 1998-2011, ilustrando a matriz $\mathbf{V T}_{\text {virs. }}$. . . . . 45

12 Tempo de amostragem (view time) do LIS ente 1998-2011, para cada ponto da grade de $0,25^{\circ} \times 0,25^{\circ}$ de latitude e longitude, ilustrando a matriz $\mathbf{V T}_{\text {lis. }} .45$

13 Número total de raios (flashes) observados pelo LIS em cada região de $0,25^{\circ}$

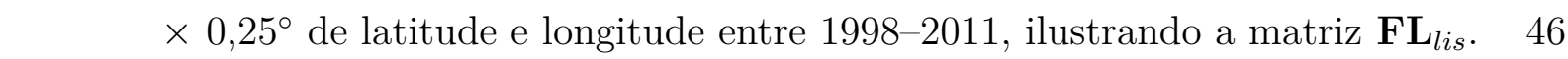

14 Número total de tempestades elétricas observadas em cada região de $0,25^{\circ}$

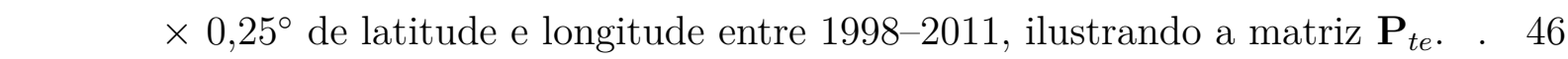

15 Ciclo diurno das tempestades elétricas observadas em hora local (HL). Os valores de probabilidade foram normalizados pelo total dos 157592 sistemas identificados . . . . . . . . . . . . . . . . 50 50

16 Ciclo diurno em hora local para as tempestades elétricas observadas em cada região de 10 por 10 graus de latitude e longitude. Os valores de probabilidade são mostrados em porcentagem e foram normalizados pelo total de 157592 sistemas observados. . . . . . . . . . . . . . . . . . . . . . 51

17 Ciclo anual das tempestades elétricas observadas em hora local. Os valores de probabilidade foram normalizados pelo total dos 157592 sistemas identificados. . . . . . . . . . . . . . . 53

18 Ciclo anual em hora local para as tempestades elétricas observadas em cada região de 10 por 10 graus de latitude e longitude. Os valores de probabilidade são mostrados em porcentagem e foram normalizados pelo total de 157592 sistemas observados. As linhas horizontais cortam o valor de 0,7 do máximo de probabilidade, utilizado como limiar para definir as estações de tempestades elétricas. . . . . . . . . . . . . . . . . . 53 
19 Distribuição de densidade anual de tempestades elétricas. As cores correspondem ao número de tempestades elétricas por passagens do VIRS por \begin{tabular}{|c|}
\hline quilômetro quadrado multiplicado por $10^{-4}\left(\left[\mathrm{~km}^{-2}\right]\right)$ em cada pronto da \\
\hline
\end{tabular} \begin{tabular}{|l}
\hline grade de $0,25^{\circ} \times 0,25^{\circ}$ de latitude e longitude. $\ldots \ldots \ldots \ldots$ \\
\hline
\end{tabular}

20 Distribuição de densidade anual de raios. As cores representam o número \begin{tabular}{|c|}
\hline de raios por ano por quilômetro quadrado $\left(\left[\mathrm{ano}^{-1}\right]\left[\mathrm{km}^{-2}\right]\right)$ em cada ponto \\
\hline
\end{tabular}

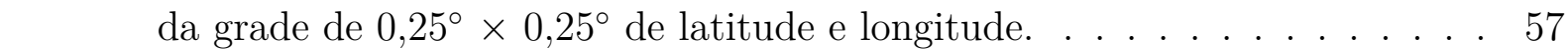

21 Distribuição de densidade sazonal de raios. As cores representam o número de raios por ano por quilômetro quadrado $\left(\left[\mathrm{ano}^{-1}\right]\left[\mathrm{km}^{-2}\right]\right)$ em cada ponto da grade de $0,25^{\circ} \times 0,25^{\circ} . \ldots \ldots \ldots$. . . . . . . . . . . 60

22 Distribuição de densidade geográfica sazonal das tempestades elétricas. \begin{tabular}{|c|c|}
\hline As cores representam o número de sistemas por órbita do TRMM por \\
\hline
\end{tabular} quilômetro quadrado $\left(\left[\mathrm{km}^{-2}\right]\right)$ em cada ponto da grade de $0,25^{\circ} \times 0,25^{\circ}$. Os valores da barra de cor devem ser multiplicados por $10^{-4}$. . . . . . . . 61

23 Distribuição de densidade de raios por tempestade elétrica. As cores representam o número de raios por tempestades elétricas multiplicado por $10^{-2}$ por ano por quilômetro quadrado $\left(10^{-2}\left[\mathrm{ano}^{-1}\right]\left[\mathrm{km}^{-2}\right]\right)$ em cada ponto da grade de $0,25^{\circ} \times 0,25^{\circ}$. . . . . . . . . . . . . . . . . . 63

24 Densidade de probabilidade de FTA e FT. . . . . . . . . . . . . . . . . 64

25 Densidade de probabilidade cumulativa de FTA e FT. . . . . . . . . . . . . 64

26 Visualização das tempestades elétricas com os maiores valores de FTA: \begin{tabular}{|c|c|}
\hline$T_{b}$ do topo da nuvem, $Z_{c}$ a $2 \mathrm{~km}$ de altitude e perfis médios de $Z_{c}$ da \\
\hline
\end{tabular} precipitação convectiva (cor vermelha), estratiforme (azul) e total (preta). . 65

27 Visualização das tempestades elétricas com os maiores valores de FT: $T_{b}$ do topo da nuvem, $Z_{c}$ a $2 \mathrm{~km}$ de altitude e perfis médios de $Z_{c}$ da precipitação convectiva (cor vermelha), estratiforme (azul) e total (preta). . . . . . . . . 66

28 Dispersão entre as áreas das tempestades elétricas e os valores de FTA e FT. As linhas horizontais marcam os valores de FTA (cor preta) e FT (cor azul) referente ao 90o percentil das respectivas amostragem. . . . . . . . . 67

29 Dispersão entre o volume de chuva das tempestades elétricas e os valores de FTA e FT. As linhas horizontais marcam os valores de FTA (cor preta) e FT (cor azul) referente ao 90ํㅜ percentil das respectivas amostragem. . . . 67 
30 Densidade de probabilidade de extensão em área das 9475 tempestades elétricas com valores extremos de FTA e das 9475 tempestades elétricas com valores extremos de FT. . . . . . . . . . . . . . . . 68

31 Densidade de probabilidade de temperatura de brilho em infravermelho \begin{tabular}{|c|}
\hline (VIRS $10,8 \mu \mathrm{m})$ do topo das nuvens das 9475 tempestades elétricas com \\
\hline
\end{tabular} \begin{tabular}{|c|}
\hline valores extremos de FTA e das 9475 tempestades elétricas com valores \\
\hline
\end{tabular}

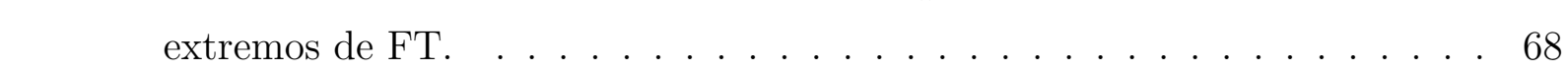

32 Densidade de probabilidade das frações de áreas de chuva das tempestades elétricas extremas de FTA, que foram classificadas (2A23) como convectiva (vermelha), estratiforme (bege) e outros (verde), em relação a toda a área de chuva observada pelo PR; das frações de chuva total (preta), que correspondem às frações das áreas de chuva observadas pelo PR em relação a $A_{t}$

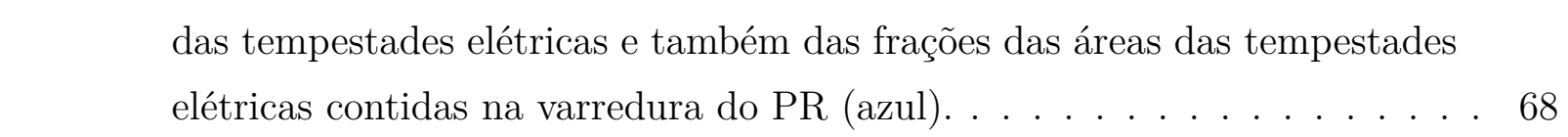

33 Densidade de probabilidade cumulativa das frações de áreas de chuva das

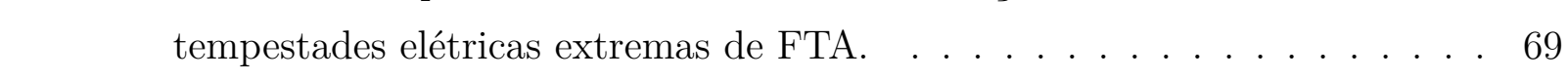

34 Densidade de probabilidade das frações de áreas de chuva das tempestades \begin{tabular}{|c|}
\hline elétricas extremas de FT, que foram classificadas (2A23) como convectiva \\
\hline (vermelha),
\end{tabular} (vermelha), estratiforme (bege) e outros (verde), em relação a toda a área de chuva observada pelo PR; das frações de chuva total (preta), que correspondem às frações das áreas de chuva observadas pelo PR em relação a $A_{t}$ das tempestades elétricas e também das frações das áreas das tempestades elétricas contidas na varredura do PR (azul). . . . . . . . . . . . . . 69

35 Densidade de probabilidade cumulativa das frações de áreas de chuva das

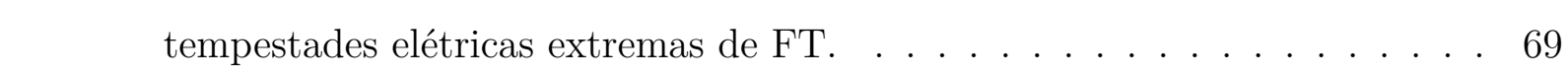

$36 \quad$ Núcleos de raios das tempestades elétricas. Os pontos "."na cor verde são os \begin{tabular}{|c|}
\hline eventos e os símbolos de positivo "+"na cor preta são os raios. Os pixeis em \\
\hline vermelho são as regiões dos núcleos de raios, definidas a partir da projeção
\end{tabular} \begin{tabular}{l}
\hline vermelho são as regióes dos núcleos de raios, definidas a partir da projeção \\
\hline dos eventos em uma grade regular de $0,05^{\circ}$. . . . . . . . . . . . . 70
\end{tabular}

37 CFADs para os extremos de FTA. Porção da precipitação sem raios. . . . . 71

38 CFADs para os extremos de FT. Porção da precipitação sem raios. . . . . . . 72

39 CFADs para os extremos de FTA. Porção da precipitação com raios. . . . . 73 
40 CFADs para os extremos de FT. Porção da precipitação com raios. . . . . 74

41 CCFDs para os extremos de FTA. Porção da precipitação sem raios. . . . . 77

42 CCFDs para os extremos de FT. Porção da precipitação sem raios. . . . . 78

43 CFTDs para os extremos de FTA. Porção da precipitação com raios. . . 81

44 CCFTDs para os extremos de FTA. Porção da precipitação com raios. . . . 82

45 CFTDs para os extremos de FT. Porção da precipitação com raios. . . . . 83

46 CCFTDs para os extremos de FT. Porção da precipitação com raios. .. . 84

47 Região central da Bacia do Rio Amazonas, entre 10-0S e 70-60W. . . . . . . 85

48 Quadrante que abrange a região central da Bacia do Rio da Prata, entre $30^{\circ}-20^{\circ}$ Sul e $60^{\circ}-50^{\circ}$ Oeste. . . . . . . . . . . . . . . . . . . . . 88

49 Distribuição geográfica dos valores do 95o percentil da amostra de probabilidade do índice FTA a cada região de 2,5 por 2,5 graus de latitude e longitude. . . . . . . . . . . . . . . . . . . 89

50 Distribuição geográfica dos valores do 99ํㅜ percentil da amostra de probabilidade do índice FTA a cada região de 2,5 por 2,5 graus de latitude e longitude. . . . . . . . . . . . . . . . . . . 89

51 Distribuição geográfica dos valores do $95^{\circ}$ percentil da amostra de probabilidade do índice FT a cada região de 2,5 por 2,5 graus de latitude e longitude. . . . . . . . . . . . . . . . . . . . 89

52 Distribuição geográfica dos valores do 99o percentil da amostra de probabilidade do índice FT a cada região de 2,5 por 2,5 graus de latitude e longitude. . . . . . . . . . . . . . . . . . . 90 


\section{LISTA DE TABELAS}

$1 \quad$ Principais parâmetros do sinal eletromagnético transmitido e recebido pelo PR (adaptada de Kummerow et al.[(1998), NASDA](2001)). . . . . . . . . . 38

2 Canais do VIRS e objetivos das medidas de radiância espectral conforme cada comprimento de onda $(\lambda)$ (adaptada de Kummerow et al. [1998),

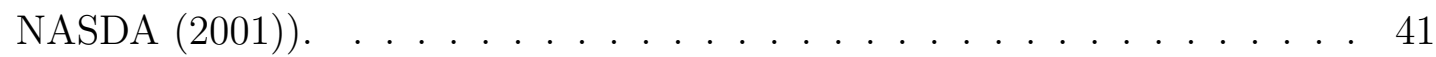

3 Variáveis dos produtos do TRMM que foram utilizadas na identificação e descrição das tempestades elétricas. . . . . . . . . . . . . . . . . . . . . 42

4 Principais características do ciclo anual de probabilidade de ocorrência de tempestades elétricas observadas entre 1998-2011, em cada região de 10 por 10 graus de latitude longitude. . . . . . . . . . . . . . . . . . . . 54

5 Total de tempestades elétricas observadas entre 1998-2011, para cada período de três meses associados as estações do ano. . . . . . . . . . . . . . . . . . 59 


\section{SUMÁRIO}

\begin{tabular}{ll}
\hline LISTA DE SÍMBOLOS & 18
\end{tabular}

\begin{tabular}{lll}
\hline & INTRODUÇÃO & 21
\end{tabular}

1.1 INTENSIDADE CONVECTIVA E A PRECIPITAÇÃO OBSERVADA POR RADAR . . . . . . . . . . . . . . . . . 25

1.2 TEORIAS DE ELETRIFICAÇÃO DAS NUVENS . . . . . . . . . . . . . . 30

1.2 .1 Eletrificação por Convecção . . . . . . . . . . . . . . . . . . . . . . 31

1.2 .2 Eletrificação por Precipitação . . . . . . . . . . . . . . . . . . . . 32

1.3 PROPOSTA $\ldots \ldots \ldots \ldots \ldots \ldots \ldots$

\begin{tabular}{lll}
\hline 2 & DADOS E METODOLOGIA & 37
\end{tabular}

2.1 O SATÉLITE TRMM . . . . . . . . . . . . . . . . 37

2.1 .1 Radar de Precipitação . . . . . . . . . . . . . . . . . . 38

2.1 .2 Sensor imageador de raios . . . . . . . . . . . . . . . . . . . . 39

2.1 .3 Radiômetro no visível e infravermelho . . . . . . . . . . . . . . . . . 41

2.2 REANÁLISES (R2) DO NCEP-DOE . . . . . . . . . . . . . . . . 41

2.3 DADOS $\ldots \ldots \ldots \ldots \ldots$

2.4 TEMPESTADES ELÉTRICAS $\ldots \ldots \ldots \ldots$. . . . . . . . . . . . . . . 42

2.5 SEVERIDADE: TAXA DE RAIOS . . . . . . . . . . . . . . . . . . . . 44

2.6 DISTRIBUIÇÕES GEOGRÁFICAS DE DENSIDADES . . . . . . . . . . 45

2.7 MORFOLOGIA DA ESTRUTURA TRIDIMENSIONAL DA PRECIPITAÇÃO 47

2.7 .1 Distribuições de probabilidades com a altitude . . . . . . . . . . . . 48 
$2.7 .2 \quad$ Distribuições de probabilidades em função da temperatura . . . . . 48

3 MARCO DAS TEMPESTADES ELÉTRICAS NA AMÉRICA DO SUL 50

3.1 CICLO DIURNO $\ldots \ldots \ldots \ldots \ldots \ldots$

3.2 CICLO ANUAL . . . . . . . . . . . . . . . . . . . 52

$3.3 \quad$ DISTRIBUIÇÃO DE DENSIDADES GEOGRÁFICAS . . . . . . . . . . . 56

4 TEMPESTADES ELÉTRICAS SEVERAS

4.1 ÁREA E TEMPERATURA DO TOPO DA NUVEM . . . . . . . . . . . 66

4.2 SEVERIDADE COM BASE NA ESTRUTURA 3D DA PRECIPITAÇÃO 70

$4.2 .1 \quad$ A precipitação 3D e o perfil atmosférico de temperatura. . . . . . . 79

4.3 SEVERIDADE REGIONALIZADA $\ldots \ldots \ldots \ldots \ldots$

$\begin{array}{lll}5 & \text { CONCLUSÃO } & 91\end{array}$

5.1 MARCO DAS TEMPESTADES ELÉTRICAS . . . . . . . . . . . . . . . . 92

5.2 TEMPESTADES ELÉTRICAS SEVERAS . . . . . . . . . . . . . . . . . 94

5.3 IMPLICAÇÕES PARA A ELETRIFICAÇÃO DAS NUVENS . . . . . . . 97

\begin{tabular}{ll}
\hline REFERENNCIAS & 98
\end{tabular}

$\begin{array}{ll}\text { Índice Remissivo } & 107\end{array}$ 


\section{LISTA DE SIGLAS E ABREVIATURAS}

AS

CAPE Energia potencial convectiva, do inglês, Convective Available Potential Energy

CCFAD Diagramas de Contorno de Frequência Cumulativa por Altitude, do inglês, Contour Cumulative Frequency by Altitude Diagram

CCFTD Diagrama de Contorno de Frequência Cumulativa por Temperatura, do inglês, Contour Cumulative Frequency by Temperature Diagram

CFAD Diagrama de Contorno de Frequência por Altitude, do inglês, Contour Frequency by Altitude Diagram

CFTD Diagrama de Contorno de Frequência por Temperatura, do inglês, Contour Frequency Temperature Diagram

DJF Dezembro, janeiro e fevereiro

DMSP Defense Meteorological Satellite Program observations

GOES Geostationary Operational Environmental Satellite

HL Hora local

JAXA Japan Aerospace Exploration Agency

JJA Junho, julho e agosto 
LIS Sensor imageador de raios, do inglês Lightning Imaging Sensor.

LIS Sensor imageador de raios

MAM Março, abril e maio

NASA National Aeronautics and Space Administration

NCEP National Centers for Environmental Prediction

NCEP-DOE National Centers for Environmental Prediction - Department of Energy

NCEP-NCAR National Centers for Environmental Prediction - National Center for Atmospheric Research

OSO Orbiting Solar Observatory

PCT Polarization Corrected Temperature

PFs Precipitation Features

PR Precipitation Radar

PRF Frequência de repetição do pulso, do inglês Pulse Repetition Frequency

R1 Reanálises do NCEP-NCAR

R2 Reanálises 2 do NCEP-DOE

SCM Sistema Convectivo de Meso-escala

SIRT Sferics Infrared Rainfall Technique

SMAS Sistema de Monção da América do Sul

SON Setembro, outubro e novembro

STARNET Sferics Timing and Ranging Network

TMI TRMM Microwave Imager

TRMM Tropical Rainfall Measuring Mission 
VIRS

Radiômetro no visível e infravermelho, do inglês Visible and InfraRed Scanner 


\section{LISTA DE SÍMBOLOS}

\begin{tabular}{|c|c|}
\hline$A_{t}$ & Área da tempestade elétrica \\
\hline$D_{h}$ & Diâmetro do hidrometeoro \\
\hline$F T$ & Taxa de raios por tempo [raios minuto $\left.^{-1}\right]$ \\
\hline$F T A$ & $\begin{array}{l}\text { Taxa de raios por tempo por área } \\
{\left[\text { raios } \mathrm{dia}^{-1} \mathrm{~km}^{-2}\right]}\end{array}$ \\
\hline$M_{h}$ & Massa do hidrometeoro \\
\hline$N_{f l}$ & Número de flashes \\
\hline$P_{r}$ & Potência recebida \\
\hline$R_{h}$ & Raio do hidrometeoro \\
\hline$T_{b}$ & Temperatura de brilho \\
\hline$V T_{m}$ & Tempo médio de visada do LIS \\
\hline$Z$ & Fator de refletividade do radar \\
\hline$Z_{c}$ & Fator de refletividade corrigido \\
\hline$Z_{m}$ & $\begin{array}{l}\text { Fator de refletividade sem correção de ate- } \\
\text { nuação e ground clutter }\end{array}$ \\
\hline$\Delta V$ & $\begin{array}{l}\text { Elemento de volume }(\Delta V) \text { iluminado pelo ra- } \\
\text { dar }\end{array}$ \\
\hline$\alpha$ & Parâmetro de tamanho \\
\hline$\eta$ & Refletividade do Radar \\
\hline$\lambda$ & Comprimento de onda \\
\hline $\mathbf{D E}_{r t}$ & Matriz de densidade de raios por tempestades \\
\hline $\mathbf{V} \mathbf{T}_{l i s}$ & $\begin{array}{l}\text { Matriz do tempo total da visada do sensor LIS } \\
\text { sobre a superfície }\end{array}$ \\
\hline$\pi$ & $\begin{array}{l}\text { Relação entre o perímetro e o diâmetro da cir- } \\
\text { cunferência }\end{array}$ \\
\hline$\rho$ & Densidade \\
\hline$\sigma$ & Seção de retroespalhamento \\
\hline$|K|$ & Grandeza relacionada ao índice de refração \\
\hline${ }^{\circ} \mathrm{C}$ & Grau Celsius \\
\hline$f$ & Distância focal \\
\hline$f(x)=?$ & Função de uma variável \\
\hline
\end{tabular}


$\begin{array}{ll}f_{c d f}(x, y) & \text { Função densidade de probabilidade cumula- } \\ & \text { tiva com duas variáveis } \\ f_{p d f}(x, y) & \text { Função densidade de probabilidade com duas } \\ & \text { variáveis } \\ \% & \text { Nos diagramas, CFAD, CCFAD, CFTD e }\end{array}$ CCFTD, representam: a porcentagem de perfis convectivos, estratiformes e outros, respectivamente

A Angstron

2c Distância focal

A Nas figuras que ilustram as tempestades elétricas, refere-se à área total $\left(A_{t}\right)$ da tempestade elétrica.

a Semieixo maior

b Semieixo menor

e Excentricidade

$\mathrm{H}$ Nos diagramas, CFAD, CCFAD, CFTD e CCFTD, representam: o nível de altitude, em quilômetros, onde ocorreu o máximo de ocorrências de $Z_{c}$

L Nos diagramas, CFAD, CCFAD, CFTD e CCFTD, representam: o número de ocorrência de $Z_{c}$ no nível de altitude de máxima ocorrência

N Nos diagramas, CFAD, CCFAD, CFTD e CCFTD, representam: o número de tempestades elétricas computadas 
P Nos diagramas, CFAD, CCFAD, CFTD e CCFTD, representam: número de perfis do PR computados

R Taxa de precipitação 


\section{INTRODUÇÃO}

Desde Whipple (1929), ao associar medidas de campo eletrostático com as observações meteorológicas de superfície dos dias com tempestades elétricas, verifica-se que a América, África e Continente Marítimd ${ }^{1}$ são as chaminés de descargas elétricas atmosféricas - raios - globais. Em 1929 já se observava que a maior intensificação do campo elétrico de bom tempo está relacionada à atividade de tempestades elétricas sobre a América do Sul (AS). Apesar da Teoria do Circuito Elétrico Atmosférico Global mostrar que a América é a chaminé dominante no processo de manutenção do circuito elétrico atmosférico global, não era possível saber se a maior intensidade do campo eletrostático estava associada com uma maior taxa de raios (DOLEZALEK, 1972).

Os estudos de Vorpahl (1967), Sparrow e Ney (1970), utilizando imagens dos satélites Orbiting Solar Observatory (OSO) e de Turman (1978), com satélite do Defense Meteorological Satellite Program observations (DMSP), foram importantes para o entendimento da atividade elétrica atmosférica global com base na frequência de ocorrência de raios e não na frequência global de dias de tempestades elétricas como descrito em Brooks (1925). Com o uso do sensor de raios Supplementary Sensor L (SSL 2 ) a bordo do DMSP 8531, Turman (1978) calculou a taxa de raios total - raios intranuvens e nuvem-solo conjuntamente - por unidade de área de um complexo de tempestades $\left(4 \times 10^{-5} \mathrm{~s}^{-1} \mathrm{~km}^{-2}\right)$ e a taxa de raios total por unidade de área observada pelo SSL $\left(6 \times 10^{-8} \mathrm{~s}^{-1} \mathrm{~km}^{-2}\right)$, equivalente a uma taxa de raios global de $31 \mathrm{~s}^{-1}$, valor menor do que estimado em Brooks (1925), de $100 \mathrm{~s}^{-1}$.

Em Orville e Spencer (1979), a taxa de raios global foi calculada e obtidos valores correspondentes com os estimados por Brooks (1925). Orville e Spencer (1979) obtiveram pela primeira vez a taxa de raios global para cada mês do ano, proporcionando uma

\footnotetext{
${ }^{1}$ Região da Indonésia que abrange o Sudeste da Ásia, Filipinas e Papua-nova Guiné (RAMAGE, 1968 NEALE; SLINGO, 2003).

${ }^{2}$ Composto por uma matriz de $3 \times 4$ (12) fotodiodos de silício $(0,4-1,1 \mu \mathrm{m}$, com pico de resposta em $0,8 \mu \mathrm{m})$ capazes de contar os brilhos transientes associados a ocorrência de raios a cada segundo. Devido a altitude de $830 \mathrm{~km}$ da órbita do DMSP 8531, a matriz de fotodiodos do SSL possuiu um campo de visada aproximadamente $2200 \mathrm{~km} \times 3000 \mathrm{~km}$.
} 
compreensão sobre a sazonalidade da taxa de raios global. Constatou-se que a taxa de raios total sobre o continente era entre 8-20 vezes maior do que sobre o oceano e que durante o verão do hemisfério Norte a taxa de raios global era 1,4 vezes maior do que durante o verão do hemisfério Sul.

Considerando observações mais recentes de raios total, como em (CHRISTIAN et al., 2003), que utilizaram dados Optical Transient Detector (OTD) a bordo do satélite MicroLab-1, estimou-se que a taxa de raios na média anual sobre o oceano era de $5 \mathrm{~s}^{-1}$, sobre as regiões continentais entre $31-49 \mathrm{~s}^{-1}$ e a média anual da taxa de raios global de $44 \pm 5 \mathrm{~s}^{-1}$. Por meio de mapas da distribuição da densidade geográfica de raios, verificouse que as maiores extensões em área com as maiores ocorrências de raios por quilômetro quadrado por ano ficavam situadas sobre o continente Americano e Africano, sendo a Bacia do Rio Congo a região mais extensa com as maiores taxas de raios do globo. Atualmente, com as observações do OTD e do Lightning Imaging Sensor (LIS) a bordo do satélite Tropical Rainfall Measuring Mission (TRMM) estima-se uma taxa de raios global de 46 $\mathrm{s}^{-1}$ e o local com a maior densidade de raios anual global é a região oeste do Congo com $160 \mathrm{~km}^{-2}$ ano $^{-1}$ (CECIL et al., 2014).

Williams e Sátori (2004) buscaram entender a maior resposta da Curva de Carnegie associada ao horário de maior atividade de tempestades elétricas sobre a América fazendo um estudo comparativo entre as regiões da Bacia Amazônica e Bacia do Congo. Sobre a bacia hidrográfica congolesa, a taxa de raios por $\mathrm{km}^{2}$ por ano são maiores enquanto que os sistemas precipitantes sobre a Bacia Amazônica possuem menor densidade de raios, porém maior volume de chuva. Com base nas observações de Soula et al. (2003), Williams e Sátori (2004) sugerem que a chuva eletricamente carregada sobre a Bacia Amazônica pode funcionar como um processo de carregamento da superfície terrestre com cargas negativas, ou seja, pode funcionar como bateria do Circuito Elétrico Global.

Apesar da contribuição meridional na média anual da taxa de raios global ser liderada pelo continente Africano, durante o inverno e a primavera austral da América as taxas de raios são maiores sobre a América (CHRISTIAN et al., 2003). Em Albrecht et al. (2011), a partir de treze anos de dados do LIS, foi constatado que o local da maior densidade anual de raios global estava na região do Lago Maracaibo na Venezuela, sugerindo uma mudança do máximo de densidade de raios do Congo para o Lago Maracaibo.

Portanto no contexto das medidas globais de raios, a América do Sul encontra-se em um dos locais mais eletricamente ativos do globo. Saber quando e onde as tempestades elétricas ocorrem, bem como, quais os locais em que os sistemas são mais eficientes na 
produção de raios, torna-se fundamental para o planejamento da infraestrutura dos países sul-americanos, no sentido de garantir segurança no transporte aéreo, fluvial e terrestre, nas linhas de transmissão de dados e de energia elétrica, etc, setores estratégicos que quando paralisados devidos aos danos causados pela queda de raios refletem em prejuízos em cascata em todos os setores econômicos.

Por exemplo, uma falha no sistema de distribuição de energia elétrica pode cessar a energia elétrica de um bairro, cidade, etc. Pode causar queima de equipamentos eletroeletrônicos devido sobre tensão elétrica, quedas na rede de internet, o que pode paralisar setores como: educação, pesquisa, comércio e industrias. Também gera grande número de ações judiciais indenizatórias contra as operadoras do sistema de energia, sobrecarregando o sistema judiciário. No Brasil, as empresas prestadoras de serviços de fornecimento de energia elétrica ao consumidor lideram as reclamações nos PROCONs ao lado de empresas de telecomunicações, evidenciando a falta de infraestrutura destes setores (G1, 2014b; G1, 2014a FOLHA, 2015, FOLHA, 2012, PROCON-SP, 2014). Em Pinto Jr. (2005), INPE (2007), estimam-se prejuízos na ordem de 1 bilhão de dólares anuais em função da densidade de raios observada apenas sobre o Brasil.

Além dos raios que atingem o solo - raios nuvem-solo - causando danos à sociedade, as tempestades elétricas indicam condições dinâmicas e termodinâmicas associadas à convecção profunda na atmosfera, pois o processo de eletrificação dos hidrometeoros relacionado com a formação de um raio depende da capacidade do ar quente e úmido da superfície romper a estabilidade atmosférica e atingir altitude entre 4-15 km, regiões acima da isoterma de $0{ }^{\circ} \mathrm{C}$ (DOSWELL, 2001; ZIPSER et al., 2006). Por exemplo, MacGorman et al. (1989), Carey e Rutledge (1998), Gatlin e Goodman (2010), Schultz et al. (2011) e Williams et al. (1999) mostram que condições de tempo severo (frentes de rajadas com velocidade superior a $92,6 \mathrm{~km} \mathrm{~h}^{-1}$, queda de granizo com diâmetro maior do que $1,9 \mathrm{~cm}$ ou tornados) são geralmente precedidas de um salto na taxa de raios total das tempestades elétricas associado ao intenso crescimento de hidrometeoros na região mista.

Neste sentido, técnicas de seleção de sistemas meteorológicos a partir de dados de sensoriamento remoto combinadas com as medidas da taxa de raios, são de grande importância para o monitoramento de tempo severo.

Diversos estudos definiram sistemas meteorológicos fazendo o agrupamento de regiões na superfície a partir de limiares de temperatura de brilho observadas em satélite. Maddox (1980) observou a ocorrência de duas regiões: uma com temperatura de brilho $\leqslant$ $-32{ }^{\circ} \mathrm{C}(241 \mathrm{~K})$ e área $\geqslant 100000 \mathrm{~km}^{2}$; outra região menor, no interior da região maior, 
com temperatura de brilho $\leqslant-52{ }^{\circ} \mathrm{C}(221 \mathrm{~K})$ e área $\geqslant 50000 \mathrm{~km}^{2}$, que estavam associadas com Sistemas Convectivos de Meso-escala (SCM) nos Estados Unidos. Mapes e Houze Jr. (1993) utilizaram esta metodologia e também fazem uma síntese de trabalhos que buscaram selecionar clusters de nuvens a partir de limiares de temperatura de brilho em infravermelho. Considerando monitoramento de sistemas sobre a AS, destaco os estudos de Machado et al. (1998), Laurent et al. (2002) que foram precursores para a operacionalização do sistema ForTraCC descrito em Vila et al. (2008).

Em termos do monitoramento de sistemas juntamente com a taxa de raios, Morales e Anagnostou (2003) desenvolveram o Sferics Infrared Rainfall Technique (SIRT), um algoritmo hidroestimador a partir do estudo de regiões com temperatura de brilho em infravermelho do Geostationary Operational Environmental Satellite (GOES) coincidentes com medidas de raios da Sferics Timing and Ranging Network (STARNET) e a precipitação observada pelo Precipitation Radar (PR) a bordo do satélite TRMM. Os dados da STARNET foram utilizados para definir clusters de nuvens com raios e sem raios, em que os raios estiveram associados aos núcleos mais intensos de precipitação. Foi observado que as descargas localizadas pela STARNET, em 90\% dos casos, estiveram associados a regiões com temperatura de brilho em infravermelho menores do que $258 \mathrm{~K}$.

Em Houze Jr. (1993), Linhas de Instabilidades (LI) foram definidas observando extensões com chuva contínua observada por radar. Em Mohr e Zipser (1996), Sistemas Convectivos de Meso-escala sobre os trópicos foram observados a partir do espalhamento radiativo em micro-ondas ( $85 \mathrm{GHz}$ Polarization Corrected Temperature (PCT)), em que regiões contínuas $\geqslant 2000 \mathrm{~km}^{2}$ com $\mathrm{PCT} \leqslant 250 \mathrm{~K}$ foram os principais critérios para a identificação dos sistemas.

Combinando dados do PR e o TRMM Microwave Imager (TMI) abordo do satélite TRMM, Nesbitt et al. (2000) desenvolveram uma metodologia para selecionar sistemas precipitantes denominados como Precipitation Features (PFs), em que o principal critério de seleção foi identificar a área contínua de chuva na superfície, seja estimada pelas medidas de refletividade do radar $\mathrm{PR}$ ou pelo espalhamento radiativo em micro-ondas registrado pelo TMI, quando os sistemas possuíram extensão maior do que a varredura do PR. A partir desta metodologia, Cecil et al. (2005) mostraram que apenas 2,4\% das PFs observadas pelo TRMM em todo globo entre 12/1997-10/2000 possuíram atividade elétrica, e para a AS, as PFs classificadas como as mais intensas e consequentemente com as maiores taxas de raios, concentraram-se na região da Bacia do Prata.

Mais tarde, Zipser et al. (2006) utilizou medidas dos sensores do TRMM associadas 
à intensidade convectiva das PFs, estimando os locais das tempestades elétricas mais severas do globo. Apenas em 0,1\% da amostragem das PFs (período de 7 anos) foram observadas taxa de raios acima de $32,9 \mathrm{~min}^{-1}$. Entre as regiões do globo com as maiores concentrações de PFs que indicaram valores extremos (0,001\%), seja de taxa de raios, seja de mínimas temperaturas de brilho (85 e $37 \mathrm{GHz}$ ) ou de máxima altitude com 40 dBZ de fator de refletividade do radar, encontra-se a região Sul da AS que engloba a Bacia do Prata e o extremo Norte da Cordilheira dos Andes que abrange a Colômbia e região do Lago Maracaibo na Venezuela.

Com base em estudos a respeito da severidade dos sistemas como em Doswell (2001), Brooks et al. (2003), Zipser et al. (2006), em que as medidas associadas à intensidade convectiva indicaram os locais com condição de tempo severo, o estudo da morfologia da estrutura tridimensional da precipitação observadas pelo PR associado com a taxa de raios observada pelo LIS pode esclarecer informações a respeito da intensidade convectiva, de modo a verificar a relação entre a taxa de raios e a severidade dos sistemas.

\subsection{INTENSIDADE CONVECTIVA E A PRECIPITAÇÃO OBSERVADA POR RA- DAR}

A Refletividade do Radar $(\eta)$

$$
\eta=\sum_{i=1,2,3 \ldots}^{\Delta V} \sigma_{i}
$$

é o somatório da seção de retroespalhamento $(\sigma)$ dos hidrometeoros $(i)$ contidos em um elemento de volume $(\Delta V)$ iluminado - gate - do feixe do radar (BATTAN, 1973).

Considerando que o parâmetro de tamanho $(\alpha)$, dado pela relação

$$
\alpha=\frac{2 \pi R_{h}}{\lambda}
$$

em que $R_{h}$ é o raio do hidrometeoro e portanto, $2 \pi R_{h}$ representa a área da seção transversal do hidrometeoro precipitável na atmosfera e $\lambda$ o comprimento de onda emitido pelo radar. Quando $\alpha<<1$, o espalhamento da radiação eletromagnética pelas partículas será do tipo Rayleigh. Neste caso, a seção transversal de retroespalhamento $\sigma$ pode ser escrita como

$$
\sigma=\frac{\lambda^{2} \alpha^{6}}{\pi}|K|^{2}
$$

em que $|K|^{2}$ corresponde ao índice de refração dos hidrometeoros. Como a equação 2 depende do raio do hidrometeoros $R_{h}$, podemos reescrever a equação 3 considerando o 
diâmetro

$$
D_{h}=2 R_{h}
$$

Então, substituindo as equações 2 e 4 em 3 , obtemos que

$$
\sigma=\frac{\pi^{5} K^{2}}{\lambda^{4}} D_{h}^{6}
$$

Considerando o hidrometeoro como esférico, podemos relacionar o $D_{h}$ com a sua quantidade de massa, sendo

$$
D_{h}=\left(\frac{6 M_{h}}{\pi \rho}\right)^{\frac{1}{3}},
$$

em que, $\rho$ é a densidade e $M_{h}$ a massa do hidrometeoro.

Então substituindo a equação 6 em 5 , obtém-se

$$
\sigma=\frac{36 \pi^{3}|K|^{2}}{\lambda^{4} \rho^{2} M_{h}^{2}}
$$

Portanto, observe que a Refletividade do Radar $\eta$ (equação 1) depende de uma relação entre quantidade de massa $M_{h}$, densidade $\rho$ e também do índice de refração $|K|^{2}$ dos hidrometeoros, conforme mostra a equação 7. Entretanto, o radar mede apenas a potência do sinal retroespalhado $\left(P_{r}\right)$. Logo, pode-se ter uma ideia da concentração de obstáculos espalhadores, porém não podemos ter certeza a respeito da massa, índice de refração e densidade dos alvos.

O que se faz para estimar a chuva é considerar que todos os alvos associados ao espalhamento do feixe do radar são gotas de água líquida esféricas.

Neste caso, podemos combinar as equações 1 e 5 , obtendo $\eta$ em função do Fator de Refletividade do radar $(Z)$, em que

$$
\eta=\frac{\pi^{5}|K|^{2}}{\lambda^{4}} \sum_{i=1,2,3 \ldots}^{\Delta V} D_{h_{i}}^{6}
$$

sendo

$$
Z=\sum_{i=1,2,3 \ldots}^{\Delta V} D_{h_{i}}^{6},
$$

o Fator de Refletividade do Radar.

Conforme a equação do radar descrita em Battan (1973), cada medida de $P_{r}$ depende de parâmetros fixos como ganho da antena, potência do sinal transmitido, largura de pulso, efeito de lóbulo, comprimento de onda e ângulo sólido associado ao feixe emitido. 
Considerando que todas as constantes que envolvem a equação do radar equivalem a $C$ e $r$ sendo a distância entre o radar e o alvo espalhador, temos que a cada gate do radar, $P_{r}$ será

$$
P_{r}=C \frac{|K|^{2}}{r^{2}} Z .
$$

Desta maneira, a partir da $P_{r}$ medida pelo radar, sabendo a distância $r$ do alvo e considerando que a chuva é composta de esferas de água líquida $\left(\left|K_{\text {agua }}\right|^{2}=0,931\right)$, podemos determinar $Z$, pois

$$
Z=\frac{P_{r} r^{2}}{C|K|^{2}} .
$$

Conforme mostra a equação $9, Z$ depende de $D_{h}$ que está associado com a massa ou o volume de chuva pela equação 6 .

No entanto, ao observar o perfil vertical do Fator de Refletividade do Radar $Z$, verificase que o feixe atinge regiões na atmosfera com temperaturas abaixo de $0{ }^{\circ} \mathrm{C}$. Nestes casos, a potência $P_{r}$ estará também associada ao espalhamento em gelo de nuvem ao invés de apenas água líquida. Também, mesmo sabendo as distâncias $r$ dos alvos espalhadores, não podemos afirmar sobre a temperatura da atmosfera para cada distância $r$ do radar, se haverá água super-resfriada acima da isoterma de $0{ }^{\circ} \mathrm{C}$ ou haverá granizo caindo abaixo da isoterma de $0{ }^{\circ} \mathrm{C}$. Então, os dados brutos das observações de radar consideram $|K|^{2}$ como constante, geralmente $\left|K_{\text {agua }}\right|^{2}=0,931$.

Aplicando $10 \log _{10}$, na equação 11, e assumindo $\left|K_{\text {agua }}\right|^{2}=0,931$ e $\left|K_{\text {gelo }}\right|^{2}=0,197$, para uma mesma medida de $P_{r}$, as diferenças observadas nos valores de $Z$ em dB irão corresponder a

$$
\begin{aligned}
& d B Z_{\text {agua }}-d B Z_{\text {gelo }}=10 \log _{10}\left(\left|K_{\text {gelo }}\right|^{2}\right)-10 \log _{10}\left(\left|K_{\text {agua }}\right|^{2}\right) \\
& d B Z_{\text {agua }}-d B Z_{\text {gelo }}=-6,7 d B Z,
\end{aligned}
$$

mostrando que devido ao índice de refração do gelo ser menor do que o índice de refração da água $\left(\left|K_{\text {agua }}\right|^{2}>\left|K_{\text {gelo }}\right|^{2}\right)$, ao considerar $\left|K_{\text {agua }}\right|^{2}$ em regiões que os hidrometeoros estão congelados, haverá uma redução de 6,7 dBZ em relação à considerar $\left|K_{\text {gelo }}\right|^{2}$.

Nas observações de $Z$ no perfil vertical, a região ou camada de derretimento do gelo é bastante marcada, pois haverá uma redução de $\simeq 7 \mathrm{dBZ}$ em regiões acima da isoterma de $0{ }^{\circ} \mathrm{C}$ devido ao congelamento dos hidrometeoros, enquanto que logo abaixo da isoterma de $0{ }^{\circ} \mathrm{C}$, haverá um aumento de $Z$ devido ao derretimento dos hidrometeoros. Conforme descrevem Austin e Bemis (1950), quando há derretimento de flocos de neve no perfil atmosférico, observa-se um aumento da Refletividade - $\eta$ - logo abaixo da isoterma de 
$0{ }^{\circ} \mathrm{C}$ denominado como banda brilhante e que este aumento de $\eta$ pode não estar associado apenas com a mudança da constante dielétrica do gelo para água líquida, mas conforme ilustra a figura 1 processos de colisão-coalescência causam um efeito de aumento contínuo da refletividade abaixo do nível de congelamento e o aumento da velocidade terminal das gotas favorece as rupturas e a evaporação, causando redução dos diâmetros das gotas e consequentemente diminuindo $\eta$, fatores estes que irão influenciar sobre a banda brilhante observada por radar.

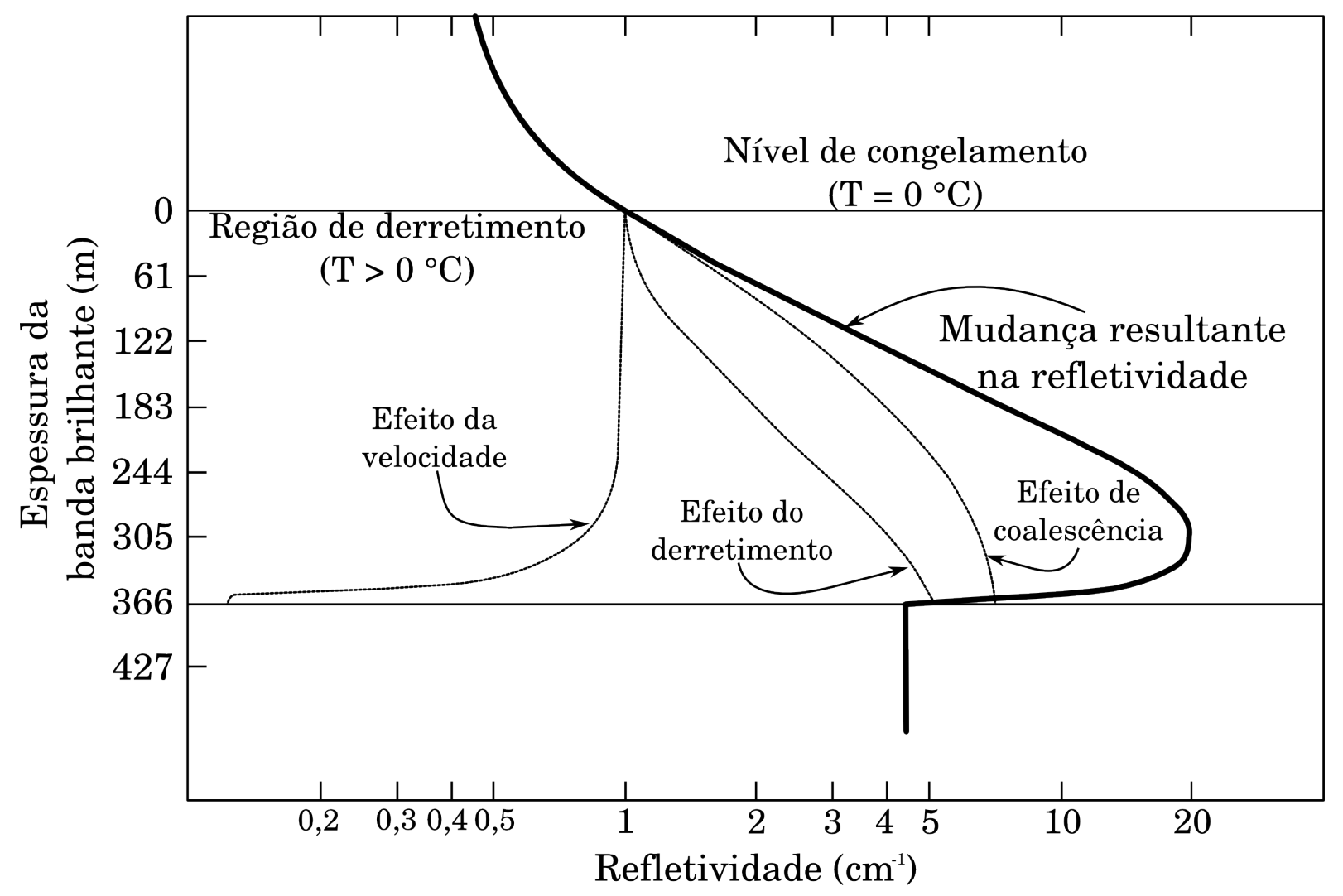

Figura 1: Efeitos que influenciam sobre a banda brilhante observada por radar (adaptada de Austin e Bemis (1950)).

Estes efeitos sobre o perfil de $Z$ na região de derretimento foram explorados em Fabry e Zawadzki (1995) para identificar processos de agregação, acreção e colisão coalescência, observados a partir de flutuações nos valores de $Z$ acima e abaixo do nível de congelamento, pois acima do nível de congelamento, um aumento nos valores de $Z$ conforme sugere a curva da figura 1 referente ao efeito de coalescência, pode estar associado a processos de crescimento de cristais de gelo, flocos de neve (agregação) e granizo (acreção), sendo que abaixo do nível de derretimento, as flutuações de $Z$ foram associadas à colisãocoalescência, rupturas e evaporação das gotas.

Em Fabry e Zawadzki (1995), os processos de crescimentos de hidrometeoros também foram estudados a partir da espessura da camada de derretimento, pois está relacionada 
com o lapse-rate da atmosfera (AUSTIN; BEMIS, 1950; MASON, 1971, p. 462). Em uma atmosfera instável, com convecção profunda e precipitação convectiva, a camada de transição de fase de gelo para a água liquida é perturbada por correntes ascendentes. A mudança do índice de refração da água não ocorre apenas logo abaixo de $0{ }^{\circ} \mathrm{C}$, pois no ambiente convectivo teremos água super-resfriada em temperaturas de $-15{ }^{\circ} \mathrm{C}$, o que intensifica o processo de acreção podendo gerar granizo que cai derretendo até a superfície. Nestes casos espera-se uma camada de derretimento mais espessa, sem a definição da banda brilhante.

Considerando um regime de precipitação estratiforme, que é governado por processos de agregação, será observada a banda brilhante e uma camada de derretimento menos espessa, pois os flocos de neve possuem velocidade terminal e densidade inferior ao granizo/saraiva e o graupel, portanto, percorrem um caminho menor até o derretimento (FABRY; ZAWADZKI, 1995).

Estes efeitos no perfil de $Z$ refentes aos processos de formação dos hidrometeoros e que dependem da intensidade convectiva do ambiente são ilustrados de maneira sintética na figura 2. A partir de um sistema de tempestade observado pelo TRMM, podemos analisar a média dos perfis estratiformes (menor intensidade convectiva) e a média dos perfis convectivos (maior intensidade convectiva) separadamente, identificando os principais processos de nuvem descritos nesta sessão. 


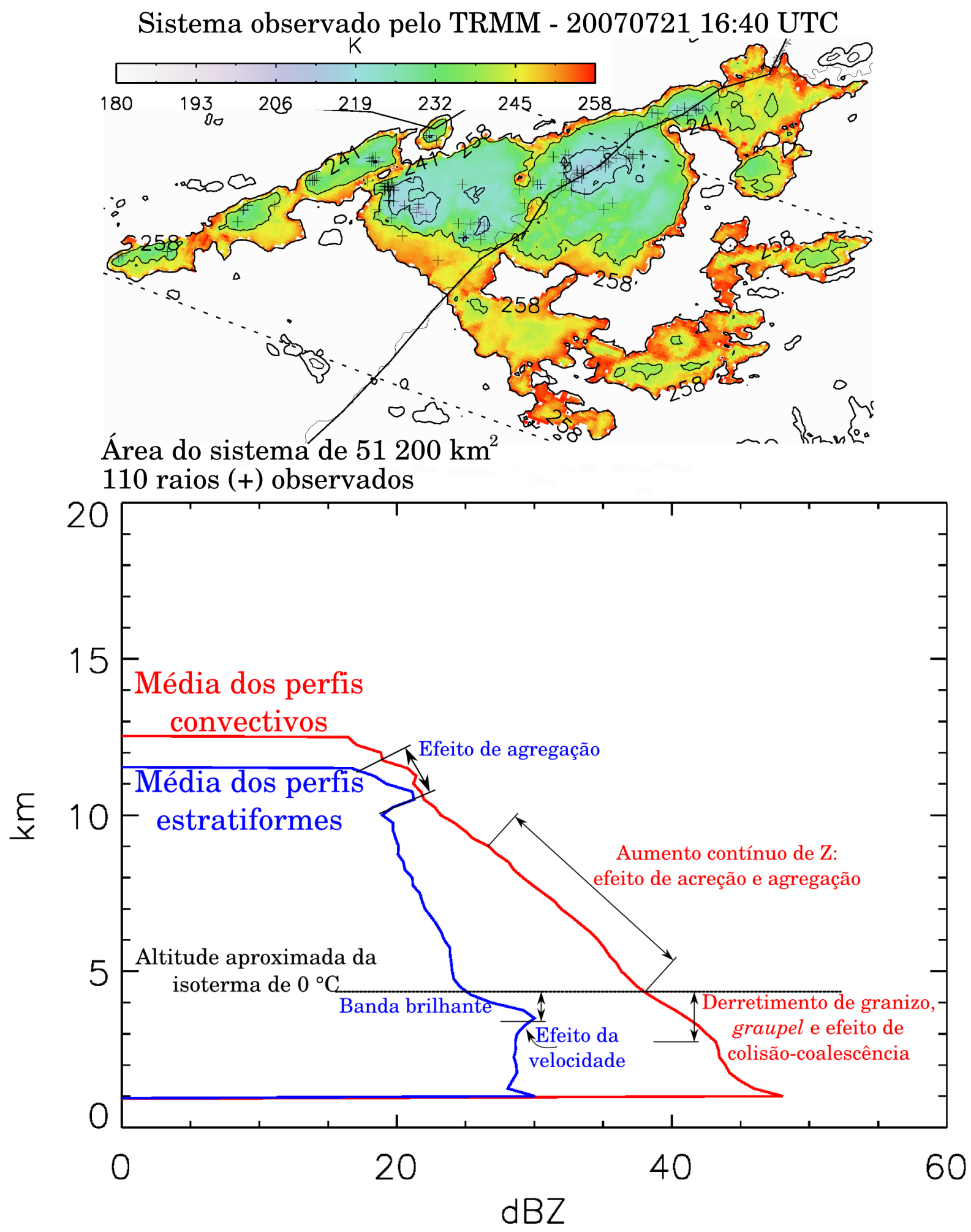

Figura 2: Interpretação dos perfis médios de $Z$ observado pelo PR a bordo do TRMM para uma determinada tempestade elétrica. A barra de cores corresponde a temperatura de brilho em infravermelho observada pelo Visible and Infrared Scanner (VIRS). 


\subsection{TEORIAS DE ELETRIFICAÇÃO DAS NUVENS}

Os processos de eletrificação das nuvens são intrínsecos ao processo de desenvolvimento da precipitação, especialmente em regiões com temperaturas entre $-5^{\circ} \mathrm{C} \mathrm{e}-40{ }^{\circ} \mathrm{C}$, portanto, está fortemente relacionado ao crescimento do gelo de nuvem (MASON, 1953).

A partir de medidas em superfície, observa-se que os campos eletrostáticos produzidos pelas tempestades elétricas são da ordem de dezenas de milhares de volts por metro, que correspondem a centros de cargas nas nuvens com dezenas de coulombs. Williams (1989) mostra uma síntese de trabalhos com medidas de campo eletrostático de tempestades elétricas no período entre 1752 e 1989 relatando que na maioria das observações a curva de campo elétrico observada correspondia com a perturbação causada por uma estrutura tripolar de cargas nas nuvens, havendo um centro de carga positivo na parte superior, um centro de carga negativo na região central e um centro de carga positivo menos intenso na base da nuvem conforme mostra a figura 3.

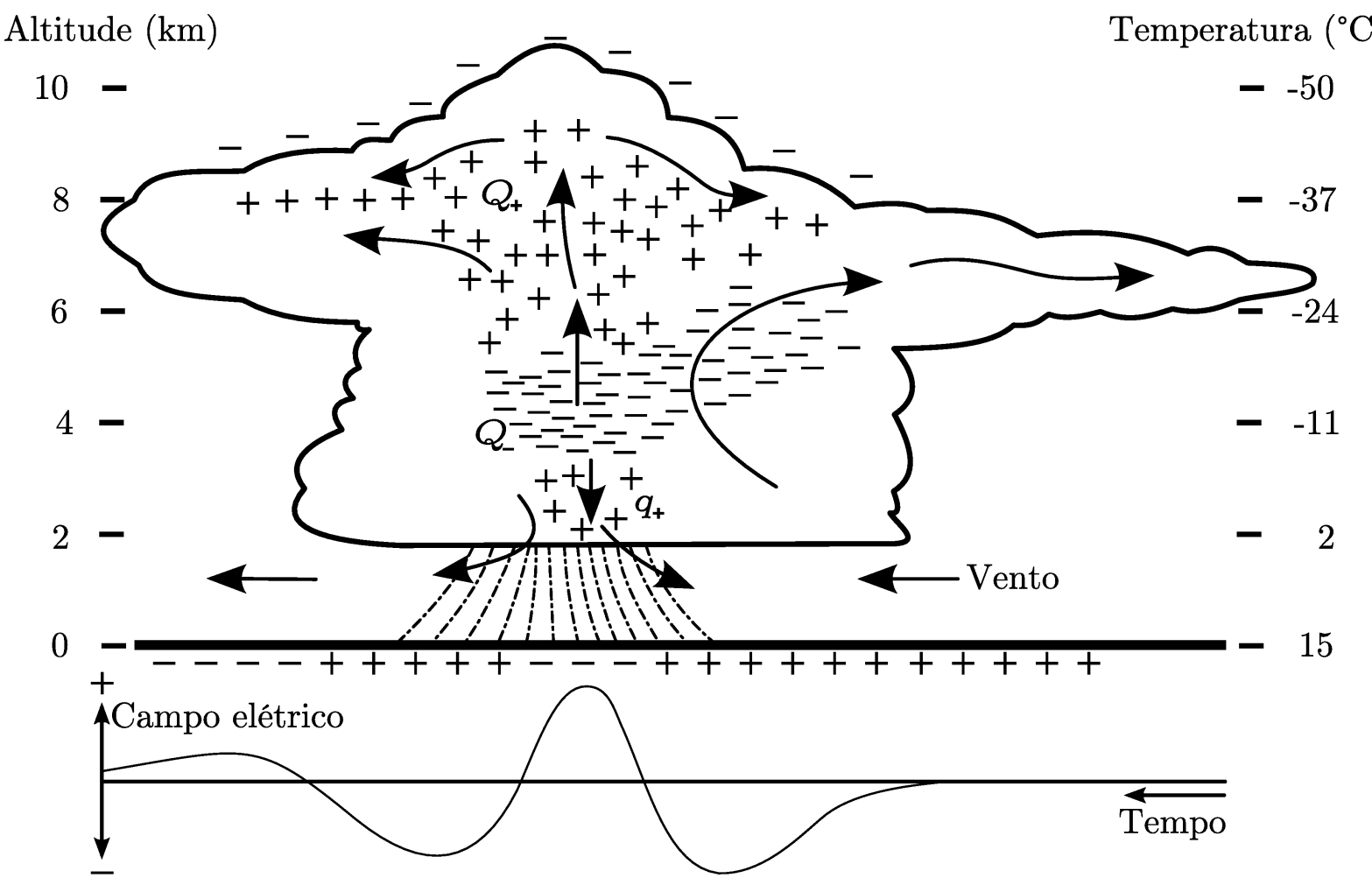

Figura 3: Representação do tripolo eletrostático de uma tempestade elétrica. A medida de campo eletrostático na superfície (parte inferior da figura), corresponde aos centros de cargas $Q_{+}, Q_{-}$e $q_{+}$(adaptada de Ogawa (1995)).

Mesmo que o modelo do tripolo eletrostático proposto por Williams (1989) seja uma teoria condizente com a estrutura de cargas dominante em uma tempestade elétrica, considerando sondagens de campo elétrico no interior das tempestades Rust e Marshall (1996) 
verificam que os centros de cargas podem estar distribuídos de maneira mais complexa. Stolzenburg et al. (1998) criou um modelo conceitual para a estrutura de cargas das tempestades elétricas exposto na figura 4 , sugerindo que nas regiões onde ocorrem ventos ascendentes pode haver 4 ou mais centros de carga enquanto as regiões com correntes descendentes, 6 ou mais centros de cargas.

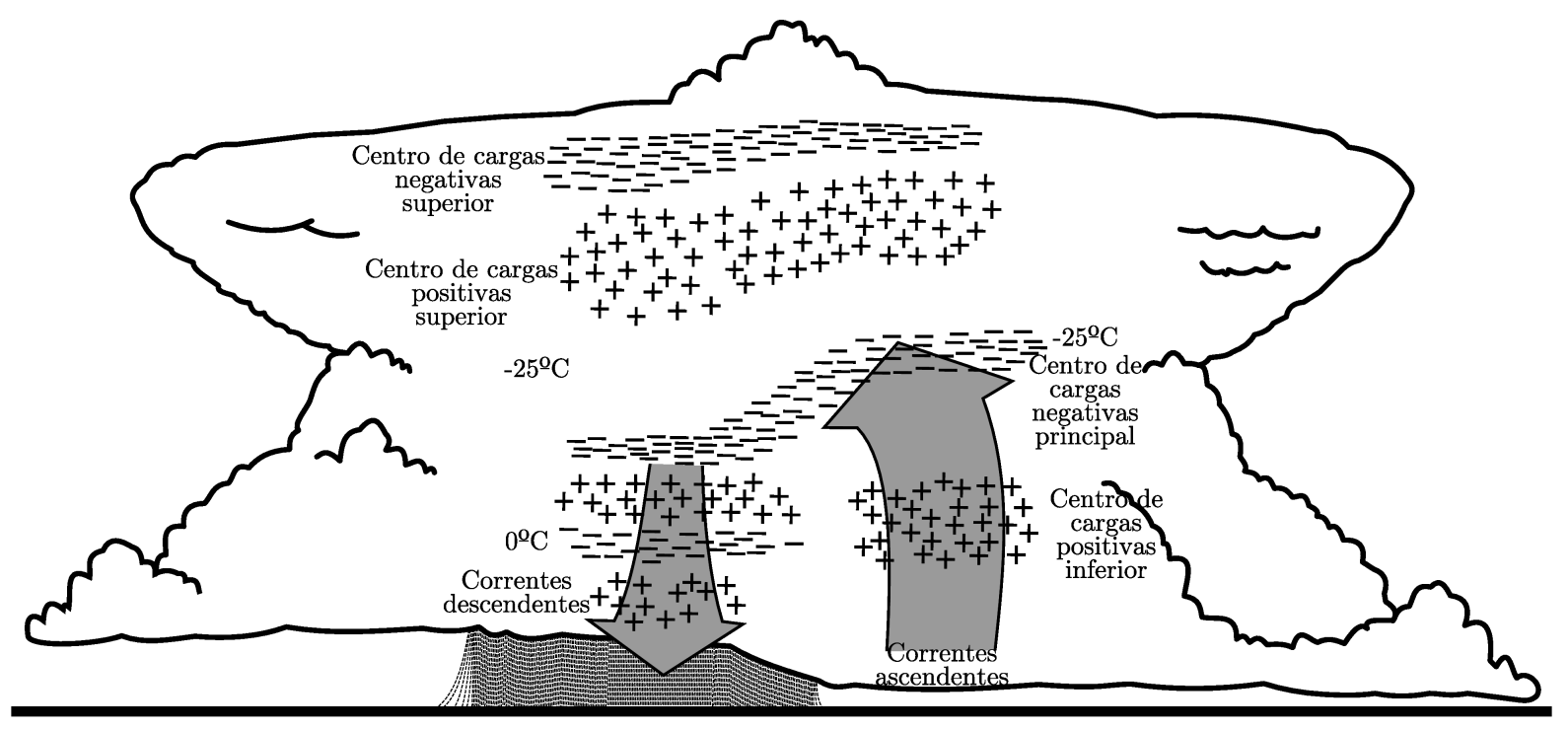

Figura 4: Estrutura elétrica de uma tempestade elétrica idealizada a partir de sondagens de campo eletrostático realizadas no interior de nuvens de tempestades (adaptada de Stolzenburg et al. (1998)).

De modo a explicar os intensos campos elétricos associados às nuvens de tempestades elétricas e o confinamento dos centros de cargas em regiões com temperaturas entre $-5{ }^{\circ} \mathrm{C}$ e $-40^{\circ} \mathrm{C}$, as teorias de eletrificação de hidrometeoros podem ser divididas em duas grandes frentes teóricas: Eletrificação por Convecção e a Eletrificação por Precipitação.

\subsubsection{Eletrificação por Convecção}

Pressupõe-se que as cargas elétricas são geradas por fontes externas às nuvens, associadas a ionização de moléculas do ar atmosférico por átomos radioativos na superfície terrestre ou por radiação cósmica (WILSON, 1956, GRENET, 1947; VONNEGUT et al., 1962; PHILLIPS, 1967).

Devido a esta distribuição de íons livres na atmosfera, o campo elétrico de bom tempo atrai os íons positivos para próximo à superfície terrestre e quando há rompimento da estabilidade atmosférica, o movimento ascendente transporta os íons positivos próximos a superfície terrestre para o interior das nuvens, como ilustrado na figura 5a. Conforme a nuvem se desenvolve verticalmente, íons negativos são atraídos pelas cargas positivas 
introjetadas na nuvem tornando o seu topo negativamente carregado, como ilustra a figura 5b. Com o acúmulo de íons negativos no topo das nuvens e a atuação de correntes descendentes, ocorre estranhamento lateral das cargas negativas do topo da nuvem concentrando regiões de cargas negativas próximas a base da nuvem nas regiões laterais e intensificando a atração de íons positivos a partir da superfície, como ilustra a figura $5 \mathrm{c}$ (VONNEGUT et al., 1962; WAGNER; TELFORD, 1981; VONNEGUT et al., 1995).

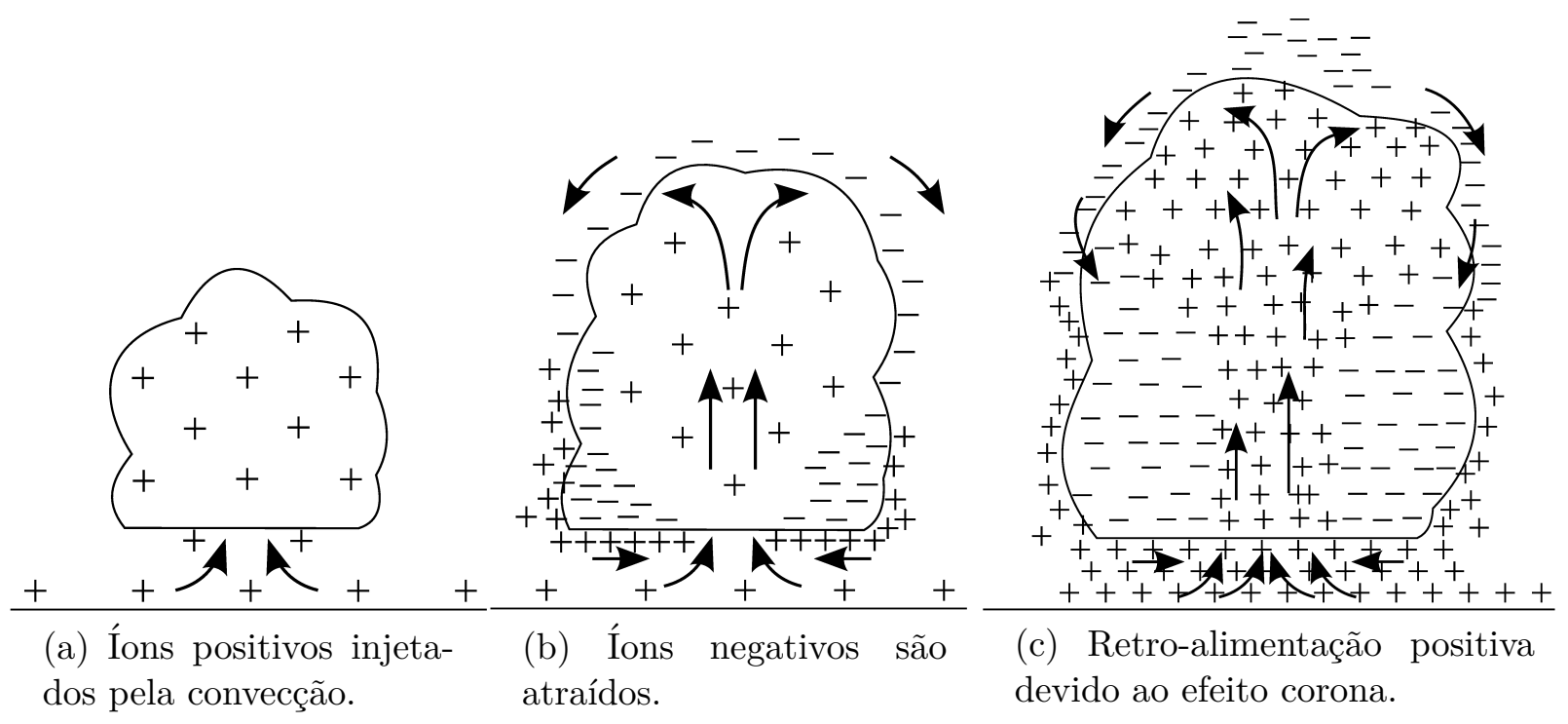

Figura 5: Representação do processo convectivo de eletrização.

Phillips (1967) e Vonnegut (1991) mostram evidências que comprovam a participação da Eletrização por Convecção na eletrificação das nuvens de tempestades elétricas. Porém verifica-se que a disponibilidade de íons da atmosfera não é suficiente para proporcionar centros de cargas tão intensos conforme se observa nas medidas de campo eletrostático.

\subsubsection{Eletrificação por Precipitação}

A Teoria de Eletrificação por Precipitação sugere que os processos de eletrização das nuvens estão associados com a formação e interação entre os hidrometeoros e as propriedades físicas da água. É o mecanismo mais aceito para explicar a estrutura dos centros de cargas observados nas tempestades elétricas conforme as observações em Stolzenburg et al. (1998) e Williams (1989), pois sugere que uma região de centro de carga é definida a partir da sedimentação de uma população de partículas com quantidade de massa equivalentes, pois passaram por condições de crescimento semelhantes, adquirindo uma mesma polaridade elétrica.

Durante o processo de crescimento de hidrometeoros de nuvem, poderá haver trans- 
ferência de cargas entre os mesmos, especialmente quando há colisões em que o tempo de colisão é pequeno, gerando fricção e se houver rupturas de gotas ou de cristais de gelo (LENARD, 1892; REYNOLDS et al., 1957; MATTHEWS; MASON, 1964; JONAS; MASON, 1968, SIMPSON, 1909). Durante o crescimento e as colisões dos hidrometeoros, a eletrificação poderá ocorrer por Processo Indutivo ou Processo Não-indutivo.

\section{Processo indutivo}

Ocorre quando há colisões entre os hidrometeoros e não ocorre coalescência ou acreção portanto, torna-se mais provável na colisão entre o graupe $3^{3}$ e cristais de gelo.

As colisões ocorrem sobre a influência de um campo elétrico E já existente na nuvem, provocando a polarização do graupel e dos cristais de gelo conforme na figura 6, para situação antes da colisão. Depois da colisão conforme mostra a ilustração na figura 6 , cargas são transferidas, tornando o graupel carregado com carga negativa e os cristais de gelo com carga positiva ou falta de elétrons.
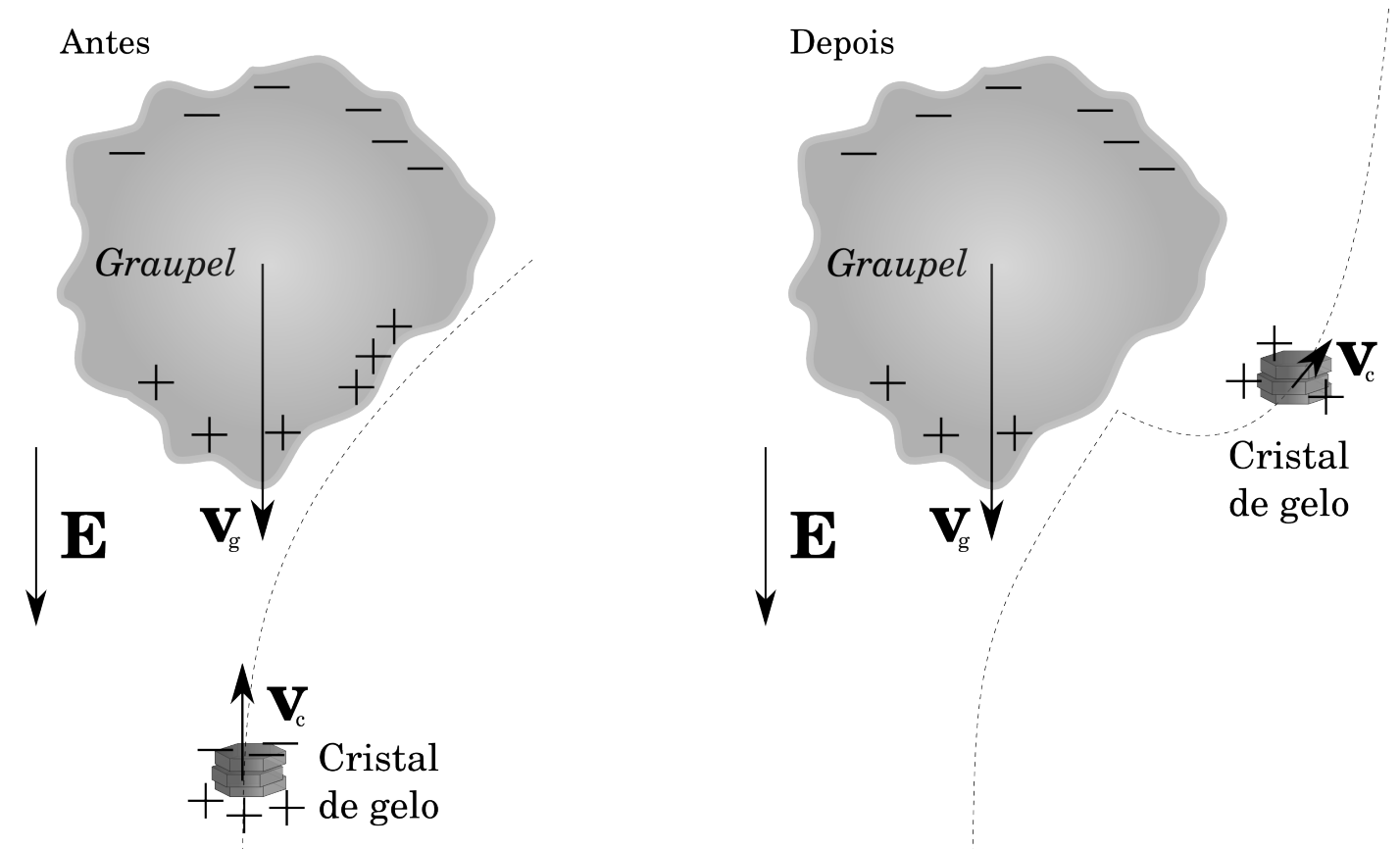

Figura 6: Eletrização dos hidrometeoros por processo indutivo. A ilustração representa a configuração das cargas antes e depois da colisão.

Porém, MacGorman e Rust (1998) apontam que a intensidade do campo elétrico de bom tempo não possui intensidade suficiente para polarizar as partículas de gelo de nuvem.

\footnotetext{
${ }^{3}$ Granizo com diâmetro menor que $2 \mathrm{~mm}$.
} 
Então, o processo de colisão indutivo deve ocorrer após um mecanismo de eletrização nãoindutivo promover um campo elétrico $\mathbf{E}$ no interior da nuvem.

\section{Processo não-indutivo}

Conforme diversos estudos dos mecanismos de eletrificação de nuvem realizados em laboratórios que buscaram recriar as condições atmosféricas relacionadas ao crescimento dos hidrometeoros, foi constatado que o carregamento não-indutivo depende: do tamanho dos hidrometeoros, do conteúdo de água líquida dentro da nuvem, da temperatura e da velocidade de impacto entre os hidrometeoros (REYNOLDS et al., 1957; TAKAHASHI, 1978; BAKER; DASH, 1994; SAUNDERS et al., 1999; PEREYRA et al., 2000). Em Takahashi (1978) e Takahashi e Miyawaki (2002), descreve-se que o mecanismo mais eficiente de eletrização dos hidrometeoros envolve a colisões entre o graupel/granizo com neve seca.

No trabalho de Saunders (2008) são expostos alguns dos principais resultados de experimentos de laboratório que investigaram a carga, positiva ou negativa, adquirida pelo graupel durante o processo de acreção em função da temperatura e o conteúdo de água líquida. Na figura 7 , podemos observar diferentes curvas que marcam a fronteira entre o carregamento positivo e negativo do graupel. Apesar de diferenças entres as curvas, que são associadas às diferentes características das câmaras de nuvens que cada autor utilizou, observa-se que em temperaturas mais altas do que $-10{ }^{\circ} \mathrm{C}$, o carregamento é positivo, para temperaturas mais baixas do que $-10{ }^{\circ} \mathrm{C}$ o carregamento é negativo, e que o aumento da taxa de acreção pode tornar o carregamento positivo do graupel em regiões com temperaturas abaixo de $-10{ }^{\circ} \mathrm{C}$.

Considerando o estudo de Faraday (1859), observa-se que em temperaturas logo abaixo de $0{ }^{\circ} \mathrm{C}$, partículas de gelo podem possuir uma camada de água líquida super-resfriada com aproximadamente $10 \AA$. Neste ambiente, segundo Fletcher (1968), as moléculas de água tendem a orientar a parte negativa do seu dipolo elétrico permanente para a superfície da água, em contato com o ar. Esse efeito também pode ser observado em partículas de gelo derretendo em temperaturas logo acima de $0{ }^{\circ} \mathrm{C}$, conforme sugerido em Fletcher (1968).

No trabalho de Baker et al. (1987), observa-se que a camada de água líquida superresfriada sobre o gelo, também denominada como camada de água quase-líquida, pode crescer/diminuir por difusão de vapor, e que se a taxa de difusão de vapor for maior sobre a camada quase-líquida do que sobre a porção de gelo, a partícula de gelo adquiri carga positiva e quando a taxa de difusão de vapor é maior sobre o gelo do que sobre a camada 


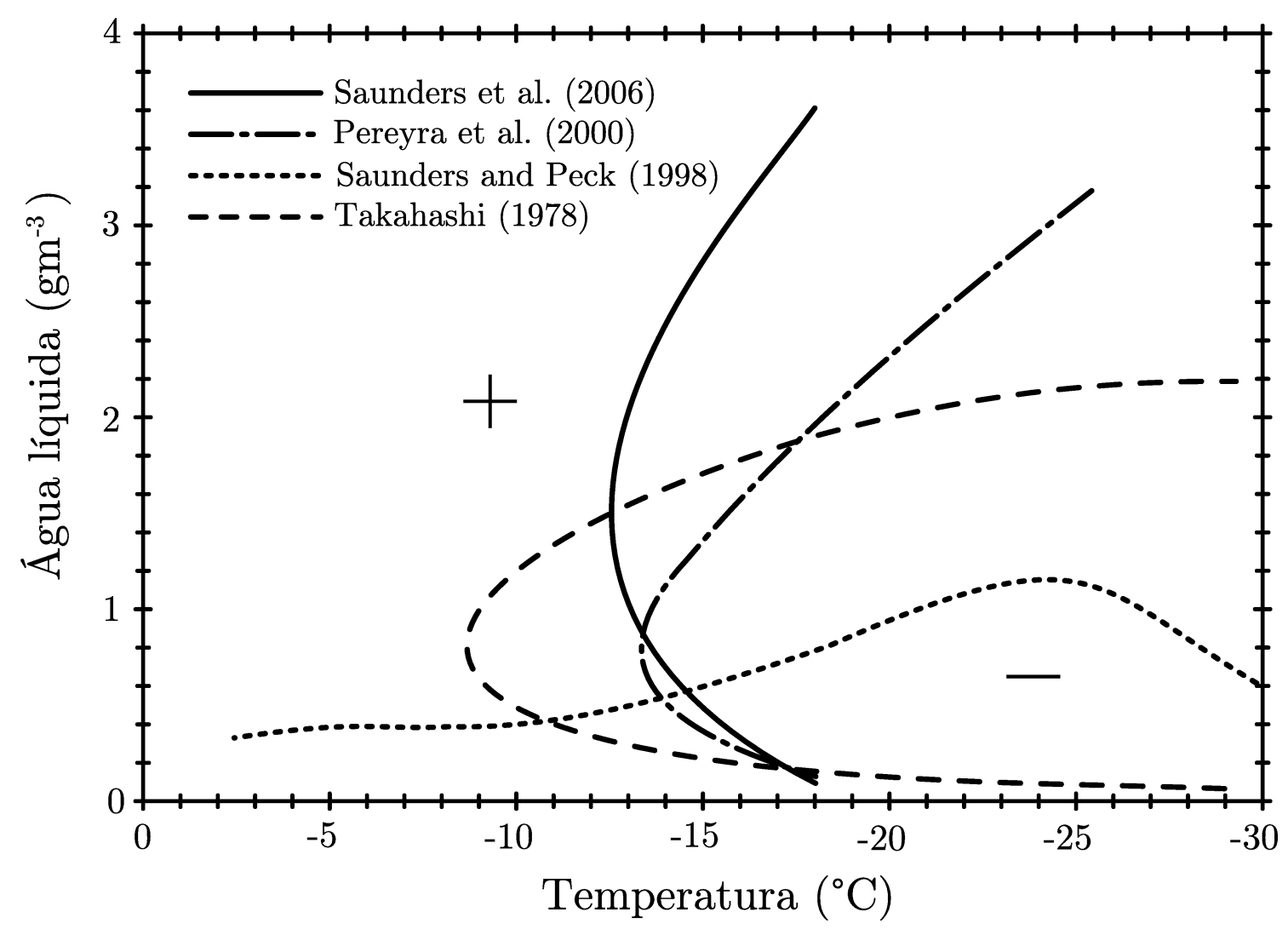

Figura 7: Sinal da carga adquirida pelo gelo durante o processo de acreção, conforme diferentes experimentos realizados em laboratório (adaptada de Saunders (2008)).

de água quase-líquida, a carga adquirida pelo gelo é negativa. Também é constatado que as partículas de gelo que possuem esta camada de água quase-líquida, ao colidirem com outras partículas podem trocar massa e carga entre si, sendo que, geralmente as partículas com maior quantidade de água líquida transferem massa para as partículas com menor quantidade de água quase-líquida (BAKER; DASH, 1994).

O efeito termoelétrico no gelo também contribui para a eletrização das partículas de gelo sob a influência de gradientes de temperatura, pois há dissociação da água em frações com dimensões moleculares das partículas de gelo, gerando disponibilidade de íons de $\mathrm{H}^{+}$ e $\mathrm{OH}^{-}$. Como a mobilidade do íon de hidrogênio é maior do que da hidroxila devido ao peso molecular, nas regiões mais quentes ocorre maior difusão de íons de hidrogênio deixando maiores concentrações de hidroxilas $\left(\mathrm{OH}^{-}\right)$sobre o gelo, portanto proporcionando o carregamento negativo de determinada porção da partícula de gelo e aumentando a disponibilidade de íons positivos $\left(\mathrm{H}^{+}\right)$no ambiente de nuvem (LATHAM; MASON, 1961). 


\subsection{PROPOSTA}

A condição de tempo severo em Brooks et al. (2003), tratada em termos da ocorrência de granizo, rajadas de ventos e ocorrência de tornados, foi diagnosticada a partir de observações e variáveis meteorológicas associadas com a intensidade convectiva. No entanto, os estudos de MacGorman et al. (1989), Carey e Rutledge (1998), Gatlin e Goodman (2010), Schultz et al. (2011), Williams et al. (1999) e Cecil et al. (2005) buscaram encontrar relações entre a taxa temporal de raios dentro das tempestades elétricas com a ocorrência de tempo severo e observaram que os lightning jumps precediam a ocorrência de eventos de tempo severo em algumas situações.

Por outro lado, as tempestades potencialmente severas foram identificadas e estudadas em Zipser et al. (2006) por meio do banco de dados das FPs desenvolvido em Nesbitt et al. (2000), enquanto que os estudos de Albrecht et al. (2011), Christian et al. (2003) e Cecil et al. (2014) concentraram-se em descrever somente a distribuição de densidade geográfica de raios sobre globo.

A intensidade convectiva das PFs em Cecil et al. (2005), Zipser et al. (2006) e Rasmussen e Houze Jr. (2011), foram investigadas conforme o volume de chuva observado pelo PR ou altura de $40 \mathrm{dBZ}$ ou espalhamento de gelo ou taxa de raios no tempo, porém as tempestades elétricas não foram classificadas em função da sua densidade espaço temporal de raios ou frequência de ocorrência.

Apesar de Zipser et al. (2006) mostrarem o ciclo diurno e o ciclo anual das PFs potencialmente severas sobre o globo e em Christian et al. (2003) e Cecil et al. (2014) o ciclo diurno e o ciclo anual de ocorrência de raios global, carece na literatura estudos a respeito do ciclo diurno e ciclo anual focado nas tempestades elétricas, de modo a descrever o marco das tempestades elétricas para diferentes regiões da América do Sul.

Nesta pesquisa realiza-se um estudo focado nos sistemas precipitantes que possuem atividade elétrica - as tempestades elétricas - apenas sobre a América do Sul a partir das observações orbitais do satélite TRMM, mais especificamente do sensor de raios LIS, do radiômetro Visible and InfraRed Scanner (VIRS) e do radar PR, desde o início de 1998 até o final de 2011.

A intensidade das tempestades elétricas neste trabalho de pesquisa é estudada com base nas observações de raios do LIS e aspectos morfológicos como: dimensões relacionadas a extensão dos sistemas e a estrutura tridimensional da precipitação observada pelo PR. No entanto, a intensidade convectiva das tempestades elétricas com base nas observações 
do PR é investigada a partir das distribuições de probabilidade de ocorrência dos perfis de refletividade do PR em função da altitude, conforme em Petersen e Rutledge (2001) e também a partir das distribuições de probabilidade de ocorrência dos perfis de refletividade do PR em função da temperatura do perfil atmosférico, pois os processos de eletrificação de nuvem dependem essencialmente da temperatura (entre $-5{ }^{\circ} \mathrm{C} \mathrm{e}-40{ }^{\circ} \mathrm{C}$ ), conteúdo de água líquida e velocidade vertical (TAKAHASHI, 1978; SAUNDERS, 2008) e considerando uma grande extensão como é o caso do continente Sul-americano teremos variação das alturas das isotermas com a latitude, estações do ano e passagens de sistemas sinóticos.

Mesmo que a intensidade convectiva possa ser mensurada pela altura de $40 \mathrm{dBZ}$ observada pelo PR (ZIPSER et al., 2006; RASMUSSEN; HOUZE Jr., 2011), a condição de tempo severo, deve estar mais relacionada com a intensificação dos processos microfísicos que corroboram com os processos de eletrificação de nuvens associados a convecção intensa, como por exemplo o processo de acreção que envolve a formação do graupel e o granizo e que podem ser estimados pelas observações de refletividade de radares meteorológicos, conforme descreve-se em 1.1 (AUSTIN; BEMIS, 1950; FABRY; ZAWADZKI, 1995, MASON, 1971, p. 462).

Portanto, diante lacunas identificadas na literatura refente ao estudo de sistemas precipitantes associados a condição de tempo severo e estudos das distribuições de densidade geográficas de raios, de maneira mais específica, esta tese propõe-se a:

- Construir um banco de dados de tempestades elétricas do TRMM sobre a América do Sul a partir das observações orbitais do sensor de raios LIS, do radiômetro Visible and InfraRed Scanner (VIRS) e do radar PR, desde o início de 1998 até o final de 2011.

- Determinar o marco das tempestades elétricas na AS a partir do ciclo diurno e ciclo anual para diferentes regiões da América do Sul.

- Construir o mapa de densidade geográfica de tempestades elétricas e o mapa da densidade de raios por tempestade elétrica, evidenciando as regiões e estações do ano em que os processos de eletrificação das tempestades elétricas são mais eficientes na produção de raios.

- Caracterizar a severidade das tempestades elétricas em função da sua taxa de raios no tempo (raios $\left[\mathrm{min}^{-1}\right]$ ) e da sua taxa de raios no tempo por área (raios $\left[\mathrm{min}^{-1}\right]$ $\left.\left[\mathrm{km}^{-2}\right]\right)$. 
- Identificar processos microfísicos (AUSTIN; BEMIS, 1950, FABRY; ZAWADZKI, 1995: MASON, 1971, p. 462) com base no estudo da morfologia da estrutura tridimensional da precipitação observada pelo PR que indique quais as tempestades elétricas que representam maior intensidade convectiva: as com elevados números de raios durante os $\simeq 90$ segundos que o TRMM as observa ou as com elevadas densidades de raios na superfície. 


\section{DADOS E METODOLOGIA}

A Metodologia consiste fundamentalmente na construção de um subconjunto de dados das observações dos sensores VIRS, LIS e PR a bordo do satélite TRMM, durante o período entre 1998 e 2011. Além dos dados satelitais, as reanálises 2 do National Centers for Environmental Prediction - Department of Energy (NCEP-DOE) em níveis de pressão foram utilizadas para calcular os valores de temperatura nos níveis correspondentes as altitudes de medidas do PR.

As informações dos diferentes sensores foram combinadas de maneira a identificar sistemas denominados como tempestades elétricas, definidas como nuvens que possuíram pelo menos um raio - flash - detectado pelo LIS.

\subsection{O SATÉLITE TRMM}

O satélite Tropical Rainfall Measuring Mission - TRMM faz parte de uma missão conjunta entre a National Aeronautics and Space Administration (NASA) e a Japan Aerospace Exploration Agency (JAXA), com o objetivo de estimar a distribuição espaço-temporal da chuva e do fluxo de calor latente para a região tropical e subtropical terrestre. Estas informações são fundamentais para avaliar modelos atmosféricos globais e climáticos principalmente quando se trata de previsão do tempo e clima nos trópicos (KUMMEROW et al., 1998; SIMPSON et al., 1988).

O satélite TRMM foi lançado em 28 de novembro de 1997 entrando em órbita circular baixa de $350 \mathrm{~km}$ de altitude com inclinação de $35^{\circ}$ e período de 90 minutos. Originalmente a missão TRMM teria 3 anos, porém, devido ao sucesso até o ano de 2000, seu tempo foi prolongado e em agosto de 2001 sua órbita foi elevada até 402,5 km de altitude. Devido as suas características orbitais, o TRMM sobrevoa 2 vezes ao dia uma região de $10^{\circ} \times 10^{\circ}$ de latitude e longitude (SIMPSON et al., 1988). Em outubro de 2014, o satélite TRMM começou a descender e em 08 de Abril de 2015 atingiu a órbita de descomissionamento (NATIONAL AERONAUTICS AND SPACE ADMINISTRATION, 2014, NATIONAL 


\section{AERONAUTICS AND SPACE ADMINISTRATION, 2015).}

Os instrumentos a bordo do TRMM são: radar de precipitação (Precipitation Radar - PR), radiômetro de micro-ondas (TRMM Microwave Imager - TMI), radiômetro no visível e no infravermelho (Visible and Infrared Scanner - VIRS), radiômetro para medir a energia radiante da terra e das nuvens (Clouds and the Earth's Radiant Energy System - CERES) e sensor para imageamento de relâmpagos (Lightning Imaging Sensor - LIS). A figura 8, ilustra algumas das principais características de varreduras (KUMMEROW et al. 1998).

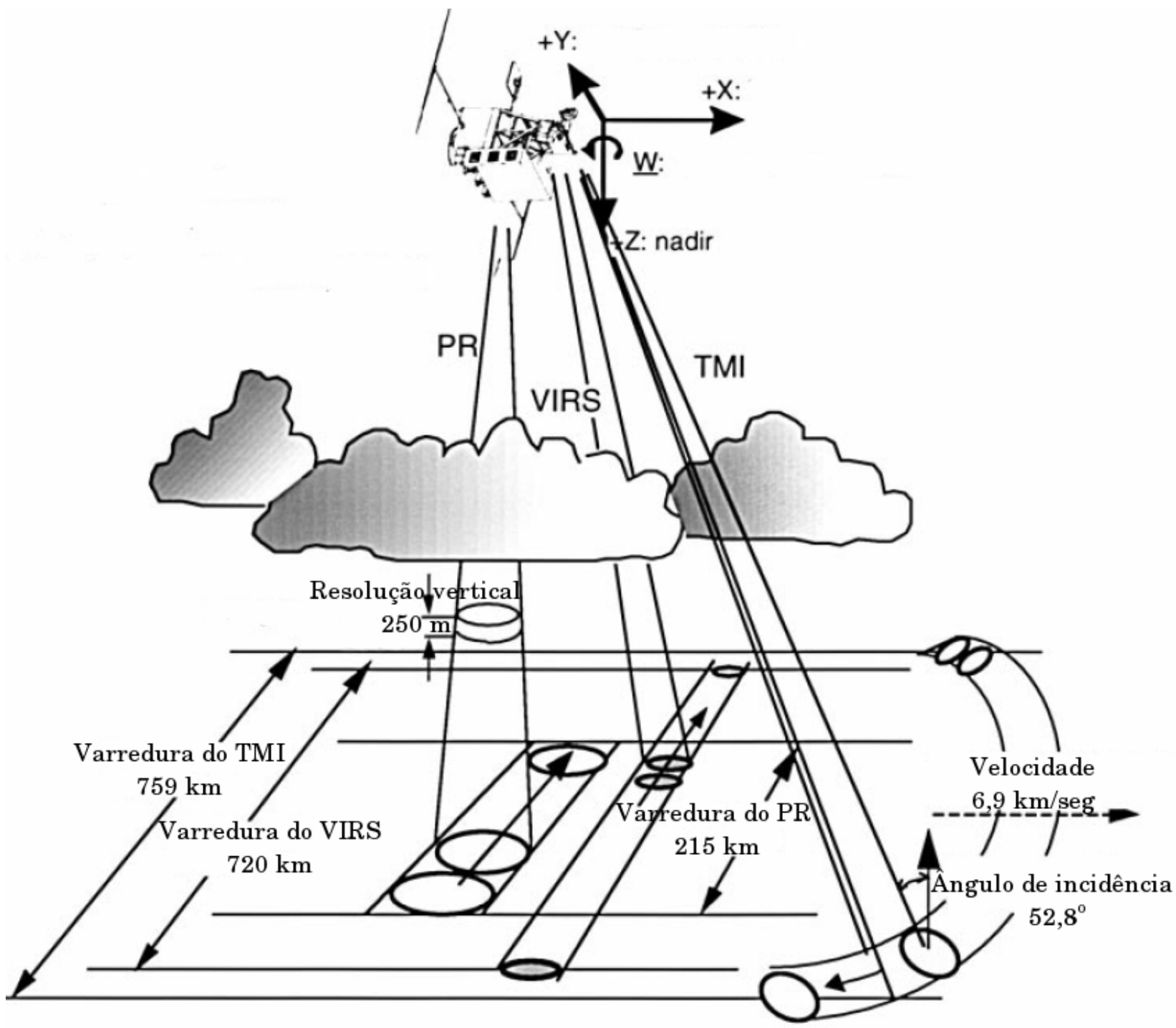

Figura 8: Ilustração do satélite TRMM e as principais características de varredura dos sensores (adaptada de Kummerow et al. (1998)). 


\subsubsection{Radar de Precipitação}

O radar de precipitação (PR) é o principal instrumento do satélite TRMM. Trata-se do primeiro radar meteorológico lançado no espaço sendo a maior inovação apresentada pela missão TRMM. Os objetivos do PR são prover a estrutura tridimensional da precipitação e quantificar as taxas de precipitação sobre os continentes e oceanos. (KUMMEROW et al., 1998).

Tabela 1: Principais parâmetros do sinal eletromagnético transmitido e recebido pelo PR (adaptada de Kummerow et al. (1998), NASDA (2001)).

\begin{tabular}{lc}
\hline \hline Item & Especificações \\
\hline Frequência & $13,796,13,802 \mathrm{GHz}$ \\
Sensibilidade & $\leq 0,7 \mathrm{~mm} \mathrm{~h}^{-1}$ (Sinal/Ruído por pulso $\left.\simeq 0 \mathrm{~dB}\right)$ \\
Transmissor/Receptor: & \\
Tipo & $\mathrm{SSPA}$ and LNA $(128$ channels $)$ \\
Potência máxima & $\geq 500 \mathrm{~W}$ \\
Largura do pulso & $1,6 \mu \mathrm{s} \times 2$ canais \\
Frequência de repetição do pulso (PRF) & $2776 \mathrm{~Hz}$ \\
\hline
\end{tabular}

Os principais parâmetros relacionados ao feixe eletromagnético do PR são listados na tabela 1. Em relação à antena do PR, possui uma largura de feixe de $0,71^{\circ} \times 0,71^{\circ}$ disposta em um painel com abertura de $2,0 \mathrm{~m} \times 2,0 \mathrm{~m}$. Sua varredura transversal (crosstrack) de $\pm 17^{\circ}$ é composta por 49 feixes. Após (antes) a elevação do satélite TRMM, o PR observa uma faixa na superfície de $247 \mathrm{~km}(215 \mathrm{~km})$ e resolução horizontal no nadir de $5,0 \mathrm{~km}(4,3 \mathrm{~km})$. Verticalmente o PR registra 80 medidas ao longo de uma faixa de $20 \mathrm{~km}$ a partir da superfície, com resolução de $250 \mathrm{~m}$. O PR realiza $\simeq 9150$ varreduras por órbita, o que corresponde a uma matriz tridimensional de $49 \times 80 \times 9150$ gates: 49 feixes na varredura horizontal, com 80 níveis verticais e $\simeq 9150$ varreduras horizontais.

As medidas de potência recebida $\left(P_{r}\right)$, associadas com a secção transversal de retroespalhamento sem correção de atenuação e ground clutter, são armazenadas no produto 1B21. A equação do radar conforme as especificações do PR é aplicada nos dados de $P_{r}$ e são convertidos para o fator de refletividade $\left(Z_{m}\right)$ em dBZ, definindo então o produto $1 \mathrm{C} 21$.

No produto 2A25 calcula-se a taxa de precipitação (R). É quando faz-se necessário corrigir o efeito de atenuação e ground clutter de $Z_{m}$ obtendo o fator refletividade corrigido $\left(Z_{c}\right)$ (IGUCHI; MENEGHINI, 1994 ; MENEGHINI et al., 2000; IGUCHI et al., 2000). No cálculo de $\mathrm{R}$ são utilizadas as classificações dos perfis verticais como convectivo, estratiforme e outros do produto 2A23 (AWAKA et al., 1997). 


\subsubsection{Sensor imageador de raios}

O imageador de raios (LIS) é um sensor óptico capaz de detectar e localizar raios individualmente, a partir da emissão óptica resultante da dissociação, excitação e recombinação dos constituintes atmosféricos durante uma descarga atmosférica.

O sistema de imageamento do LIS é constituído por um telescópio com razão focal de $f / 1,6$ expandindo o feixe luminoso observado, que passa por um filtro de interferência no comprimento de onda de 777,4 nm e com largura de banda de $1 \mathrm{~nm}$ e atinge uma matriz de $128 \times 128 \mathrm{CCD}^{4}$. Acoplada a matriz de CCDs, uma lente angular proporciona um campo de visão panorâmico de $80^{\circ} \times 80^{\circ}$, que corresponde a uma área na superfície terrestre de $668 \mathrm{~km} \times 668 \mathrm{~km}$ depois da elevação, ou $580 \mathrm{~km} \times 580 \mathrm{~km}$ antes da elevação. Um pixel do campo de visão do LIS no nadir possui resolução de 4,3 km depois da elevação e 3,7 km antes da elevação, sendo que, nas regiões mais externas da sua varredura a resolução depois (antes) da elevação atinge $12 \mathrm{~km}(10,4 \mathrm{~km})$. Para identificar os raios o LIS utiliza um sistema de amostragem que captura 500 imagens por segundo CHRISTIAN et al. 2000; BOCCIPPIO et al., 1996; NASDA, 2001).

Conforme descrito em Christian et al. (2000), a identificação dos raios depende do brilho difuso e transiente observado no topo das tempestades elétricas. Dependendo das posições das CCDs que são sensibilizadas e do intervalo de tempo entre os brilhos subsequentes nas nuvens, o algoritmo de processamento de imagens do LIS identifica eventos, grupos e os raios. Os eventos, correspondem as posições das CCDs em que a irradiação detectada excede a irradiação do plano de fundo que é determinada a cada medida do LIS, os grupos são os agrupamentos de eventos que podem ser interpretados como descargas de retorno - strokes - e os raios - flashes - são agrupamentos espaçotemporal de grupos de eventos. Os raios do LIS correspondem aos raios totais observados na atmosfera, i.e., intranuvens e nuvem-solo.

A figura 9 ilustra como é feita a identificação dos eventos, grupos até a caracterização de um raio. Observe na figura $9 \mathrm{a}$ que em $t=0 \mathrm{~ms}$, as CCDs, 1, 2 e 3 foram sensibilizadas e o algoritmo definiu o grupo de evento $a$ candidato a ser um raio $A$. Quando $t=100 \mathrm{~ms}$, as CCDs, 4, 5 e 6, são sensibilizadas e temos 2 grupos de eventos, $a$ e $b$, espacialmente e temporalmente $(<330 \mathrm{~ms}$ ) próximos, portanto, os grupos a e $b$ integram o mesmo raio $A$, como ilustra a figura 9b. Quando $t=350 \mathrm{~ms}$, as CCDs 9 e 10 são sensibilizadas como mostra a figura $9 \mathrm{c}$. As CCDs 9 e 10 não estão próximas dos grupos $a$ e $b$ que compõe o

\footnotetext{
${ }^{4} \mathrm{O}$ CCD (charge-coupled device) é um dispositivo eletrônico que mede corrente elétrica gerada por efeito fotoelétrico amplamente utilizado para obter imagens digitalmente.
} 
raio $A$, portanto, o algoritmo define o grupo $d$ e um novo candidato a raio $B$. Na figura 9d o raio $B$ possui mais dois grupos, e e $f$. Na figura 9e note que a CCD 13 coincide com a posição 2, inicialmente em 9a mas como o intervalo de tempo entre as figuras 9a e $9 \mathrm{e}$ é superior a $330 \mathrm{~ms}$, o grupo $g$ também definiu o novo raio $C$ (CHRISTIAN et al., 2000).

O LIS possui a capacidade de identificar descargas nuvem-solo e intranuvens, tanto no período diurno quanto noturno. Conforme Boccippio et al. (2002) a eficiência de detecção de raios do LIS é maior no período noturno, com $93 \pm 4 \%$, enquanto que no período diurno é de $73 \pm 11 \%$. Com a velocidade orbital de $11 \mathrm{~km} \mathrm{~s}^{-1}$, o sensor LIS possui um campo de visão que permite a observação de um ponto (view time) na Terra por até $\simeq 100$ segundos no nadir, tempo suficiente para a estimativa da taxa de raios de uma tempestade (CHRISTIAN et al., 1992, NASDA, 2001).

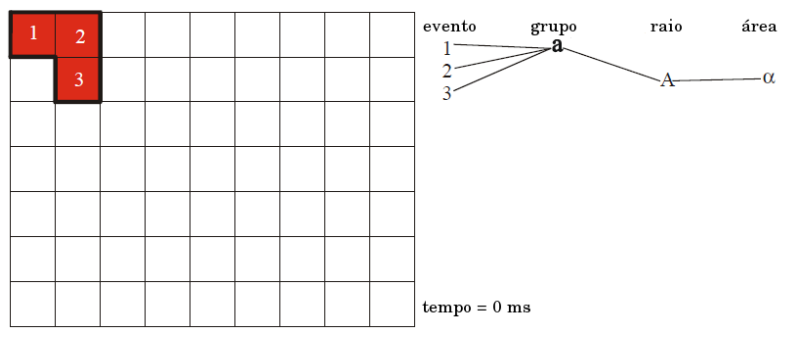

(a)

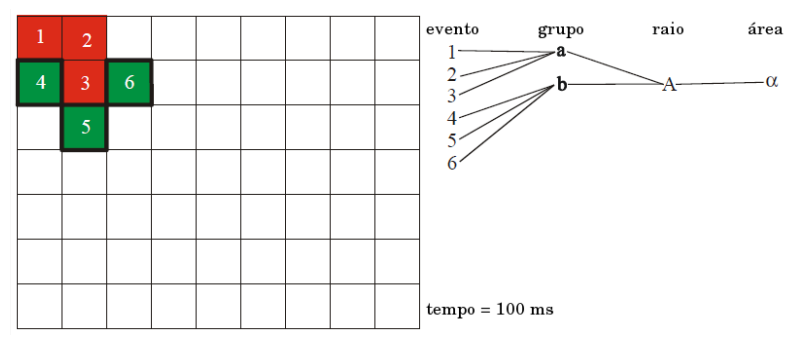

(b)

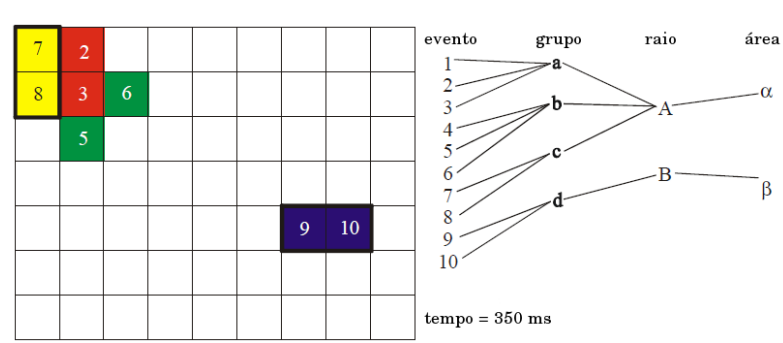

(c)

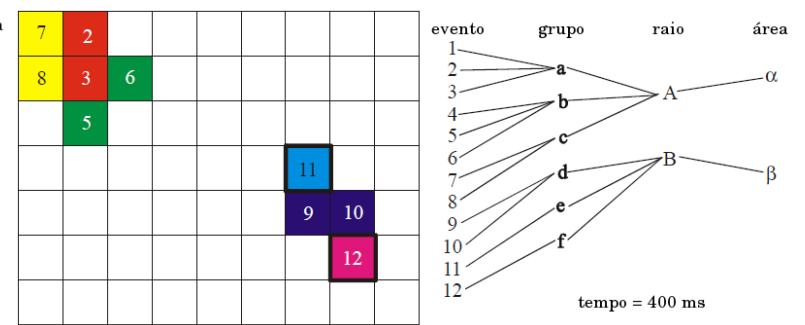

(d)

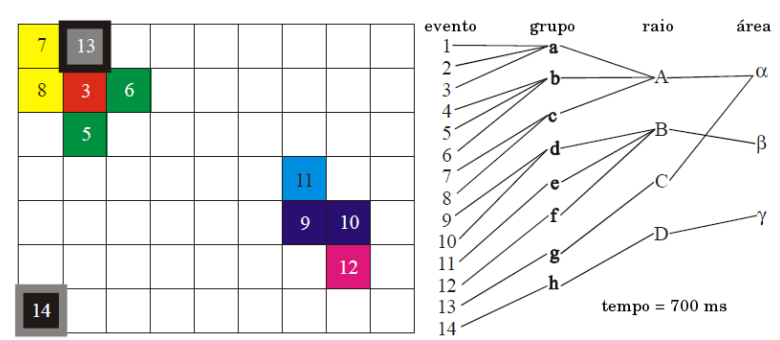

(e)

Figura 9: Ilustração do algoritmo de identificação de eventos, grupos e os raios do LIS (CHRISTIAN et al. 2000). 


\subsubsection{Radiômetro no visível e infravermelho}

O Radiômetro no visível e infravermelho (VIRS) é um radiômetro de varredura transversal de $\pm 45^{\circ}$, observando uma faixa de $720 \mathrm{~km}$ na superfície terrestre com uma resolução de 2,11 km no nadir. Após a elevação do satélite, o VIRS passou a observar uma faixa de $833 \mathrm{~km}$ com 2,4 km de resolução no nadir. O VIRS mede a radiância em 5 bandas espectrais entre 0,63-12,03 $\mu \mathrm{m}$, conforme mostra a tabela 2 (KUMMEROW et al., 1998).

Tabela 2: Canais do VIRS e objetivos das medidas de radiância espectral conforme cada comprimento de onda $(\lambda)$ (adaptada de Kummerow et al. (1998), NASDA (2001)).

\begin{tabular}{cccccc}
\hline \hline & Canal 1 & Canal 2 & Canal 3 & Canal 4 & Canal 5 \\
\hline$\lambda(\mu \mathrm{m})$ & $0,623 \pm 0,088$ & $1,610 \pm 0,055$ & $3,784 \pm 0,340$ & $10,826 \pm 1,045$ & $12,028 \pm 1,055$ \\
\hline
\end{tabular}

O conjunto de dados das radiâncias espectrais calibradas, a partir das observações periódicas de referências ópticas como a Lua, o Sol e uma cavidade de corpo negro a bordo do satélite, representam o produto 1B01 (KUMMEROW et al., 1998.

Nesta pesquisa, utilizamos apenas a radiância do canal 4 que corresponde ao comprimento de onda $(\lambda)$ de $10,8 \mu \mathrm{m}$, pois considerando a Lei de Planck, os dados de radiância de $\lambda=10,8 \mu \mathrm{m}$ podem ser convertidos em temperatura de brilho $\left(T_{b}\right)$ e a emissão do topo das nuvens associadas à emissão de um corpo negro.

\subsection{REANÁLISES (R2) DO NCEP-DOE}

Os dados de altura geopotencial e temperatura são utilizados para converter a altura do feixe do PR em um eixo de temperatura. Para tanto, utiliza-se dos dados das reanálises 2 (R2) do NCEP-DOE.

As reanálises são um conjunto de campos meteorológicos consistidos dinamicamente e termodinamicamente em um modelo de circulação atmosférica global a partir de dados de radio-sonda, aviões e satélites (KALNAY et al., 1996). Os campos disponíveis são: magnitude e direção de ventos, temperatura, umidade relativa, altura geopotencial entre outros.

O projeto R2 - NCEP-DOE Atmospheric Model Intercomparison Project (AMIP-II) reanalysis - representa correções aplicadas no projeto das reanálises R1, que busca corrigir erros humanos e erros de versões anteriores de modelos atmosféricos utilizados no processo de integração e assimilação que envolvem a construção das reanálises (KANAMITSU et al., 2002). 


\subsection{DADOS}

Os dados referentes as observações do TRMM foram obtidos a partir do servidor de FTP da NASA (ftp://disc2.nascom.nasa.gov) e do NCEP (ftp://ftp.cdc.noaa.gov).

Foram utilizados os dados de temperatura e altura geopotencial em 17 níveis de pressão das reanálises 2 do NCEP-DOE e os arquivos orbitais do TRMM, produto 1B01 e 2A25 ambos na versão 7, para o período entre janeiro de 1998 e dezembro de 2011.

Os dados do LIS refentes ao tempo de visada (view time), eventos, grupos e raios foram concedidos pela pesquisadora Albrecht (2010), quem processou estes dados na NASA, projetando os dados do tempo de visada do LIS para uma grade regular com resolução espacial de $0,25^{\circ}$, próxima à resolução da varredura do PR. Originalmente os dados do tempo de visada do LIS são fornecidos na base de dados do LIS com resolução de $0,5^{\circ}$.

Para este trabalho de pesquisa os dados do TRMM e da R2 foram amostrados sobre a região limitada entre $10^{\circ}$ Norte $-40^{\circ}$ Sul e $90^{\circ}-30^{\circ}$ Oeste, que abrange toda a extensão da América do Sul e oceanos adjacentes.

Na tabela 3 são apresentadas as medidas extraídas de cada sensor do TRMM e respectiva fonte.

Tabela 3: Variáveis dos produtos do TRMM que foram utilizadas na identificação e descrição das tempestades elétricas.

\begin{tabular}{lcc}
\hline \hline Variável & Sensor TRMM & Produto \\
\hline Latitude & VIRS & 1B01 \\
Longitude & VIRS & $1 \mathrm{~B} 01$ \\
Radiância $(10,8 \mu \mathrm{m})$ & VIRS & $1 \mathrm{~B} 01$ \\
Latitude & PR & $2 \mathrm{~A} 25$ \\
Longitude & PR & $2 \mathrm{~A} 25$ \\
Fator de refletividade $Z_{c}$ & PR & $2 \mathrm{~A} 25$ \\
Chuva na superfície & PR & $2 \mathrm{~A} 25$ \\
Tipo de chuva & PR & $2 \mathrm{~A} 23$ \\
Latitude eventos $/$ grupos $/$ raios & LIS & $(\overline{\text { ALBRECHT }}, \overline{2010})$ \\
Longitude eventos $/$ grupos $/$ raios & LIS & $(\overline{\text { ALBRECHT }}, \overline{2010})$ \\
Tempo de visada $0,25^{\circ} \times 0,25^{\circ}$ & LIS & $(\overline{\text { ALBRECHT }}, \overline{2010})$ \\
\hline
\end{tabular}

\subsection{TEMPESTADES ELÉTRICAS}

As tempestades elétricas, como já definido anteriormente, são nuvens que durante o seu ciclo de vida apresentaram ao menos um raio. 
Dessa maneira, para criar o banco de dados de nuvens de tempestades elétricas deste trabalho de pesquisa, a equação de Planck foi aplicada nos dados de radiância espectral do produto 1B01, canal 4 do VIRS $(10,8 \mu \mathrm{m})$ e as regiões com temperatura de brilho $\left(T_{b}\right)$ inferiores à $258 \mathrm{~K}$ e com pelo menos um raio do LIS observado definiram as áreas das tempestades elétricas $\left(A_{t}\right)$ (MORALES; ANAGNOSTOU, 2003).

A partir do agrupamento dos sistemas, clusters com $T_{b} \leq 258 \mathrm{~K}$, foram extraídas as variáveis listadas na tabela 3 refentes as observações do PR e LIS para a mesma região em que o cluster de tempestade elétrica foi observado.

Como os sensores do TRMM possuem diferentes resoluções espaciais, as observações orbitais do VIRS, PR e LIS, foram todas projetadas em uma grade regular com $0,05^{\circ} \times$ $0,05^{\circ}$ de resolução, de maneira a verificar as medidas do PR, LIS e VIRS para uma mesma tempestade elétrica.

Cada tempestade elétrica identificada foi armazenada na forma de um arquivo HDF contendo medidas coincidentes do VIRS, LIS e PR.

Inicialmente foram identificadas 154189 tempestades elétricas. Entretanto, 331 tempestades elétricas não corresponderam a um único sistema convectivo ou multicelular, pois esses núcleos convectivos com raios estavam embebidos em grandes sistemas como Frentes e a ZCAS.

Ao ajustar a área das tempestades elétricas a área de uma elipse, os 331 sistemas considerados "enormes" possuíram distância focal (2c) maior do que $2500 \mathrm{~km}$. Na figura 10. temos a representação de um dos sistemas considerados como "enorme".

Nestes 331 sistemas, foi feita uma redefinição do limiar de $T_{b}$ que define $A_{t}$, em que $A_{t}$ passou a ser definida como regiões com $T_{b} \leq 221 \mathrm{~K}$ e com pelo menos um raio observado pelo LIS. Regiões com temperatura de brilho em infravermelho inferiores a $221 \mathrm{~K}$ são consideradas como a parte mais ativa dos sistemas convectivos de meso-escala identificados em Maddox (1980).

Com a recategorização dos sistemas "enormes", o número total de tempestades elétricas que passaram a integrar esta pesquisa é de 157592. 

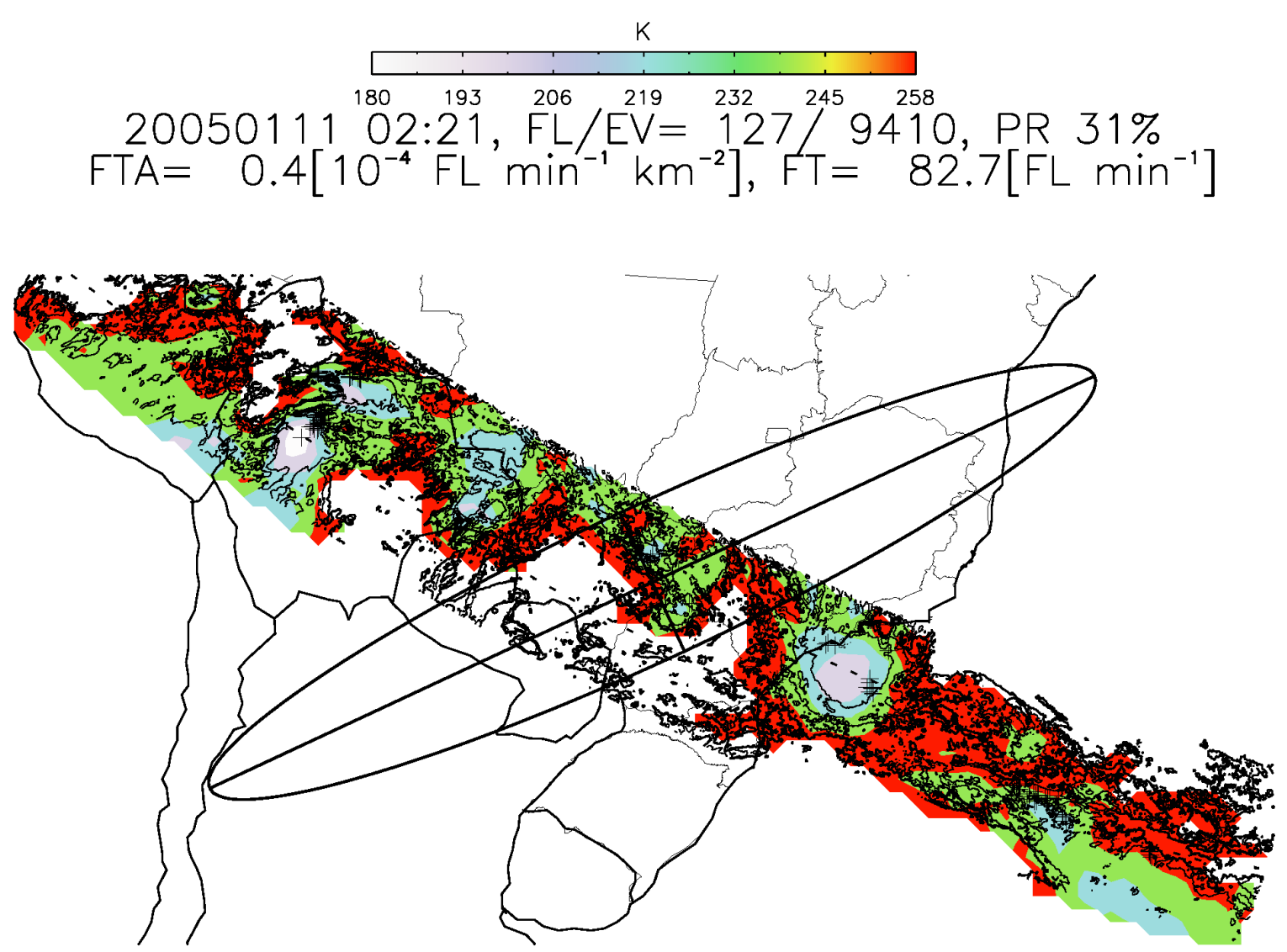

$A=2.14 E+06 \mathrm{~km}^{2},(a=2087.9, b=326.9,2 c=4124.3) \mathrm{km}, e=0.9877$

Figura 10: Nuvem de tempestade elétrica considerada "enorme". Na parte superior e inferior da figura, há informações referentes a data e hora em que o sistema foi observado, número de raios e eventos (FL/EV), fração do sistema observado pelo PR, área do sistema (A), semieixo maior (a), menor (b), distância focal (2c) e excentricidade (e) de uma elipse ajustada às dimensões do sistema, a qual está plotada sobre a região geográfica. A barra de cores corresponde as temperaturas de brilho em infravermelho (VIRS 10,8 $\mu \mathrm{m}$ ) do topo da tempestade elétrica. 


\subsection{SEVERIDADE: TAXA DE RAIOS}

Condições de tempo severo, como frentes de rajadas, queda de granizo e tornados estão associados com um aumento abrupto na taxa de raios total das tempestades elétricas, principalmente governado por raios intra-nuvens (MACGORMAN et al., 1989; CAREY; RUTLEDGE, 1998; WILLIAMS et al., 1999; GATLIN; GOODMAN, 2010; SCHULTZ et al., 2011).

Portanto, a taxa de raios $\left(\left[\mathrm{min}^{-1}\right]\right)$ do LIS observada sobre a área que define uma tempestade elétrica pode indicar condições de tempo severo. Os sistemas precipitantes, (precipitation features - PFs) definidos em Nesbitt et al. (2000), com as maiores taxas de raios por minuto, conforme mostram Cecil et al. (2005), Zipser et al. (2006), corresponderam aos sistemas com os maiores volumes de chuvas, mínimas temperaturas de brilho em mico-ondas, máximos valores de refletividade do PR, e de acordo com estes autores pode ser indicativo da presença de fortes correntes ascendentes.

Neste trabalho de pesquisa a taxa de raios das tempestades elétricas será avaliada a partir de dois índices:

- FT - A taxa de raios no tempo, sendo a razão entre o número de raios $\left(N_{f l}\right)$ e o tempo médio $\left(V T_{m}\right)$ de observação do LIS sobre a tempestade elétrica, conforme descreve a equação 14 .

$$
F T=\frac{N_{f l}}{V T_{m}} 60\left[\mathrm{~min}^{-1}\right]
$$

- FTA - A taxa de raios por tempo normalizada pela área da tempestade elétrica, sendo a razão entre o número de raios $\left(N_{f l}\right)$, o tempo médio $\left(V T_{m}\right)$ observação do LIS e a extensão em área $A_{t}$ da tempestade elétrica observada, conforme descreve a equação 15 .

$$
F T A=\frac{N_{f l}}{V T_{m} A_{t}} 60\left[\mathrm{~min}^{-1} \mathrm{~km}^{-2}\right]
$$

Note que o fator 60 que multiplica tanto a equação 14 quanto a 15 é aplicado para converter o tempo de visada do LIS de segundos $\left(V T_{m}\right)$ para minutos de observações, pois, em geral a severidade é quantificada em raios por minuto. 


\subsection{DISTRIBUIÇÕES GEOGRÁFICAS DE DENSIDADES}

As distribuições geográficas são estudadas a partir da densidade de raios, densidade de tempestades elétricas e densidade de raios por tempestades elétricas. Estas três grandezas de densidades buscam mostrar as regiões de maior e menor ocorrência de raios e de tempestades elétricas e também identificar os locais em que as tempestades elétricas produzem mais (menos) raios por número de tempestades, i.e., apresentam processos de eletrificação mais (menos) eficazes.

O que se torna fundamental na construção destes mapas da distribuição geográfica de densidades de ocorrências é considerar quantas vezes ou qual o tempo que o satélite ficou observando cada parte da região de estudo, pois latitudes mais altas possuem maior número de amostragens do que em latitudes mais baixas por causa das características da orbita baixa do satélite TRMM. Portanto, qualquer análise de densidade geográfica relacionada às observações do TRMM que não considere o número de passagens ou tempo em que o sensor observou a região projetada na superfície será tendenciosa.

Mesmo que o satélite TRMM visite o mesmo lugar do globo duas vezes por dia em função de sua órbita com altitude de 402,5 km (350 km antes da elevação) e inclinada $35^{\circ}$ (KUMMEROW et al., 1998), entre o período de 1998-2011, o satélite passou 10000 vezes mais sobre a região extra-tropical ( $\geq 20^{\circ}$ latitude) do que na região tropical, como mostra a figura 11 que apresenta o número de órbitas sobrevoadas pelo VIRS em cada ponto da grade de $0,25^{\circ} \times 0,25^{\circ}$ de latitude e longitude na América do Sul. Este efeito decorre da região onde o satélite atinge a latitude máxima.

Agora levando em consideração o tempo de amostragem do LIS (view time), figura 12 . o número de dias de amostragem em cada ponto da grade regular $\left(0,25^{\circ} \times 0,25^{\circ}\right)$ projetada sobre AS revela que durante os 14 anos o LIS observou 10 dias a mais na latitude $34^{\circ}$ Sul do que em $0^{\circ}$. Logo, se estas regiões com maior tempo de amostragem forem eletricamente ativas, é de se esperar um alto número de raios observados se comparadas com $0^{\circ}$ de latitude.

Portanto, as figuras 12 e 11 representam duas matrizes: $\mathbf{V T}_{\text {lis }}$ (figura 12 referente ao tempo de amostragem do LIS sobre cada ponto de grade $\left(0,25^{\circ} \times 0,25^{\circ}\right.$ de latitude e longitude) e $\mathbf{V T}_{\text {virs }}$ (figura 11, refente ao número de vezes que o VIRS sobrevoou cada ponto de grade $\left(0,25^{\circ} \times 0,25^{\circ}\right.$ de latitude e longitude), as quais são utilizadas para normalizar as medidas de raios observados pelo LIS e tempestades elétricas definidas por meio do canal 4 do VIRS $\left(T_{b} \leq 258 \mathrm{~K}\right)$. 
As medidas tanto de raios do LIS quanto de regiões sobre a superfície terrestre com ocorrência de tempestades elétricas definidas pelo VIRS $\left(T_{b} \leq 258 \mathrm{~K}\right)$, também foram projetadas em uma grade de $0,25^{\circ} \times 0,25^{\circ}$ de latitude e longitude, sobre à região de estudo. Foi obtida a matriz $\mathbf{F L}_{\text {lis }}$ em que cada posição da matiz corresponde a um ponto da grade $\left(0,25^{\circ} \times 0,25^{\circ}\right.$ de latitude e longitude $)$ com o acumulado de raios ocorridos entre 1998-2011, bem como foi obtida a matriz $\mathbf{P}_{t e}$ com o total de tempestades elétricas ocorridas em cada ponto da grade $\left(0,25^{\circ} \times 0,25^{\circ}\right.$ de latitude e longitude) sobre a AS.

Na figura 14, que ilustra a matriz $\mathbf{P}_{t e}$, há uma extensa região na parte Sul da AS em que se observa um elevado número de sistemas, mas este máximo não indica maior ocorrência de tempestades elétricas e sim maior frequência de passagem do satélite TRMM. No entanto, a ilustração da matriz $\mathbf{F L}_{l i s}$ como mostra a figura 13 , revela que no extremo norte da cordilheira dos Andes, mesmo que o satélite sobrevoe menos esta região

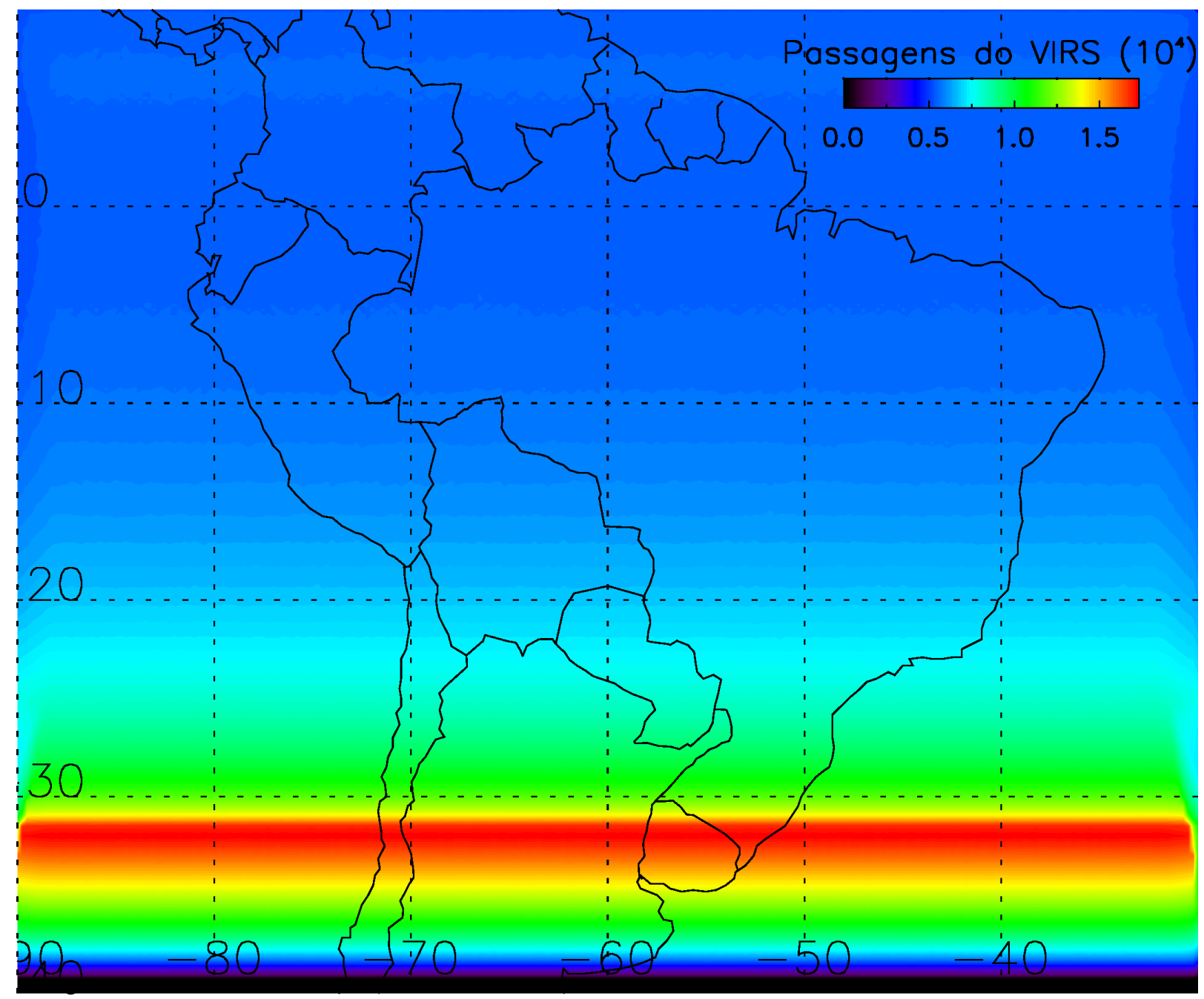

Figura 11: Número de sobrevoos do VIRS em cada ponto da grade de $0,25^{\circ} \times 0,25^{\circ}$ de latitude e longitude entre 1998-2011, ilustrando a matriz $\mathbf{V T}_{\text {virs }}$. 


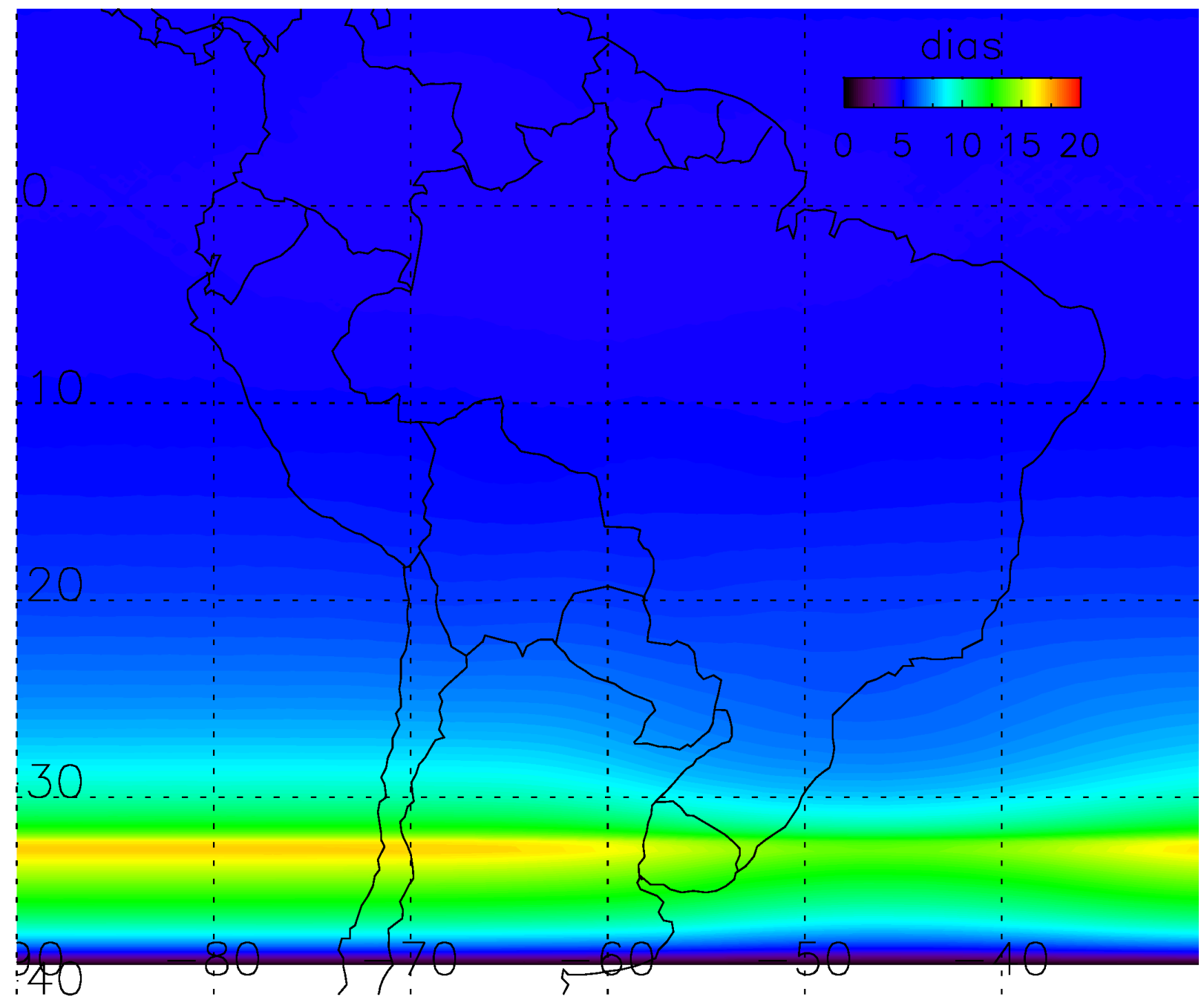

Figura 12: Tempo de amostragem (view time) do LIS ente 1998-2011, para cada ponto da grade de $0,25^{\circ} \times 0,25^{\circ}$ de latitude e longitude, ilustrando a matriz $\mathbf{V T}_{\text {lis }}$.

próxima da linha do equador, os acumulados de raios são maiores do que sobre a região Sul da AS.

Devemos também levar em consideração que os pontos de uma grade regular em graus de latitude e longitude não possuem áreas iguais, pois o comprimento de arco de $0,25^{\circ}$ na direção zonal depende da latitude da região. Assim a matriz que corresponde à área da grade regular $\left(\mathbf{A}_{g}\right)$ foi calculada e considera nos cálculos de densidades.

Portanto a partir das grandezas $\mathbf{F L}_{\text {lis }}, \mathbf{P}_{t e}, \mathbf{V} \mathbf{T}_{\text {lis }}, \mathbf{V} \mathbf{T}_{\text {virs }}$ e $\mathbf{A}_{g}$, podemos determinar a densidade de raios $\mathbf{D E}_{f l}$, a densidade de tempestades elétricas $\mathbf{D} \mathbf{E}_{t e}$ e a densidade raios por tempestades elétricas $\mathbf{D E} \mathbf{E}_{r t}$.

A densidade de raios $\mathbf{D E} \mathbf{E}_{f l}$ é calculada conforme a equação 16 , que apresenta a razão entre $\mathbf{F L}_{l i s}, \mathbf{V T}_{\text {lis }}$ e $\mathbf{A}_{g}$ multiplicada por 24 horas $\times 60$ minutos $\times 60$ segundos $\times 365,25$ 


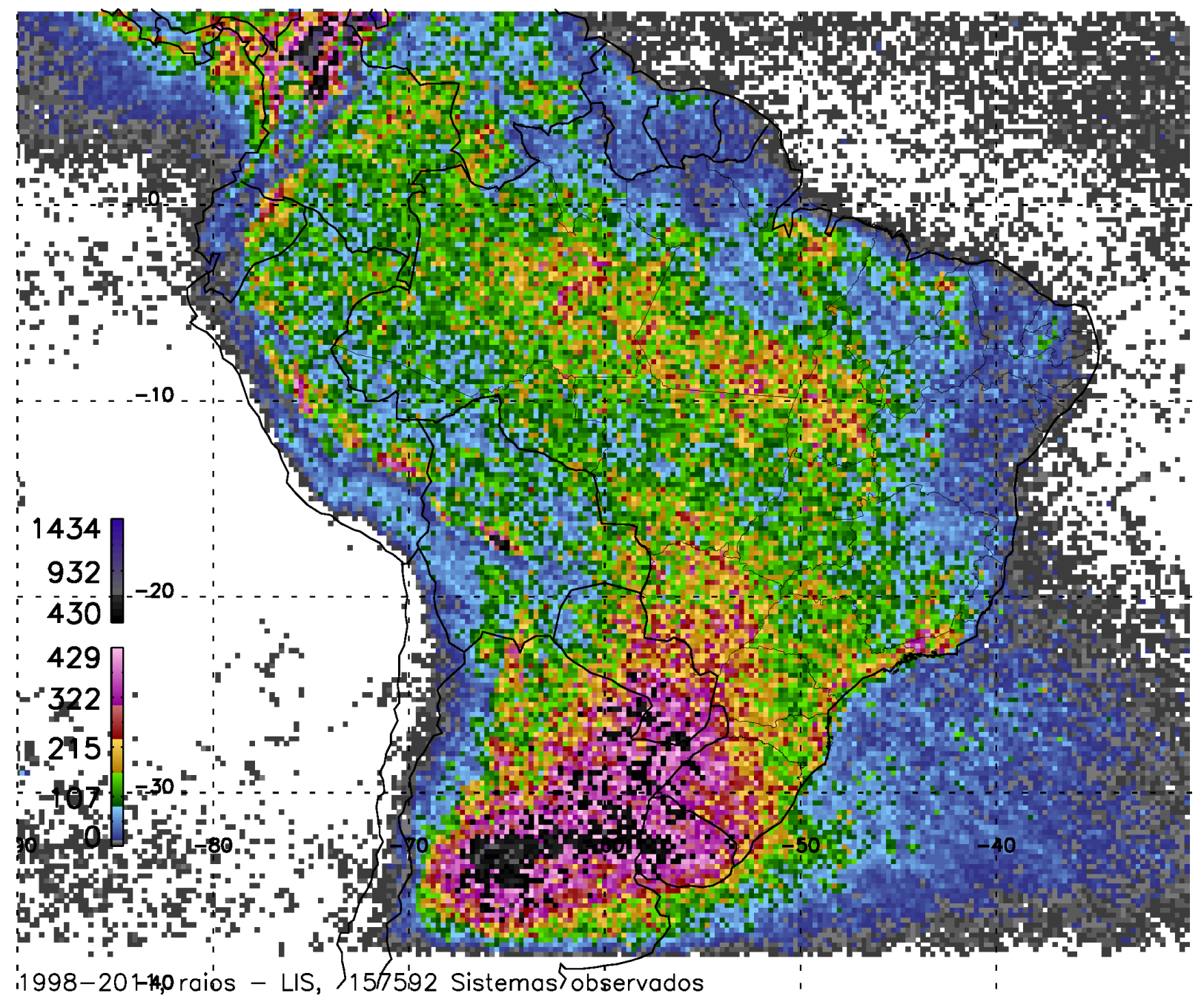

(a)

Figura 13: Número total de raios (flashes) observados pelo LIS em cada região de $0,25^{\circ} \times 0,25^{\circ}$ de latitude e longitude entre 1998-2011, ilustrando a matriz $\mathbf{F} \mathbf{L}_{l i s}$.

dias, o que converte o tempo de observação do LIS originalmente em segundos para anos. A densidade de raios, portanto, é uma grandeza que representa o número de raios por ano por quilômetro quadrado ([ano $\left.\left.{ }^{-1}\right]\left[\mathrm{km}^{-2}\right]\right)$.

$$
\mathbf{D E}_{f l}=\frac{\mathbf{F L}_{l i s}}{\mathbf{V T}_{l i s} \mathbf{A}_{g}} 31557600
$$

Analogamente a densidade de tempestades elétricas $\left(\mathbf{D E}_{t e}\right)$ é obtida. Porém, conforme descrito em 2.1. o tempo de amostragem do LIS e do VIRS são distintos. Enquanto o LIS é um sistema de imageamento, o VIRS é um radiômetro que realiza varreduras durante a trajetória do satélite. Portanto, na obtenção da densidade de tempestades elétricas é considerado o número de sobrevoos do VIRS em cada ponto da grade de $0,25^{\circ} \times 0,25^{\circ}$ de 


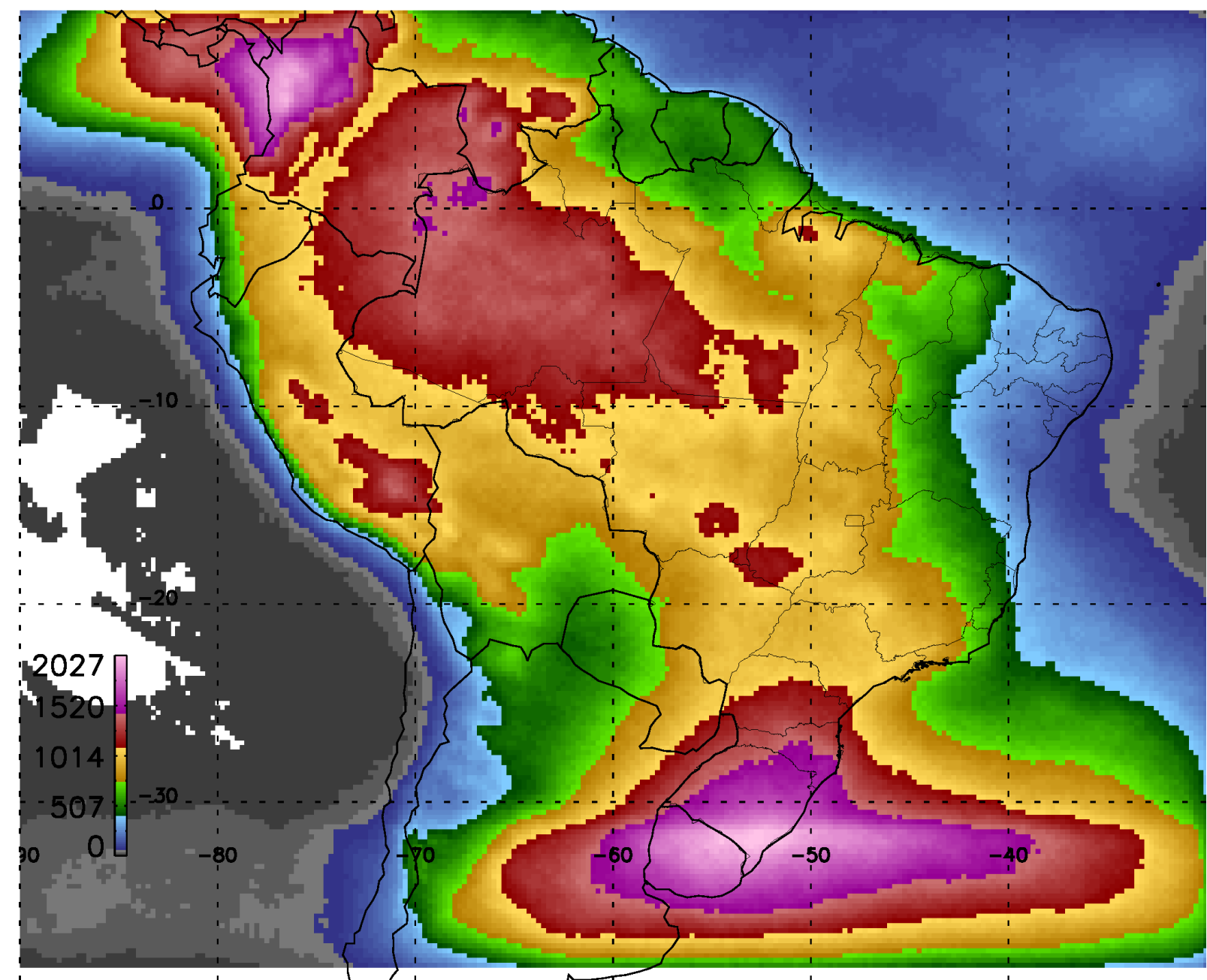

'1998-201-1,0 Total, [ Tempestad'es elétricas ], 157592 Sistemasí observados

Figura 14: Número total de tempestades elétricas observadas em cada região de $0,25^{\circ} \times 0,25^{\circ}$ de latitude e longitude entre 1998-2011, ilustrando a matriz $\mathbf{P}_{t e}$.

latitude e longitude. Desta forma, $\mathbf{D E}_{t e}$ é obtida conforme a equação 17, que define uma grandeza que representa o número de tempestades elétricas por órbita por quilômetro quadrado $\left(\left[\mathrm{km}^{-2}\right]\right)$.

$$
\mathbf{D E}_{t e}=\frac{\mathbf{P}_{t e}}{\mathbf{V T}_{v i r s} \mathbf{A}_{g}}
$$

A partir da metodologia do cálculo de $\mathbf{D E}_{f l}$, equação 16 e $\mathbf{D E}_{t e}$, equação 17 , cria-se a densidade raios por tempestades elétricas $\mathbf{D E} \mathbf{E}_{r t}$, em que

$$
\mathbf{D E}_{r t}=\frac{\mathbf{F L}_{l i s}}{\mathbf{V T}_{l i s} \mathbf{A}_{g} \mathbf{P}_{t e}} 31557600
$$




\subsection{MORFOLOGIA DA ESTRUTURA TRIDIMENSIONAL DA PRECIPITAÇÃO}

O estudo para descrever a morfologia da precipitação foi realizado com base nas observações do PR, buscando avaliar como a precipitação está distribuída nos níveis de altitude e como os perfis de $Z_{c}$ estão associados com os processos de crescimento de hidrometeoros e consequentemente de eletrificação.

\subsubsection{Distribuições de probabilidades com a altitude}

A partir dos perfis de $Z_{c}$ selecionados pela metodologia de identificação de tempestades elétricas, conforme descrita em 2.4 foi estudada a probabilidade de ocorrência de $Z_{c}$ por altitude através dos Diagramas de Contorno de Frequência por Altitude (CFAD, do inglês, Contour Frequency by Altitude Diagram) (YUTER; HOUZE Jr., 1995).

Conforme descrevem Yuter e Houze Jr. (1995), primeiramente obteve-se uma função de densidade de probabilidade com duas variáveis $\left(f_{p d f}(x, y)\right)$, cuja dimensão $x$ correspondeu aos valores de $Z_{c}$ e $y$ os níveis de altitude do PR. Neste estudo, a função $f_{p d f}(x, y)$ foi representada numericamente por uma matriz bidimensional com a granularidade de $1 \mathrm{dBZ}$ para cada $250 \mathrm{~m}$ de altitude. Para a obtenção dos diagramas de probabilidade normalizados por nível de altitude - CFADs -, cada nível $y$ da função $f_{p d f}(x, y)$ foi normalizado pelo número total de ocorrências de $Z_{c}$.

Os níveis y de altitude com número total de ocorrências de $Z_{c}$ menor do que $10 \%$ do nível y com a máxima ocorrência de $Z_{c}$ foram desconsiderados de todos os CFADs, pois quando a amostragem de valores de $Z_{c}$ é baixa em relação ao nível $y$ de máxima ocorrência de $Z_{c}$ (níveis mais elevados de $y \simeq 15-20 \mathrm{~km}$ ), pode-se obter valores de probabilidade próximos de $100 \%$ e que não são representativos para os CFADs (YUTER; HOUZE Jr. 1995, Apêndice A).

Com base na $f_{p d f}(x, y)$ que definiu cada CFAD, foi calculada a função densidade de probabilidade cumulativa $f_{c d f}(x, y)$ de $Z_{c}$ por altitude, que originaram os Diagramas de Contorno de Frequência Cumulativa por Altitude (CCFAD $\left.{ }^{5}\right)$.

Os CCFADs auxiliam a investigar quais as diferenças entre os perfis de $Z_{c}$ associados a diferentes percentis da amostra de probabilidade, elucidando as informações contidas nos CFADs.

\footnotetext{
${ }^{5}$ Sigla criada a partir do inglês, Contour Cumulative Frequency by Altitude Diagram
} 


\subsubsection{Distribuições de probabilidades em função da temperatura}

A distribuição vertical da precipitação está associada com o desenvolvimento vertical, porém o tipo de hidrometeoro de uma determinada altitude é função da temperatura, probabilidade de colisões e da razão de saturação naquela altura (MASON, 1971, p. 263). Os processos de eletrificação por outro lado dependem do conteúdo de água líquida, temperatura, velocidade terminal, velocidade vertical, tamanho e tipo das partículas (TAKAHASHI, 1978; SAUNDERS et al., 1999; TAKAHASHI; MIYAWAKI, 2002; ÁVILA et al., 2009).

Portanto, saber como o perfil da precipitação varia com a temperatura é preponderante para identificar qual mecanismo de crescimento dos hidrometeoros está dominando conforme o desenvolvimento e a severidade das tempestades elétricas.

Visto que neste trabalho de pesquisa investiga-se a morfologia da precipitação tridimensional das tempestades elétricas observadas pelo PR durante 14 anos, e distribuídas entre as latitudes de $10^{\circ}$ Norte e $40^{\circ}$ Sul sobre a AS e oceanos adjacentes, então, as altitudes das isotermas do perfil atmosférico para cada tempestade elétrica do TRMM será diferente conforme cada período do ano e diferentes latitudes. Portanto, converter o eixo de altitude (80 níveis) das observações do PR para um eixo de temperatura torna-se importante para podermos verificar as diferenças entre os processos de crescimento de hidrometeoros de tempestades elétricas em diferentes localidades e diferentes períodos do ano.

Para converter os níveis de altitude do PR em níveis de temperatura, utilizou-se os dados em 17 níveis de pressão das reanálises (R2) do NCEP-DOE entre 1998-2011, para as variáveis de altura geopotencial e temperatura, correspondentes ao horário mais próximo e anterior a hora em que cada tempestade elétrica foi observada pelo TRMM. A partir dos 17 níveis verticais das R2, os 80 níveis de temperaturas associados aos 80 níveis de altitude das observações do PR foram calculados através de um método de mínimos quadrados.

Após ordenar as medidas de $Z_{c}$ do $\mathrm{PR}$ referente a cada tempestade elétrica em função de um eixo de temperatura, foi elaborado o Diagrama de Contorno de Frequência por Temperatura (CFTD ${ }^{6}$.

Obteve-se a função $f_{p d f}(x, y)$, cuja a dimensão $x$ correspondeu à valores de $Z_{c}$ e $y$ os

\footnotetext{
${ }^{6}$ Sigla criada a partir da expressão em inglês, Contour Frequency Temperature Diagram, nome semelhante ao CFAD proposto em Yuter e Houze Jr. (1995)
} 
nível de temperaturas estimados a partir das R2 do NCEP-DOE. A função $f_{p d f}(x, y)$ de $Z_{c}$ por temperatura, foi representada por uma matriz bidimensional com a granularidade de $1 \mathrm{dBZ}$ para cada $2{ }^{\circ} \mathrm{C}$. Nos CFTDs, os níveis superiores e inferiores foram definidos para temperaturas entre $20^{\circ} \mathrm{C}$ e $-50^{\circ} \mathrm{C}$.

Também foi calculada a função $f_{c d f}(x, y)$ de $Z_{c}$ por temperatura, que originaram os Diagramas de Contorno de Frequência Cumulativa por Temperatura (CCFTD). 


\section{MARCO DAS TEMPESTADES ELÉTRICAS NA AMÉRICA DO SUL}

O marco das tempestades elétricas descreve os locais e quando estes sistemas ocorrem na América do Sul. Para tanto, determina-se a sazonalidade, o ciclo diurno, o ciclo anual e a densidade geográfica de raios e das tempestades elétricas.

\subsection{CICLO DIURNO}

Utilizando a base de dados de tempestades elétricas construída nesta pesquisa, determinouse a frequência de ocorrências dos sistemas no decorrer das horas solares, figura 15. Deste modo, obtivemos o ciclo diurno das tempestades elétricas por meio da distribuição de probabilidade de ocorrências.

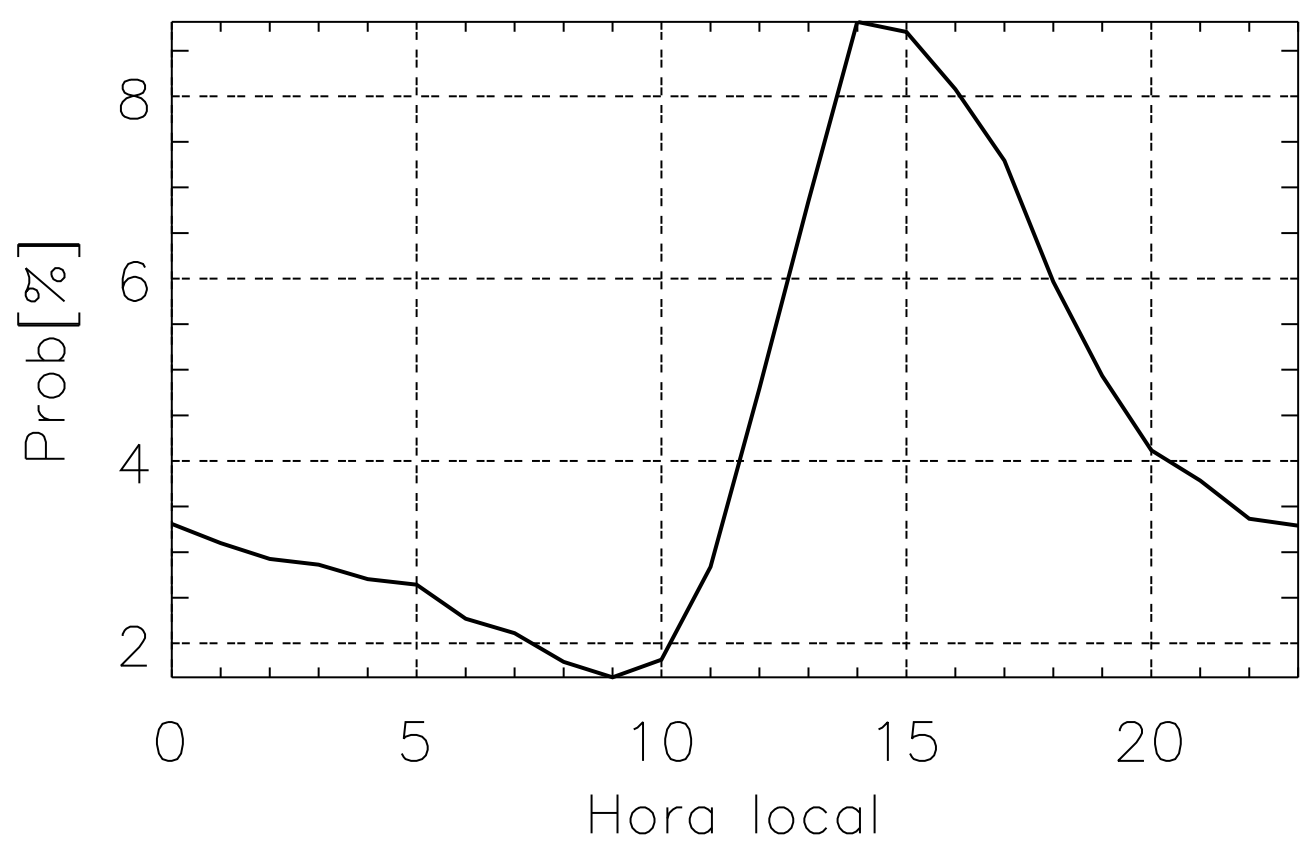

Figura 15: Ciclo diurno das tempestades elétricas observadas em hora local (HL). Os valores de probabilidade foram normalizados pelo total dos 157592 sistemas identificados. 
Observa-se que $40 \%$ das tempestades elétricas observadas pelo TRMM ocorrem entre $13 \mathrm{~h}$ e $17 \mathrm{~h}$, indicando que o aquecimento da superfície do continente que causa o aumento da camada limite planetária no decorrer do dia e que promove q quebra da estabilidade atmosférica, são ingredientes que podem aumentar a probabilidade de ocorrência em relação aos horários de menor fluxo de calor sensível para a atmosfera. Por exemplo, às $9 \mathrm{~h}$ a probabilidade de tempestade elétrica é de $1,6 \%$ e às $14 \mathrm{~h}$ é de $8,8 \%$, portanto às $14 \mathrm{~h}$ a probabilidade de ocorrência de tempestade elétrica é 5,4 vezes maior do que às 9h. Este resultado mostra que as tempestades elétricas estão associadas com a convecção diurna.

O ciclo diurno também foi estudado para cada região de 10 por 10 graus de latitude e longitude, como mostra a figura 16 .

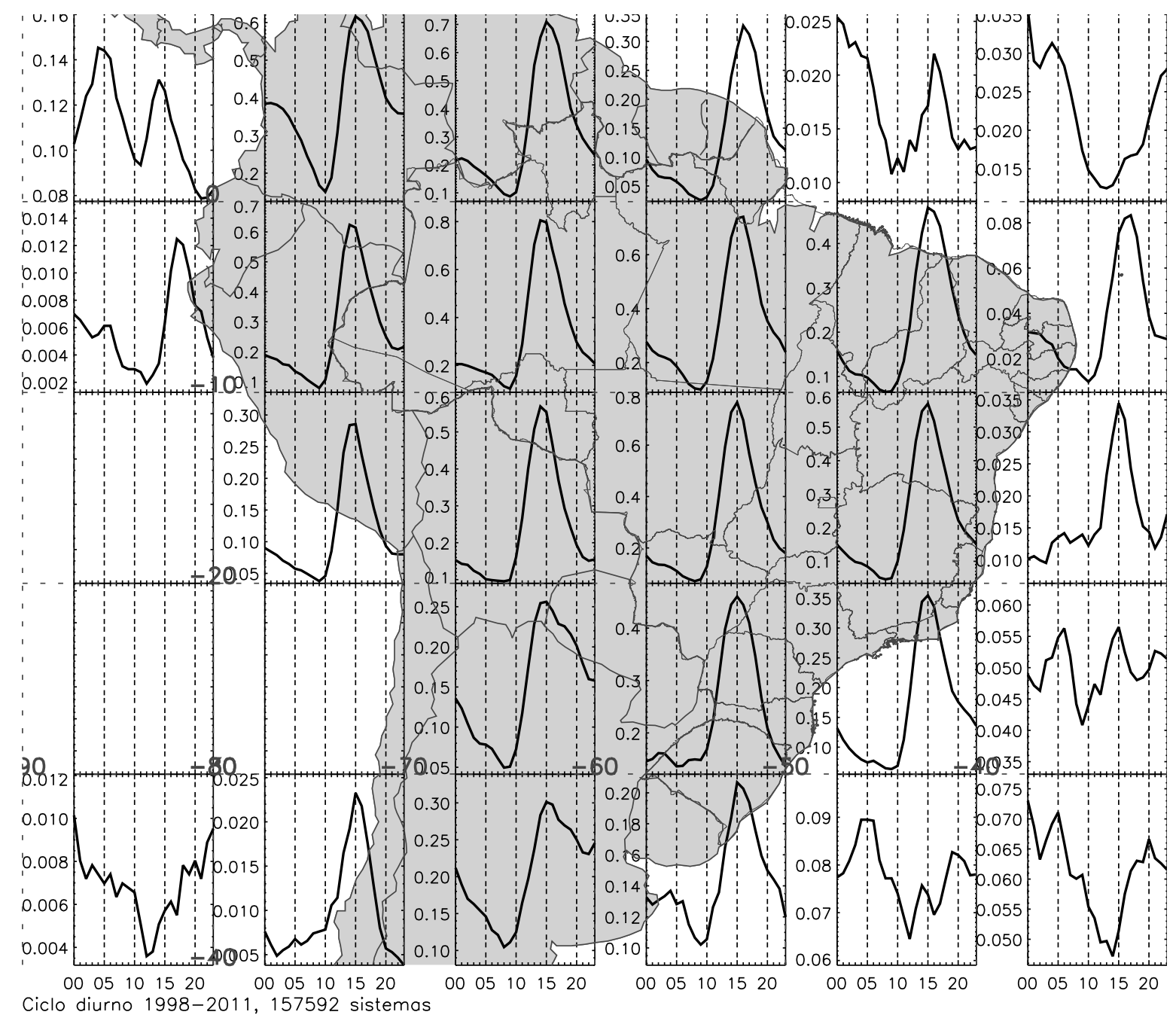

Figura 16: Ciclo diurno em hora local para as tempestades elétricas observadas em cada região de 10 por 10 graus de latitude e longitude. Os valores de probabilidade são mostrados em porcentagem e foram normalizados pelo total de 157592 sistemas observados.

Pode-se observar que existe um predomínio de ocorrências de tempestades elétricas 
entre $13 \mathrm{~h}$ e $17 \mathrm{~h}$ sobre o continente. Sobre o oceano observa-se uma distribuição bimodal, com pico no começo da noite e durante a madrugada.

Sobre os oceanos, os processos de formação de nuvens e consequentemente de formação de tempestades elétricas se mostram mais ativo no horário em que a temperatura superficial e a probabilidade de ocorrência de sistemas sobre o continente diminui. Neste horário a superfície do oceano pode estar com temperaturas maiores do que as temperaturas sobre a superfície do continente, aumentando a convergência sobre o oceano no início do período noturno, i.e., brisa continental. A atividade convectiva intensa entre 13-17h sobre o continente também aumenta a cobertura de nuvens do tipo cirrus sobre as regiões oceânicas próximas da costa inibindo a formação de nuvens (NESBITT; ZIPSER, 2003).

No oceano durante a madrugada, a temperatura da atmosfera pode decrescer mais rapidamente do que a temperatura da superfície do oceano favorecendo a troca de calor sensível entre a superfície do mar e a baixa atmosfera, podendo causar instabilidade atmosférica e desenvolvimento de tempestades elétricas.

Entre $0^{\circ}-10^{\circ}$ Norte e $80^{\circ}-70^{\circ}$ Oeste e às $0 \mathrm{~h}$, observou-se a maior probabilidade $(\simeq 0,4 \%)$ de tempestades elétricas noturnas da América do Sul, o que representou um número de 630 sistemas observados em 14 anos, apenas entre 0h e 00:59h. A circulação de vale e montanha associada com a topografia elevada na Colômbia, principalmente a região do Parque Nacional Natural Paramillo, e o Lago Maracaibo na Venezuela, e a atuação da Zona de Convergência Intertropical (ZCIT), promovem condições para o desenvolvimento de tempestades elétricas noturnas de maneira mais eficiente do que as demais regiões (B̈̈RGESSER et al., 2012; ALBRECHT et al., 2011).

Entre $0^{\circ}-10^{\circ}$ Norte e $90^{\circ}-80^{\circ}$ Oeste, abrangendo o Panamá e parte Sul da Costa Rica, e a região do Oceano Pacífico que engloba o Parque Nacional da Ilha do Coco na Costa Rica e parte das ilhas Galápagos no Equador, é a região oceânica e costeira com a maior probabilidade de ocorrência de tempestades elétricas. Observe os valores de densidade de tempestades elétricas neste quadrante geográfico, na próxima seção, em 3.3 na figura 19. O ciclo diurno das tempestades elétricas nesta região revela uma distribuição bimodal, com um pico às $4 \mathrm{~h}$ e outro às $14 \mathrm{~h}$. O pico das $14 \mathrm{~h}$ provavelmente está associado com as tempestades elétricas da região do Panamá, Costa Rica e suas respectivas regiões costeiras adjacentes, as quais sofrem maior aquecimento superficial durante o dia, enquanto o maior pico que ocorreu às 4 h provavelmente corresponde com as trocas de energia na forma de calor entre o oceano e atmosfera.

Entre $30^{\circ}-10^{\circ}$ Sul e $90^{\circ}-80^{\circ}$ Oeste e entre $30^{\circ}-20^{\circ}$ Sul e $80^{\circ}-70^{\circ}$ Oeste, região do 
Pacífico, as tempestades elétricas são mais raras do que nas demais regiões devido a atuação permanente da subsidência da Célula de Hadley que modula a Alta Subtropical do Pacífico Sul, responsável também por regiões como o Deserto do Atacama e parte do semi-árido Argentino (REBOITA et al., 2010).

Na região do Atlântico Subtropical, a probabilidade de tempestades elétricas é maior do que no Atlântico Norte. A passagem de sistemas transientes 7 entre $40^{\circ}-30^{\circ}$ Sul e $50^{\circ}-30^{\circ}$ Oeste e $30^{\circ}-20^{\circ} \mathrm{Sul}$ e $40^{\circ}-30^{\circ}$ Oeste, gera maior número de tempestades elétricas oceânicas do que com a atuação da ITCZ no Atlântico Tropical. Observa-se também que nas regiões oceânicas o ciclo diurno das tempestades elétricas indica maior atividade noturna.

A maior atividade horária de tempestades elétricas ocorreu entre $10^{\circ}-0^{\circ}$ Sul e $70^{\circ}-50^{\circ}$ Oeste e $20^{\circ}-10^{\circ} \mathrm{Sul}$ e $60^{\circ}-50^{\circ}$ Oeste. Em cada uma destas três regiões observou-se a probabilidade de aproximadamente $0,8 \%$ entre as $14 \mathrm{~h}$ e $16 \mathrm{~h}$, mostrando que em toda esta área o TRMM observou 3 tempestades elétricas a cada 2 dias, apenas durante estas duas horas.

Entre $30^{\circ}-20^{\circ} \mathrm{Sul}$ e $60^{\circ}-50^{\circ}$ Oeste, região de grande atividade de Sistemas Convectivos de Meso-escala (SCM) conforme descrevem Durkee e Mote(2009), encontra-se um máximo durante a tarde e os sistemas noturnos tiveram probabilidade de ocorrência 2,7 vezes menor do que os valores encontrados sobre os vales na Colômbia e Venezuela, mostrando que a ocorrência dos SCM noturnos no Sul da América do Sul, não possui probabilidade de ocorrência que se destaca-se em relação a atividade de tempestades elétricas noturnas nas demais regiões continentais.

\subsection{CICLO ANUAL}

Quando se analisa a sazonalidade por meio da distribuição de probabilidade a cada mês do ano, observa-se uma distribuição bimodal com o maior pico em Outubro, período de transição entre a estação seca e chuvosa (primavera), e um segundo pico em Março, período também de transição, mas entre a estação chuvosa e seca (outono). Após o mês de outubro, a probabilidade de ocorrências de tempestades elétricas segue decrescendo até fevereiro e em março há um crescimento. Apesar do aumento da probabilidade de tempestades elétricas em março na AS, em dezembro, janeiro e fevereiro, a probabilidade de tempestade elétrica é entre 1-4\% maior do que em março, conforme mostra a figura

\footnotetext{
${ }^{7}$ Frentes frias associadas a sistemas de baixa pressão.
} 
17.

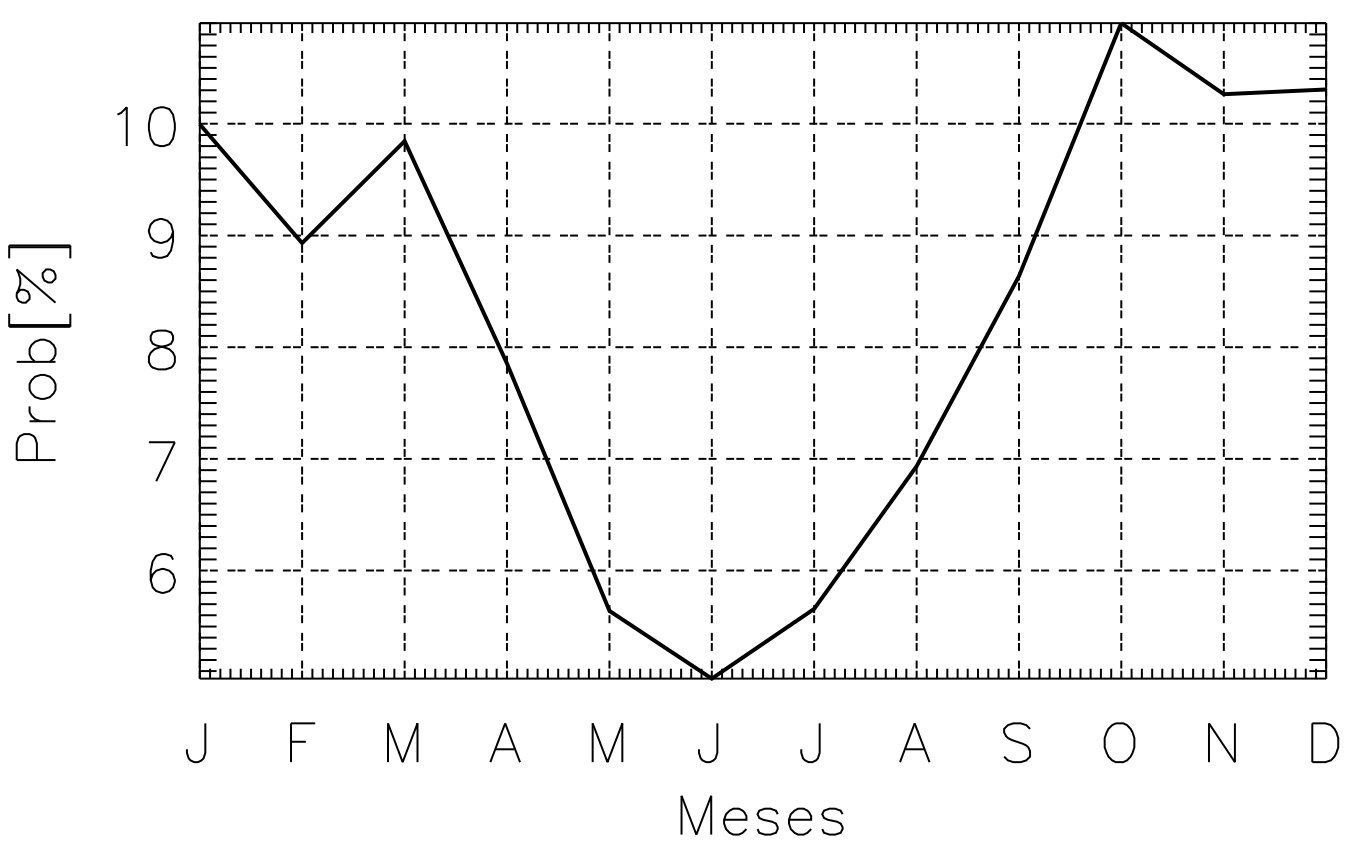

Figura 17: Ciclo anual das tempestades elétricas observadas em hora local. Os valores de probabilidade foram normalizados pelo total dos 157592 sistemas identificados.

A maior probabilidade foi de 10,9\% no mês de outubro, conforme mostra a figura 17. De outubro até março foram observadas $60,2 \%$ das tempestades elétricas. Em junho observou-se a mínima probabilidade de tempestades elétricas com valor de 5,1\%. Portanto, entre o período de máximo e mínimo anual o número de ocorrência de tempestades elétricas se reduz aproximadamente pela metade.

O ciclo anual das tempestades elétricas também foi estudado para cada região de 10 por 10 graus de latitude e longitude. O valor de setenta por cento da máxima probabilidade de tempestade elétrica em cada região foi definido como limiar para considerar que a ocorrência de tempestades elétricas aumentou o suficiente para definir uma estação e este valor é representado pela linha horizontal que corta cada gráfico em cada ponto da grade de $10^{\circ} \times 10^{\circ}$ de latitude e longitude da figura 18 . O valor de $70 \%$ da máxima probabilidade de tempestade elétrica foi escolhido pelo fato de definir uma estação de $\simeq 4$ meses na média entre as regiões de $10^{\circ} \times 10^{\circ}$ de latitude e longitude.

A tabela 4 mostra os meses de duração das estações de tempestades elétricas de acordo com cada região conforme mostra a figura 18 .

Na região entre $40^{\circ}-20^{\circ}$ Sul e $70^{\circ}-60^{\circ}$ Oeste (linhas 21 e 27 da tabela 4), entre o 


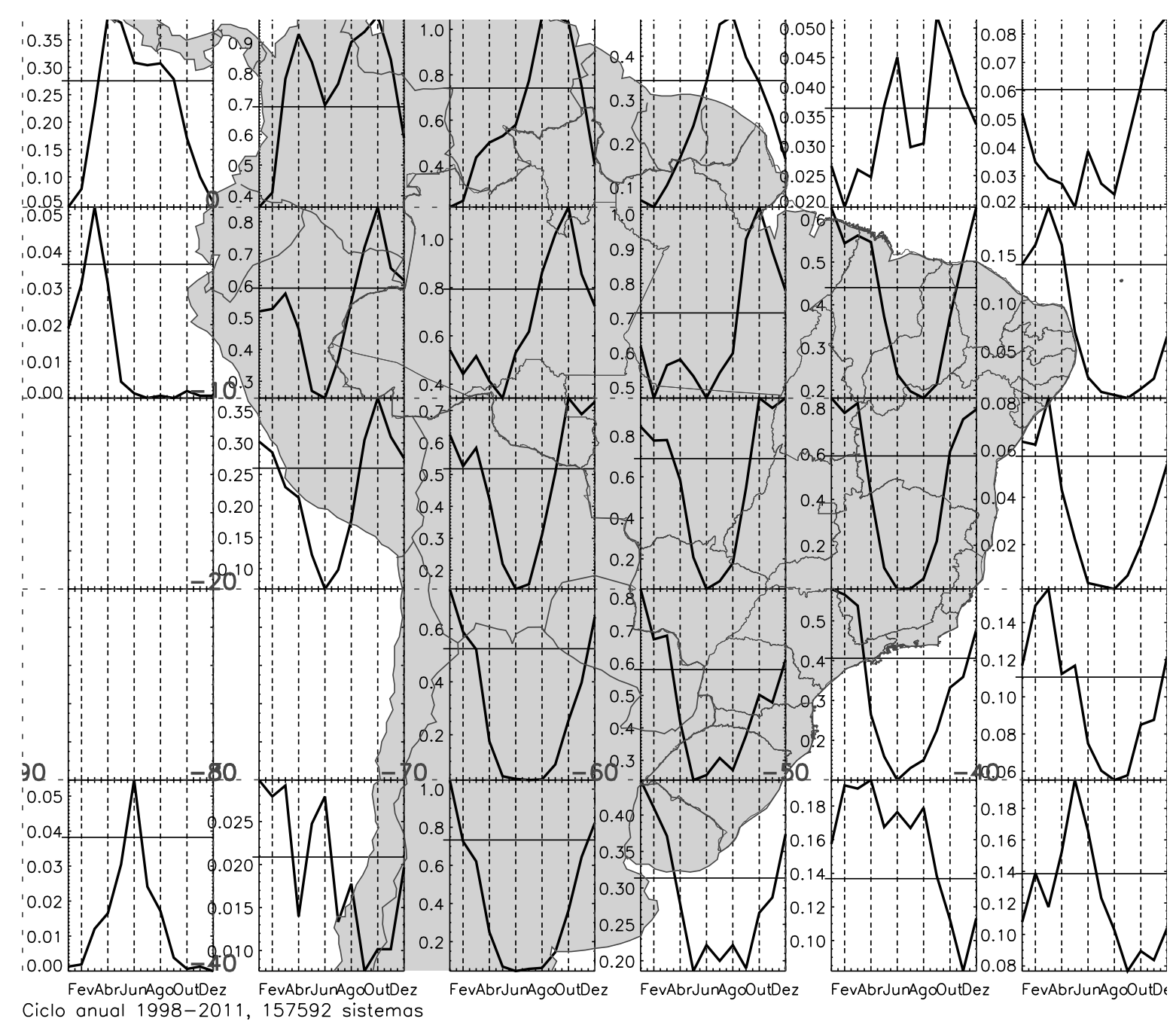

Figura 18: Ciclo anual em hora local para as tempestades elétricas observadas em cada região de 10 por 10 graus de latitude e longitude. Os valores de probabilidade são mostrados em porcentagem e foram normalizados pelo total de 157592 sistemas observados. As linhas horizontais cortam o valor de 0,7 do máximo de probabilidade, utilizado como limiar para definir as estações de tempestades elétricas.

clima semi-árido na Argentina e parte da Bacia do Prata, local das tempestades mais severas e de maior probabilidade de ocorrência de núcleos de convecção profunda da AS como apontam Cecil et al. (2005), Zipser et al. (2006), Romatschke e Houze (2010), foi encontrada a estação de tempestades elétricas com a maior amplitude entre o máximo de ocorrências em janeiro e o mínimo em junho. A probabilidade de tempestades elétricas em junho foi aproximadamente 10 vezes menor do que em janeiro.

Sobre a Colômbia e parte Oeste da Venezuela que abrange o lago Maracaibo, região referente à linha 2 da tabela 4 , foi a região em que o TRMM observou o maior número de tempestades elétricas (14 232). Nesta região a estação de tempestades elétricas dura 9 meses, com dois picos: abril e outubro. 
Tabela 4: Principais características do ciclo anual de probabilidade de ocorrência de tempestades elétricas observadas entre 1998-2011, em cada região de 10 por 10 graus de latitude longitude.

\begin{tabular}{|c|c|c|c|c|c|}
\hline & Localização & $\begin{array}{l}\text { Número de } \\
\text { sistemas }\end{array}$ & $\begin{array}{l}\text { Estação } \\
\text { (meses) }\end{array}$ & $\begin{array}{l}\text { Duração } \\
\text { (meses) }\end{array}$ & Máximo \\
\hline 1 & $0^{\circ}-10^{\circ} \mathrm{N}, 90^{\circ}-80^{\circ} \mathrm{O}$ & 4173 & Abr-Set & 6 & Abr \\
\hline 2 & $0^{\circ}-10^{\circ} \mathrm{N}, 80^{\circ}-70^{\circ} \mathrm{O}$ & 14232 & Mar-Nov & 9 & Out \\
\hline 3 & $0^{\circ}-10^{\circ} \mathrm{N}, 70^{\circ}-60^{\circ} \mathrm{O}$ & 11946 & Jul-Nov & 5 & Ago-Set \\
\hline 4 & $0^{\circ}-10^{\circ} \mathrm{N}, 60^{\circ}-50^{\circ} \mathrm{O}$ & 4895 & Jul-Set & 3 & Ago \\
\hline 5 & $0^{\circ}-10^{\circ} \mathrm{N}, 50^{\circ}-40^{\circ} \mathrm{O}$ & 645 & $\begin{array}{l}\text { Mai-Jun, } \\
\text { Set-Nov }\end{array}$ & 5 & Set \\
\hline 6 & $0^{\circ}-10^{\circ} \mathrm{N}, 40^{\circ}-30^{\circ} \mathrm{O}$ & 824 & Out-Dez & 3 & Dez \\
\hline 7 & $10^{\circ}-0^{\circ} \mathrm{S}, 90^{\circ}-80^{\circ} \mathrm{O}$ & 225 & Mar & 1 & Mar \\
\hline 8 & $10^{\circ}-0^{\circ} \mathrm{S}, 80^{\circ}-70^{\circ} \mathrm{O}$ & 10014 & Set-Dez & 4 & Out \\
\hline 9 & $10^{\circ}-0^{\circ} \mathrm{S}, 70^{\circ}-60^{\circ} \mathrm{O}$ & 12605 & Ago-Nov & 4 & Out \\
\hline 10 & $10^{\circ}-0^{\circ} \mathrm{S}, 60^{\circ}-50^{\circ} \mathrm{O}$ & 12590 & Set-Dez & 4 & Out \\
\hline 11 & $10^{\circ}-0^{\circ} \mathrm{S}, 50^{\circ}-40^{\circ} \mathrm{O}$ & 7863 & $\begin{array}{l}\text { Jan-Abr, } \\
\text { Nov-Dez }\end{array}$ & 6 & Jan \\
\hline 12 & $10^{\circ}-0^{\circ} \mathrm{S}, 40^{\circ}-30^{\circ} \mathrm{O}$ & 1363 & $\mathrm{Fev}-\mathrm{Abr}$ & 3 & Mar \\
\hline 13 & $20^{\circ}-10^{\circ} \mathrm{S}, 90^{\circ}-80^{\circ} \mathrm{O}$ & 1 & $-0-$ & $-0-$ & $-0-$ \\
\hline 14 & $20^{\circ}-10^{\circ} \mathrm{S}, 80^{\circ}-70^{\circ} \mathrm{O}$ & 4344 & $\begin{array}{l}\text { Jan-Fev, } \\
\text { Set-Dez }\end{array}$ & 6 & Out \\
\hline 15 & $20^{\circ}-10^{\circ} \mathrm{S}, 70^{\circ}-60^{\circ} \mathrm{O}$ & 8895 & $\begin{array}{l}\text { Jan-Mar, } \\
\text { Out-Dez }\end{array}$ & 6 & Out \\
\hline 16 & $20^{\circ}-10^{\circ} \mathrm{S}, 60^{\circ}-50^{\circ} \mathrm{O}$ & 10973 & $\begin{array}{l}\text { Jan-Mar, } \\
\text { Out-Dez }\end{array}$ & 6 & Out \\
\hline 17 & $20^{\circ}-10^{\circ} \mathrm{S}, 50^{\circ}-40^{\circ} \mathrm{O}$ & 8524 & $\begin{array}{l}\text { Jan-Mar, } \\
\text { Out-Dez }\end{array}$ & 6 & Jan \\
\hline 18 & $20^{\circ}-10^{\circ} \mathrm{S}, 40^{\circ}-30^{\circ} \mathrm{O}$ & 625 & Jan-Mar & 3 & Mar \\
\hline 19 & $30^{\circ}-20^{\circ} \mathrm{S}, 90^{\circ}-80^{\circ} \mathrm{O}$ & 32 & $-0-$ & $-0-$ & $-0-$ \\
\hline 20 & $30^{\circ}-20^{\circ} \mathrm{S}, 80^{\circ}-70^{\circ} \mathrm{O}$ & 32 & -0 & -0 & -0 \\
\hline 21 & $30^{\circ}-20^{\circ} \mathrm{S}, 70^{\circ}-60^{\circ} \mathrm{O}$ & 5607 & Dez-Mar & 4 & Jan \\
\hline 22 & $30^{\circ}-20^{\circ} \mathrm{S}, 60^{\circ}-50^{\circ} \mathrm{O}$ & 8885 & Dez-Mar & 4 & Jan \\
\hline 23 & $30^{\circ}-20^{\circ} \mathrm{S}, 50^{\circ}-40^{\circ} \mathrm{O}$ & 6121 & Dez-Mar & 4 & Jan \\
\hline 24 & $30^{\circ}-20^{\circ} \mathrm{S}, 40^{\circ}-30^{\circ} \mathrm{O}$ & 1884 & Dez-Mai & 4 & Mar \\
\hline 25 & $40^{\circ}-30^{\circ} \mathrm{S}, 90^{\circ}-80^{\circ} \mathrm{O}$ & 258 & Jun & 1 & Jun \\
\hline 26 & $40^{\circ}-30^{\circ} \mathrm{S}, 80^{\circ}-70^{\circ} \mathrm{O}$ & 366 & $\begin{array}{l}\text { Jan-Mar, } \\
\text { Mai-Jun }\end{array}$ & 5 & Jan \\
\hline 27 & $40^{\circ}-30^{\circ} \mathrm{S}, 70^{\circ}-60^{\circ} \mathrm{O}$ & 7652 & Dez-Jan & 2 & Jan \\
\hline 28 & $40^{\circ}-30^{\circ} \mathrm{S}, 60^{\circ}-50^{\circ} \mathrm{O}$ & 5440 & Dez-Mar & 4 & Jan \\
\hline 29 & $40^{\circ}-30^{\circ} \mathrm{S}, 50^{\circ}-40^{\circ} \mathrm{O}$ & 2949 & Jan-Set & 9 & Abr \\
\hline 30 & $40^{\circ}-30^{\circ} \mathrm{S}, 40^{\circ}-30^{\circ} \mathrm{O}$ & 2301 & Abr-Jun & 3 & Mai \\
\hline
\end{tabular}

A partir da definição dos meses de duração da estação de tempestades elétricas em cada região da AS conforme a tabela 4, pode-se verificar se estação de tempestade elétrica está associada com a estação chuvosa de cada região. Em Morales (2010), a partir de dados de raios do LIS e da taxa de precipitação estimada pelo PR, mostra que a definição de 
uma estação de raios na AS não implica na definição de uma estação chuvosa.

Durante o final do verão boreal, entre julho e setembro, a estação chuvosa começa a se deslocar do Hemisfério Norte para o Hemisfério Sul, de Noroeste da AS para Sudeste da AS intensificando-se progressivamente até atingir os maiores acumulados de chuva entre dezembro e janeiro (GRIMM, 2003; REBOITA et al., 2010; MARENGO et al., 2012; SHI et al. 2009; BOMBARDI, 2008; CUSTÓDIO, 2013). Porém, os períodos das máximas probabilidades de ocorrência de tempestades elétricas do TRMM durante o ciclo anual, não ocorrem em fase com os máximos anuais de precipitação em algumas regiões da AS.

Na parte central da AS, linhas $8,9,10,14,15,16$ da tabela $4\left(20^{\circ}-0^{\circ}\right.$ Sul e $80^{\circ}-$ $50^{\circ}$ Oeste), as tempestades elétricas ocorrem com maior frequência em outubro, entre a estação seca e chuvosa. Porém os máximos sazonais de precipitação nesta região ocorrem defasados aproximadamente em 5 meses do máximo de tempestades elétricas, entre os meses de fevereiro e abril (GRIMM, 2003, REBOITA et al., 2010, SHI et al., 2009, BOMBARDI, 2008, CUSTÓDIO, 2013).

Na região Sul da AS, à Leste da Cordilheira dos Andes referentes às linhas 21 e 27 da tabela 4, a estação de tempestades elétricas ocorre entre dezembro e janeiro, em fase com a estação chuvosa. Aqui, a probabilidade de tempestades elétricas aumenta quando o Jato de Baixos Níveis da América do Sul (JBNAS) intensifica o transporte de umidade entre a Bacia Amazônica e a Bacia do Prata durante a atuação do Sistema de Monção da América do Sul (SMAS) (MARENGO et al., 2004).

A região Sul e Sudeste do Brasil, referentes às linhas 17, 22, 23 e 28 da tabela 4 . a estação de tempestades elétricas ocorre também em fase com o período de máxima configuração do SMAS, entre dezembro e janeiro. Petersen et al. (2002), mostram que mudanças na circulação atmosférica durante o período chuvoso associadas às fases ativa e de pausa da SMAS, descritas por Jones e Carvalho (2002), Carvalho et al. (2004), influenciam na densidade de raios sobre a AS, indicando que, nas regiões em que a estação de tempestades elétricas coincide com os meses de atuação da ZCAS, a variabilidade intrasazonal do SMAS torna-se importante para a ocorrência de tempestades elétricas.

Apesar da convergência em grande escala associada a ZCAS, sua atuação contínua durante meses poderia diminuir a instabilidade atmosférica devido a chuvas contínuas e baixa incidência de radiação de onda curta na superfície, o que reduziria a temperatura da superfície, diminuindo o lapse-rat 8 . As pausas do SMAS podem ser importantes para o aumento do lapse-rate da atmosfera e quando há novamente uma fase ativa do SMAS,

\footnotetext{
${ }^{8}$ Termo utilizado para expressar a taxa de variação de temperatura com a altitude da atmosfera.
} 
a atmosfera possui energia e umidade suficientes para eventos de tempestades elétricas.

Na região da costa Nordeste da AS, referente às linhas 12 e 18 da tabela 4, a estação de tempestades elétricas possui máxima atividade em março e mínimo em torno de agosto. Nestas regiões o máximo sazonal de precipitação ocorre em fase com o máximo sazonal de tempestades elétricas, porém, durante o período pós-monção na AS (GRIMM, 2003, REBOITA et al., 2010; SHI et al., 2009, BOMBARDI, 2008, CUSTÓDIO, 2013).

As regiões oceânicas, referentes às linhas, 1, 5, 7, 25, 29 e 30 da tabela 4 o pico de atividade de tempestades elétricas não ocorre entre outubro e março como mostra o ciclo anual total da figura 17, mas entre março e setembro durante o outono e inverno austral. Durante o inverno, a diferença entre a temperatura da superfície do continente e a temperatura da superfície do oceano é menor, o que favorece a convergência sobre o oceano ativando os processos de eletrificação fora do período de maior insolação. Conforme o ciclo anual da precipitação na AS mostrado em Custódio (2013), observa-se que o máximo sazonal de precipitação observada pelo PR nestas regiões oceânicas ocorrem em fase com os máximos sazonais de tempestades elétricas desta pesquisa.

A região do Atlântico Tropical refente à linha 6 da tabela 4 possui o máximo sazonal de ocorrência de tempestades elétricas em dezembro, enquanto o máximo sazonal de precipitação ocorre durante o outono austral (CUSTÓDIO, 2013).

\subsection{DISTRIBUIÇÃO DE DENSIDADES GEOGRÁFICAS}

Considerando o método descrito em 2.6, referente ao cálculo da densidade de tempestades elétricas e da densidade de raios, foram obtidos os mapas da densidade total de tempestades elétricas e de raios, figuras 19 e 20, assim como os mapas da densidade sazonal de raios e de tempestades elétricas que são mostrados nas figuras 21 e 22.

Tanto a densidade total quanto a densidade sazonal de raios apresentadas nesta seção, não correspondem à amostragem total de raios observados pelo LIS corrigida pela eficiência como é mostrado em trabalhos como Albrecht et al. (2011), Cecil et al. (2014), mas correspondem ao subconjunto dos raios do LIS, os quais estiveram contidos dentro da área das tempestades elétricas, conforme descreve a metodologia de identificação das tempestades elétricas em 2.4. Portanto, nesta pesquisa, o leitor poderá observar valores de densidade de raios anuais inferiores aos trabalhos que consideram todos os raios observados pelo LIS e com correção da eficiência de detecção.

Das 79932 órbitas do TRMM entre 1998-2011, apenas 63613 passaram sobre a 
região da AS definida nesta pesquisa. Foram identificadas 157592 tempestades elétricas, portanto, o TRMM observou aproximadamente 5 sistemas a cada 2 órbitas sobre a região da AS. O mapa na figura 19 mostra quantas vezes foram observadas tempestades elétricas nos sobrevoos do VIRS sobre cada ponto da grade de $0,25^{\circ} \times 0,25^{\circ}$ de latitude e longitude. Note que uma tempestades elétrica é um fenômeno que cobre entre dezenas e milhares de pontos de grade de $0,25^{\circ} \times 0,25^{\circ}$, não sendo um fenômeno pontual como o raio é considerado.

Os maiores valores da escala de densidade de tempestades elétricas na figura 19 , estiveram entre a 2,5-4,7 $\times 10^{-4} \mathrm{~km}^{-2}$ (cores em vermelho e pink). Considerando a área de um ponto da grade de $0,25^{\circ} \times 0,25^{\circ} \mathrm{com} 772 \mathrm{~km}^{2}$, os valores entre $2,5-4,7 \times 10^{-4}$ $\mathrm{km}^{-2}$ revelam que neste ponto de grade foi observado entre 2-4 tempestades elétricas a cada 10 passagens do VIRS.

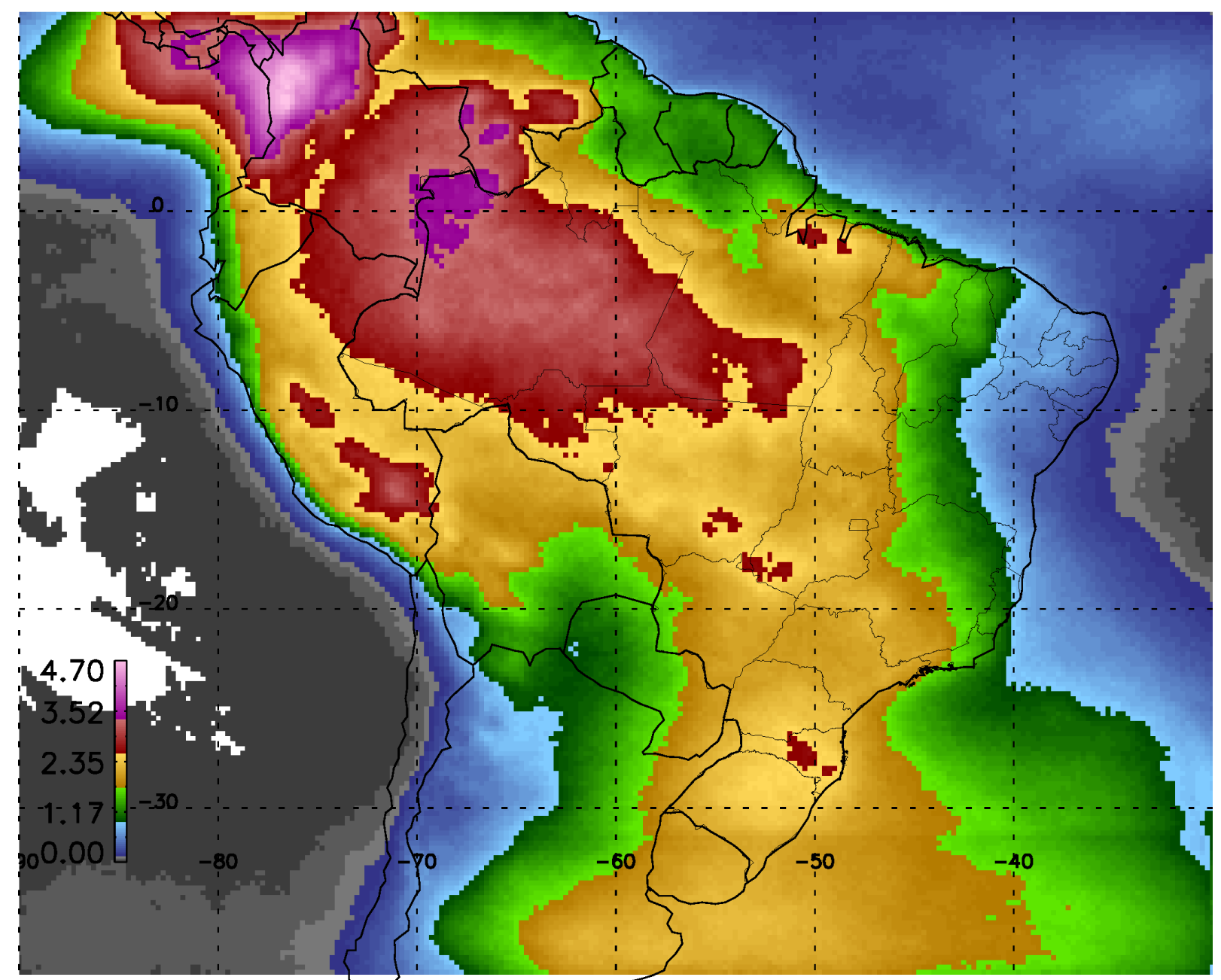

1998-201-40 Tempestades elétricas por órbita 1,0-4 $\left[\mathrm{km}^{-2}\right]$, 1575',92 Sistemas ob'servados

Figura 19: Distribuição de densidade anual de tempestades elétricas. As cores correspondem ao número de tempestades elétricas por passagens do VIRS por quilômetro quadrado multiplicado por $10^{-4}\left(\left[\mathrm{~km}^{-2}\right]\right)$ em cada pronto da grade de $0,25^{\circ} \times 0,25^{\circ}$ de latitude e longitude. 
As regiões de maiores densidades de tempestades elétricas situam-se na parte Norte e Nordeste da AS. Observam-se duas extensas regiões com as máximas densidades: uma na Colômbia associado ao extremo Norte da Cordilheira dos Andes, outra ao Norte/Noroeste da Floresta Amazônica, abrangendo a parte brasileira, colombiana, venezuelana e peruana.

A costa Oeste da Colômbia e Panamá destaca-se como a região de maior densidade de tempestades elétricas costeiras, pois o escoamento atmosférico predominantemente de Leste devido a convergência dos Alísios - ZCIT - ao encontrar o extremo Norte da Cordilheira dos Andes entre 0-10 $0^{\circ}$ Norte, sofre pertubações que disparam tempestades elétricas que continuam a se propagar em sentido Oeste para o Pacífico tropical.

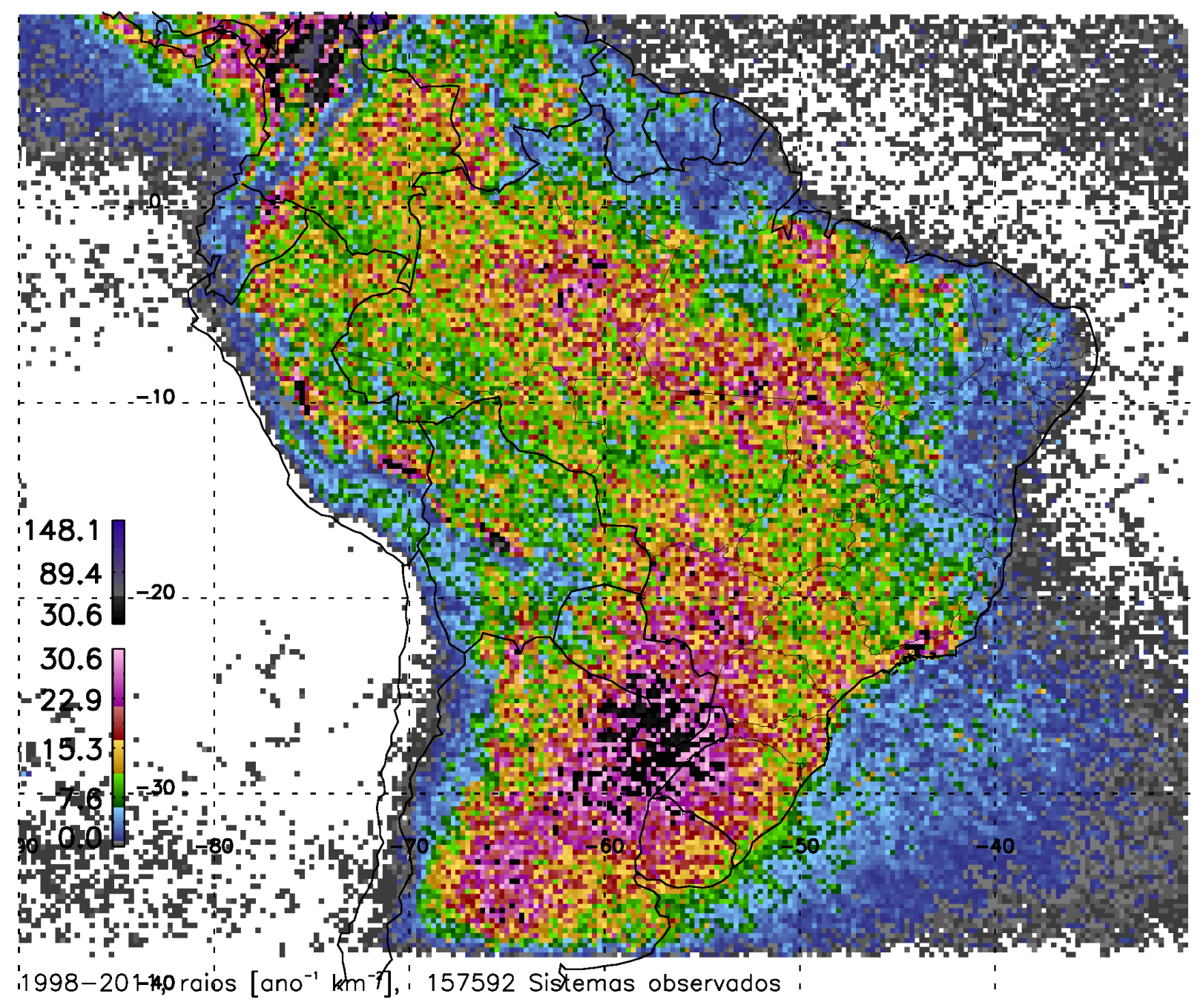

Figura 20: Distribuição de densidade anual de raios. As cores representam o número de raios por ano por quilômetro quadrado $\left(\left[\mathrm{ano}^{-1}\right]\left[\mathrm{km}^{-2}\right]\right)$ em cada ponto da grade de $0,25^{\circ} \times 0,25^{\circ}$ de latitude e longitude.

A maior extensão em área das máximas densidades de tempestades elétricas sobre a AS foi observada na região da Floresta Amazônica, principalmente a Oeste e Sudoeste do Pico 
da Neblina, região da cabeceira do Rio Negro, de tríplice fronteira entre Brasil, Colômbia e Venezuela. É notável que a topografia da região Amazônica aumenta a densidade de tempestades elétricas como é o caso da região do Pico da Neblina, principalmente entre a Venezuela e o Brasil, porém esta vasta região contínua com valores de densidade de tempestades elétricas superior a $2,5 \times 10^{-4} \mathrm{~km}^{-2}$, sugere que os efeitos da circulação atmosférica de grande escala e processos termodinâmicos conforme aponta Albrecht et al. (2011), são os principais agentes de instabilidade atmosférica que promovem o maior número de tempestades elétricas da AS.

No entanto, ao analisar a densidade de raios juntamente com a densidade de tempestades elétricas, observa-se que na região central do estado do Amazonas, há pontos da grade de $0,25^{\circ} \times 0,25^{\circ}$ com valores entre $30-40$ raios por ano por quilômetro quadrado (ano ${ }^{-1}$ $\mathrm{km}^{-2}$ ), como mostra a figura 20 , e densidades de sistemas, figura 19 , entre 2,9-3,5 $\times 10^{-4}$ tempestades elétricas por quilômetro quadrado $\left(\mathrm{km}^{-2}\right)$. Na região Norte da Argentina, Sudoeste e Sul do Paraguai, valores de densidade de raios de mesma magnitude são observados, porém com uma densidade de sistemas entre $1,0-1,8 \times 10^{-4} \mathrm{~km}^{-2}$. Portanto, podemos afirmar que nas regiões de máxima densidade de raios sobre a Bacia do Prata, as tempestades elétricas produziram entre 195-323\% mais raios por quilômetro quadrado por ano do que em relação as tempestades elétricas observadas sobre as regiões de máximas densidades de raios sobre a Bacia Amazônica, ou seja, sobre a Bacia Amazônica as tempestades elétricas são menos eficazes em produzir raios do que na Bacia Platina.

Região de topografia elevada como ao Noroeste do Lago Titicaca no Peru e algumas regiões do Planalto Brasileiro como sobre a Serra Catarinense e o Parque Nacional das Emas ao Sudoeste de Goiás foram também regiões com as maiores densidades de tempestades elétricas da AS.

No estado do Pará, região do deságue do Rio Amazonas no Oceano Atlântico, sobre o Parque Estadual Charapucu e região de deságue do Rio Tocantis no Oceano Atlântico, próximo a cidade de Belém, foram observados também valores de densidades de tempestades elétricas e de densidade de raios entre os maiores registrados sobre AS e não possuem topografia elevada, mas o efeito de brisa de rio e brisa marítima combinados com a circulação de grande escala predominantemente de leste favorecem a dinâmica para a formação de linhas de instabilidade que se formam na costa e se propagam continente a dentro (KOUSKY, 1980; COHEN et al., 1995, ALCÂNTARA, 2010.

Nas figuras 21 e 22, a distribuição de densidade geográfica de raios e de tempestades elétricas, foi calculada para os períodos associados a cada estação do ano: dezembro, 
janeiro e fevereiro (DJF); março, abril e maio (MAM); junho, julho e agosto (JJA) e setembro, outubro e novembro (SON). A tabela 5 mostra o acumulado de sistemas observados em cada estação do ano.

Na primavera austral (SON), é quando o continente sul-americano recebe a maior incidência de raios. Ao avaliar a densidade de raios tanto sobre a Bacia do Prata quanto sobre a Bacia Amazônica, observa-se que as maiores densidades de raios ocorreram em SON. Os valores de densidade de raios no mapa da figura 21d sobre ambas as bacias hidrográficas mostram valores entre 4-11 raios $\mathrm{mes}^{-1} \mathrm{~km}^{-2}\left(50-130\right.$ raios ano $\left.{ }^{-1} \mathrm{~km}^{-2}\right)$. Portanto, mesmo que haja maior número de tempestades elétricas sobre a Bacia do Prata durante o verão, as tempestades elétricas de primavera foram as responsáveis pelas maiores densidades de raios durante o ano.

No estudo da sazonabilidade das tempestades elétricas mostrado na seção anterior 3.2, na figura 18 , entre $30^{\circ}-20^{\circ}$ Sul e $60^{\circ}-50^{\circ}$ Oeste, observa-se um máximo local de probabilidade ( $0,5 \%$ que representou 789 sistemas) de tempestades elétricas em outubro e que não correspondeu ao período da estação de tempestades elétricas desta região. Portanto, em algumas regiões como é o caso da região central da Bacia do Prata, o pico da estação de tempestades elétricas não ocorre em fase com a estação em que se observa a máxima densidade de raios. Neste caso as tempestades elétricas responsáveis pelas maiores densidades anuais de raios da região precederam a estação de tempestades elétricas e ao verificar o ciclo anual da chuva em Grimm (2003), Reboita et al. (2010), SHI et al. (2009), Custódio (2013), verifica-se que a estação de tempestades elétricas ocorreu em fase com a estação chuvosa.

Tabela 5: Total de tempestades elétricas observadas entre 1998-2011, para cada período de três meses associados as estações do ano.

\begin{tabular}{cc}
\hline \hline Estação & Número de sistemas \\
\hline Verão - DJF & 46077 \\
Outono - MAM & 36804 \\
Inverno - JJA & 16850 \\
Primavera - SON & 57861 \\
\hline
\end{tabular}

Durante DJF, quando o SMAS se configura na AS, as mais extensas regiões com as maiores densidades de raios concentram-se: sobre a Argentina; Paraguai; Mato Grosso do Sul; Sul de Mato Grosso; Sudeste brasileiro, principalmente sobre toda a extensão da Serra do Mar entre Santa Catarina e Rio de Janeiro e entre Minas Gerais e o Rio de Janeiro onde localiza-se o Parque Nacional Itatiaia e o Pico das Agulhas Negras; interior de São Paulo; Sul e Sudoeste de Minas Gerais; região central de Tocantis; Norte do Maranhão; e 

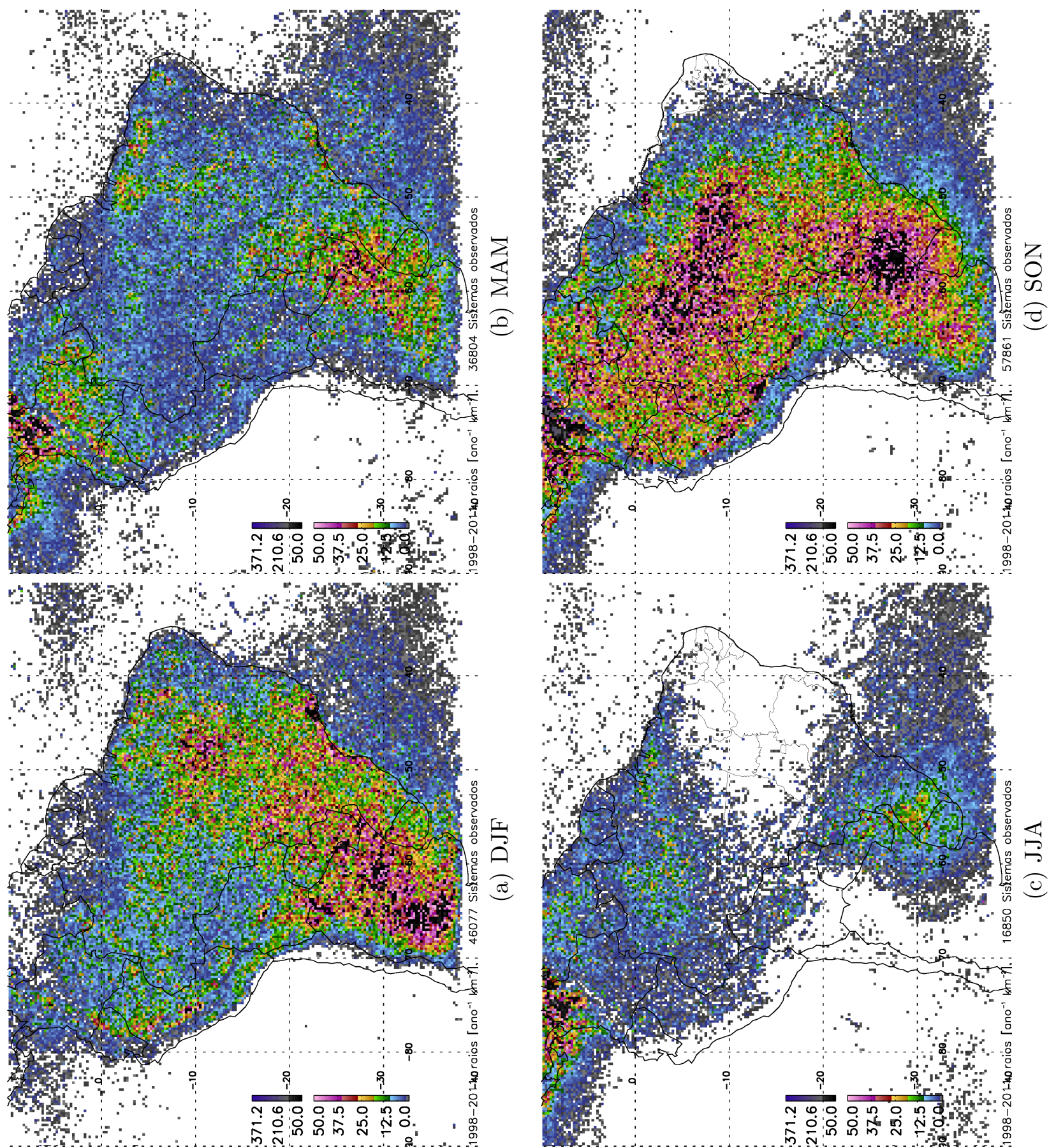

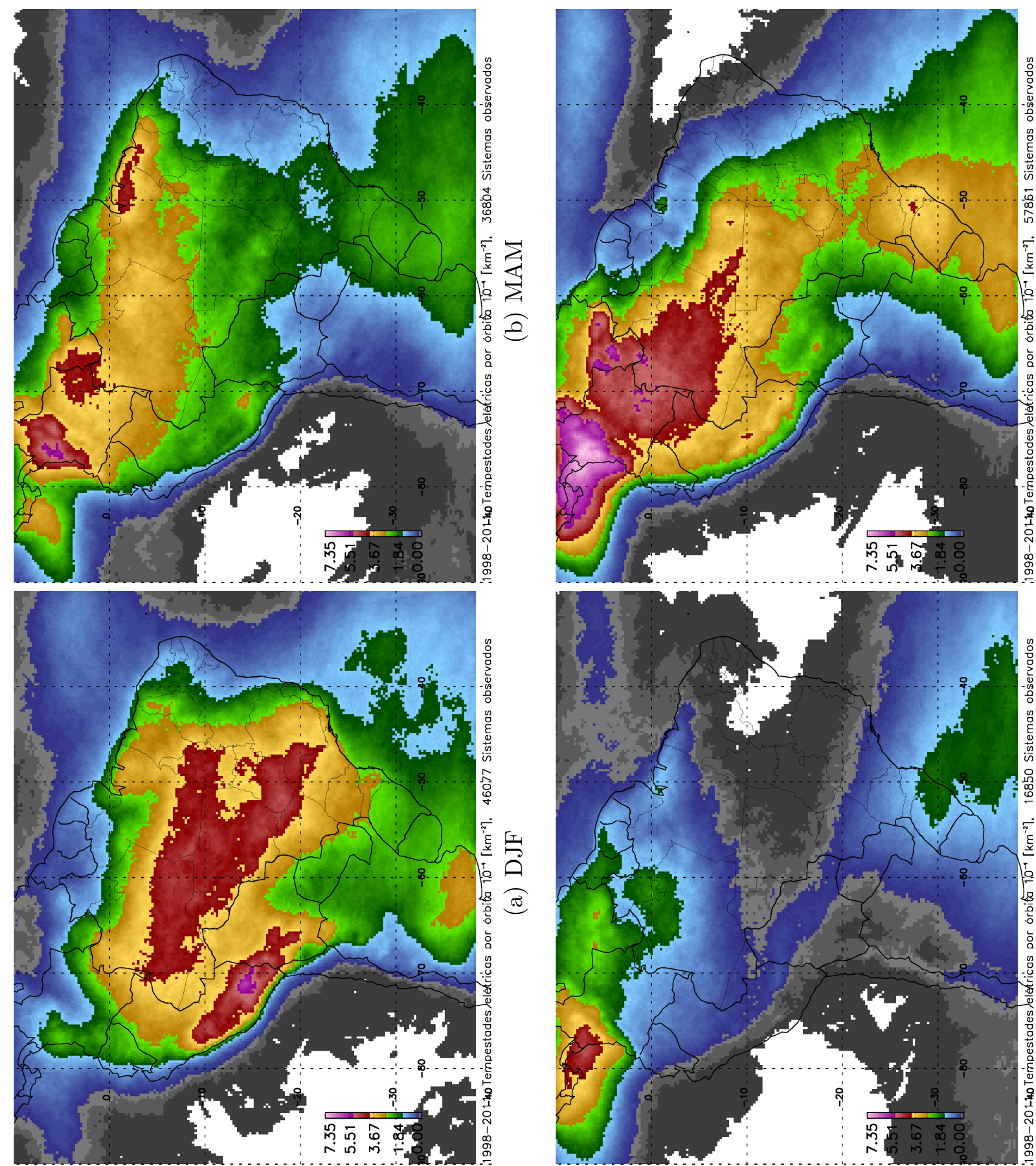
Norte do Pará região da cidade de Belém.

Em MAM, período pós-monção na AS, observamos as tempestades elétricas bastante concentradas na região Norte e Nordeste da AS, como mostra a figura 22b. Durante este período observou-se pontos de grade no mapa da figura 21b, sobre as regiões de Sertão e Agreste Nordestino, no estado da Paraíba entre as cidade de Corema e Patos, também no Rio Grande do Norte sobre a região da bacia do Rio Piranha-Açu, com valores em torno de 4 raios mês ${ }^{-1} \mathrm{~km}^{-2}$ (50 raios ano $\left.{ }^{-1} \mathrm{~km}^{-2}\right)$.

No geral, ao comparar as figuras 21 e 22 observa-se que as regiões de máxima densidade sazonal de raios não são as regiões de máxima densidade sazonal de tempestades elétricas. As máximas densidades de raios geralmente ficam situadas em regiões deslocadas das máximas densidades de sistemas. Por exemplo, a maior área continua da AS com densidade anual de raios superior a 25 raios ano ${ }^{-1} \mathrm{~km}^{-2}$, como mostra a figura 20, ocorre na região Sul da AS. Tanto na figura 19 quanto na figura 22 , podemos observar um gradiente de sistemas nesta região que marca a transição entre o clima Desértico no Deserto do Atacama e Semi-árido da Argentina para o Clima Subtropical Úmido, promovendo um ambiente de transição seco para úmido permanente para os sistemas que iniciam-se principalmente na região da Serra de Córdoba na Argentina e se propagam para Noroeste.

Nas regiões das cidades de Belém e Norte do Maranhão as máximas densidades anuais de tempestades elétricas coincidem com as regiões de máximas densidades anuais de raios, porém observou-se maiores densidades de raios em DJF, figura 21a, e maiores densidades de tempestades elétricas em MAM, figura 22b.

Sobre a região do Lago Maracaibo na Venezuela, a maior densidade sazonal de tempestades elétricas foi observada em SON, figura 22d, em fase com a máxima densidade sazonal de raios que ocorreu em SON, figura 21d. Aqui o aumento da densidade de raios está relacionado ao aumento sazonal do número de sistemas. Durante a primavera austral - SON - as tempestades elétricas na foz do Rio Catatumbo produziram 31 raios mês ${ }^{-1}$ $\mathrm{km}^{-2}$ (371,2 raios ano ${ }^{-1} \mathrm{~km}^{-2}$ ). Em Albrecht et al. (2011), a região do Lago Maracaibo foi apontada como o máximo global anual das observações do TRMM.

A partir do estudo das densidades anuais de tempestades elétricas e densidades anuais de raios, foi calculada a densidade de raios por tempestades elétricas conforme descreve a equação 18 , e a matriz $\mathbf{D E}_{r t}$ é projetada geograficamente como mostra a figura 23. Os valores desta grandeza (raios $\left[\mathrm{ano}^{-1}\right]\left[\mathrm{km}^{-2}\right]$ por tempestade), correspondem à eficiência de produção de raios por tempestade elétrica em cada área associada aos pontos de $0,25^{\circ}$ $\times 0,25^{\circ}$ de latitude e longitude. 
A região da Bacia do Paraguai-Paraná-Prata foi a maior extensão contínua com as maiores densidades de raios por tempestade elétrica. Porém destacam-se regiões como: a Serra do Mar abrangendo o Vale do Ribeira em São Paulo, Pico das Agulhas Negras em Minas Gerais, região serrana do Rio de Janeiro; parte Sul do Tocantis; parte Leste e Norte do Pará e Leste do estado do Amazonas. Estas regiões podem indicar locais cuja a topografia ou circulação local intensificam os sistemas.

Os maiores valores da escala de cores da figura 23 , foram observados sobre a região do Lago Maracaibo. Conforme o mapa da figura 20, sabemos que o ponto de grade com a máxima densidade de raios sobre a região do Lago Maracaibo $\left(148,1 \mathrm{ano}^{-1} \mathrm{~km}^{-2}\right)$, mostra que sobre a extensão de $772 \mathrm{~km}^{2}$ (área do ponto de grade de $0,25^{\circ} \times 0,25^{\circ}$ ), ocorreram 114333 raios ano ${ }^{-1}$. O máximo valor de $11,73 \times 10^{-2} \mathrm{ano}^{-1} \mathrm{~km}^{-2}$ da figura 23 mostra que, sobre a área do ponto de grade de máxima densidade de raios por tempestade, cada tempestade elétrica observada contribuiu em média com 91 raios ano $^{-1}$, portanto, 1256 tempestades elétricas foram responsáveis por toda a produção de raios do ponto de grade.

Regiões no pico da Cordilheira dos Andes são bastante eficientes, principalmente na

A região à Leste da cidade de Cochabamba na Bolívia se mostra como umas das mais eficientes na produção de raios por tempestades elétricas, revelando pontos de grade com

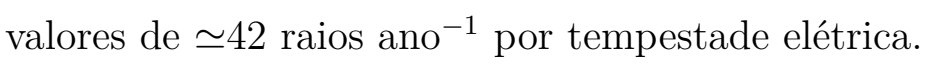




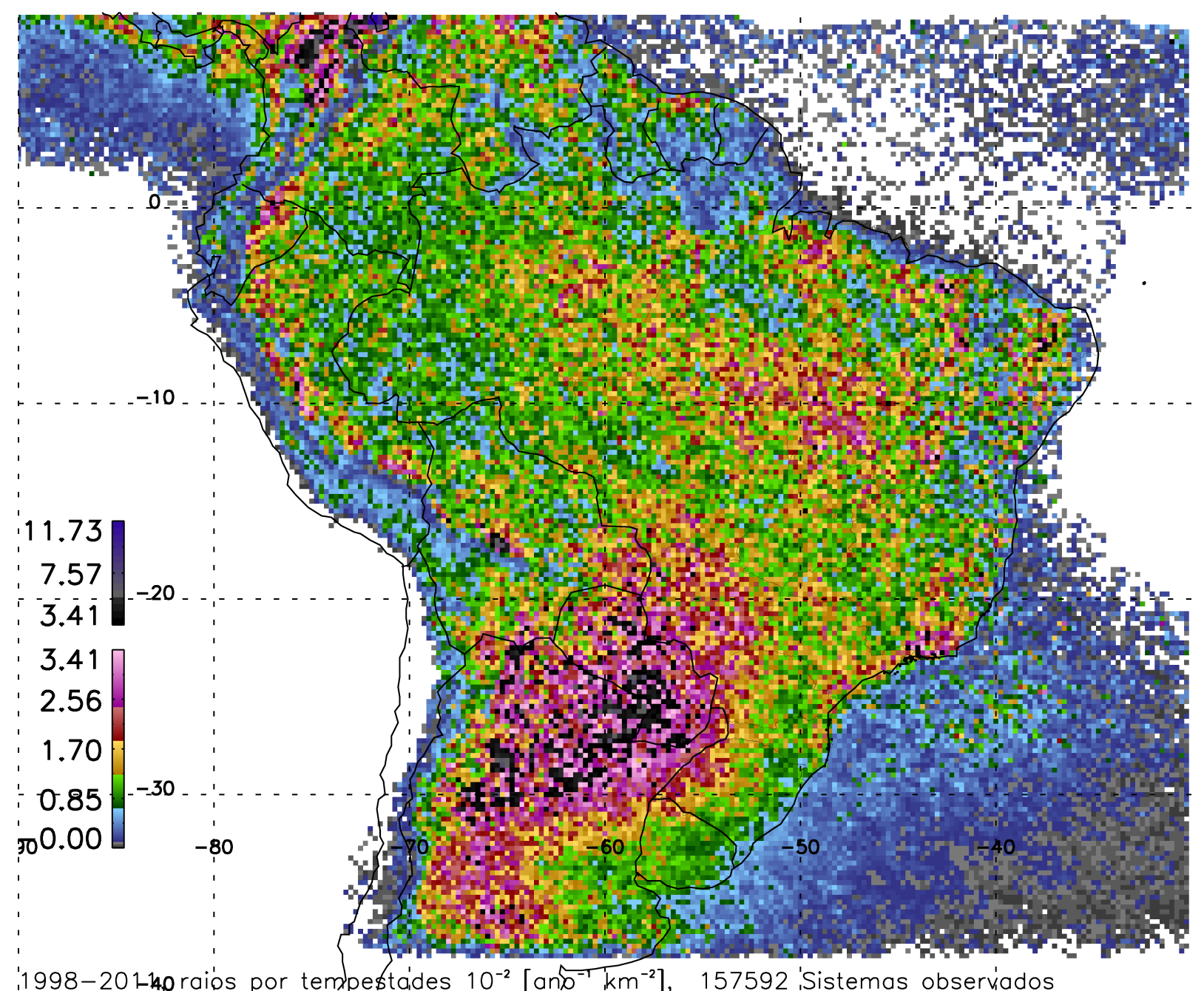

Figura 23: Distribuição de densidade de raios por tempestade elétrica. As cores representam o número de raios por tempestades elétricas multiplicado por $10^{-2}$ por ano por quilômetro quadrado $\left(10^{-2}\left[\mathrm{ano}^{-1}\right]\left[\mathrm{km}^{-2}\right]\right)$ em cada ponto da grade de $0,25^{\circ} \times 0,25^{\circ}$. 


\section{TEMPESTADES ELÉTRICAS SEVERAS}

Conforme descrito em 2.5, as taxas de raios das tempestades elétricas neste trabalho de pesquisa estão associadas aos índices FTA e FT. Nesta seção identifica-se qual desses índices podem melhor associar-se com a intensidade convectiva das tempestades elétricas.

Como a intensidade convectiva - severidade - será avaliada a partir da taxa de raios (FTA e FT) e o estudo da morfologia da estrutura tridimensional da precipitação observada pelo $\mathrm{PR}$, foram selecionados apenas os sistemas que possuíram $V T_{m}$ maior ou igual a 1 minuto e com pelo menos um pixel do campo de visão do PR contido na área do sistema com chuva válida, totalizando 94733 tempestades elétricas do TRMM.

As equações 14 e 15 foram aplicadas nas 94733 tempestades elétricas selecionadas, e então estudadas as distribuições de probabilidades dos índices FTA e FT (figuras 24 e 25). Conforme mostra a figura 24. tratam-se de distribuições exponenciais negativas de probabilidade. Os valores de FTA e FT para cada quantil da amostragem de tempestades elétricas, tanto para as mais frequentes quanto as mais raras, podem ser verificados por meio da distribuição cumulativa de probabilidade de FTA e FT mostradas na figura 25.

Na mediana da amostragem de FTA, as tempestades elétricas tiveram 2,3 × $10^{-4}$ raios

$\min ^{-1} \mathrm{~km}^{-2}$ e na mediana da amostragem de $\mathrm{FT}$, foram 3,4 raios $\mathrm{min}^{-1}$. O maior número de tempestades elétricas possuem os menores valores FTA e FT, conforme é mostrado na figura 24. Note que o primeiro degrau referente à curva da distribuição cumulativa de FT na figura 25. corresponde a 28,9\% da amostragem das 94733 tempestades elétricas do TRMM e o primeiro degrau da distribuição cumulativa de FTA (figura 25) corresponde a $9,8 \%$ de 94733 .

Os sistemas potencialmente severos são selecionados pelo $90^{\circ}$ percentil das amostragens de probabilidades de FTA e FT, que correspondem aos $10 \%$ mais intensos e mais raros valores de FTA e FT ocorridos. Portanto, pressupõe-se que as tempestades elétricas as quais provavelmente causaram chuva de granizo, rajadas de ventos com quedas de árvores e construções ou tornados devem estar associadas aos sistemas com valores extremos de 


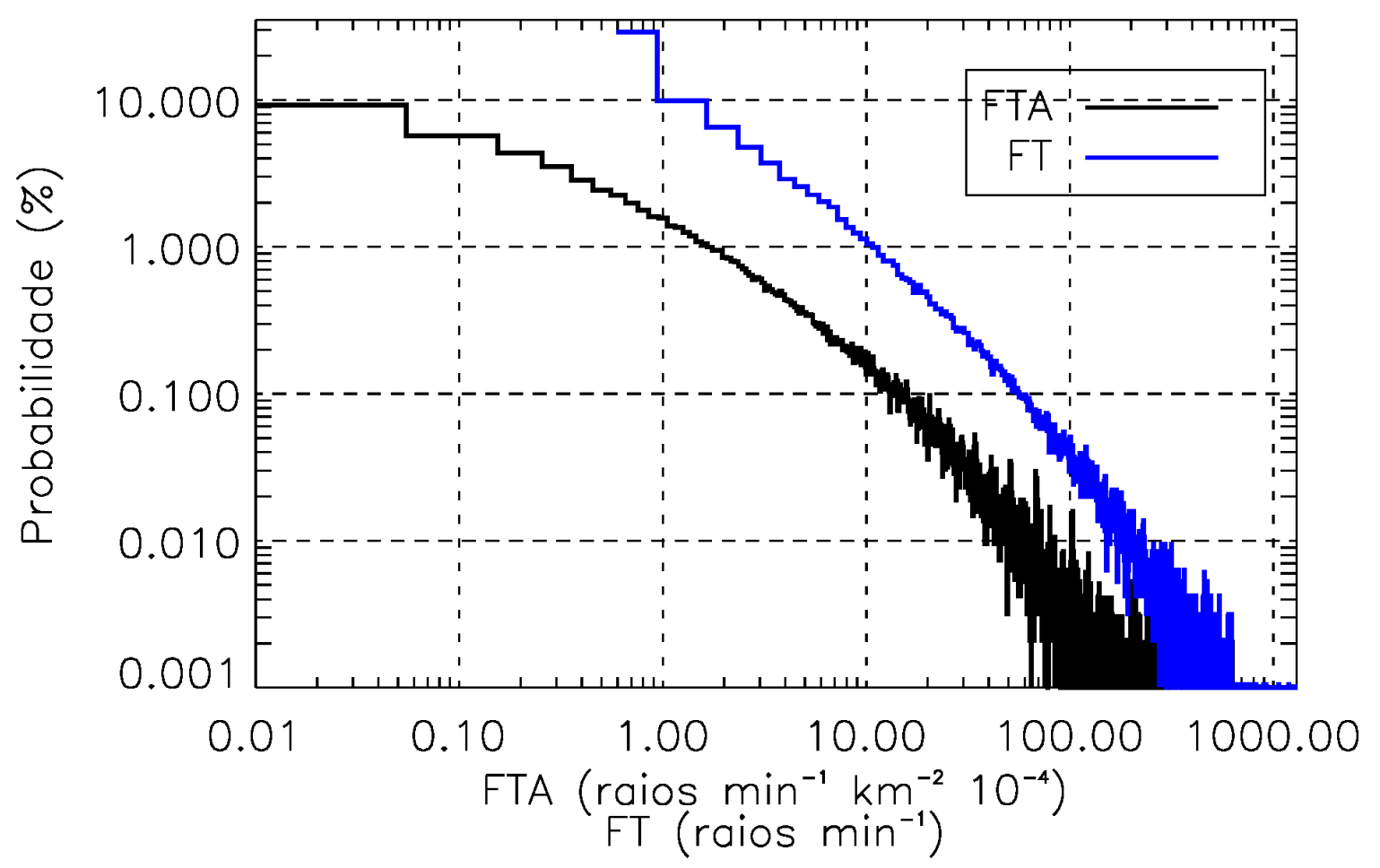

Figura 24: Densidade de probabilidade de FTA e FT.

FTA ou FT.

Desta forma, temos dois grupo de tempestades elétricas do TRMM extremas, um composto por 9475 tempestades elétricas com valores extremos de FTA e outro com

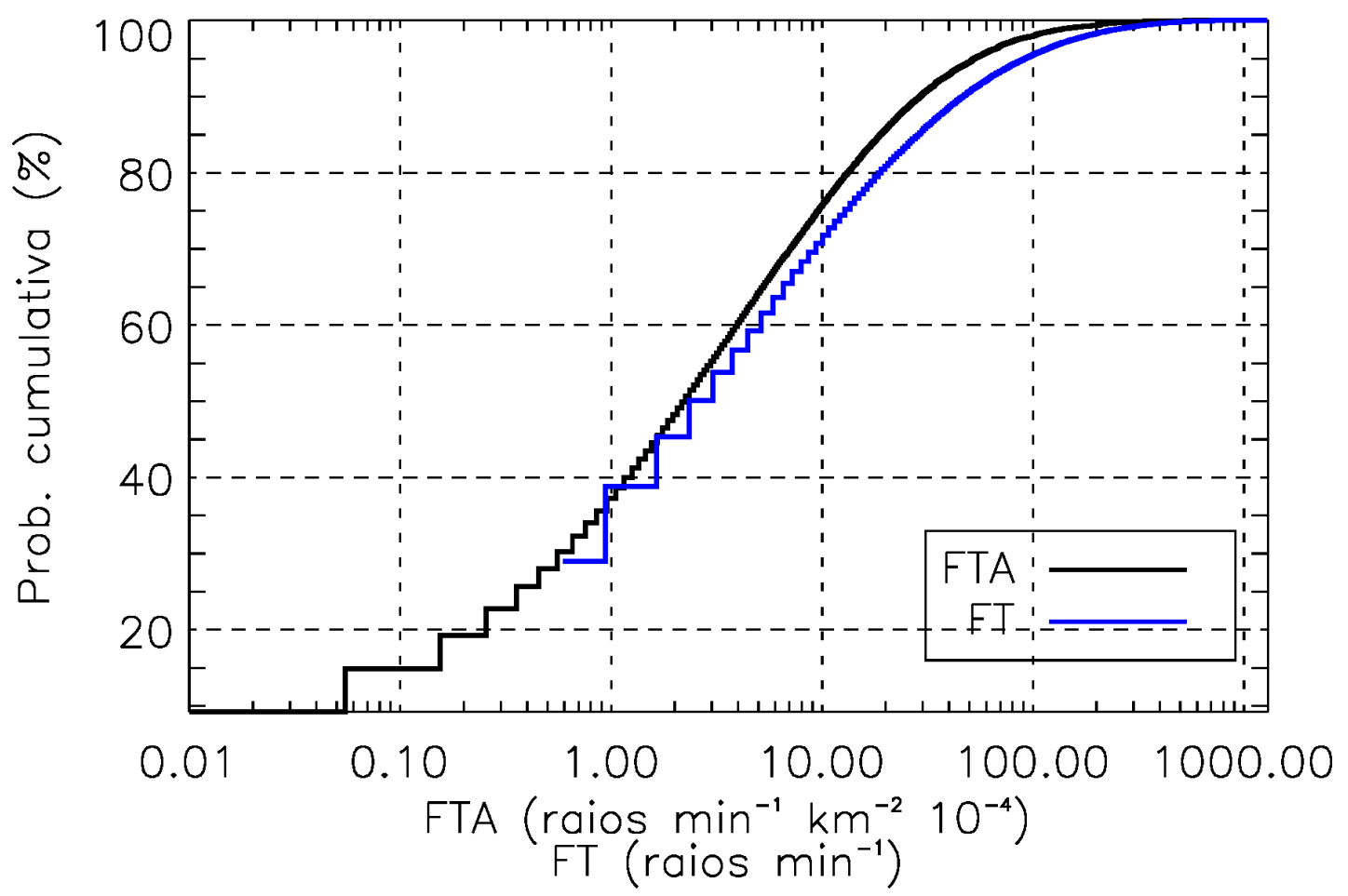

Figura 25: Densidade de probabilidade cumulativa de FTA e FT. 
9475 tempestades elétricas com valores extremos de FT. Os valores extremos de FTA estiveram entre $29,3-1258,7 \times 10^{-4}$ raios por minuto por quilômetro quadrado ([min $\left.{ }^{-1}\right]$ $\left.\left[\mathrm{km}^{-2}\right]\right)$, enquanto os FT extremos estiveram entre 47,2-1283,6 raios por minuto ([min $\left.\left.{ }^{-1}\right]\right)$. Observe que os extremos do índice FT correspondem as taxas de raios no tempo das PFs de categoria três, quatro e cinco de Cecil et al. (2005), as quais produziram entre 30,91351 raios $\mathrm{min}^{-1}$, que totalizaram 5727 PFs observadas sobre o globo em 3 anos de dados do TRMM. Neste trabalho de pesquisa, que considera apenas a região da AS, porém 14 anos de dados do TRMM, os extremos de FT (47,2-1283,6 raios min $\left.^{-1}\right)$ representam um total de 9475 tempestades elétricas do TRMM.

As figuras 26 e 27 ilustram as medidas do TRMM que compõem os arquivos HDF de tempestades elétricas para 3 sistemas com FTA extremos e 3 sistemas com FT extremos e que possuíram pelo menos $50 \%$ da sua área dentro da visada do PR.

Na parte superior e inferior dos painéis representados pelas figuras 26 e 27, há informações referentes a data e hora em que o sistema foi observado, número de raios/eventos (FL/EV), fração do sistema observado pelo PR, valores dos índices FTA e FT, área do sistema (A), semieixo maior (a), menor (b), distância focal (2c) e excentricidade (e) de uma elipse ajustada as dimensões do sistema. As barras de cores correspondem aos valores de $T_{b} \leq 258 \mathrm{~K}$ que definem a área das tempestades elétricas e ao lado os valores de $Z_{c}$ referente à precipitação a $2 \mathrm{~km}$ de altitude. À direita dos mapas que representam o topo das nuvens de tempestades elétricas e a chuva em $2 \mathrm{~km}$, são plotados os perfis médios de $Z_{c}$ por altitude, classificados como convectivos e estratiformes, nas cores vermelha e azul respectivamente e o perfil médio de $Z_{c}$ considerando todos os perfis: convectivo, estratiforme e outros, que é representado pela curva na cor preta.

Observe que o valor mínimo de FT foi de 0,6 raios por minuto, diferente de Cecil et al. (2005), que considerou a mínima taxa de raios no tempo para as PFs de 0,7 raios por minutos. Porém a resolução espacial da projeção do tempo de visada do LIS utilizada nesta tese possui resolução de $0,25^{\circ} \times 0,25^{\circ}$ de latitude e longitude (ALBRECHT et al. 2011). Ao considerar a velocidade e altura da órbita do satélite, o tempo de observação do LIS em um ponto de $0,25^{\circ} \times 0,25^{\circ}$ na superfície terrestre pode atingir até 102 segundos na região zenital. Então, as tempestades elétricas que possuíram apenas 1 raio e $V T_{m}$ de $\simeq 100$ segundos, tiveram o mínimo valor de FT de 0,6 raios $\mathrm{min}^{-1}$, sendo esta, a taxa mínima de raios no tempo detectável em uma tempestade elétrica do TRMM neste estudo. 
(K)

(dBZ)
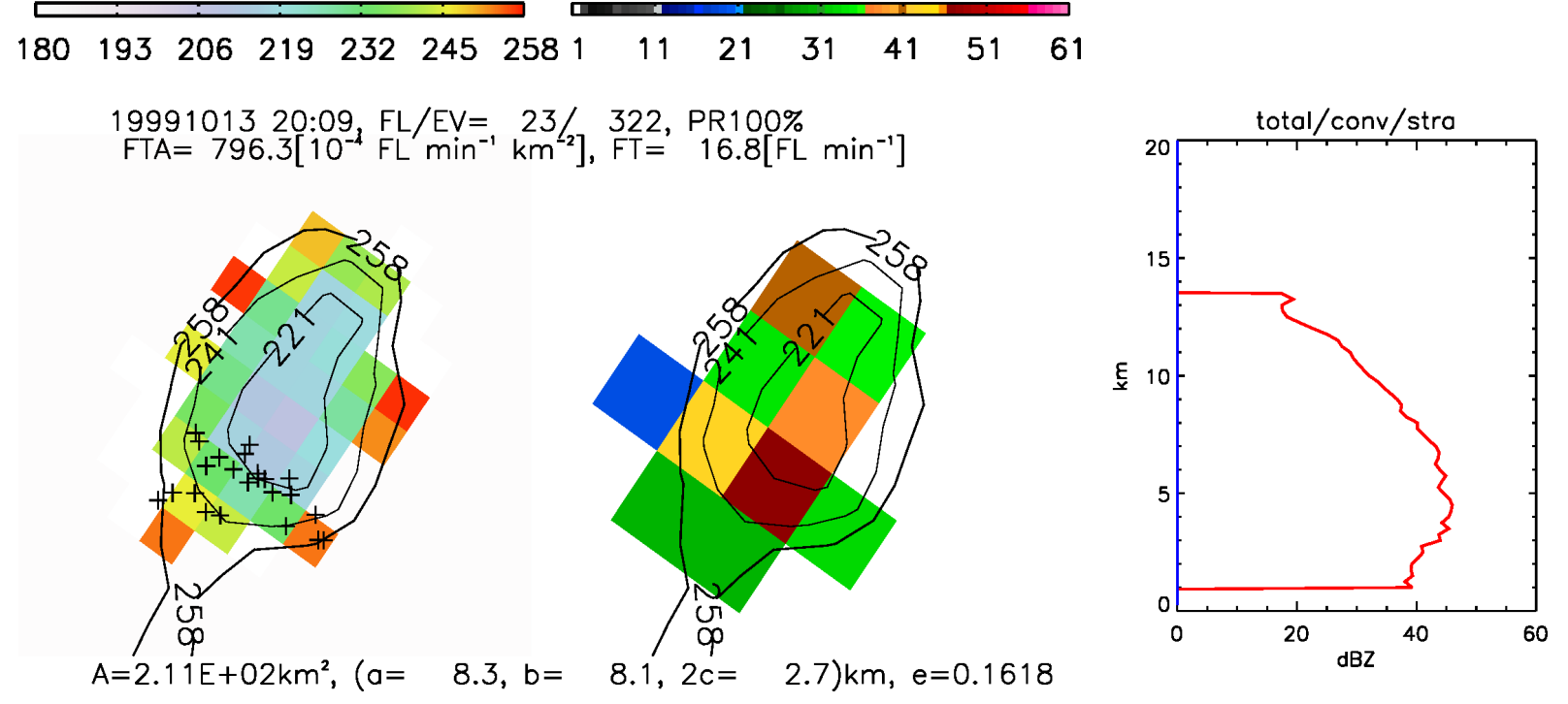

(a)
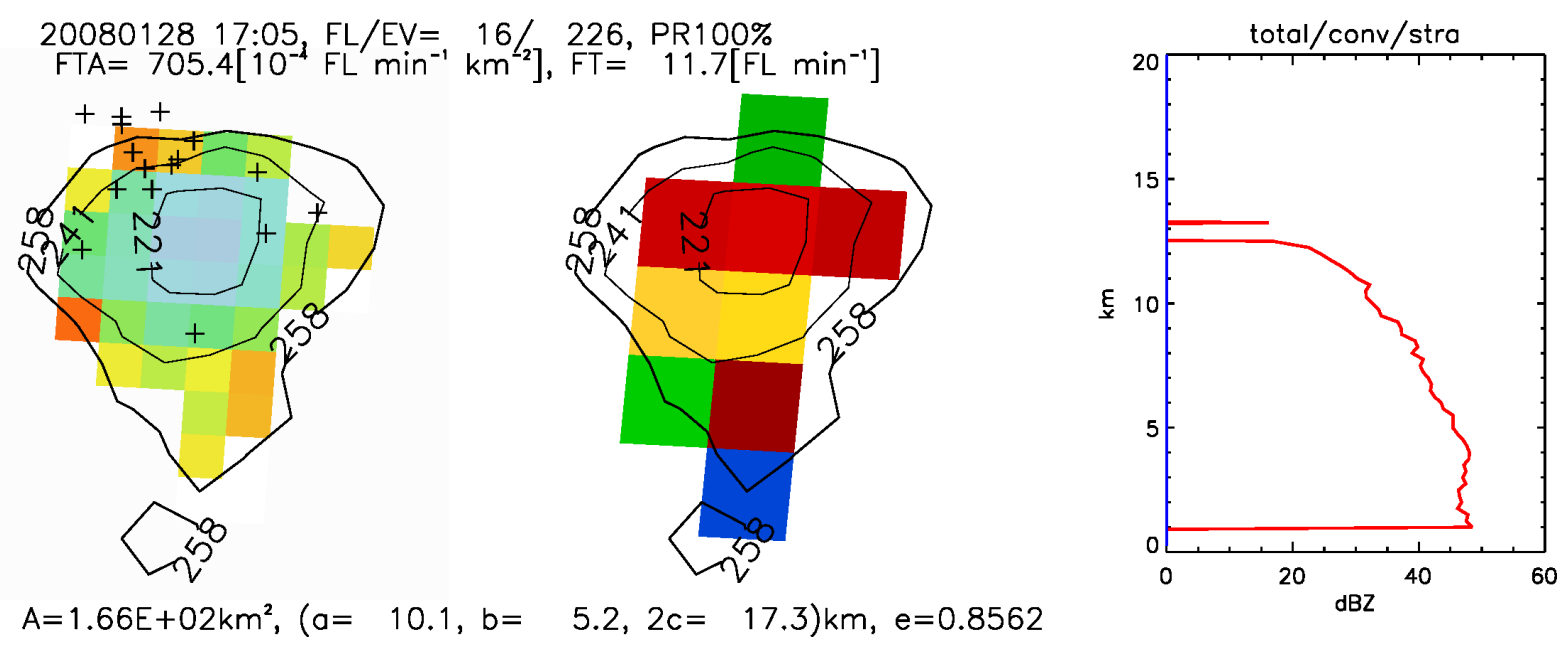

(b)
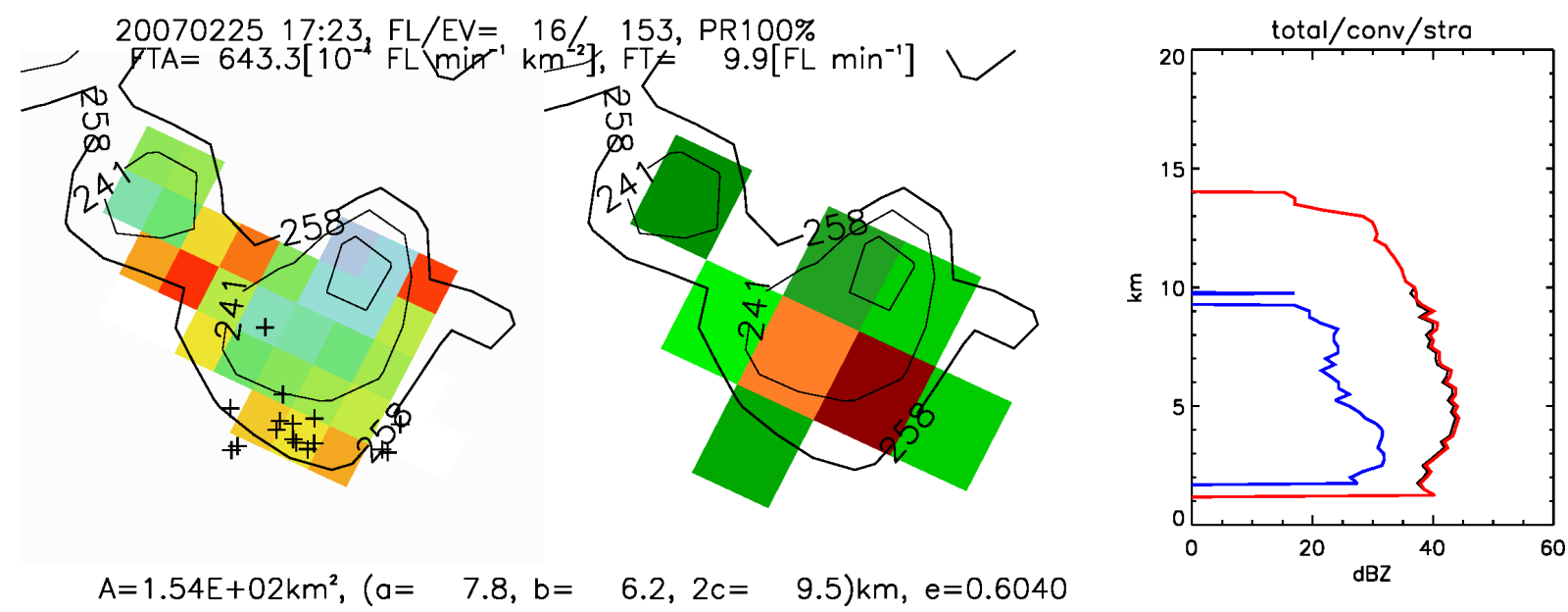

(c)

Figura 26: Visualização das tempestades elétricas com os maiores valores de FTA: $T_{b}$ do topo da nuvem, $Z_{c}$ a $2 \mathrm{~km}$ de altitude e perfis médios de $Z_{c}$ da precipitação convectiva (cor vermelha), estratiforme (azul) e total (preta). 
(K)

(dBZ)
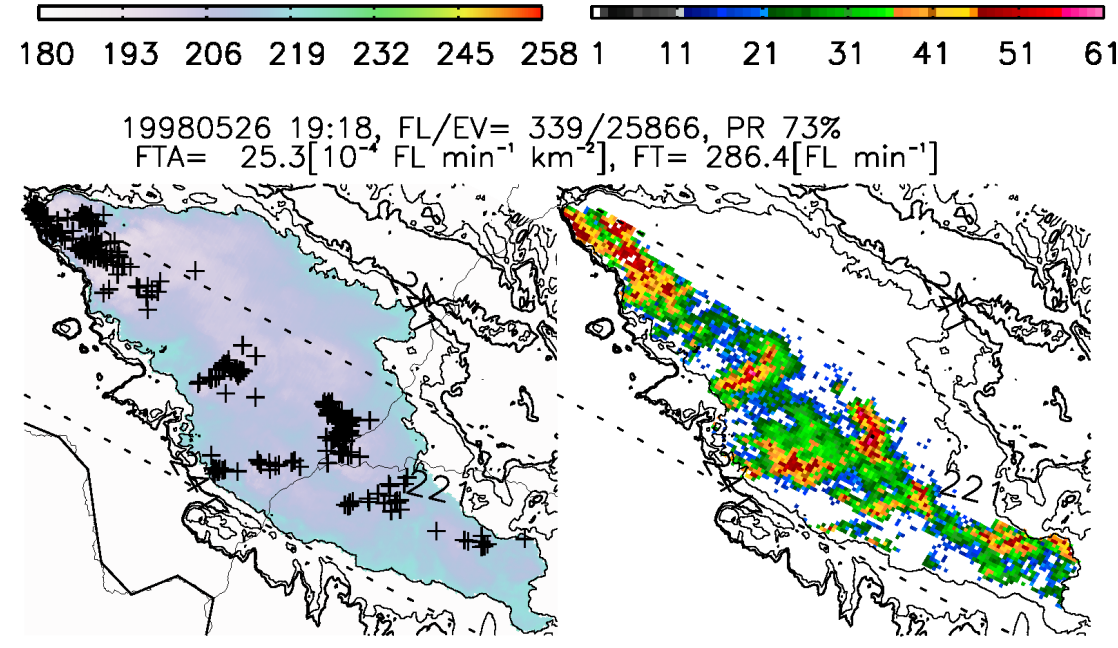

$A=1.13 E+05 \mathrm{~km}^{2}, \quad(a=288.5, b=124.9,2 c=520.1) \mathrm{km}, e=0.9014$

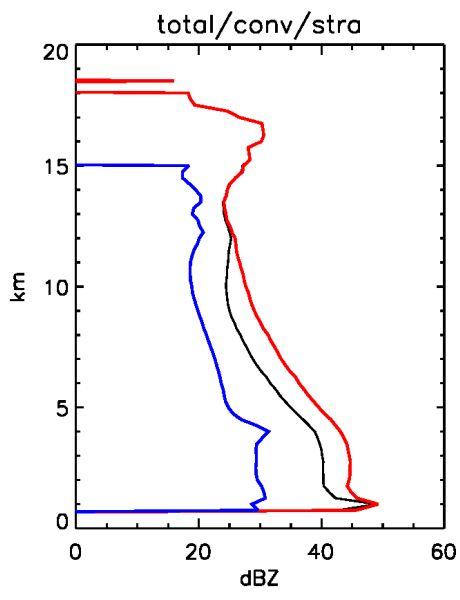

(a)

$1998112323: 43, \mathrm{FL} / \mathrm{EV}=360 / 15873, \mathrm{PR} 83 \%$
$\mathrm{FTA}=74.8\left[10^{-4} \mathrm{FL} \mathrm{min}^{-1} \mathrm{~km}^{-2}\right], \mathrm{FT}=257.7\left[\mathrm{FL} \mathrm{min}{ }^{-1}\right]$

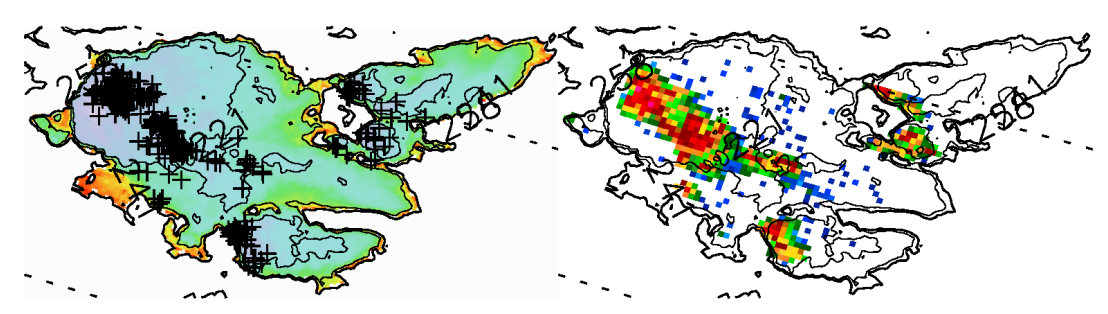

$A=3.45 E+04 \mathrm{~km}^{2},(a=182.0, b=60.3,2 c=343.5) \mathrm{km}, e=0.9436$

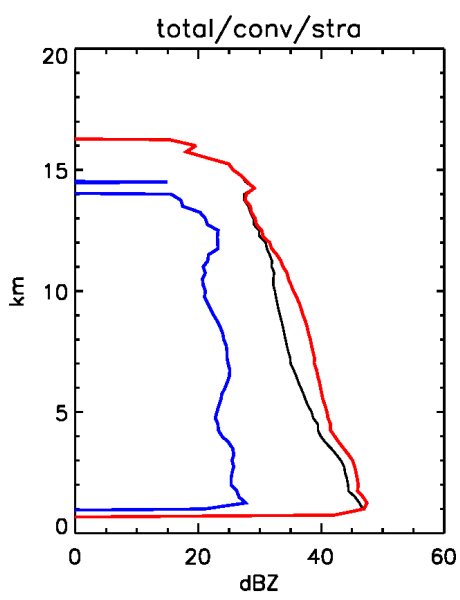

(b)

19980704 06:02, $\mathrm{FL} / \mathrm{EV}=251 / 20257, \mathrm{PR} 99 \%$

$\mathrm{FTA}=74.8\left[10^{-4} \mathrm{FL} \mathrm{min}^{-1} \mathrm{~km}^{-2}\right], \mathrm{FT}=249.5\left[\mathrm{FL} \mathrm{min}{ }^{-1}\right]$

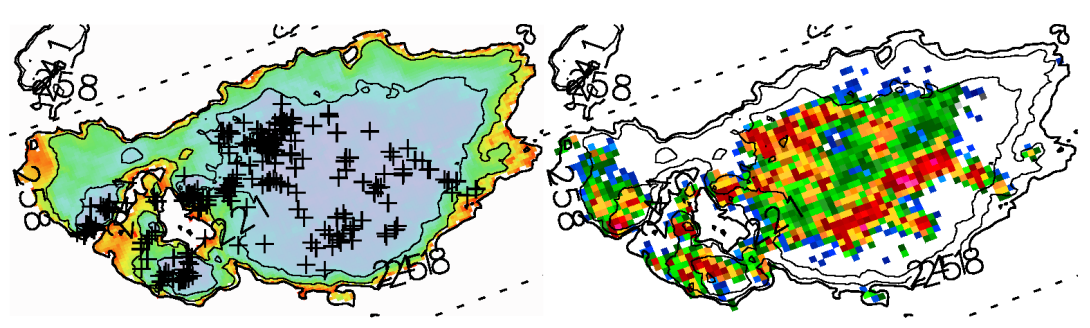

$A=3.34 E+04 \mathrm{~km}^{2},(a=159.3, b=66.7,2 c=289.4) \mathrm{km}, e=0.9083$

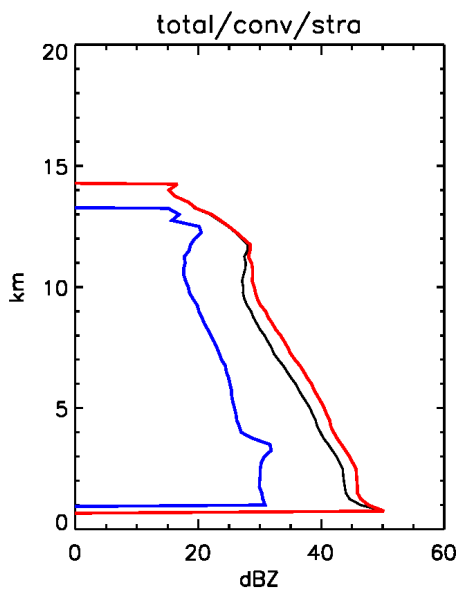

(c)

Figura 27: Visualização das tempestades elétricas com os maiores valores de FT: $T_{b}$ do topo da nuvem, $Z_{c}$ a $2 \mathrm{~km}$ de altitude e perfis médios de $Z_{c}$ da precipitação convectiva (cor vermelha), estratiforme (azul) e total (preta). 


\section{1 ÁREA E TEMPERATURA DO TOPO DA NUVEM}

Na figura 28 pode-se observar a dispersão dos valore extremos de FTA e FT em função das áreas das 94733 tempestades elétricas selecionadas para o estudo da severidade neste capítulo. As linhas horizontais na figura 28 demarcam o $90^{\circ}$ percentil das amostras de probabilidades de FTA (cor preta) e FT (cor azul). Verifica-se que os sistemas com tamanho entre $10^{2}-10^{3} \mathrm{~km}^{2}$ não ultrapassam 20 raios $\min ^{-1}$ de FT e as tempestades elétricas com FT superior a 100 raios por minuto, possuíram tamanho entre $10^{4}-10^{6}$ $\mathrm{km}^{2}$ e existe uma tendência de aumento exponencial de FT conforme aumenta a área das tempestades elétricas, enquanto que FTA tende a diminui exponencialmente com o aumento da área das tempestades elétricas.

Ao normalizar a taxa de raios no tempo por $A_{t}$, o número de raios fica diluído na extensão do sistema, evidenciando que os maiores valores de FTA correspondem aos sistemas com as maiores densidades espaciais de raios, cuja a área e o número de raios são menores do que nos sistemas com extremos de FT.

Na figura 29, referente dispersão dos valores de FTA e FT em função do volume de chuva, observa-se que conforme aumenta FT o volume de chuva das tempestades elétricas também aumenta exponencialmente, de maneira semelhante ao aumento de FT com a área (figura 28). Para FTA, há um comportamento inverso. Conforme aumenta FTA, o volume de chuva dos sistemas diminui.

Conforme mostram as linhas horizontais na figura 29 que demarcam o 90 o- percentil das amostras de probabilidades de FTA (cor preta) e FT (cor azul), pode-se observar que as tempestades elétricas que causam os maiores volumes de chuva estão associadas aos extremos de FT, porém os critérios de severidade de tempd ${ }^{9}$ conforme descrevem (CAREY; RUTLEDGE, 1998; WILLIAMS et al., 1999; ZIPSER et al., 2006), não associam-se com o volume de chuva. No entanto, para populações localizadas em regiões de várzea de rios, como por exemplo a população ribeirinha da Amazônia, ou em regiões serranas como Teresópolis, Nova Friburgo, Petrópolis no Rio de Janeiro, grandes volumes de chuva podem representar condições de tempo severo, pois causam deslizamentos de terra, alagamentos, perdas de vidas, etc, que provocam danos enormes à sociedade (INPE, 2011; WIKIPEDIA, 2011; BBC, 2011).

Na figura 30 é apresentada a distribuição de probabilidade de ocorrência de área das

\footnotetext{
${ }^{9}$ Frentes de rajadas com velocidade superior a $92,6 \mathrm{~km} \mathrm{~h}^{-1}$, queda de granizo com diâmetro maior do que $1,9 \mathrm{~cm}$ ou tornados
} 


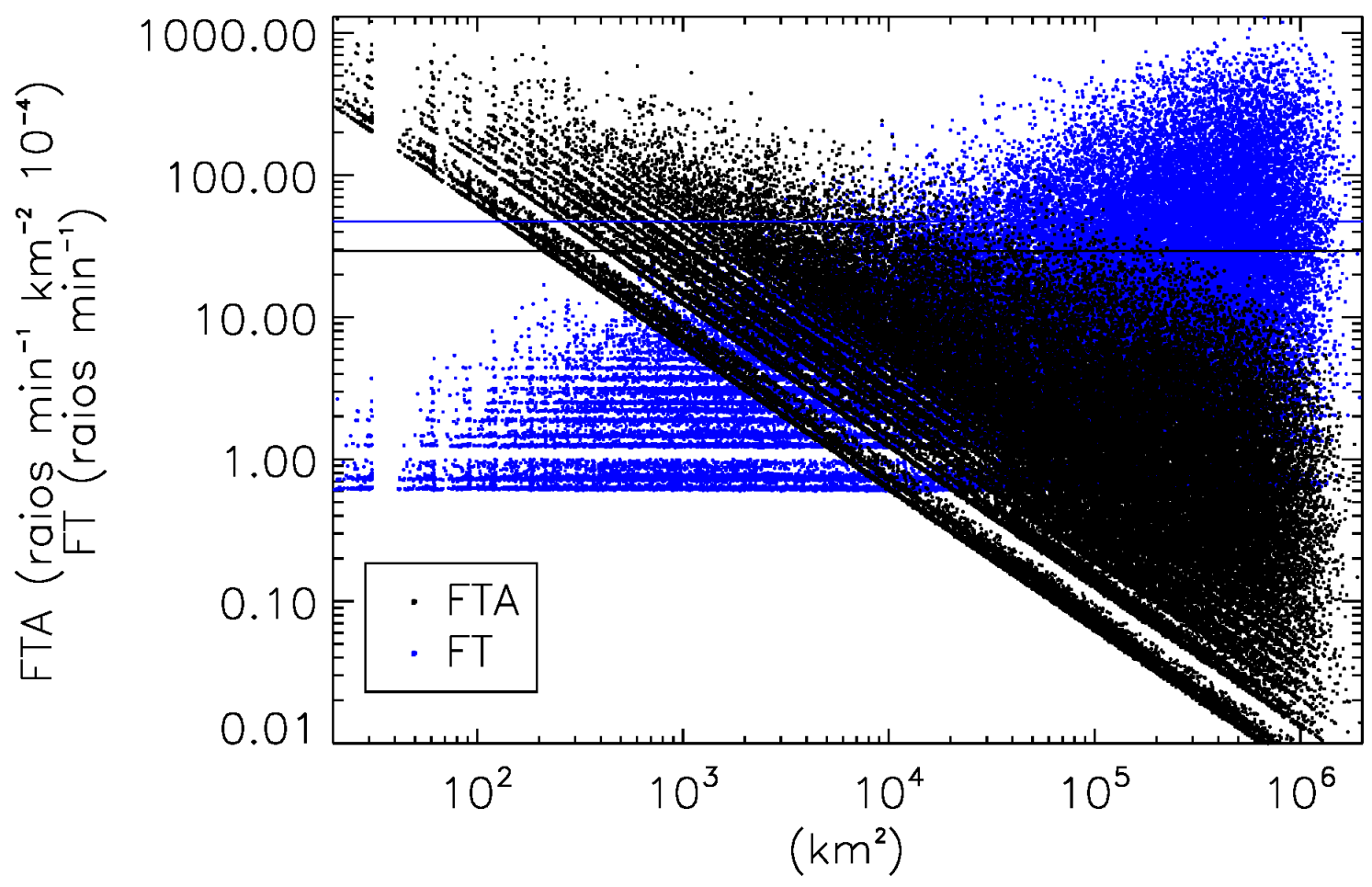

Figura 28: Dispersão entre as áreas das tempestades elétricas e os valores de FTA e FT. As linhas horizontais marcam os valores de FTA (cor preta) e FT (cor azul) referente ao 90o percentil das respectivas amostragem.

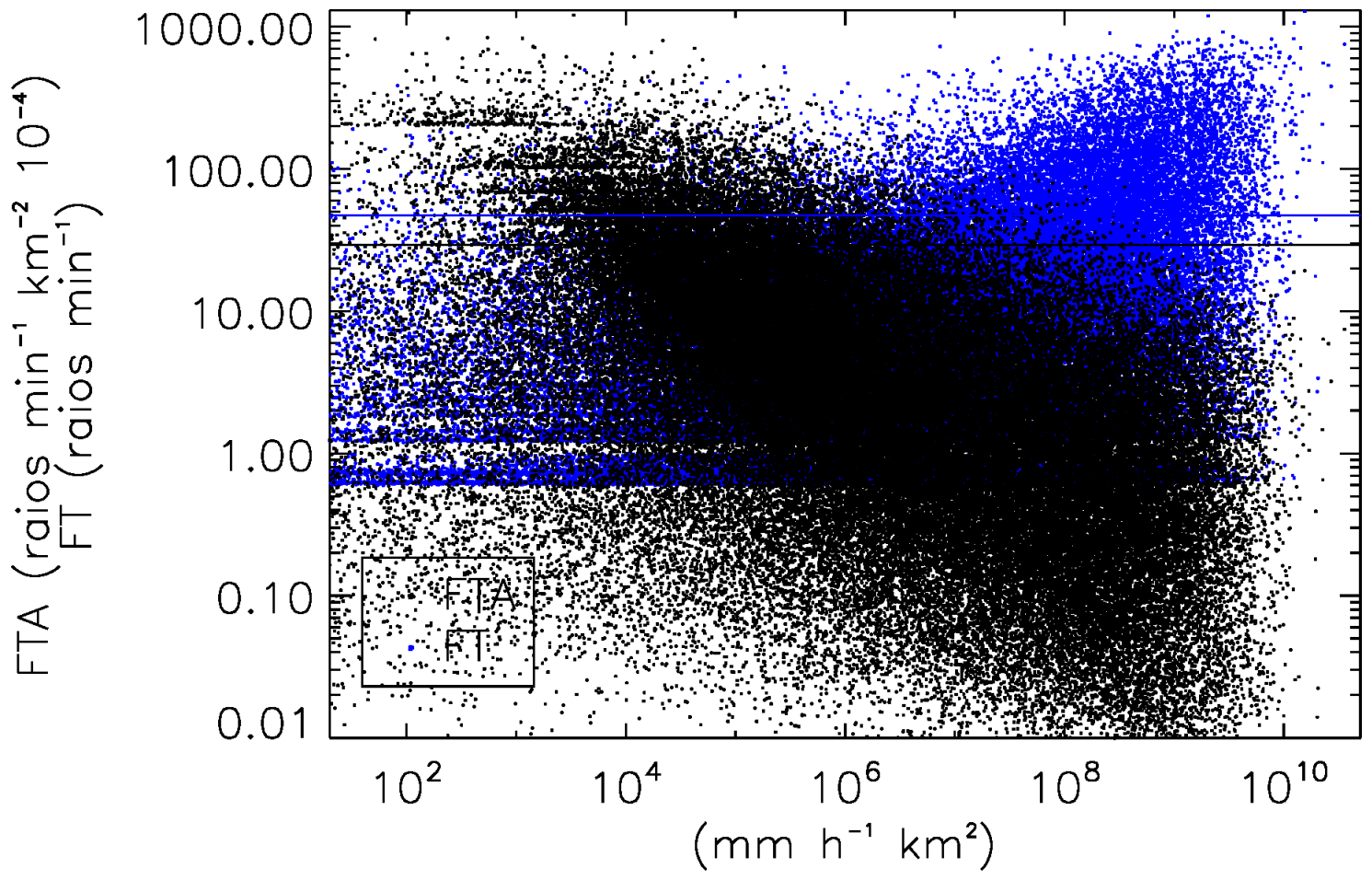

Figura 29: Dispersão entre o volume de chuva das tempestades elétricas e os valores de FTA e FT. As linhas horizontais marcam os valores de FTA (cor preta) e FT (cor azul) referente ao $90^{\circ}$ percentil das respectivas amostragem. 
tempestades elétricas apenas para os valores de FTA e FT acima do 90ํ percentil de ocorrência, 9475 sistemas extremos de FTA e 9475 sistemas extremos de FT. Observase que os valores extremos de FTA e FT correspondem a sistemas com tamanhos bem distintos. As máximas probabilidades de tempestades elétricas dos extremos de FTA ocorrem em sistemas com área 3 ordens de grandeza menor do que nos extremos de FT.

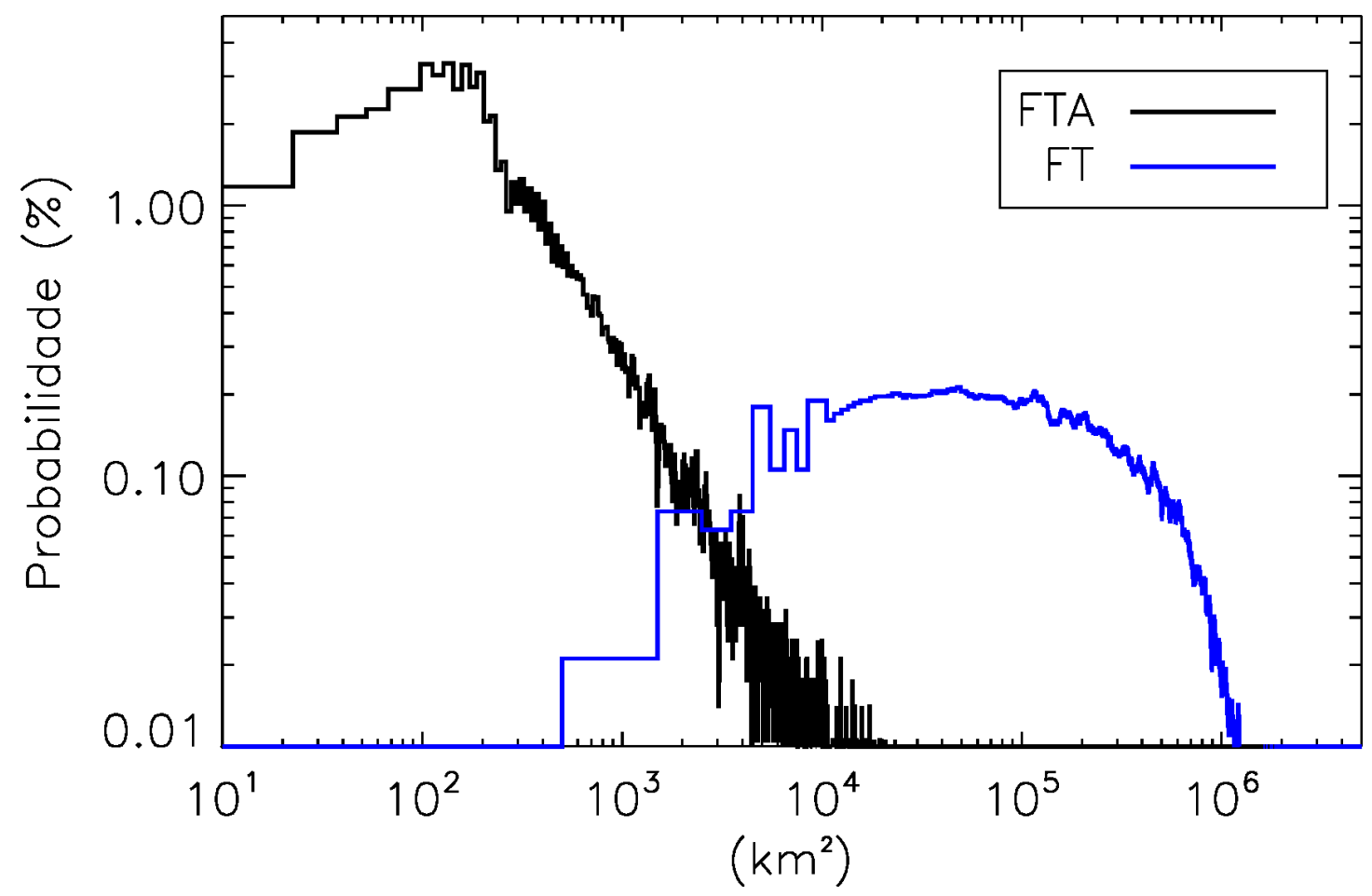

Figura 30: Densidade de probabilidade de extensão em área das 9475 tempestades elétricas com valores extremos de FTA e das 9475 tempestades elétricas com valores extremos de FT.

Considerando também apenas os extremos de FTA e FT, é mostrado na figura 31 a frequência de ocorrência dos pixeis de temperaturas de brilho $\left(T_{b} \leq 258 \mathrm{~K}\right)$ que definiram as áreas das tempestades elétricas. Observa-se que o maior valor de probabilidade para a curva das tempestades elétricas com índice extremo de FTA possui temperatura de topo de nuvens aproximadamente $10 \mathrm{~K}$ mais frias do que mostra o maior valor de probabilidade para das tempestades elétricas com índice extremo de FT, indicando que a convecção nos sistemas extremos de FTA é mais profunda na atmosfera.

Morales e Anagnostou (2003) ao desenvolver o algoritmo SIRT, mostram que as regiões com temperatura de brilho inferior a $215 \mathrm{~K}$ e com ocorrência de sferics foram as regiões categorizadas como de maior precipitação associada. Nesta tese, ao selecionar as tempestades elétricas com índice extremo de FTA, $\simeq 39 \%$ dos pixeis de $T_{b}$ correspondem a $T_{b}$ inferior a 215 , enquanto que $\simeq 29 \%$ dos pixeis de $T_{b}$ das tempestades elétricas extremas de FT tiveram $T_{b}$ inferior a 215 . 


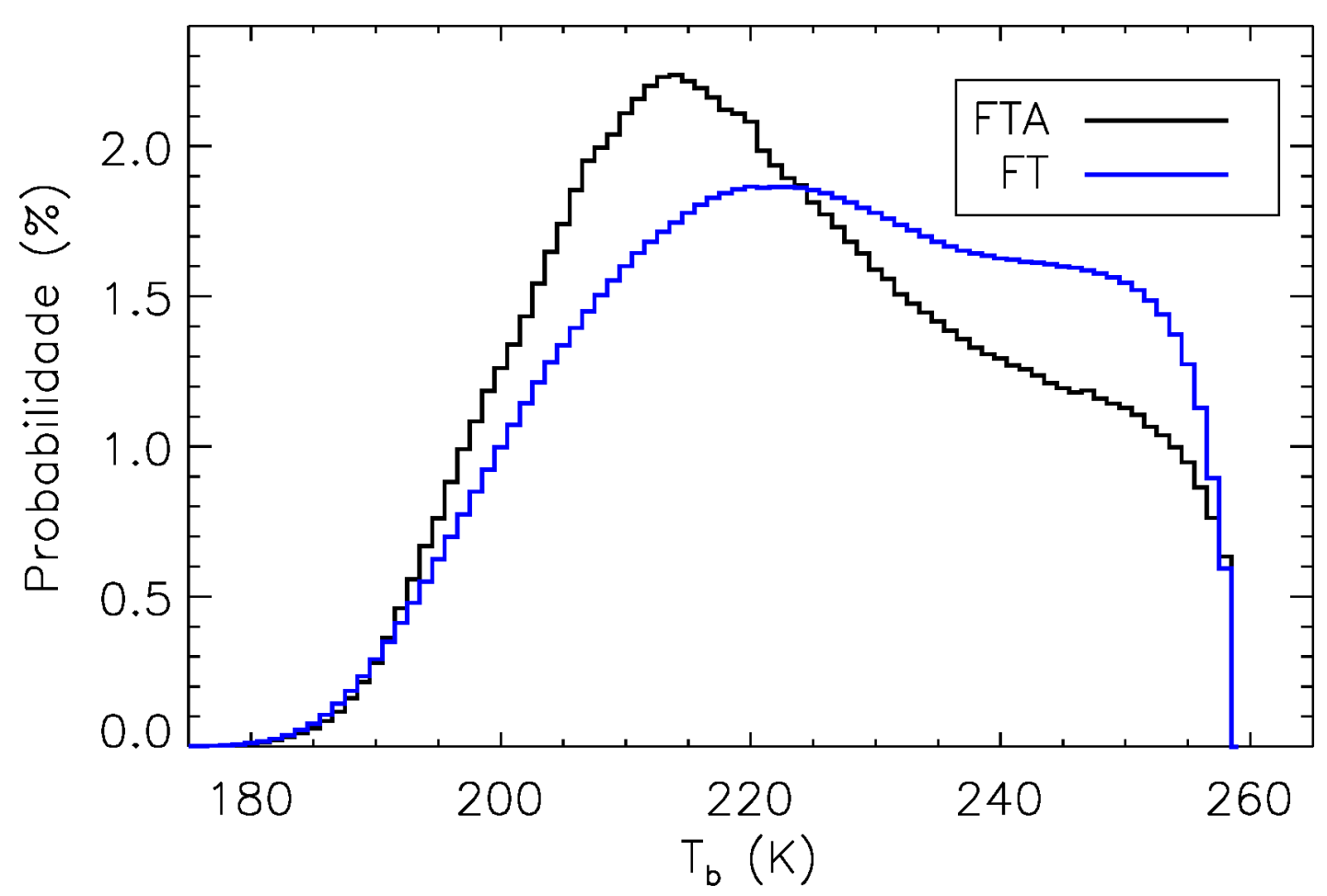

Figura 31: Densidade de probabilidade de temperatura de brilho em infravermelho (VIRS $10,8 \mu \mathrm{m})$ do topo das nuvens das 9475 tempestades elétricas com valores extremos de FTA e das 9475 tempestades elétricas com valores extremos de FT.

Nas figuras 32, 33, 34 e 35, apresenta-se o estudo das probabilidades das frações de chuva para as tempestades elétricas com valores extremos de FTA e FT. As curvas denominadas como convectivo, estratiforme e outros, correspondem à fração de área de chuva associada aos perfis do PR classificados como convectivo, estratiforme e outros em relação a área total de chuva do sistema. A curva denominada na legenda como chuva total corresponde à fração da área de chuva em relação à área total $\left(A_{t}\right)$ da tempestade elétrica que é definida pela $T_{b} \leq 258 \mathrm{~K}$. A curva denominada como varredura do PR, mostra a fração da $A_{t}$ que esteve dentro do alcance da varredura do PR.

Verifica-se na curva denominada como varredura do PR na figura 34 que para a maioria dos sistemas com FT extremo, o PR conseguiu observar apenas $30 \%$ da $A_{t}$ das tempestades elétricas. Na curva denominada como varredura do PR da figura 32 referente às tempestades elétricas com FTA extremo, o PR observou com a maior probabilidade $100 \%$ de $A_{t}$, efeito que se deve ao diferente tamanho dos sistemas extremos de FTA em relação aos extremos de FT, como mostra a figura 30 . A mediana da amostragem de fração de chuva total das tempestades elétricas extremas de FTA (figura 32 ) mostra o valor de $62 \%$, enquanto a mediana da amostragem de fração de chuva total das tempestades elétricas extremas de FT (figura 34), foi de apenas 5\%, pois a varredura do PR é menor do que a do VIRS e as tempestades elétricas com os maiores valores de FT abrangem uma 


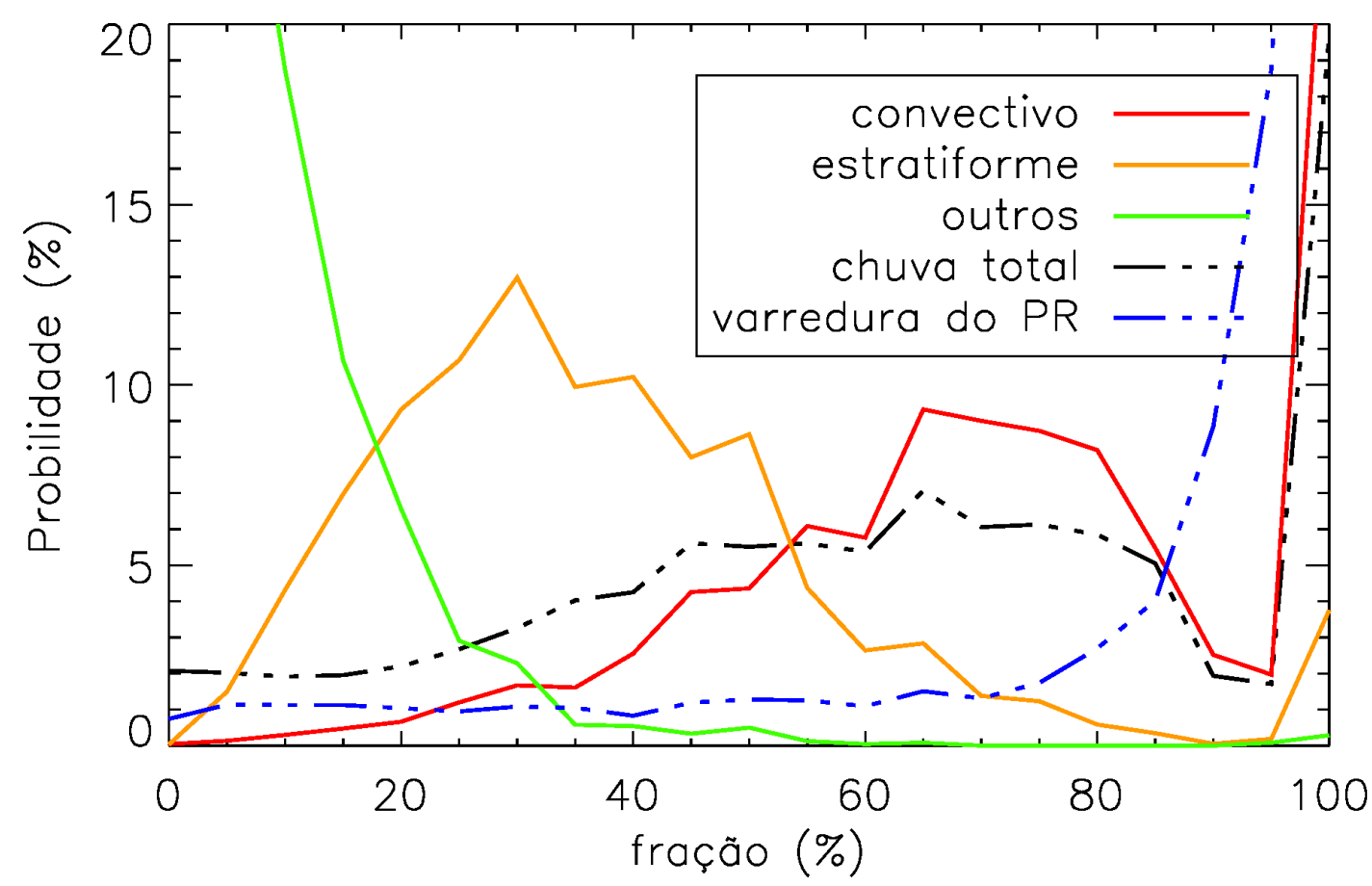

Figura 32: Densidade de probabilidade das frações de áreas de chuva das tempestades elétricas extremas de FTA, que foram classificadas (2A23) como convectiva (vermelha), estratiforme (bege) e outros (verde), em relação a toda a área de chuva observada pelo PR; das frações de chuva total (preta), que correspondem às frações das áreas de chuva observadas pelo PR em relação a $A_{t}$ das tempestades elétricas e também das frações das áreas das tempestades elétricas contidas na varredura do PR (azul).

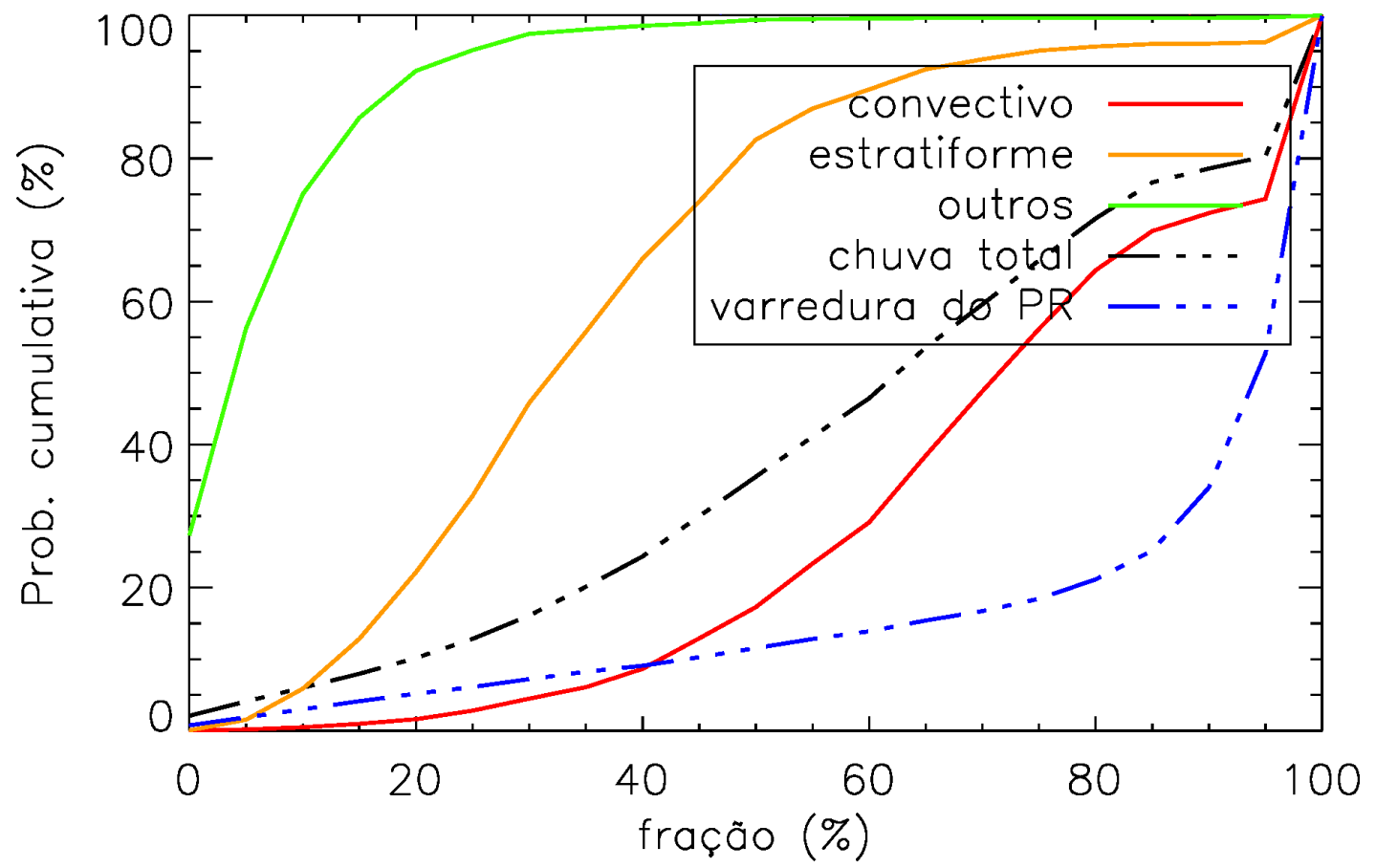

Figura 33: Densidade de probabilidade cumulativa das frações de áreas de chuva das tempestades elétricas extremas de FTA. 


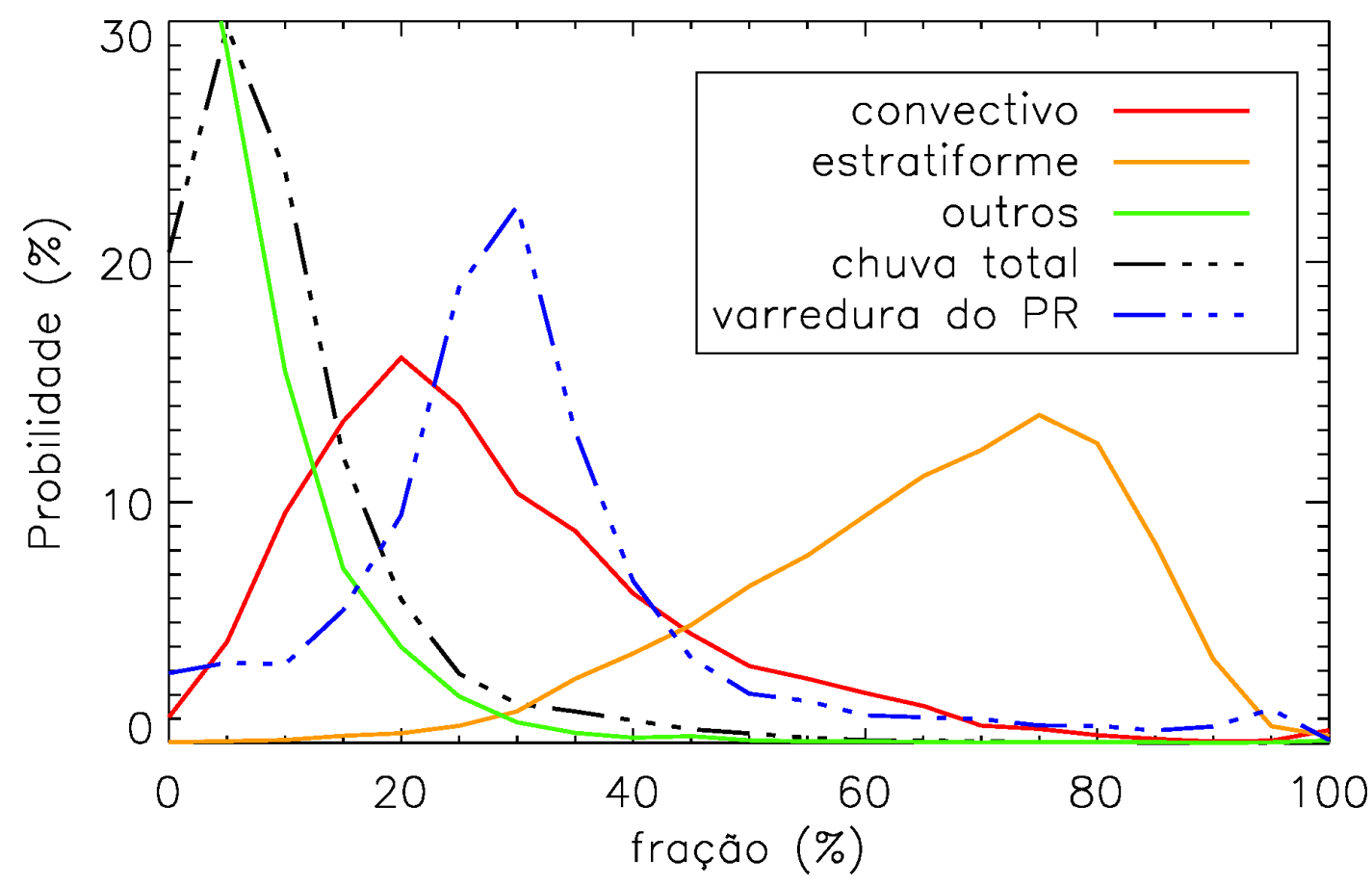

Figura 34: Densidade de probabilidade das frações de áreas de chuva das tempestades elétricas extremas de FT, que foram classificadas (2A23) como convectiva (vermelha), estratiforme (bege) e outros (verde), em relação a toda a área de chuva observada pelo PR; das frações de chuva total (preta), que correspondem às frações das áreas de chuva observadas pelo $\mathrm{PR}$ em relação a $A_{t}$ das tempestades elétricas e também das frações das áreas das tempestades elétricas contidas na varredura do PR (azul).

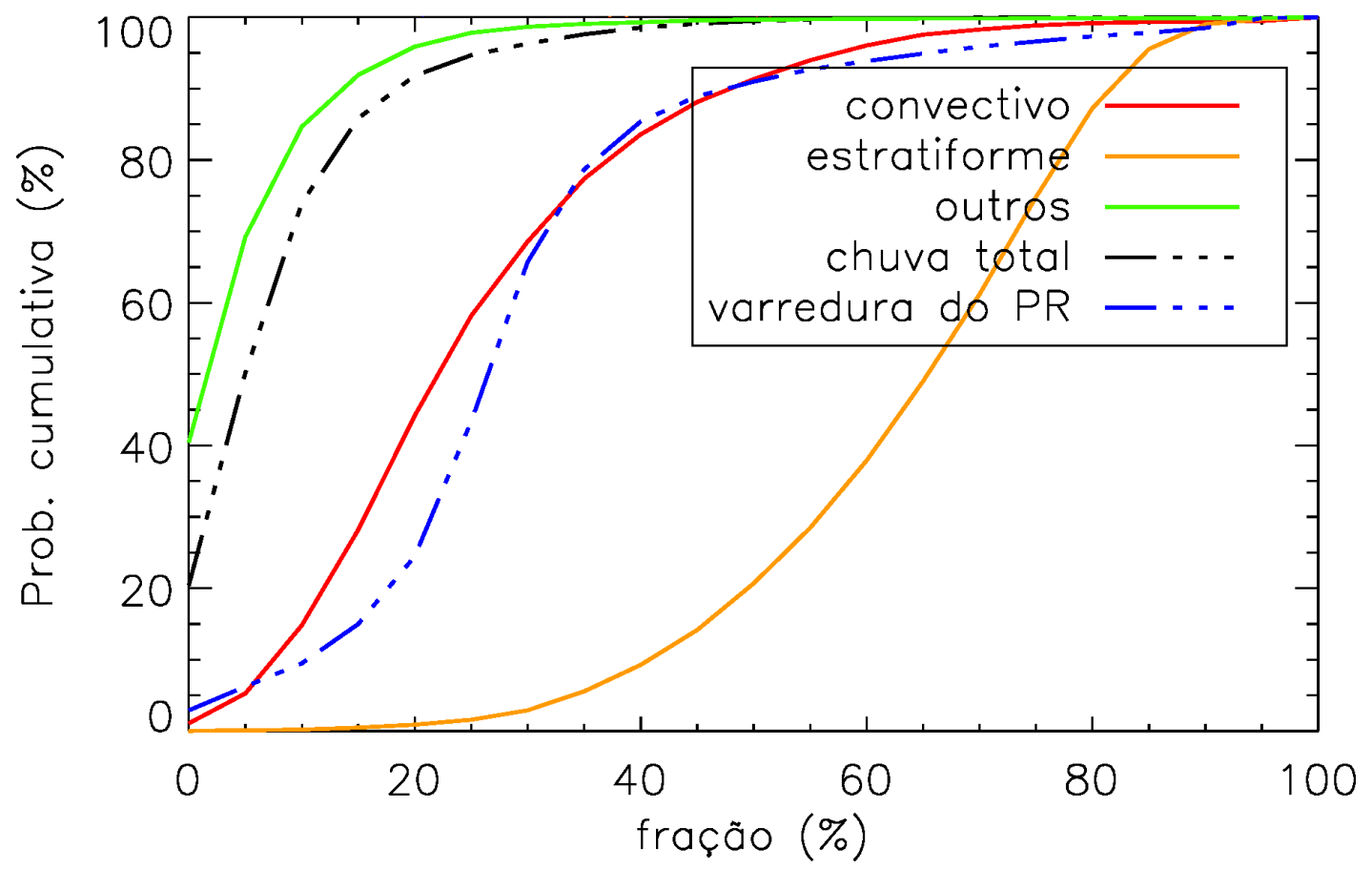

Figura 35: Densidade de probabilidade cumulativa das frações de áreas de chuva das tempestades elétricas extremas de FT. 
extensão que ultrapassa o alcance do PR.

Apesar da diferença de amostragem espacial do PR para com os FTA e FT, a amostragem estatística é suficiente para mostrar que na mediana, FTA tem $72 \%$ de fração convectiva e $32 \%$ estratiforme, conforme verifica-se nos valores de fracão de chuva associado ao $50^{\circ}$ percentil das distribuições cumulativas de probabilidade da figura 33 . Por outro lado, o 50 percentil das distribuições cumulativas da figura 35 mostram que os extremos de FT tem $22 \%$ de fração convectiva e $65 \%$ de fração estratiforme.

Estes resultados corroboram com as observações de Rasmussen e Houze Jr. (2011), em que os extensos sistemas convectivos estiveram associados com regiões de vasta extensão estratiforme. Anteriormente Leary e Houze Jr. (1979), observaram que sistemas convectivos em desenvolvimento tem a maior área convectiva, enquanto os em dissipação e mais fracos possuem maior área estratiforme. A distribuição de probabilidade de $T_{b}$ da figura 31. mostra que os extremos de FTA tem topos mais frios, o que se espera de nuvens em desenvolvimento. Portanto, a maior fração convectiva e menor tamanho das tempestades elétricas com FTA extremos sugerem sistemas em via de maturar ou sistemas novos que conforme vão entrando em estágio maduro e dissipativo, vão ganhando área de chuva estratiforme e podem começar a se enquadrar no grupo dos extremos de FT.

\subsection{SEVERIDADE COM BASE NA ESTRUTURA 3D DA PRECIPITAÇÃO}

Nesta etapa iremos avaliar a intensidade convectiva com base nos perfis de $Z_{c}$ do PR. Para tanto, foram calculados os CFADs das tempestades elétricas extremas de FTA e FT, para suas frações com raios (figuras 39 e 40) e sem raios (figuras 37, 38), para os extremos ocorridos em cada região de 10 por 10 graus de latitude e longitude na superfície sobre a AS. Para localizar a caixa $\left(10^{\circ} \times 10^{\circ}\right)$ em que cada sistema esteve contido, foi calculada a latitude e longitude do centro geométrico da área definida por cada sistema. Novas amostragens de probabilidade de FTA e FT, foram obtidas da mesma maneira que mostrado na figura 24 ou 25 , porém para cada região de $10^{\circ} \times 10^{\circ}$. O estudo da precipitação tridimensional foi feito apenas para as tempestades elétricas com valores maiores ou igual ao valor do 90 percentil das amostragem de FTA e FT de cada região de $10^{\circ} \times 10^{\circ}$.

As posições geográficas dos eventos do LIS e dos perfis de $Z_{c}$ válidos do $\mathrm{PR}$, foram projetadas em uma grade regular de 0,05 graus. Os perfis de $Z_{c}$ projetados em pontos de grade em que tiveram eventos do LIS, definiram as regiões aqui denominadas como 
precipitação dos núcleos de raios. A figura 36 ilustra as regiões dos núcleos de raios das tempestades elétricas.

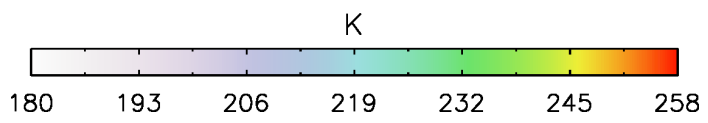

(a)

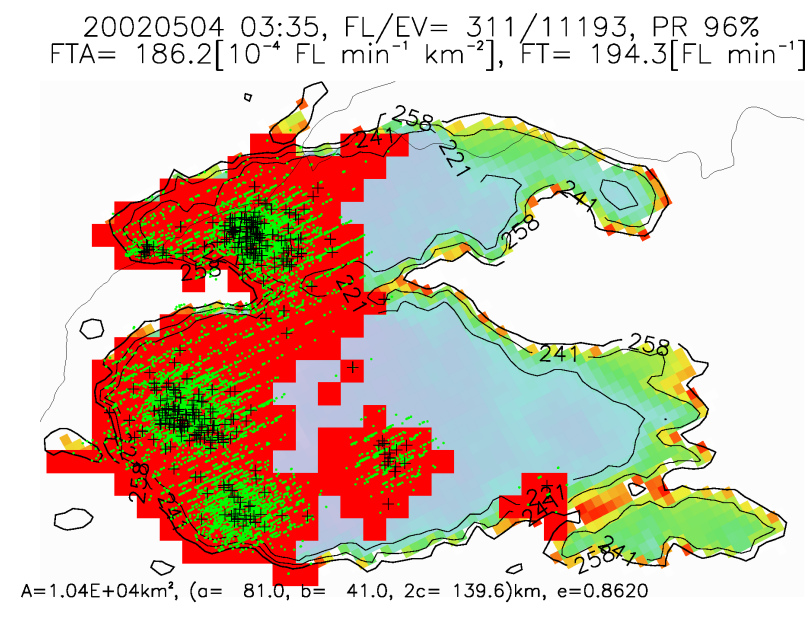

(b)

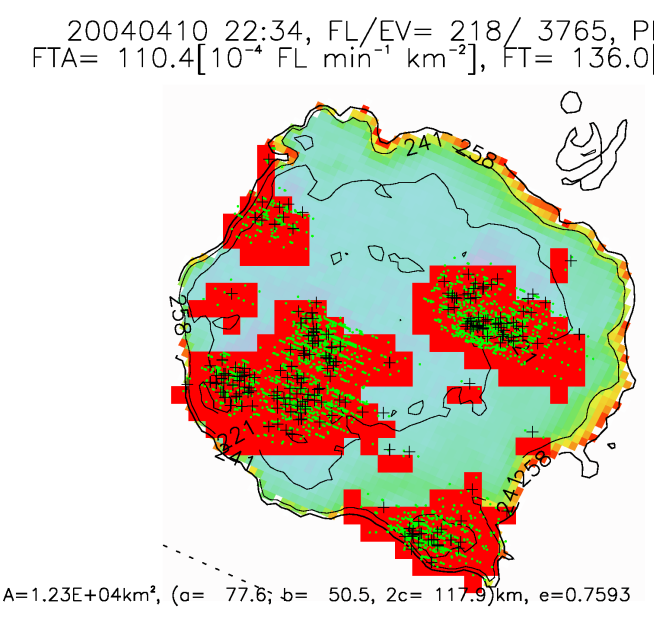

(c)

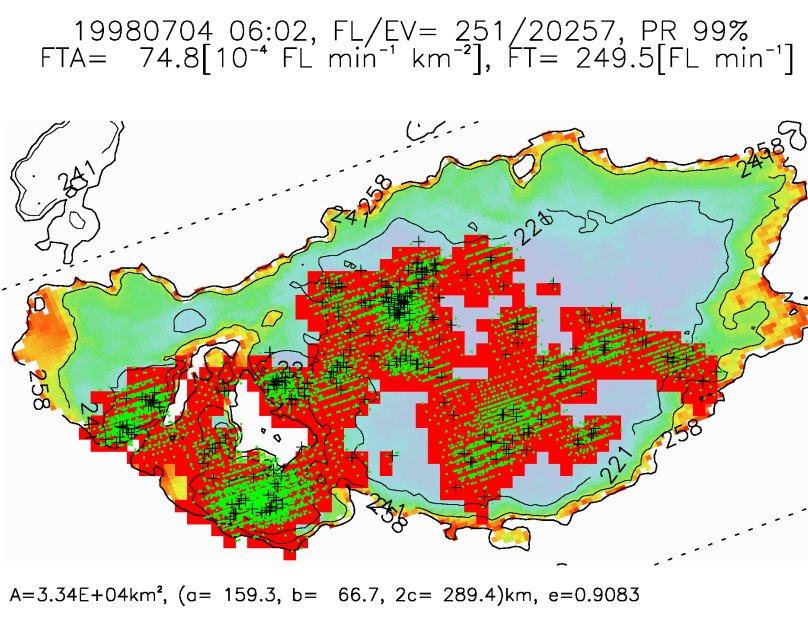

(d)

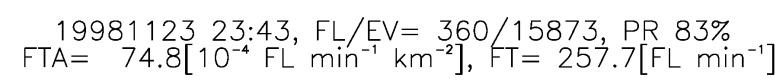

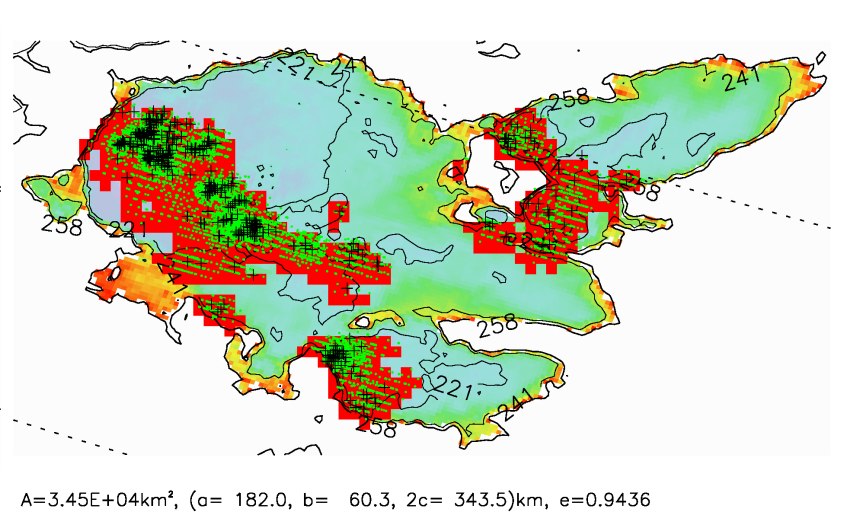

(e)

Figura 36: Núcleos de raios das tempestades elétricas. Os pontos "."na cor verde são os eventos e os símbolos de positivo "+"na cor preta são os raios. Os pixeis em vermelho são as regiões dos núcleos de raios, definidas a partir da projeção dos eventos em uma grade regular de $0,05^{\circ}$.

Após definidas as regiões eletricamente ativas de cada sistema com FTA ou FT extremo, os CFADs foram calculados para a precipitação dos núcleos de raios das tempestades elétricas, figuras 39 e 40 , e para a precipitação fora dos núcleos de raios, figuras 37 e 38.

Note que no canto superior direito de cada CFAD temos alguns valores estatísticos que representam: (\%) a porcentagem de perfis convectivos, estratiformes e outros, respectivamente; (P) o número de perfis do PR computados; (L) o número de ocorrência de 


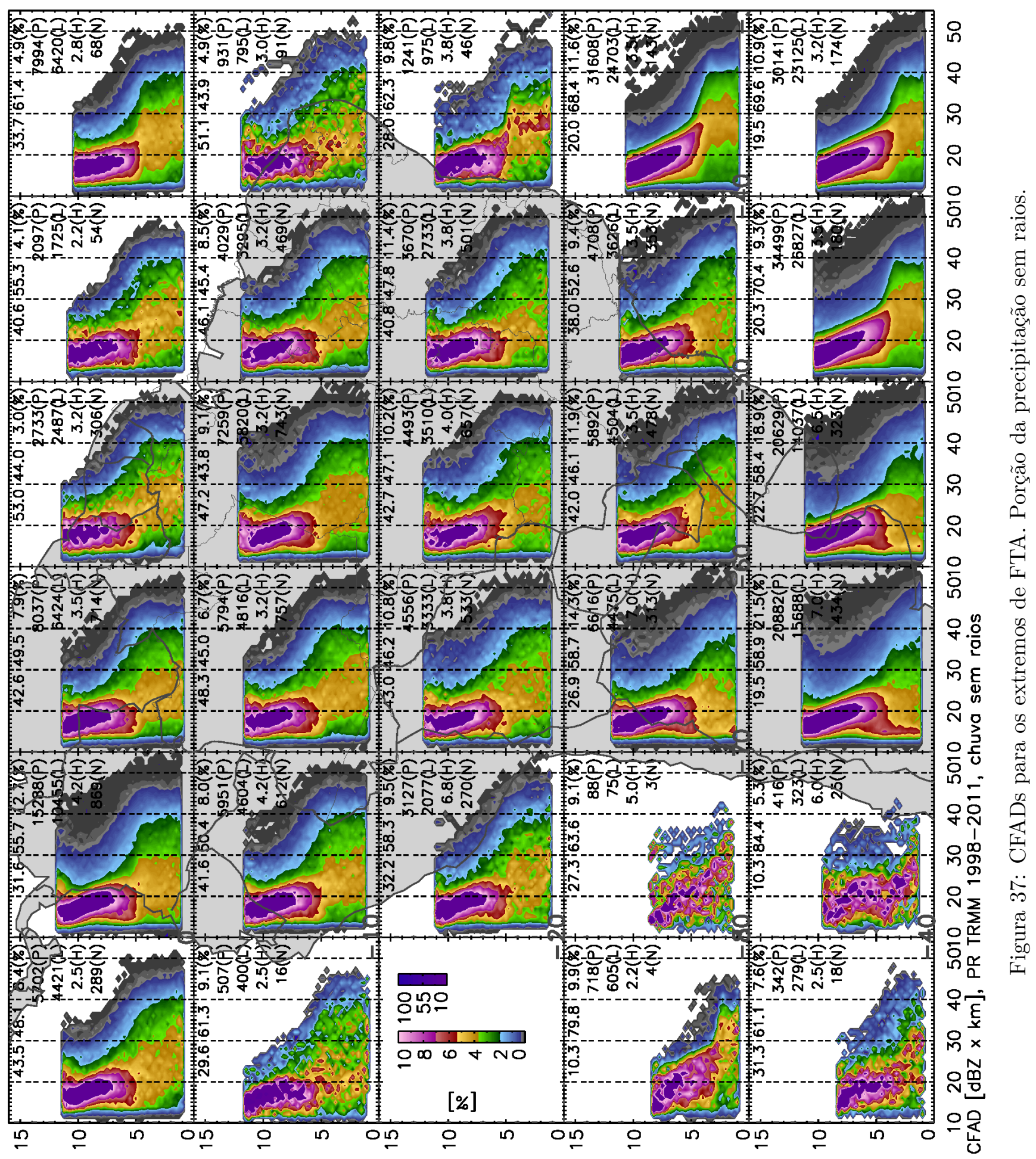




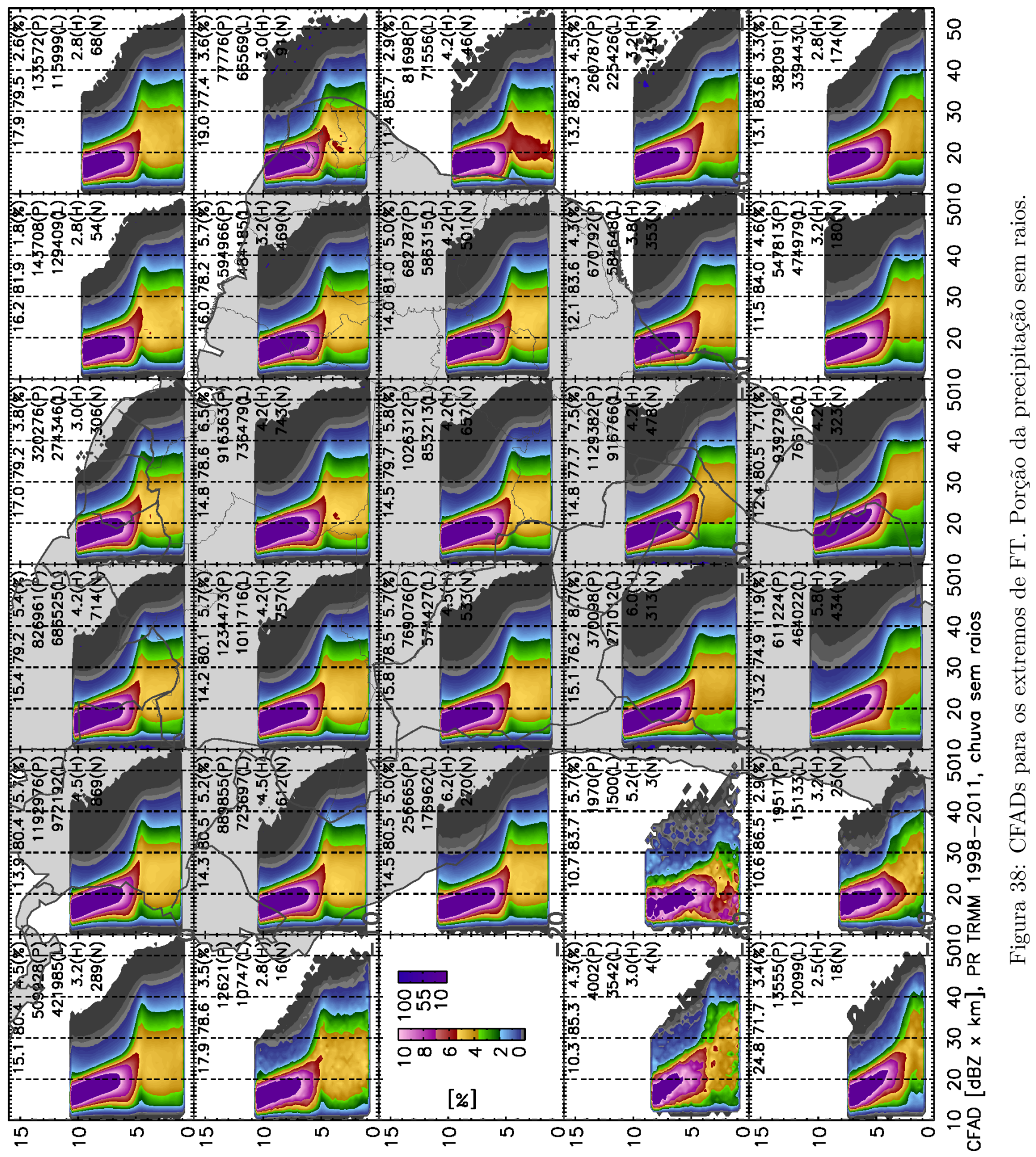




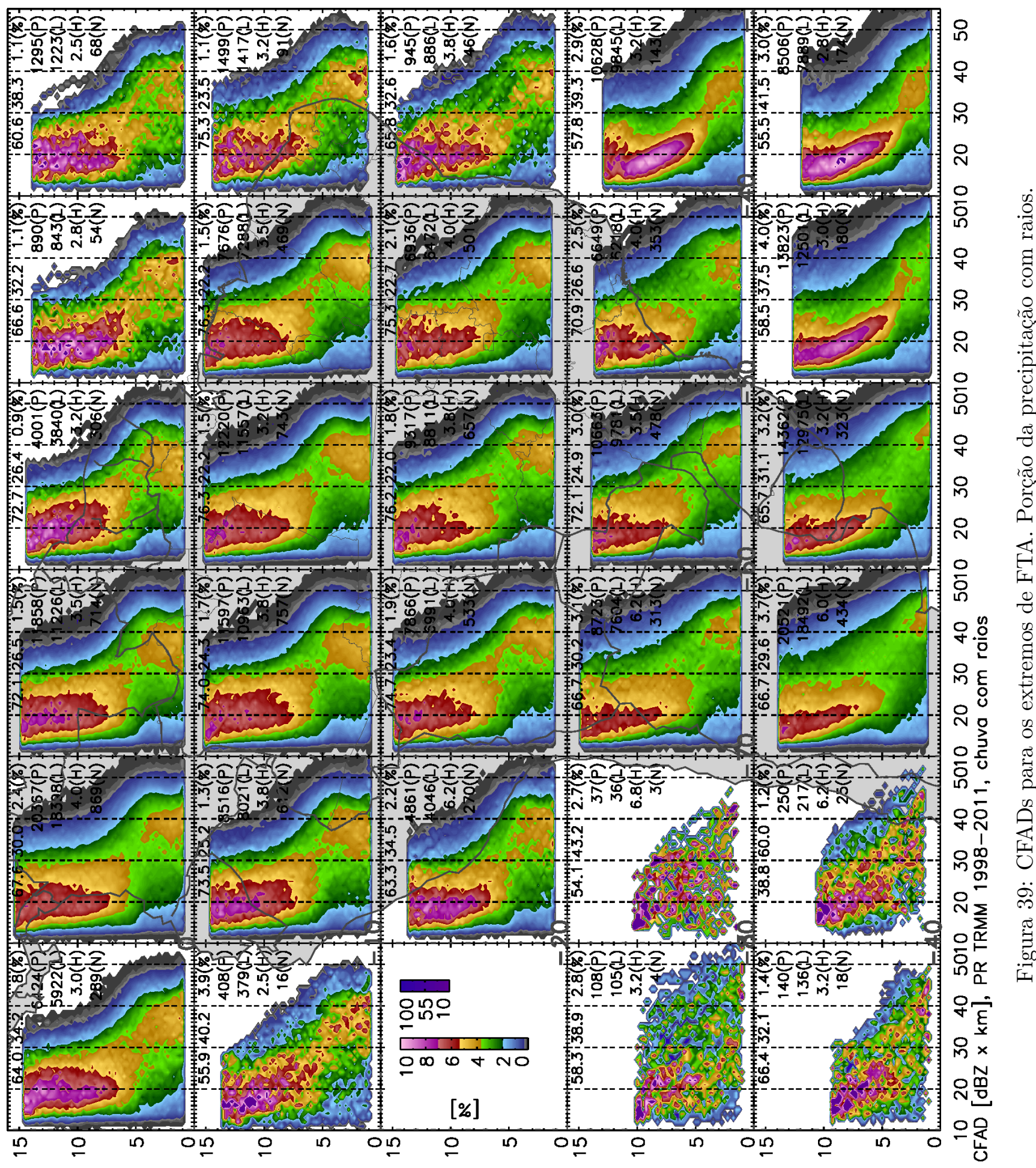




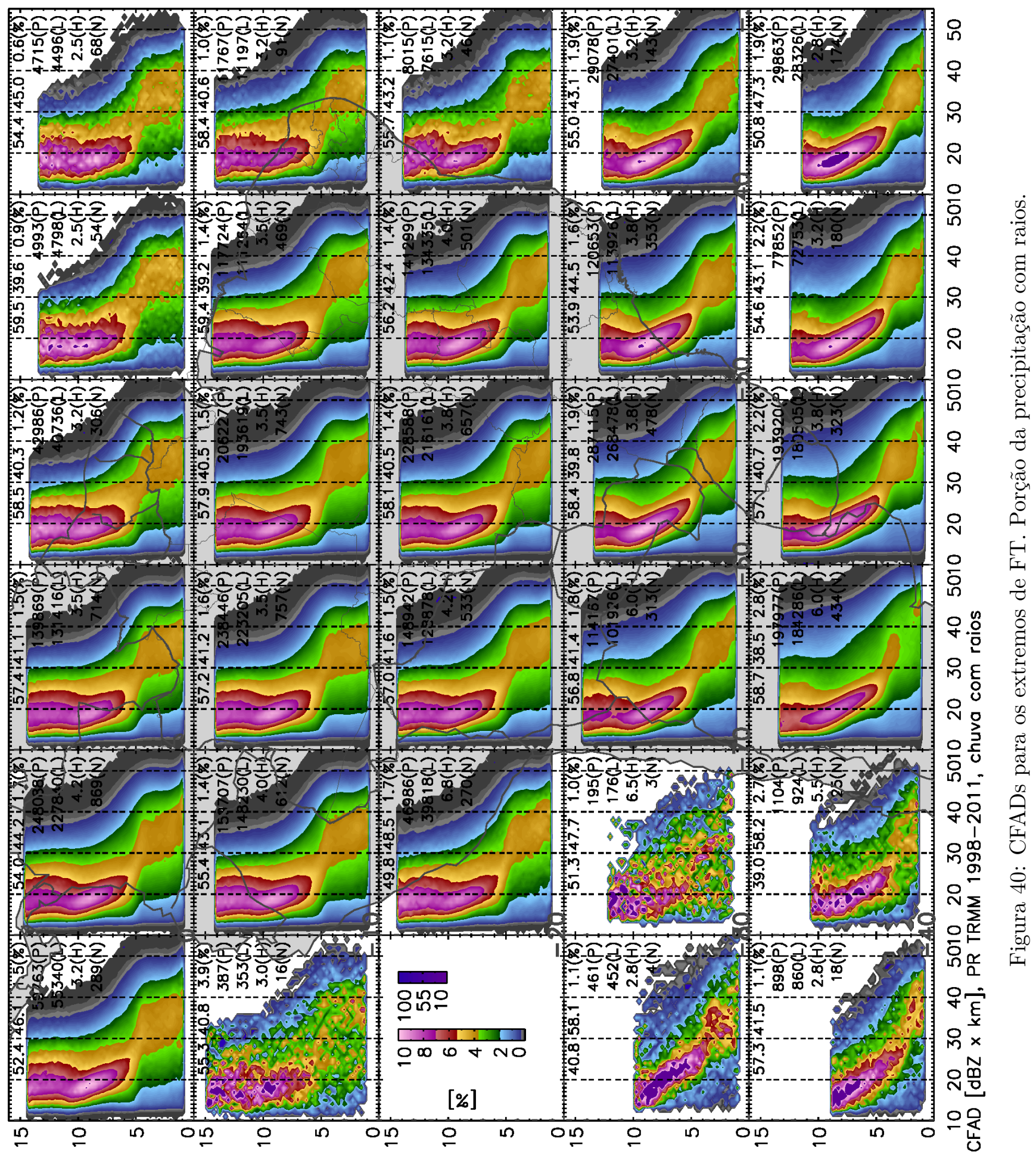


$Z_{c}$ no nível de altitude de máxima ocorrência; (H) o nível de altitude, em quilômetros, onde ocorreu o máximo de ocorrências de $Z_{c} ;(\mathrm{N})$ o número de tempestades elétricas computadas.

Comparando os CFADs da chuva com e sem raios, representados para os extremos de FTA nas figuras 39 e 37 e para os extremos de FT, nas figuras 40 e 38, é evidente que a fração das tempestades elétricas sem raios é a parte de menor velocidade vertical e a fração eletricamente ativa é a região com maior velocidade vertical. Os níveis de contorno de probabilidades dos CFADs da precipitação sem raios possuem suas máximas altitudes aproximadamente 3 quilômetros abaixo das máximas altitudes atingidas pelos contornos dos CFADs da precipitação com raios. A fração da precipitação sem raios dos sistemas é composta predominantemente por perfis estratiformes enquanto que a fração com raios os perfis convectivos são predominantes.

Se avaliarmos apenas os níveis de contorno com probabilidade entre 2-3,7\% (cor verde), os valores de $Z_{c}$ entre $0-2 \mathrm{~km}$ de altitude da porção sem raios, figuras 37 e 38, não ultrapassaram $40 \mathrm{dBZ}$ em nenhuma região da AS, enquanto que para a porção de chuvas com raios, figuras 39 e 40, os valores de $Z_{c}$ atingem 45-50 dBZ. Entre 5-7 km os contornos de probabilidade dos CFADs da precipitação com raios mostram valores de $Z_{c}$ entre 5-10 dBZ maiores do que na precipitação sem raios, pois a eletrificação das nuvens depende do crescimento dos hidrometeoros na região de fase mista. Havendo maior velocidade vertical, descargas elétricas e maior volume de água na região de fase mista, consequentemente, espera-se maiores volumes de chuvas na superfície $(0-2 \mathrm{~km})$ sobre as regiões dos núcleos de raios (PETERSEN; RUTLEDGE, 1998).

A figura 38 mostra que a precipitação sem raios dos extremos de FT na região tropical, entre $20^{\circ} \mathrm{Sul}-10^{\circ}$ Norte e $90^{\circ}-30^{\circ}$ Oeste, possui banda brilhante marcada entre $4-5 \mathrm{~km}$ de altitude, principalmente nos perfis com probabilidade de ocorrência entre 2-5,3\%, (nas cores de contorno em verde e amarelo) o que claramente demostra o predomínio de áreas estratiformes, evidenciando processos de formação de flocos de neve e agregados que são pouco eficientes no carregamento das nuvens de tempestades elétricas.

Podemos observar a banda brilhante entre $20^{\circ}$ Sul- $10^{\circ}$ Norte e $90^{\circ}-30^{\circ}$ Oeste dos sistemas com extremo de FT na porção sem raios de maneira mais elucidativa por meio dos CCFADs da figura 42, os quais evidenciam que entre o $12^{\circ}$ e o 95 o percentil da amostragem de probabilidade de $Z_{c}$ por altitude, há uma queda no valor de $Z_{c} \operatorname{logo}$ abaixo de 5 quilômetros de altitude em cada região de 10 por 10 graus.

No entanto, para a região entre $20^{\circ} \mathrm{Sul}-10^{\circ}$ Norte e $90^{\circ}-30^{\circ}$ Oeste, ao avaliar os 
CFADs da figura 37 ou CCFADs da figura 41, que representam a porção sem raios da precipitação tridimensional dos sistemas com índice extremo de FTA, não se observa banda brilhante marcada nos contornos de probabilidade de $Z_{c}$ por altitude. Conforme os níveis de altitude diminuem, não se observa uma diminuição abrupta de $Z_{c}$ logo abaixo de 5 quilômetros, devido a evaporação, o que indica menor presença de neve derretendo.

A precipitação sem raios das tempestades elétricas entre $20^{\circ}$ Sul- $10^{\circ}$ Norte e $90^{\circ}-30^{\circ}$ Oeste referente aos extremos de FT possuem a mediana das distribuições cumulativas de probabilidades com valores de $Z_{c}$ inferiores do que quando compara-se com os extremos de FTA, os quais possuem perfis de $Z_{c}$ com maior aleatoriedade, mas atingem valores de $Z_{c}$ superiores. Observe as diferenças entre os CCFADs das figuras 41 e figura 42 . Note como entre $20^{\circ} \mathrm{Sul}-10^{\circ}$ Norte e $90^{\circ}-30^{\circ}$ Oeste os contornos de probabilidade cumulativa são mais alargados para a precipitação sem raios dos extremos de FTA do que para a precipitação sem raios dos extremos de FT, indicando menor aleatoriedade dos perfis de $Z_{c}$ para os extremos de FT.

Na região entre $40^{\circ}-20^{\circ}$ Sul e $70^{\circ}-50^{\circ}$ Oeste que engloba a Bacia do Prata, a banda brilhante não é tão pronunciada na área sem raios, tanto para os extremos de FTA (figuras 37 e 41) quanto para os extremos de FT (figuras 37 e 42, como é observado nas regiões mais tropicais, entre $20^{\circ}$ Norte $-10^{\circ} \mathrm{Sul}$ e $80^{\circ}-30^{\circ}$ Oeste. Provavelmente, as condições de instabilidade baroclínica associada a passagens de sistemas transientes, e SCM conforme descrevem Durkee e Mote (2009), entre $40^{\circ}-20^{\circ}$ Sul e $70^{\circ}-50^{\circ}$ Oeste, promovem condições de cisalhamento vertical do vento que intensifica a velocidade vertical nas frações sem raios das tempestades elétricas subtropicais, o que favorece a formação de mais cristais de gelo, agregados e o graupel.

Observe como a linha de contorno no $50^{\circ}$ percentil do CCFAD entre $40^{\circ}-20^{\circ}$ Sul e $70^{\circ}-$ $50^{\circ}$ Oeste nas figuras 41 e 42 , indicam maiores valores de $Z_{c}$ para a fração sem raios das tempestades elétricas com índice FT extremo, mesmo que a estatística na parte superior direita de cada CCFAD indique maior percentual de perfis convectivos para a porção sem raios dos extremos de FTA. Porém, observe que acima do $80^{\circ}$ percentil de ocorrência de perfis de $Z_{c}$ das tempestades elétricas com FTA extremo (figura 41), os valores de $Z_{c}$ passam a ser maiores do que para as tempestades elétricas com FT extremo.

Os CFADs referentes às tempestades elétricas com FTA extremo possuem contornos de probabilidade em níveis de altitude mais elevados do que os CFADs dos sistemas com FT extremo, tanto para a fração com raios quanto para a fração sem raios da precipitação dos sistemas. Como o último nível de altitude dos CFADs deste trabalho é limitado por 


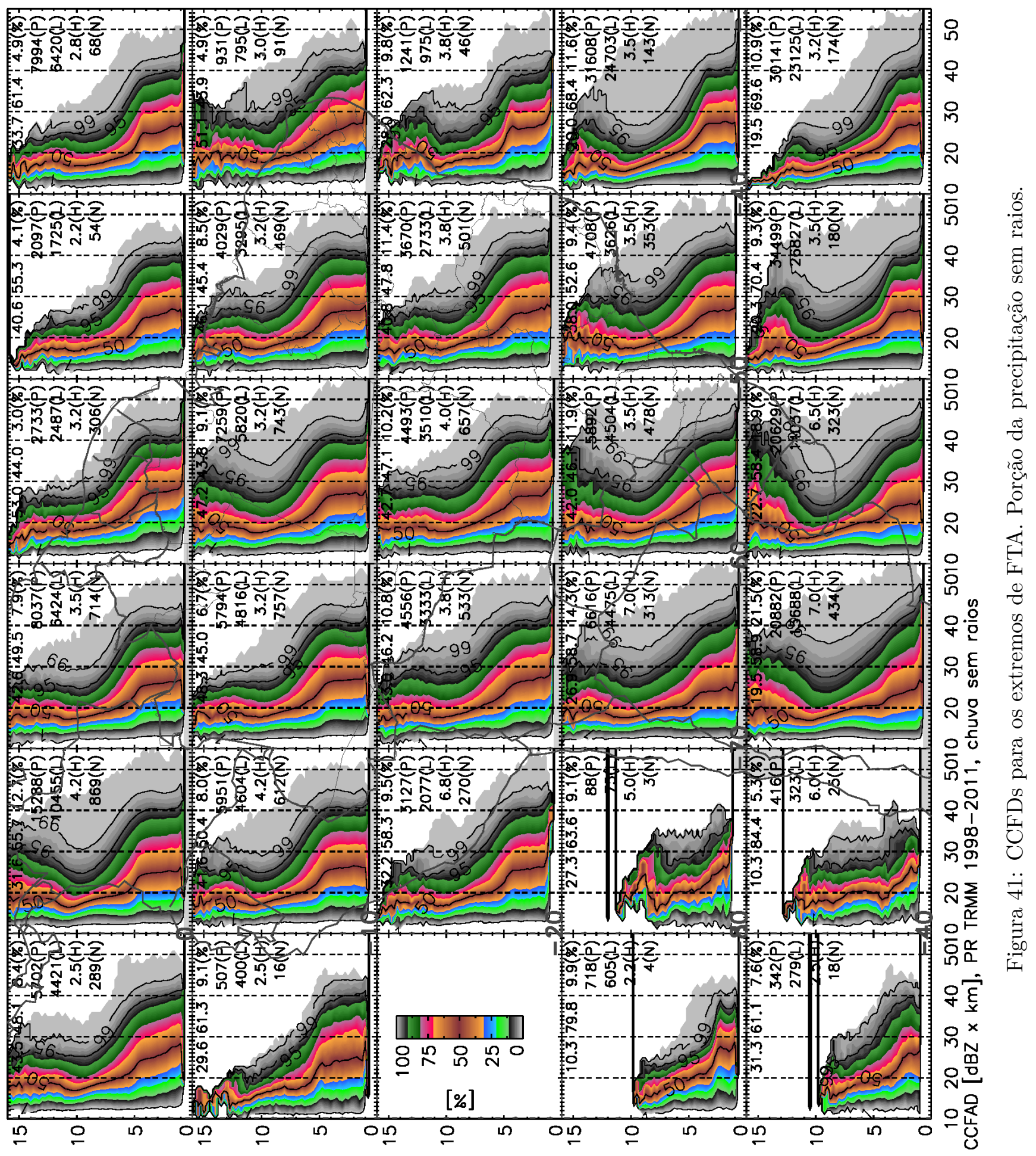




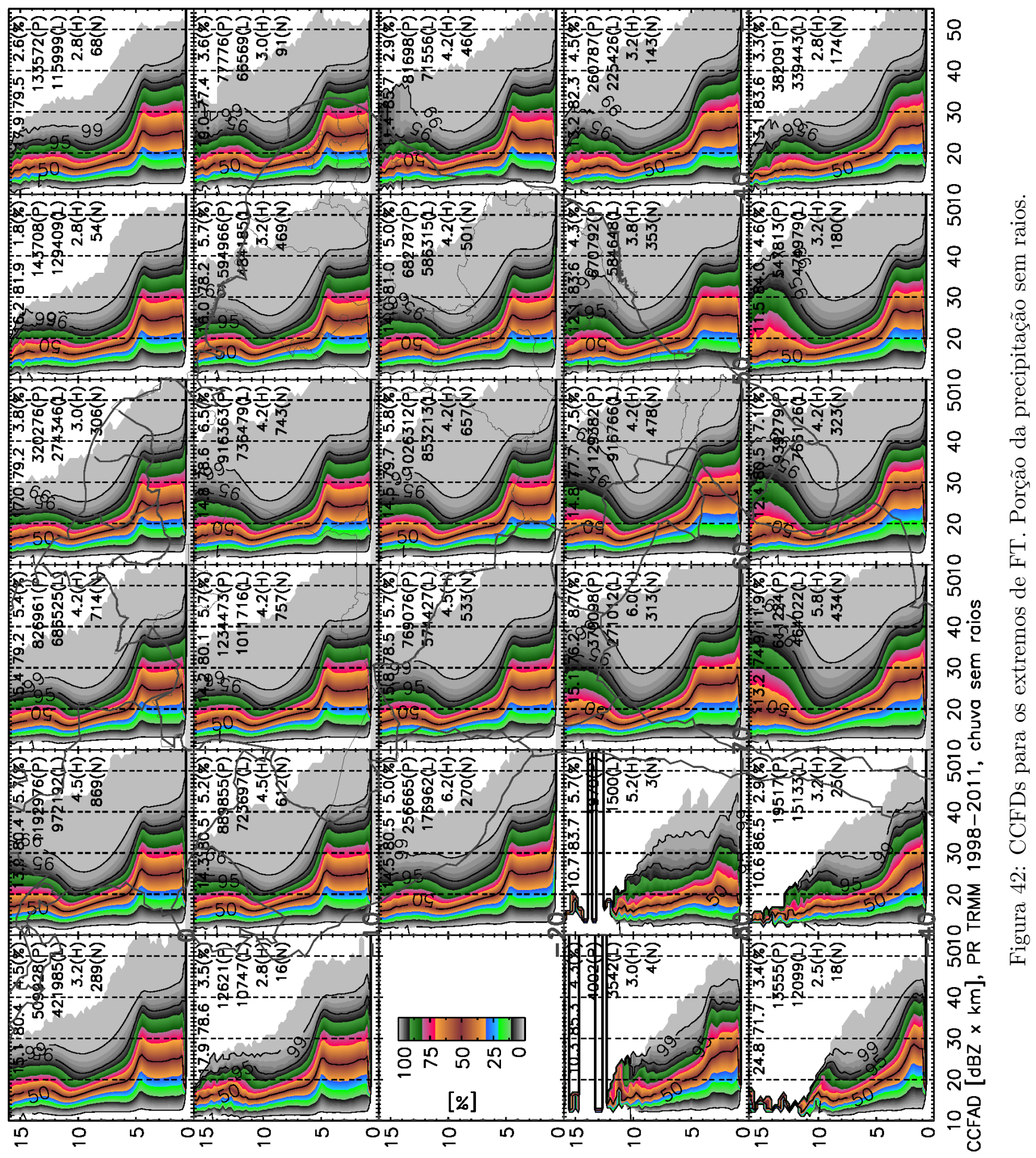


altitudes com até $10 \%$ de L, a maior definição de probabilidades de ocorrência de $Z_{c}$ em altitude indica que a convecção é mais intensa nas tempestades elétricas com FTA extremo do que nas tempestades elétricas de FT extremos.

Nos CFADs da precipitação dos núcleos de raios na figura 39, dos sistemas extremos de FTA, mostram valores de refletividade entre 1-3 dBZ maiores do que em relação aos sistemas extremos de FT da figura 40, principalmente quando observa-se os contornos de probabilidade de $Z_{c}$ acima de $5 \mathrm{~km}$ de altitude. Para a precipitação entre 0-2 $\mathrm{km}$ de altitude os valores são mais semelhantes entre as tempestades elétricas selecionadas por FTA e FT.

Os contornos de probabilidade entre 0,001-0,5\% das figuras 39 e 40 revelam os valores dos perfis de $Z_{c}$ mais raros e mais intensos ocorridos nos sistemas com índice extremo de FTA e FT, os quais provavelmente estiveram associados a condições de tempo severo, ou seja, com enchentes rápidas, alta taxa de raios, chuva de granizo, fortes rajadas de vento e tornados.

Os maiores valores de $Z_{c}$ foram registrados na análise da precipitação 3D das tempestades elétricas com FTA extremos (figura 39), entre $20^{\circ}-40^{\circ}$ Sul e $40^{\circ}-70^{\circ}$ Norte sobre a Bacia do Rio da Prata, que abrange o Sul do Brasil, Paraguai, Uruguai e Argentina, em que a precipitação dos núcleos de raios atingiram valores de $Z_{c}$ superior a $45 \mathrm{dBZ}$ entre 10-15 km de altitude e $Z_{c}$ acima de $55 \mathrm{dBZ}$ na superfície, como mostram os contornos de probabilidade entre 0,001-0,5\% da figura 39. Este efeito pode estar associado com a dinâmica de formação de Sistemas Convectivos de Meso-escala, conforme descrevem Velasco e Fritsch (1987) e Durkee e Mote (2009) somados aos efeitos de topografia, como por exemplo na região da Serra de Córdoba na Argentina, em que Rasmussen e Houze Jr. (2011) observaram grande ocorrência de convecção profunda.

\subsubsection{A precipitação 3D e o perfil atmosférico de temperatura.}

O estudo dos perfis de $Z_{c}$ por nível de temperatura é realizado por meio dos diagramas CCFTD e CFTD, expostos nas figuras 44, 46, 43, e 45, associados às tempestades elétricas com índice extremo de FTA e FT de cada região de $10^{\circ} \times 10^{\circ}$ de latitude e longitude, apenas referente a precipitação dos núcleos de raios.

Iremos avaliar a intensidade convectiva dos sistemas com índice FTA e FT extremo em determinadas regiões, não apenas por meio dos valores de $Z_{c}$, mas com base na taxa de variação de $Z_{c}$ em função da temperatura, a partir dos contornos dos CCFTDs das 
figuras 44 e 46 , que representam os perfis de $Z_{c}$ em função da temperatura para o $30^{\circ}, 50^{\circ}$, $70^{\circ}$ e $95^{\circ}$ percentil das amostragens de probabilidades expressas nos CFTDs das figuras 43 e 45.

Portanto, a partir das amostragens de probabilidade do fator de refletividade $Z_{c}$ por nível de temperatura que define os diagramas CCFTD e CFTD conforme é descrito em 2.7. extrai-se as linhas de contorno do CCFTD referentes às probabilidades cumulativas de $30 \%, 50 \%, 70 \%$ e 95\%. Desta forma, obteve-se quatro funções

$$
f(x)=y
$$

em que $y$ corresponde aos valores de $Z_{c}$ e $x$ os valores de temperatura. Fazendo a derivada

$$
f^{\prime}\left(x_{0}\right)=-\frac{y_{1}-y_{0}}{x_{1}-x_{0}}
$$

então, pode-se avaliar a taxa de variação do fator de refletividade do radar $\left(Z_{c}\right)$ por nível de temperatura $\left(\mathrm{dBZ}^{\circ} \mathrm{C}^{-1}\right)$ para diferentes regimes de precipitação, das mais frequentes até as mais raras. O sinal de menos na equação 20 deve-se ao fato da temperatura diminuir com a altitude e queremos mostrar taxas positivas associadas ao aumento de $Z_{c}$ e taxas negativas quando há diminuição de $Z_{c}$.

Para a região central da Bacia do Rio Amazonas, entre 10-0 Sul e 70-60 Oeste, os valores de $Z_{c}$ com os contornos de probabilidade do $30^{\circ}$, 50ํㅜ $70^{\circ}$ e $95^{\circ}$ percentil referente às tempestades elétricas com FTA extremo (figura 44), possuem valores entre 1-3 dBZ maiores do que os valores de $Z_{c}$ referentes as tempestades elétricas com FT extremo (figura 46), principalmente acima da isoterma de $0{ }^{\circ} \mathrm{C}$, o que indica maior concentração ou densidade ou diâmetro dos hidrometeoros na região fria ${ }^{10}$ dos núcleos de raios associados aos sistemas extremos de FTA. Este efeito pode ser observado de forma mais elucidativa na figura 47a, em que os perfis verticais de $Z_{c}$ referentes aos contornos de probabilidade cumulativa do $30^{\circ}$, $50^{\circ}$, $70^{\circ}$ e $95^{\circ}$ percentil das amostragens de perfis de $Z_{c}$ em função da temperatura para as tempestades elétricas com extremos de FTA e FT são plotados conjuntamente.

Adicionalmente, entre 10- $0^{\circ} \mathrm{Sul}$ e $70-60^{\circ}$ Oeste, na figura $47 \mathrm{~b}$, observa-se que a taxa de diminuição de $Z_{c}$ referente ao $70^{\circ}$ e $95^{\circ}$ percentil, entre $-40{ }^{\circ} \mathrm{C}$ e $-15^{\circ} \mathrm{C}$ dos extremos de FTA é maior do que nos extremos de FT. Para os percentis de $30^{\circ}$ e $50^{\circ}$, apesar da intensidade de $Z_{c}$ ser maior entre $-40{ }^{\circ} \mathrm{C}$ e $-15{ }^{\circ} \mathrm{C}$ para os extremos de FTA (ver figura 47a), as taxas de diminuição em $\mathrm{dBZ}{ }^{\circ} \mathrm{C}^{-1}$ possuem valores semelhantes (ver figura 47b).

\footnotetext{
${ }^{10} \mathrm{Com}$ temperaturas abaixo de $0^{\circ} \mathrm{C}$
} 


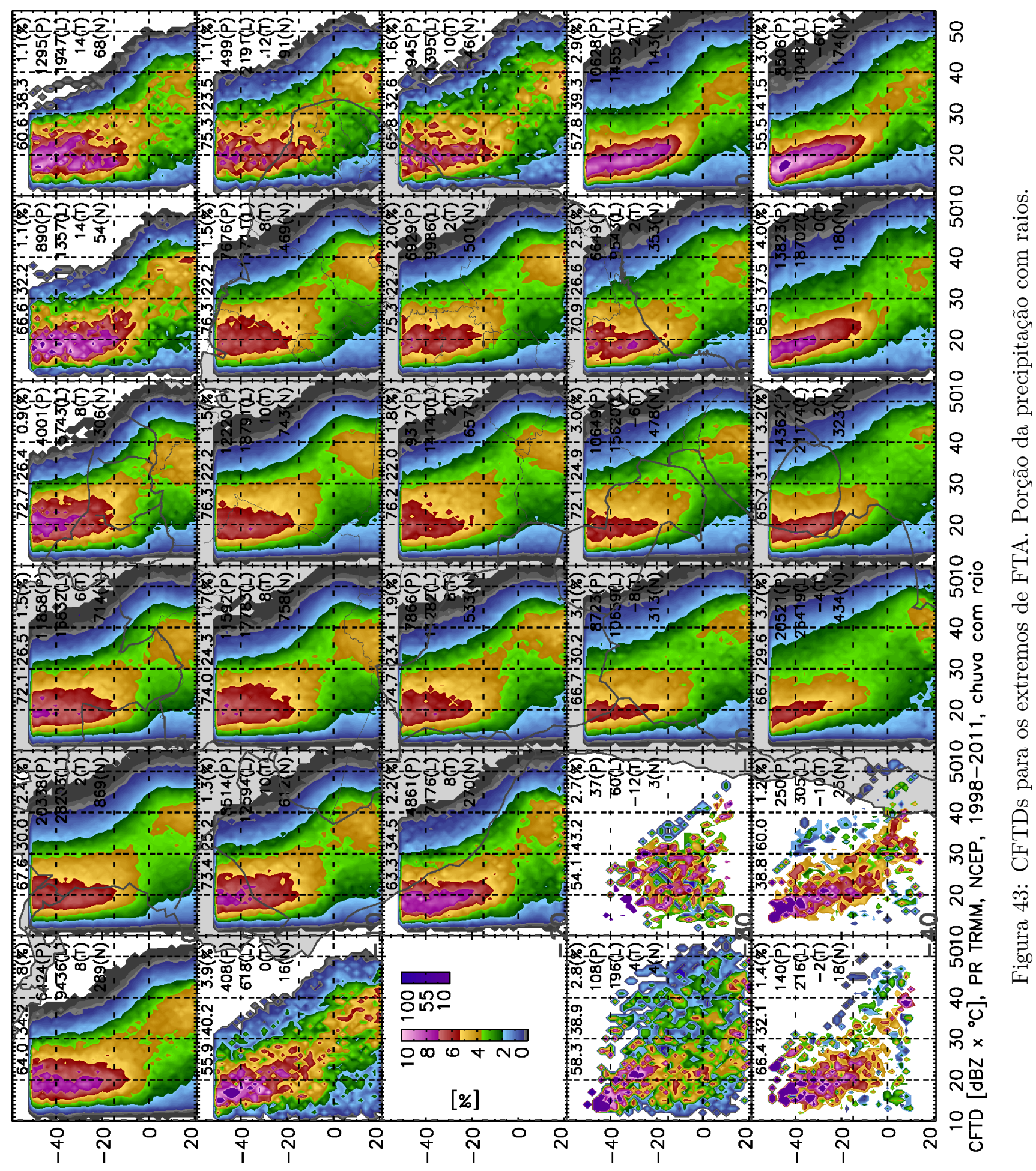




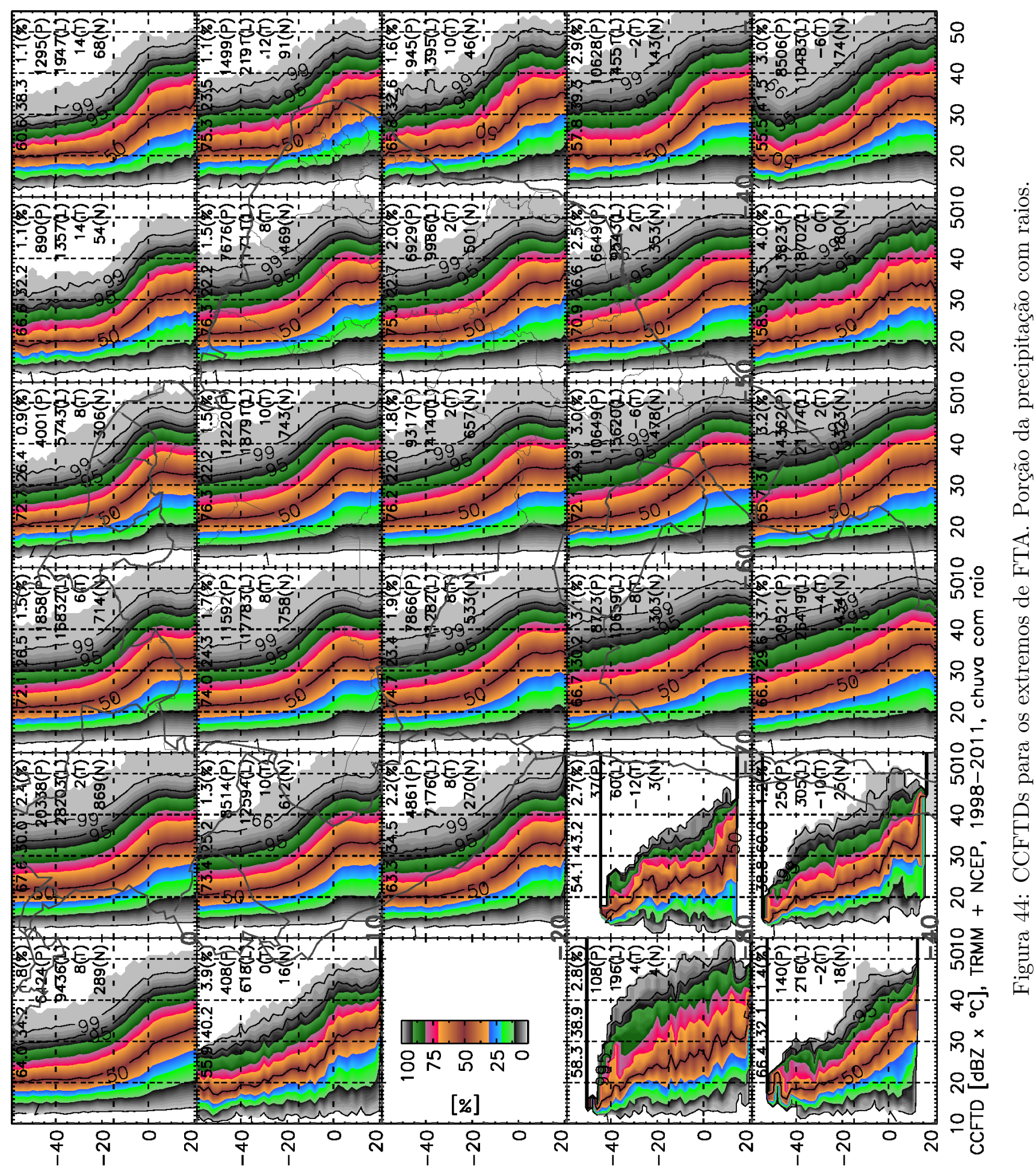




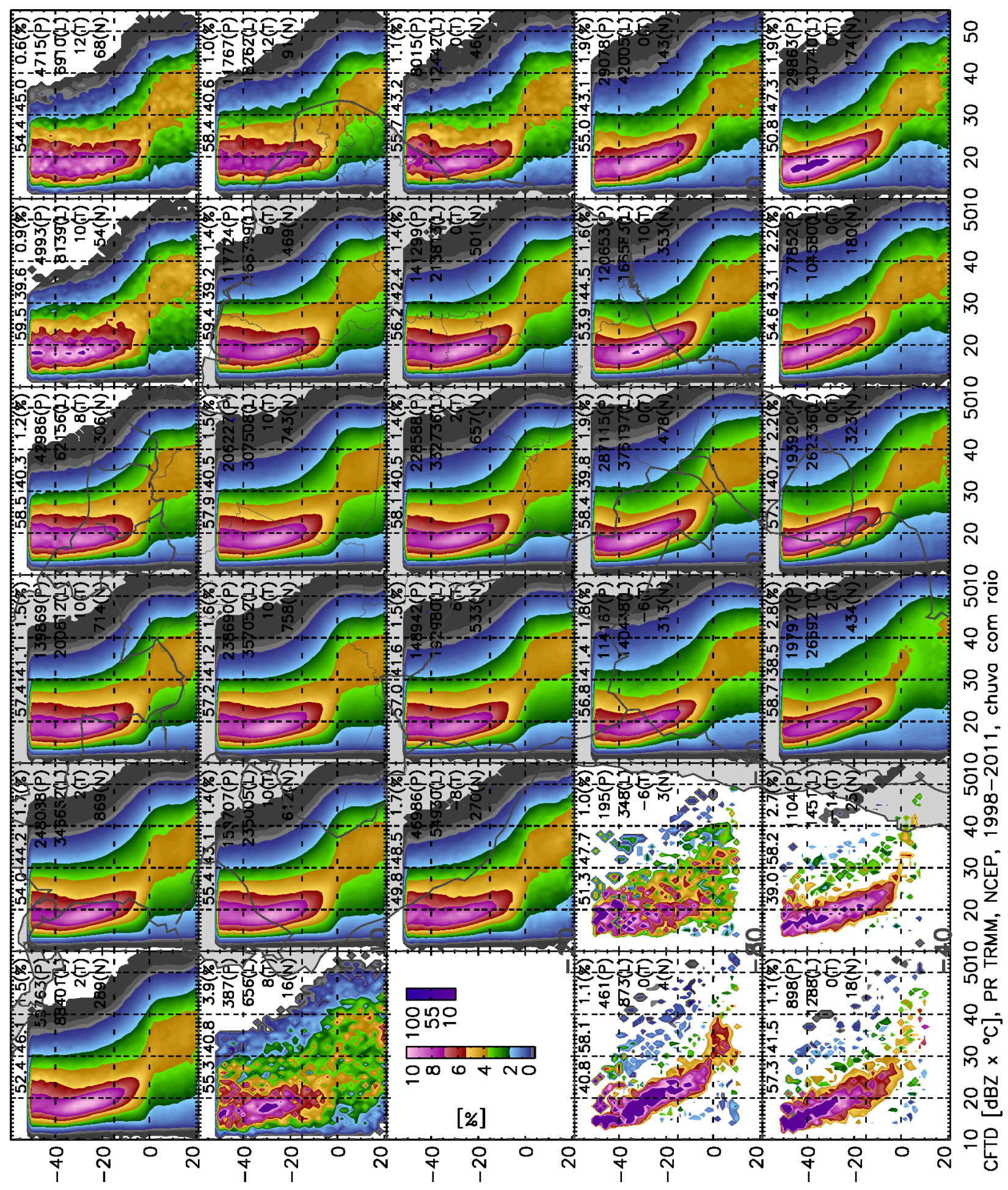




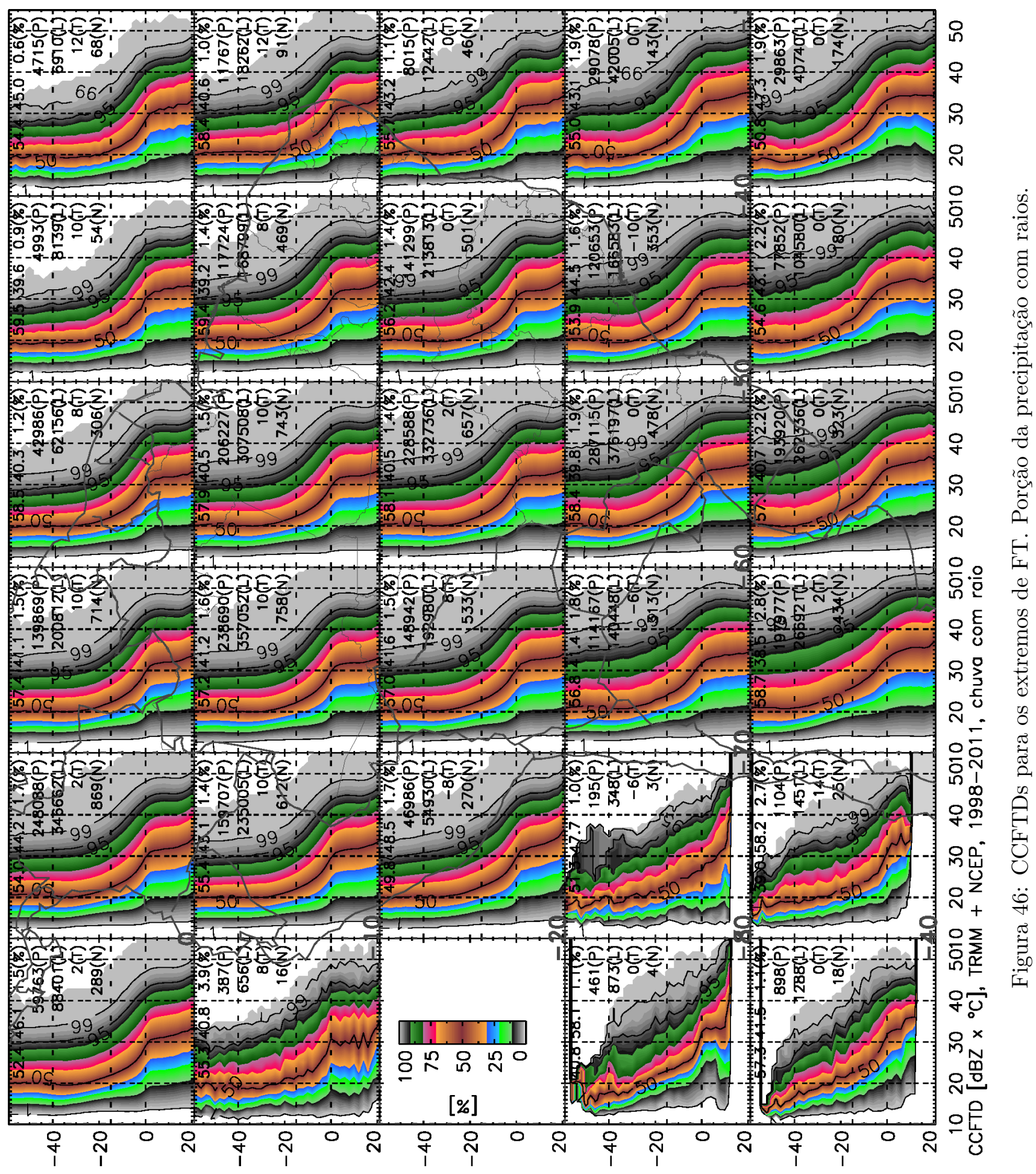




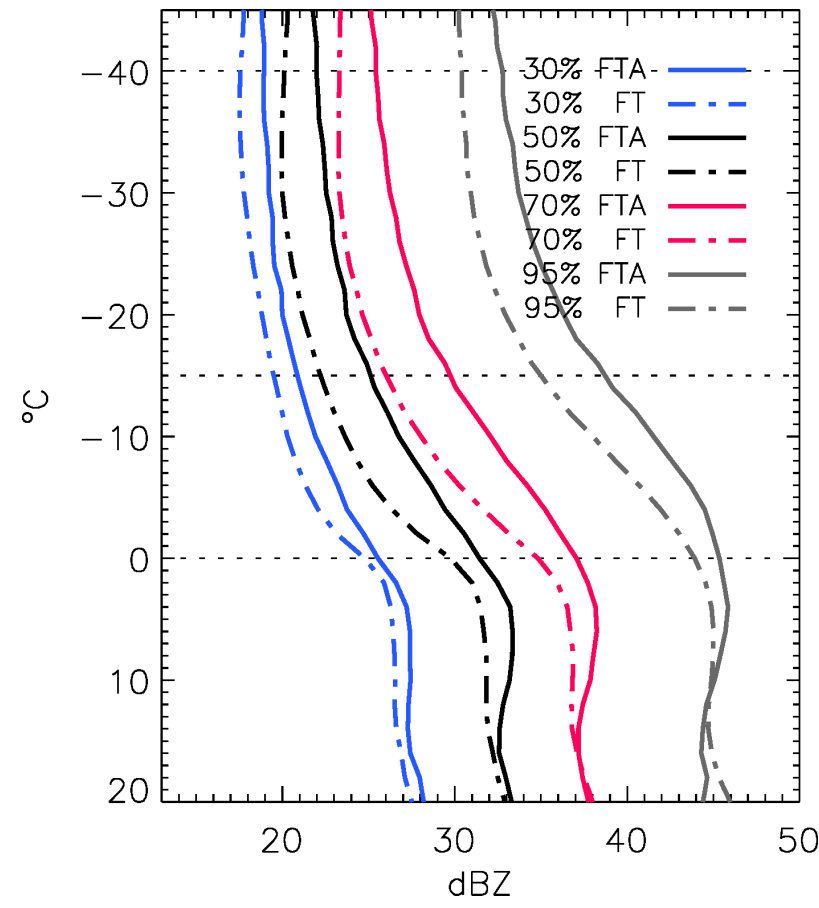

(a) Perfis verticais de $Z_{c}$ de acordo com diferentes percentis do CCFTD.

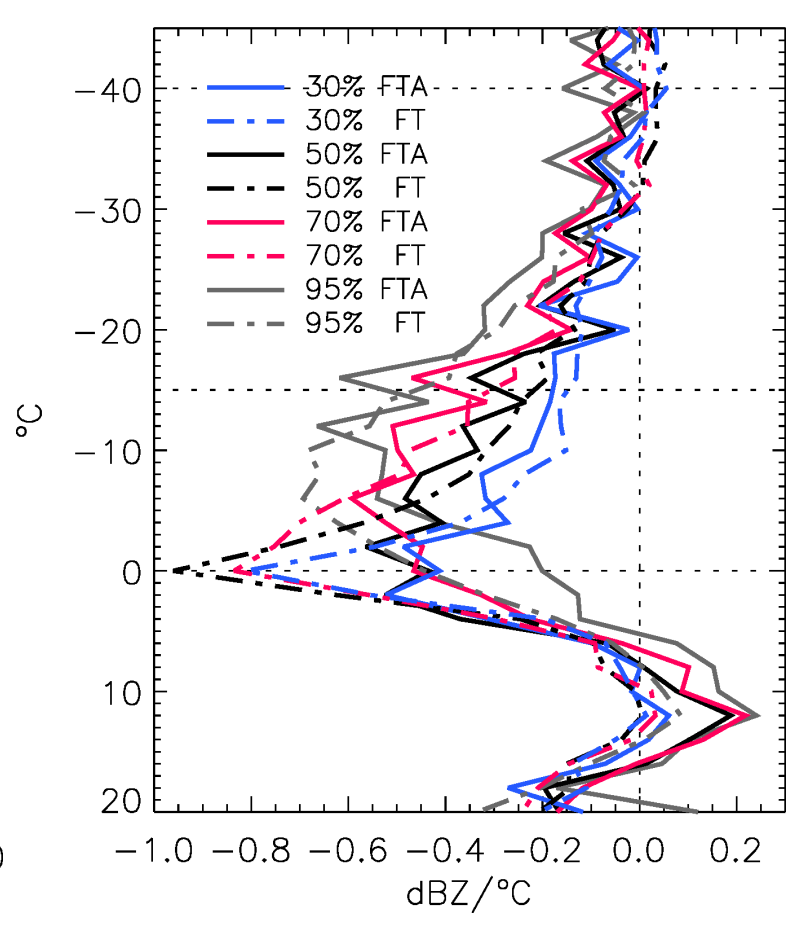

(b) Derivadas dos perfis verticais de $Z_{c}$ de diferentes percentis do CCFTD.

Figura 47: Região central da Bacia do Rio Amazonas, entre 10-0S e 70-60W.

Porém, para todos os quantis entre $-15{ }^{\circ} \mathrm{C}$ e $0{ }^{\circ} \mathrm{C}$ da figura 47 , observa-se que os valores de $Z_{c}$ para os extremos de $\mathrm{FT}$, sofreram os maiores decréscimos entre $-8{ }^{\circ} \mathrm{C}$ e $0{ }^{\circ} \mathrm{C}$, enquanto os valores de $Z_{c}$ para os extremos de FTA sofreram os maiores decréscimos entre $-20{ }^{\circ} \mathrm{C}$ $\mathrm{e}-10{ }^{\circ} \mathrm{C}$.

Quando não se observa uma diminuição abrupta de $7 \mathrm{dBZ}$ abaixo de $0{ }^{\circ} \mathrm{C}$, isso significa que entre $0{ }^{\circ} \mathrm{C} \mathrm{e}-20{ }^{\circ} \mathrm{C}$ existem partículas de gelo com densidades diversificadas, bem como água super-resfriada. Os CCFTDs das figuras 44 e 46, mostram que entre $0{ }^{\circ} \mathrm{C}$ e $-20{ }^{\circ} \mathrm{C}$ a precipitação das tempestades elétricas com FTA extremos apresentam maior amplitude $Z_{c}$, e quantis de probabilidade de $Z_{c}$ por temperatura mais alargados, mostrando os perfis são mais aleatórios do que para a precipitação dos extremos de FT, o que está associado a formação de partículas maiores e mais densas. Se as tempestades elétricas com FTA extremos são sistemas novos, as correntes ascendentes são mais intensas do que nos extremos de FT, então, há de se esperar mais gotículas pequenas nos sistemas extremos de FTA e menos gotas grandes do que em relação aos extremos de FT.

De acordo com Bigg (1953), as gotas maiores se congelam em temperaturas mais elevadas do que as gotas menores. Portanto, as gotas menores percorrem um caminho maior em altitude para atingirem temperaturas de congelamento, o que aumenta a pro- 
babilidade de colisões entre os hidrometeoros e consequentemente aumenta a eficiência de formação do granizo, pois a espessura de interação entre o graupel e gotas pequenas super-resfriadas será maior do que em relação a nuvens de tempestades elétricas com fracas correntes ascendentes e maior fração estratiforme (gotas maiores), que é evidenciado pela taxa de diminuição de $Z_{c}$ por nível de temperatura na figura 47, cujas tempestades elétricas de FTA extremo têm maior taxa de diminuição entre $-20{ }^{\circ} \mathrm{C} \mathrm{e}-10{ }^{\circ} \mathrm{C}$ e as tempestades elétricas de FT extremo têm as maiores taxas de diminuições $\left(\mathrm{dBZ}{ }^{\circ} \mathrm{C}^{-1}\right)$ entre $0{ }^{\circ} \mathrm{C}$ e $-8{ }^{\circ} \mathrm{C}$. Em termos de eletrificação, a colisão entre o graupel/granizo com cristais de gelo é muito mais eficiente do que a colisão entre agregados (TAKAHASHI, 1978; JAYARATNE et al., 1983).

Os maiores valores de $Z_{c}$ em temperaturas inferiores a $-10{ }^{\circ} \mathrm{C}$ para diferentes quantis da amostragem da probabilidade de $Z_{c}$ por temperatura dos extremos de FTA, indicam que a velocidade vertical no ambiente das tempestades elétricas com índice FTA extremo são maiores do que para os sistemas com índice FT extremo, pois os maiores valores de FTA mostram perfis de $Z_{c}$ com maior quantidade de gelo de nuvem, portanto, espera-se correntes ascendentes mais intensas nas tempestades elétricas selecionadas pelos extremos de FTA na região dos núcleos de raios para que seja possível elevar maior quantidade de água em regiões mais frias da atmosfera do que nos casos das tempestades elétricas com FT extremo. Este resultado reforça que as tempestades elétricas do grupos dos eventos extremos de FTA são sistemas novos ou em via de maturação quando as correntes ascendentes são mais intensas, enquanto o grupo dos eventos extremos de FT são sistemas maduros ou em dissipação.

O fato das taxas de crescimento em $\mathrm{dBZ}{ }^{\circ} \mathrm{C}^{-1}$ para a precipitação dos núcleos de raios das tempestades elétricas com FTA extremo serem maiores em regiões mais frias do que observa-se para as tempestades elétricas com extremos de FT, sugere que nos extremos de FTA há maior interação entre o graupel e neve seca, com possível formação de granizo compacto ou poroso, e menor interação entre graupel e neve molhada do que em relação aos extremos de FT. Conforme Takahashi (1978), a interação entre cristais de gelo e o graupel é o processo de maior eficiência na transferência de cargas entre os hidrometeoros.

Nos sistemas com FT extremos entre $10^{\circ}-0^{\circ}$ Sul e $70^{\circ}-60^{\circ}$ Oeste, a acresção ocorreu preferencialmente em temperaturas superiores a $-10{ }^{\circ} \mathrm{C}$, ambiente supostamente com maior quantidade de gotículas de água superesfriadas do que em regiões com temperaturas entre $-20^{\circ} \mathrm{C}$ e $-10{ }^{\circ} \mathrm{C}$, sugerindo maior formação de granizo esponjoso ${ }^{11}$, processo

\footnotetext{
${ }^{11}$ Granizo em que parte das gotículas de água super-resfriadas coletadas não congelam. Também denominado de granizo macio.
} 
de crescimento de hidrometeoro pouco eficiente para a eletrização (JAYARATNE et al., $1983)$.

Observe na figura $47 \mathrm{~b}$, que em $12{ }^{\circ} \mathrm{C}$, os valores de $Z_{c}$ aumentam mais para FTA do que para FT para todos os percentis de ocorrência selecionados. Este aumento de $Z_{c}$ com a diminuição da temperatura próximo da superfície representa processo de evaporação ou quebra das gotas de chuva maiores, o que pode indicar rajadas de ventos mais intensas na superfície para as tempestades elétricas com FTA extremo.

Quando comparamos a região central da Bacia do Amazonas, figura 47, com a região entre $30-20^{\circ}$ Sul e $60-50^{\circ}$ Oeste que abrange parte central da Bacia do Rio da Prata, figura 48, a microfísica de eletrificação se mostra diferente em cada local. Observa-se que no $50^{\circ}$ percentil, a taxa de diminuição em $\mathrm{dBZ}{ }^{\circ} \mathrm{C}^{-1}$ entre $-40{ }^{\circ} \mathrm{C}$ e $-20{ }^{\circ} \mathrm{C}$ é menor e os valores de $Z_{c}$ são maiores para a região da Bacia do Prata, do que para a região da Bacia Amazônica, tanto para os sistemas extremos de FTA quanto para os sistemas extremos de FT. Na atmosfera, entre $-40{ }^{\circ} \mathrm{C}$ e $-20{ }^{\circ} \mathrm{C}$ as condições de temperatura e supersaturação em relação ao gelo são favoráveis para o crescimento de cristais de gelo, mostrando que o processo de agregação é mais vigoroso sobre a Bacia do Prata do que sobre a Bacia Amazônica.

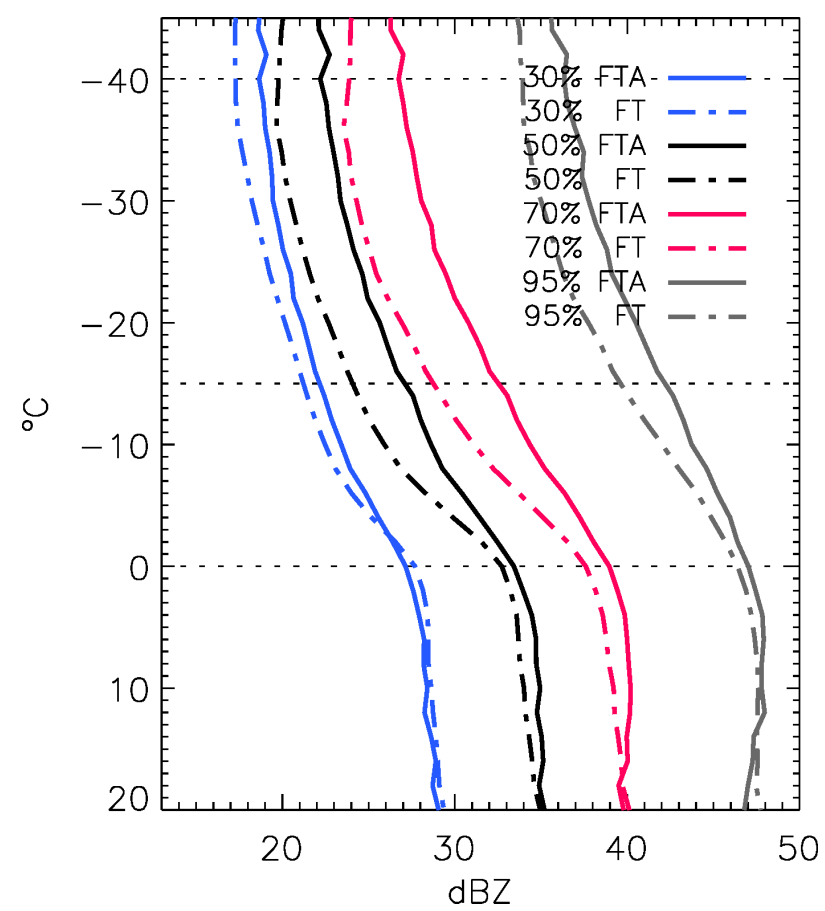

(a) Perfis verticais de $Z_{c}$ de acordo com diferentes percentis do CCFTD.

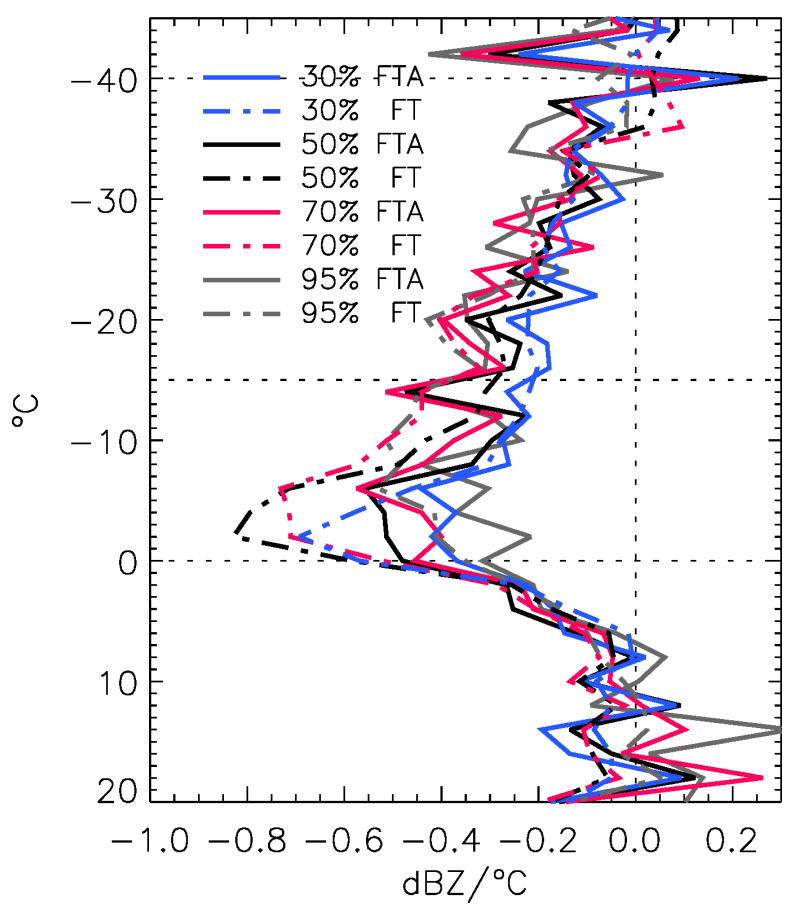

(b) Derivadas dos perfis verticais de $Z_{c}$ de diferentes percentis do CCFTD.

Figura 48: Quadrante que abrange a região central da Bacia do Rio da Prata, entre $30^{\circ}-20^{\circ}$ Sul e $60^{\circ}-50^{\circ}$ Oeste. 
Conforme Mason (1971, p. 263), as diferentes formas geométricas dos cristais de gelo irão depender da temperatura e supersaturação do ambiente atmosférico em relação ao gelo. Portanto, espera-se maior quantidade e diversidade de cristais de gelo associada à precipitação tridimensional dos núcleos de raios da região da Bacia do Prata.

Comparando as variações de $Z_{c}$ em função da temperatura referente ao $95^{\circ}$ percentil entre as figuras $47 \mathrm{~b}$ e $48 \mathrm{~b}$, observa-se que para ambos os extremos de FTA ou FT, o decrescimento de $Z_{c}$ em torno de $-15^{\circ} \mathrm{C}$ é maior para a região da Bacia do Rio Amazonas, o que indica maior formação de granizo. Provavelmente, para os perfis de $Z_{c}$ mais raros e intensos entre $10-0^{\circ} \mathrm{Sul}$ e $70-60^{\circ}$ Oeste a taxa de acreção é maior do que entre $30-20^{\circ}$ Sul e $60-50^{\circ}$ Oeste.

Porém, nos perfis de $Z_{c}$ associados às linhas de contorno dos CCFTDs expostos nas figuras $47 \mathrm{a}$ e $48 \mathrm{a}$, observa-se que para todos os quantis analisados, tanto para a chuva dos extremos de FTA quanto FT, os valores de $Z_{c}$ são mais intensos nas tempestades elétricas da região que abrange a parte central da Bacia do Prata. Então pode-se afirmar que a intensidade convectiva dos núcleos de raios entre $30^{\circ}-20^{\circ}$ Sul e $60^{\circ}-50^{\circ}$ Oeste é maior do que entre $10^{\circ}-0^{\circ}$ Sul e $70^{\circ}-60^{\circ}$ Oeste.

\subsection{SEVERIDADE REGIONALIZADA}

O estudo da densidade de probabilidade de FTA e FT, conforme mostrado na figura 24. foi feito para as tempestades elétricas ocorridas em cada região de 2,5 por 2,5 graus de latitude e longitude entre $40^{\circ}$ Norte $-10^{\circ}$ Sul e $90^{\circ}-30^{\circ}$ Oeste. Desta forma, verifica-se quais são os valores extremos de FTA e FT em cada região de $2,5^{\circ} \times 2,5^{\circ}$ sobre a América do Sul.

Os mapas das figuras 49, 50, 51, e 52, mostram os valores de FTA e FT do 95o e $99^{\circ}$ percentil de ocorrência. Pontos da grade de $2,5^{\circ} \times 2,5^{\circ}$ com menos do que 100 tempestades elétricas ocorridas nos 14 anos de dados foram preenchidos na cor branca. A barra de cores dos mapas correspondem aos valores extremos regionais, enquanto a linha de contorno na cor preta marca o extremo em relação a todas as tempestades observadas sobre a AS conforme a amostragem das tempestades elétricas exposta na figura 25.

Observa-se na figura 49, que o valor do 95o percentil da amostragem total de FTA corresponde a $52,76 \times 10^{-4}$ raios $\mathrm{min}^{-1} \mathrm{~km}^{-2}$. Porém, em algumas regiões os valores de FTA do 95o percentil das amostragens regionalizadas, atingiram $111 \times 10^{-4}$ raios $\min ^{-1} \mathrm{~km}^{-2}$. Portanto, eventos considerados extremos em relação a todo o continente 


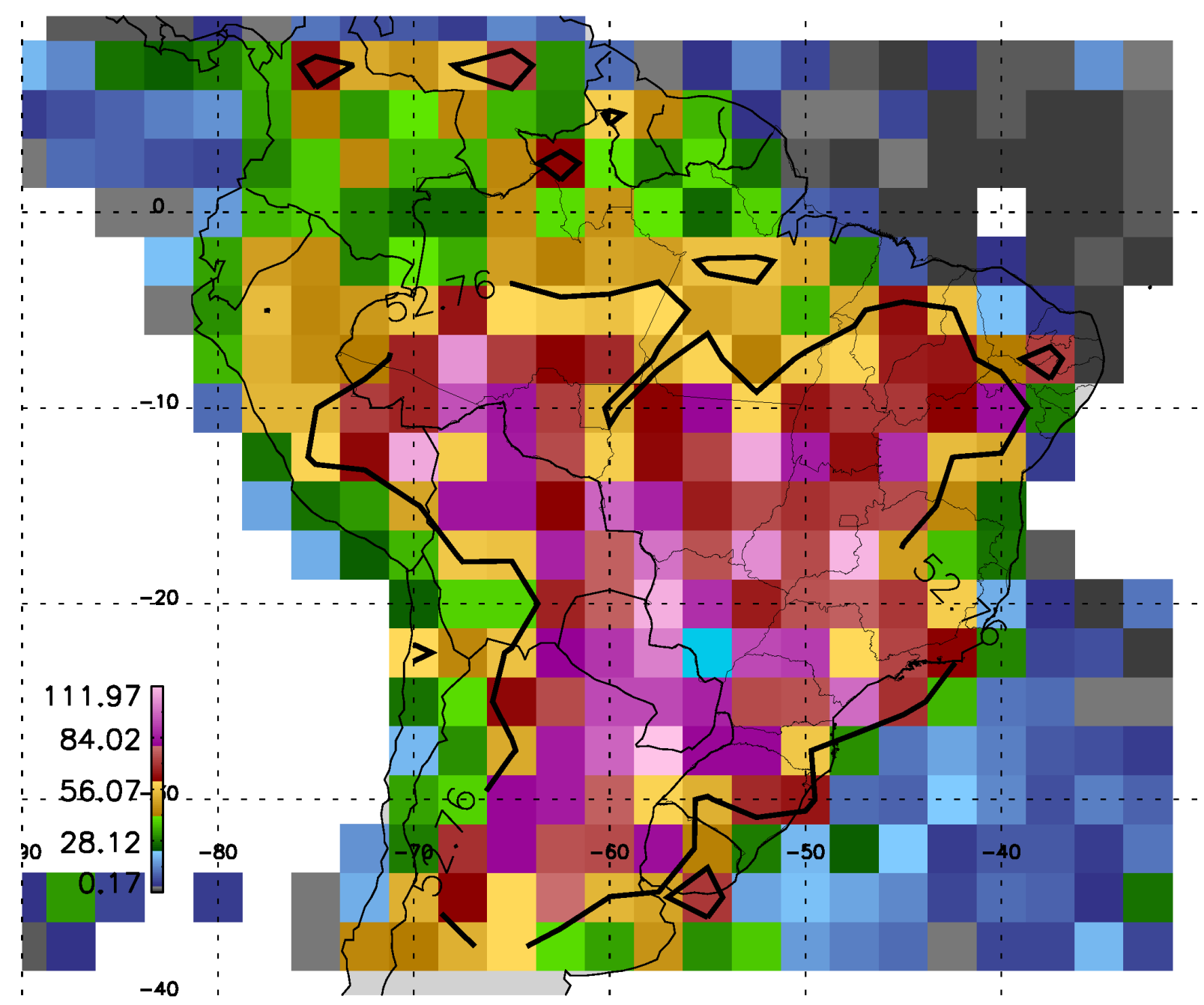

$95^{\circ}$ percentil, FTA, [ raios minutos ${ }^{-1} \mathrm{~km}^{-2} 10^{-4}$ ]

Figura 49: Distribuição geográfica dos valores do $95^{\circ}$ percentil da amostra de probabilidade do índice FTA a cada região de 2,5 por 2,5 graus de latitude e longitude.

sul-americano podem ser bem mais frequentes nas regiões em que o 95o percentil da

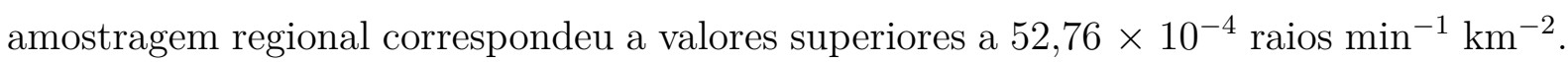

As regiões dos maiores valores do 95o e 99o percentil do índice FTA, os quais são expostos nas figuras 49 e 50, são principalmente: região ao Oeste da Cordilheira dos Andes Central até sua parte Meridional, a Bacia do Rio da Prata, região Leste da Amazônia e as regiões do planalto Brasileiro, entre o Pantanal Mato-grossense e o Planalto Central Brasileiro, entre as Bacias dos Rios Xingu, Araguaia e Tocantis e na região do Planalto Meridional Brasileiro aonde está localizado os planaltos e chapadas da Bacia do Paraná. Nestas regiões os sistemas com índice FTA extremo possuem valores superiores à $80 \times$ $10^{-4}$ raios $\mathrm{min}^{-1} \mathrm{~km}^{-2}$, conforme as cores das figuras $49 \mathrm{e} 50$.

Note que para saber aproximadamente o número de raios produzidos pelos sistemas extremos de FTA temos que multiplicar o índice FTA pela área do sistema. Por exemplo, 


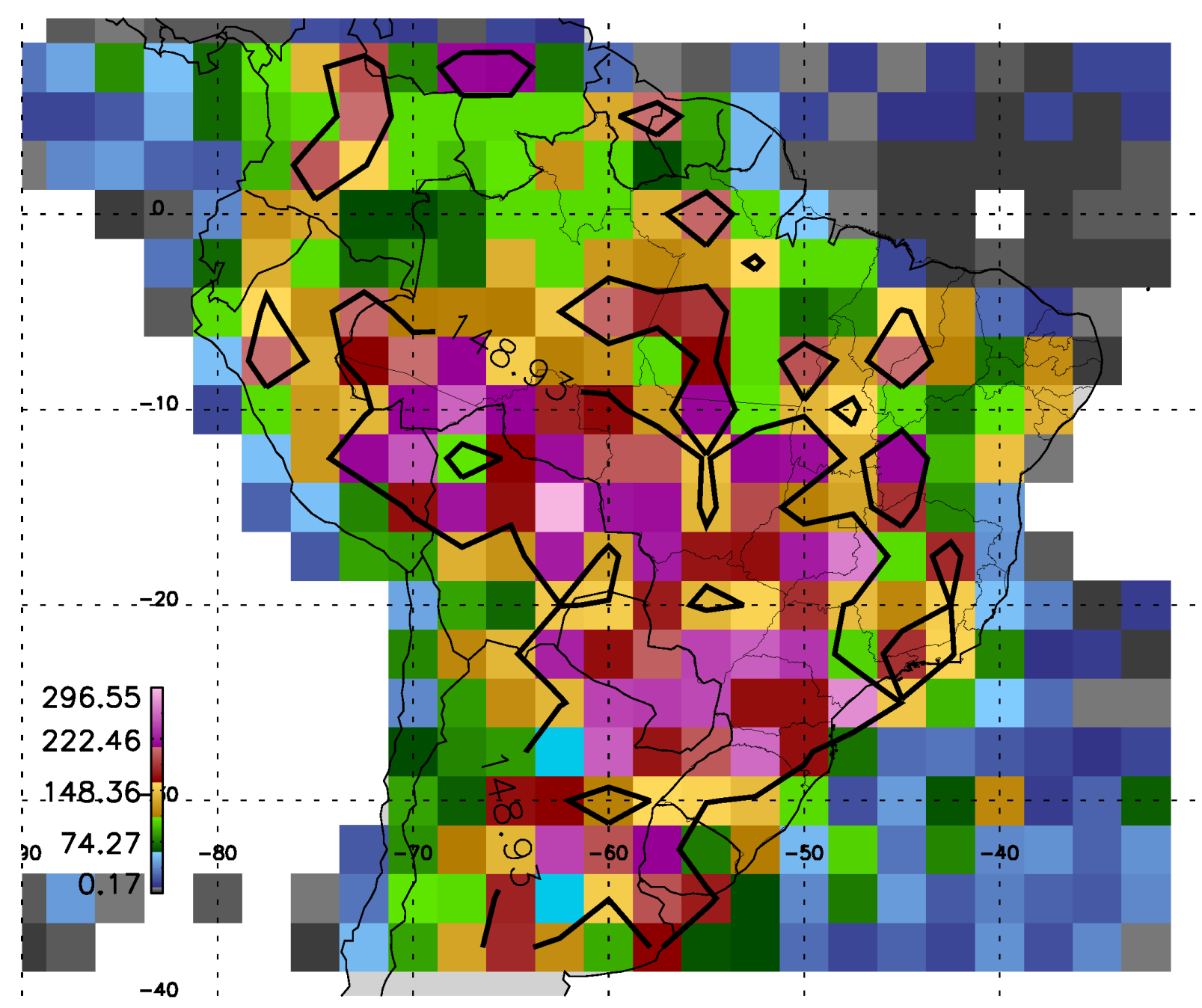

$99^{\circ}$ percentil, FTA, [ raios minutos ${ }^{-1} \mathrm{~km}^{-2} 10^{-4}$ ]

Figura 50: Distribuição geográfica dos valores do 99oㅡ percentil da amostra de probabilidade do índice FTA a cada região de 2,5 por 2,5 graus de latitude e longitude.

a equação 21, demostra que nas regiões em que os sistemas extremos possuem $100 \times$ $10^{-4}$ raios $\mathrm{min}^{-1} \mathrm{~km}^{-2}$, um sistemas severo com área de $10^{3} \mathrm{~km}^{2}$ então possui 10 raios observados pelo LIS em 1 minuto.

$$
100 \times 10^{-4}\left[\frac{1}{\operatorname{min~\mathrm {km}^{2}}}\right] 10^{3}\left[\mathrm{~km}^{2}\right]=10\left[\frac{1}{\min }\right]
$$

Os mapas das figuras 51 e 52 mostram que as Bacias: do Rio da Prata principalmente, do Rio Araguaia, Rio Xingu e Rio Tocantis, são locais em que os sistemas possuem os maiores índices de FT tanto no 95ำ quanto no 99o percentil.

Os maiores valores do 95o e 99o percentil do índice FT, figuras 51 e 52 , ficam situados na região Sul da América do Sul, compatível com a região em que Cecil et al. (2005) apontam como o local das PFs com as maiores taxas de raios por minuto da AS. 


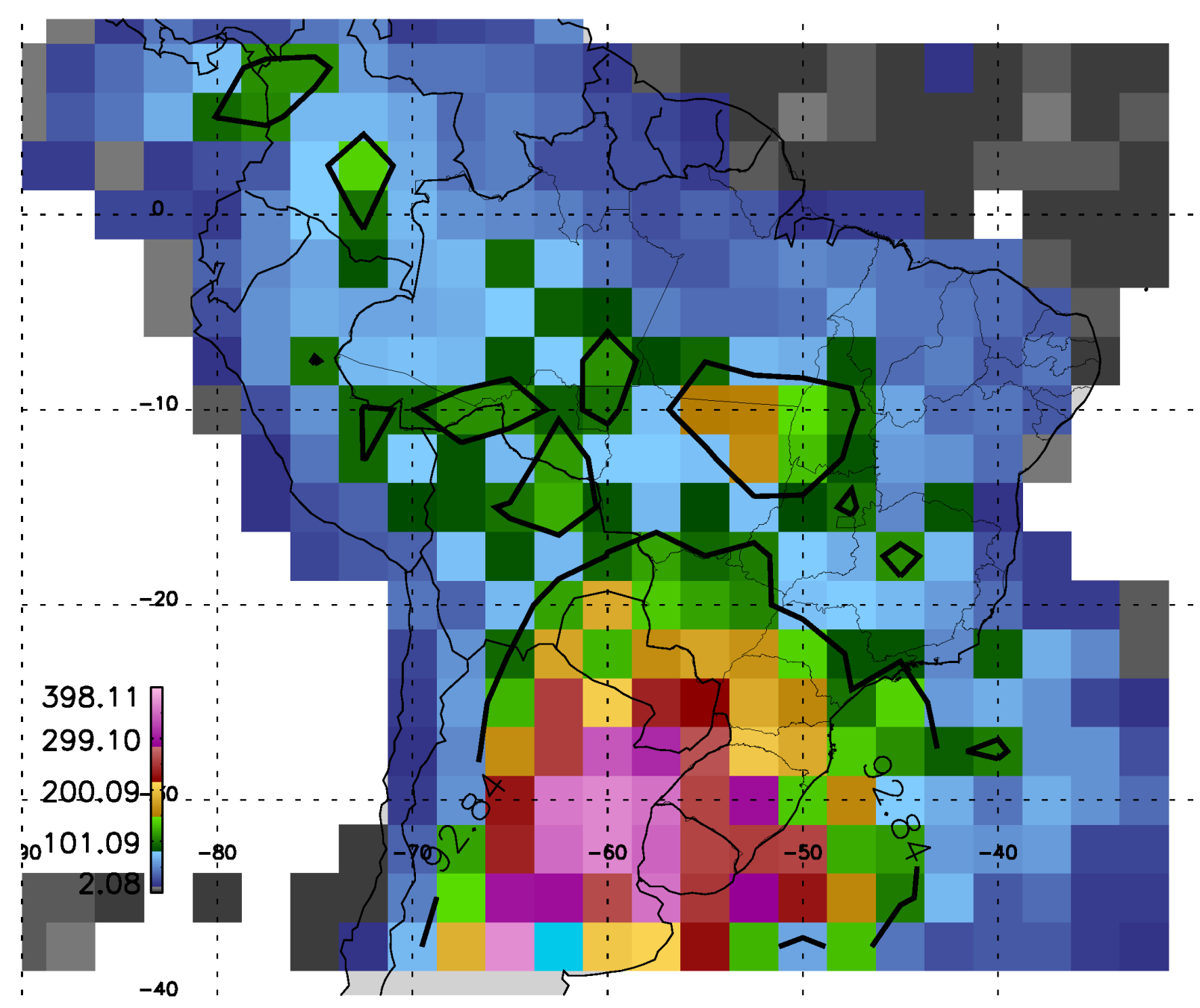

$95^{\circ}$ percentil, FT, [ roios minutos ${ }^{-1}$ ]

Figura 51: Distribuição geográfica dos valores do $95^{\circ}$ percentil da amostra de probabilidade do índice FT a cada região de 2,5 por 2,5 graus de latitude e longitude.

No entanto, os mapas dos extremos regionalizados do índice FTA mostram localidades com potencial de tempo severo em regiões mais adentro do continente sul-americano, que se estende conforme a topografia do Planalto Central e Meridional brasileiro, no Leste da Bacia Amazônia e ao Oeste da Cordilheira dos Andes.

Os maiores valores de extremos de FTA mostrados nas figuras 49 e 50 correspondem com as regiões apresentadas em Zipser et al. (2006), com os maiores valores extremos de máxima altura com refletividade superior a $40 \mathrm{dBZ}$ observadas pelo PR, enquanto os maiores valores de extremos de FT correspondem com os locais das PFs com maiores taxas de raios no tempo.

Observe que entre $40^{\circ}-20^{\circ}$ Sul e $70^{\circ}-60^{\circ}$ Oeste, os mapas desta seção revelam informações a respeito da intensidade convectiva (índices FTA e FT) das tempestades elétricas extremas sobre a AS em regiões do semiárido Argentino, as quais foram descon- 


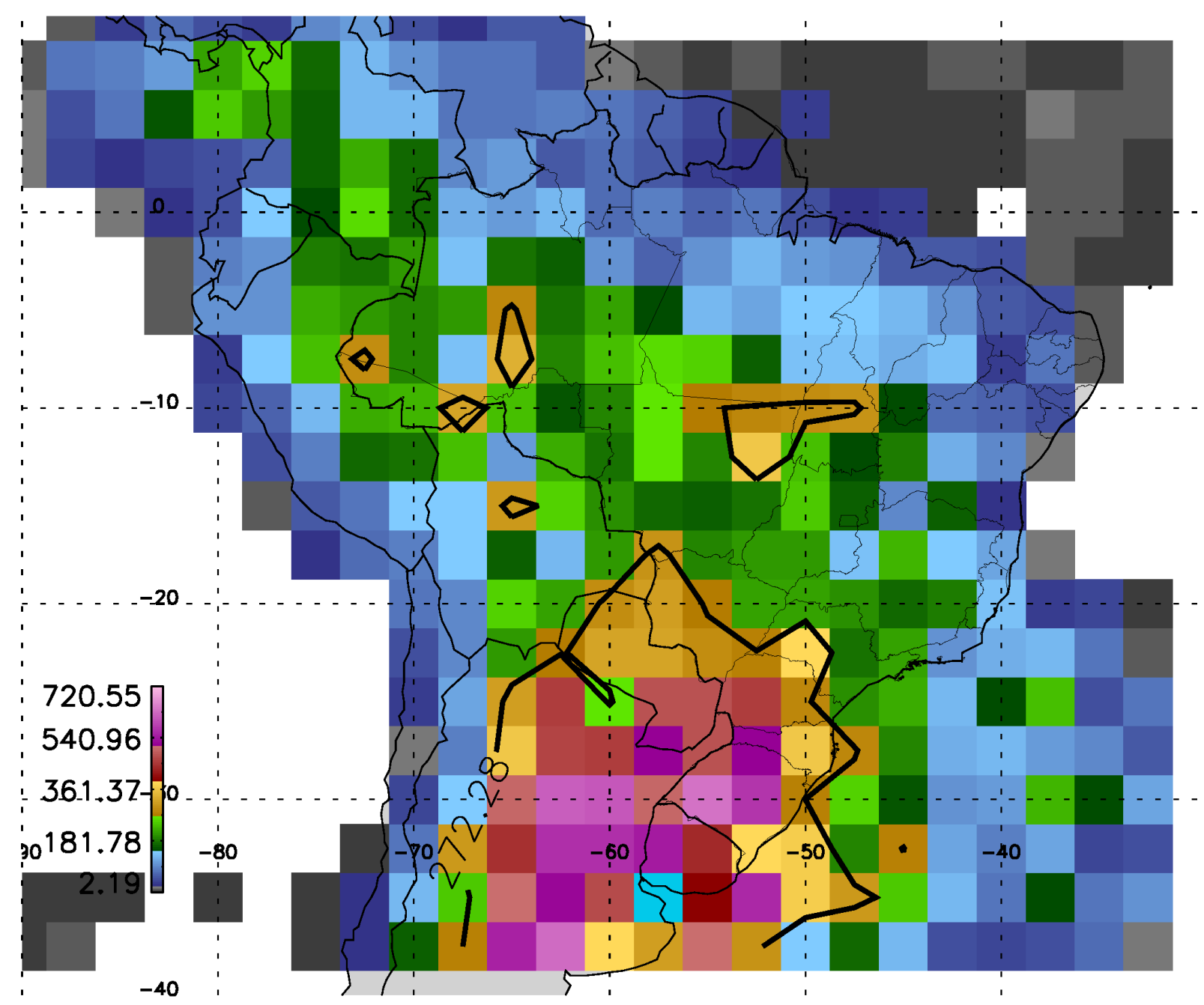

$99^{\circ}$ percentil, FT, [ roios minutos ${ }^{-1}$ ]

Figura 52: Distribuição geográfica dos valores do $99^{\circ}$ percentil da amostra de probabilidade do índice FT a cada região de 2,5 por 2,5 graus de latitude e longitude.

sideradas em Zipser et al. (2006, fig. 6a) por apresentarem baixo número de amostragem de PFs, menos do que 1000 PFs. Como podemos observar na seção 3.2, entre $40^{\circ}-20^{\circ}$ Sul e $70^{\circ}-60^{\circ}$ Oeste, observou-se a mais curta estação de tempestades elétricas da AS, porém, durante a estação de tempestades elétricas identifica-se os maiores índices extremos de FT e FTA da AS. Conforme aponta Brooks et al. (2003), esta região do semiárido Argentino ao leste da Cordilheira dos Andes possui o maior número de dias no ano com energia potencial convectiva $(\mathrm{CAPE}) \geq 2000 \mathrm{~J} \mathrm{~kg}^{-1}$.

Ao comparar os valores extremos entre o $95^{\circ}$ e $99^{\circ}$ percentil nas regiões continentais, a intensidade de ambos os índices FTA e FT aumenta em mais de 250\%. Conforme o percentil de ocorrência de FTA e FT aumenta a partir do 95o percentil, as regiões de 2,5 por 2,5 graus de latitude e longitude em que estes sistemas ocorrem são mais restritas e a intensidade convectiva (FTA e FT) aumenta aceleradamente em relação aos sistemas 
mais frequentes. 


\section{CONCLUSÃO}

Cria-se uma metodologia para caracterizar as tempestades elétricas observadas na AS a partir das medidas integradas dos sensores LIS, PR e VIRS a bordo do TRMM, durante o período de janeiro de 1998 a dezembro de 2011. As tempestades elétricas foram definidas por pixeis contíguos com $T_{b} \leq 258 \mathrm{~K}(\lambda=10,8 \mu \mathrm{m}-$ VIRS) com pelo menos um raio do LIS. Para tempestades elétricas consideras enormes, foi utilizado o limiar de $T_{b} \leq 221 \mathrm{~K}$, pois as mesmas faziam parte de sistemas frontais ou ZCAS. A partir deste procedimento foi criado um banco de dados de 157592 tempestades elétricas do TRMM, em que cada sistema é composto por: distribuição de $T_{b}$ e respetivas latitudes e longitudes do VIRS, perfis verticais de $Z_{c}$ e a classificação convectiva, estratiforme e outros, taxa de precipitação na superfície e respectivas latitudes e longitudes, localização (latitude e longitude) dos eventos, grupos e raios, do LIS e tempo de visada com resolução de $0,25^{\circ}$ $\times 0,25^{\circ}$ de latitude e longitude.

Com base neste subconjunto de dados do TRMM, o marco das tempestades elétricas na AS foi avaliado através do ciclo diurno, ciclo anual, distribuição geográfica de densidades (anual e sazonal) de raios e tempestades elétricas e por fim a densidade geográfica anual de raios por tempestades elétricas.

Para estudar a severidade das tempestades elétricas foram utilizados dois índices associados ao número de raios dos sistemas: a taxa de raios no tempo - FT - e a taxa de raios no tempo normalizado pela área do sistema - FTA. O FT é comumente utilizado para prognosticar a ocorrência de granizo e tornados (WILLIAMS et al., 1999, GOODMAN et al. 1988; SCHULTZ et al., 2011; GATLIN; GOODMAN, 2010). Já o FTA foi pensado com o intuito de estudar a eficiência das tempestades elétricas em produzir raios.

Os processos microfísicos que levam as tempestades elétricas a terem mais ou menos raios, foram investigados utilizando os CFADs (YUTER; HOUZE Jr., 1995). Entretanto, a América do Sul cobre uma vasta extensão territorial que vai do equador até os subtrópicos e a altura das isotermas podem variar significativamente e como os processos de 
eletrificação de nuvens dependem essencialmente da temperatura (TAKAHASHI, 1978), faz-se necessário converter a base de altura dos CFADs para temperaturas. Logo criou-se o diagrama CFTD que proporciona uma compreensão a respeito das mudanças de $Z_{c}$ em função da temperatura do perfil atmosférico, o que auxiliou na identificação de água super-resfriada, cristais de gelo, agregados, graupel e granizo, que são responsáveis pela transferência de cargas dentro das nuvens (TAKAHASHI, 1978; SAUNDERS, 2008).

\subsection{MARCO DAS TEMPESTADES ELÉTRICAS}

No ciclo diurno das tempestades elétricas sobre a AS, observa-se que $40 \%$ dos sistemas ocorreram entre $13 \mathrm{~h}$ e $17 \mathrm{~h}$ (HL), mostrando que o aquecimento diurno e o aumento da camada limite planetária no decorrer do dia, aumentam a probabilidade de ocorrência em 5,4 vezes (às 14h HL) em relação ao horário de menor ocorrência, às 9h HL.

No continente observa-se um predomínio da atividade elétrica entre às $13 \mathrm{~h}$ e $17 \mathrm{~h}$ HL, enquanto que no oceano existe uma variação dependendo da proximidade com o continente, mas em geral, sobre o oceano, observa-se dois máximos: um por volta das $20 \mathrm{~h}$ HL e outro entre 4-5h HL. Quando próximo do continente o pico das $20 \mathrm{~h}$ HL se desloca para as $15 \mathrm{~h}$ HL.

Apesar das tempestades elétricas sobre a AS possuírem um ciclo diurno bem definido, entre $0^{\circ}-10^{\circ}$ Norte e $80^{\circ}-70^{\circ}$ Oeste, observou-se a maior probabilidade $(\simeq 0,4 \%)$ de tempestades elétricas noturnas da América do Sul, entre 0h e 0h59min HL. A circulação de vale e montanha associada com a topografia elevada na Colômbia, principalmente a região do Parque Nacional Natural Paramillo, e o Lago Maracaibo na Venezuela, e a atuação da Zona de Convergência Intertropical (ZCIT), promovem condições para o desenvolvimento de tempestades elétricas noturnas de maneira mais eficiente do que as demais regiões da AS (ALBRECHT et al., 2011; BÜRGESSER et al., 2012).

O maior número de tempestades elétricas costeiras esteve entre $0^{\circ}-10^{\circ}$ Norte e $90^{\circ}-$ $80^{\circ}$ Oeste (Panamá e Sul da Costa Rica, Oceano Pacífico que engloba o Parque Nacional da Ilha do Coco na Costa Rica) com pico de ocorrência às 4h HL e outro às 14h HL. Possivelmente o aquecimento superficial durante o dia e as trocas de energia na forma de calor entre o oceano e a atmosfera explicam esta distribuição bimodal.

A maior atividade horária de tempestades elétricas $(0,8 \%)$, ocorreu entre $10^{\circ}-0^{\circ} \mathrm{Sul}$ e $70^{\circ}-50^{\circ}$ Oeste e $20^{\circ}-10^{\circ}$ Sul e $60^{\circ}-50^{\circ}$ Oeste, entre às $14 \mathrm{~h}$ e $16 \mathrm{~h}$ HL.

Apesar dos SCMs apresentarem um ciclo diurno com atividade noturna (VELASCO; 
FRITSCH, 1987; DURKEE; MOTE, 2009; MACHADO et al., 1998), entre 30-20 Sul e $60^{\circ}-50^{\circ}$ Oeste, as tempestades elétricas apresentaram um máximo por volta das $15 \mathrm{~h}$ HL.

No ciclo anual, a estação de tempestades elétricas na América do Sul se configura entre outubro e março e possui dois picos: outubro, período de transição entre a estação seca e chuvosa (primavera) e um segundo pico em março, período também de transição, mas entre a estação chuvosa e seca (outono).

Distribuições bimodais de atividade elétrica, março e outubro, estão restritas à parte Norte da AS entre $0^{\circ}-10^{\circ}$ Norte e $80^{\circ}-70^{\circ}$ Oeste e região Amazônica definidas entre $10^{\circ}$ Sul $-0^{\circ}$ e $80^{\circ}-50^{\circ}$ Oeste.

A parte Nordeste da AS, entre $0^{\circ}-10^{\circ}$ Norte e $70^{\circ}-50^{\circ}$ Oeste, é marcada por um máximo em agosto, verão do hemisfério Norte. No sul da AS, entre $40^{\circ}-20^{\circ}$ Sul e $70^{\circ}-60^{\circ}$ Oeste, região da Argentina e Bacia do Prata, foi encontrada a estação de tempestades elétricas mais curta (2 meses) e uma estação quase sem raios durante o inverno austral.

A região com a estação mais duradoura, 9 meses (março a novembro) e com o maior número de tempestades elétricas (14 232), foi sobre a Colômbia e parte Oeste da Venezuela que abrange até o lago Maracaibo.

Referente às distribuições de densidades geográficas, as maiores densidades de tempestades elétricas situam-se na parte Norte e Noroeste da AS, ou seja, na Colômbia associado ao extremo Norte da Cordilheira dos Andes e ao Norte/Noroeste da Floresta Amazônica respectivamente, com valores entre 3,5-4,7 $\times 10^{-4} \mathrm{~km}^{-2}$. Além disso observa-se uma vasta região com densidades superiores a $2,5 \times 10^{-4} \mathrm{~km}^{-2}$, que conta com regiões de topografia elevada como ao Noroeste do Lago Titicaca no Peru e algumas regiões do Planalto Brasileiro como sobre a Serra Catarinense e o Parque Nacional das Emas ao Sudoeste de Goias, além de grande parte da região Amazônica, Colômbia, Venezuela e Panamá.

Em termos de sazonabilidade temos que a primavera apresenta a maior atividade de tempestades elétricas (57 861) seguidas pelo verão (46 077), outono (36 804) e inverno (16 850).

Durante o verão a máxima atividade é encontrada ao Sul da Amazônia se estendendo pela parte central e Sudeste do Brasil, além da cordilheira dos Andes abrangendo o Peru e Bolívia. No Outono a maior atividade se concentra no litoral do Maranhão e Pará, Sudeste e Noroeste da Colômbia. No inverno a máxima atividade fica restrita na região costeira da Colômbia e Panamá. Finalmente na primavera observa-se o máximo se estendendo do Panamá, Colômbia, Venezuela, Sul da Venezuela, Noroeste e centro da Amazônia e 
Nordeste da Bolívia.

As maiores densidade de raios por ano por quilômetro quadrado sobre a AS são observadas: na Foz do Rio Catatumbo na Venezuela com 371,2 raios ano ${ }^{-1} \mathrm{~km}^{-2}$ e à Leste de Cochabamba na Bolívia com $\simeq 60$ raios ano ${ }^{-1} \mathrm{~km}^{-2}$. Regiões com densidades de raios entre 30-60 raios ano ${ }^{-1} \mathrm{~km}^{-2}$, correspondem ao Pico das Agulhas Negras na Serra da Mantiqueira entre Minas Gerais e o Rio de Janeiro, Pico da Neblina no Amazonas, parte central da Bacia do Prata, na cordilheira dos Andes do Peru, e extremo Norte da Cordilheira dos Andes sobre a Colômbia.

Em termos sazonais, os extremos de densidade de raios ficam restritos ao inverno e primavera. Sendo que na primavera temos as maiores densidades correspondentes aos máximos anuais, exceto Pico das Agulhas Negras e parte central da Bacia do Prata. Já no inverno basicamente sobre o extremo Norte da Cordilheira dos Andes na Colômbia e no lago Maracaibo na Venezuela. As regiões do Pico das Agulhas Negras apresenta alta atividade durante o verão e primavera, já a parte central da Bacia do Prata apresenta atividade elétrica no verão, outono e primavera.

Em termos de densidades de raios por tempestades elétricas, temos que a região do Lago Maracaibo, na Foz do Rio Catatumbo, como a mais eficiente da AS atingindo o valor máximo de $11,73 \times 10^{-2} \mathrm{ano}^{-1} \mathrm{~km}^{-2}$, mostrando que sobre a área deste ponto de grade $\left(\simeq 772 \mathrm{~km}^{2}\right)$ de máxima densidade de raios por tempestade elétricas, cada tempestade elétrica observada contribuiu em média com 91 raios ano ${ }^{-1}$. Sabendo com base no mapa de densidade geográfica anual de raios por quilômetro quadrado que ocorrem 114333 raios ano ${ }^{-1}$, então, 1256 tempestades elétricas do TRMM foram responsáveis por toda a produção de raios deste ponto de grade $\left(0,25^{\circ} \times 0,25^{\circ}\right)$.

\subsection{TEMPESTADES ELÉTRICAS SEVERAS}

As tempestades elétricas severas, ou, as mais intensas e raras, foram definidas a partir do limiar de $90 \%$ da distribuição de frequência dos índices FT e FTA, que tiveram pelo menos um perfil vertical do PR com chuva válida e $V T_{m}$ maior do que 60 segundos definindo um grupo de 9475 tempestades elétricas extremas de FTA com valores entre 29,3-1258 × $10^{-4}$ raios $\mathrm{min}^{-1} \mathrm{~km}^{-2}$, e mais 9475 tempestades elétricas extremas de FT com os valores entre 47,2-1283,6 raios $\mathrm{min}^{-1}$. Estes valores de FT são consistentes com os trabalhos de Cecil et al. (2005), que encontraram estes valores nos top 0,01\% das PFs (categorias 3, 4, 5 destes autores). 
As tempestades elétricas extremas de FTA têm $72 \%$ de fração convectiva e $32 \%$ de fração estratiforme, enquanto as tempestades elétricas extremas de FT $20 \%$ de fração convectiva e $75 \%$ de fração estratiforme. Estas características indicam que os extremos de FTA correspondem a sistemas novos ou em via de maturação, enquanto os sistemas extremos de FT correspondem a sistemas maduros ou em fase de decaimento (LEARY; HOUZE Jr., 1979).

O estudo da precipitação tridimensional por meio dos CFADs e CCFADs verifica que os perfis com raios possuem maiores valores de $Z_{c}$ e são mais profundos na atmosfera. Entre $5-7 \mathrm{~km}$ de altitude os valores de $Z_{c}$ para a precipitação com raios atingem valores entre 5 dBZ e 10 dBZ superiores do que para a precipitação sem raios, tanto para os extremos de FTA quanto FT. As regiões sem raios dos eventos extremos de FT são mais estratiformes do que para os extremos de FTA e apresentam forte assinatura da banda brilhante. Nos pixeis sem raios da precipitação dos extremos de FTA não há assinatura da banda brilhante nos sistemas sobre o continente, mas há banda brilhante sobre o oceano. Nas regiões com raios, as tempestades elétricas dos extremos de FTA possuem entre 1-3 dBZ a mais do que os valores de $Z_{c}$ dos extremos de FT, especialmente acima de $5 \mathrm{~km}$ de altitude. Do ponto de vista da intensidade convectiva, ambos FTA e FT, são mais vigorosos do equador (menos intensos) para os sub-trópicos (mais intensos).

Com a criação dos CFTDs e CCFTDs identifica-se que durante o desenvolvimento vertical, a intensidade convectiva pode ser mensurada avaliando a redução $(\simeq 7 \mathrm{dBZ})$ de $Z_{c}$ devido ao congelamento dos hidrometeoros acima da isoterma de $0{ }^{\circ} \mathrm{C}$. A condição de tempo severo, deve estar associada a um maior caminho de temperatura para o congelamento dos hidrometeoros. Com o aumento da intensidade da corrente ascendente há o aumento da concentração de gotas pequenas (BIGG, 1953), o que aumenta a concentração de água super-resfriada e a espessura da camada fria de nuvem e consequentemente expõe os hidrometeoros a um número maior de colisões, gerando maior concentração e diversidade de hidrometeoros $\overbrace{}^{12}$, envigorando os processos de eletrificação das nuvens.

A probabilidade de perfis de $Z_{c}$ por nível de temperatura (CFTD) apresenta percentis mais largos para os extremos de FTA do que nos extremos de FT. Esse efeito demonstra a maior diversidade de hidrometeoros no ambiente das tempestades elétricas extremas de FTA.

A convecção mais intensa sobre a AS consiste em um fenômeno atmosférico capaz

\footnotetext{
${ }^{12}$ Gotas de água super-resfriadas, cristais de gelo de diferente formas geométricas, agregados e flocos de neve, graupel e granizo com diferentes tamanhos e densidades
} 
de processar a energia potencial convectiva em uma área entre 50-400 km², quando há extremos de FTA, que ocorre nos estágios iniciais das tempestades elétricas. Tempestades elétricas com FT extremo, consistem em um fenômeno atmosférico com dimensões de $\simeq 50000 \mathrm{~km}^{2}$. As condições de tempo severo que são associadas com a intensidade da corrente ascendente devem ocorrer nas tempestades elétricas extremas de FT, porém quando há novas células convectivas $\left(50-400 \mathrm{~km}^{2}\right)$ com FTA extremo embebidas na extensão das tempestades elétricas maiores. Tempestades elétricas com FT extremo podem possuir grande número de raios, porém distantes entre si. Nestes casos, temos tempestades elétricas grandes em extensão, com centenas de raios por minutos, porém, com núcleos de raios com baixa eficiência espacial na produção de raios, que provavelmente não estão associadas com fortes correntes ascendentes, ou seja, com condições de tempo severo.

As tempestades elétricas associadas com condições de tempo severo devem estar contidas tanto no grupo dos valores extremos de FT quanto de FTA. A intersecção dos dois grupos de extremos indicará as regiões de máxima severidade.

Comparando as regiões da Bacia Amazônica $\left(10^{\circ}\right.$ Sul- $0^{\circ}$ e $70^{\circ}-60^{\circ}$ Oeste) e a Bacia do Prata $\left(30^{\circ}-20^{\circ} \mathrm{Sul}\right.$ e $60^{\circ}-50^{\circ}$ Oeste), observa-se que para o $95^{\circ}$ percentil do CCFTD, entre $0{ }^{\circ} \mathrm{C} \mathrm{e}-15{ }^{\circ} \mathrm{C}$, as tempestades elétricas extremas de FTA na região Amazônica decrescem $5 \mathrm{dBZ}$, enquanto que as tempestades elétricas extremas de FT decrescem $10 \mathrm{dBZ}$ e na Bacia do Prata os extremos de FTA decrescem também 5 dBZ, enquanto os extremos de FT decrescem 6 dBZ. A máxima taxa de decrescimento de $Z_{c}$ em função da temperatura $\left(50^{\circ}\right.$ percentil $)$ é de $\simeq-1 \mathrm{dBZ}{ }^{\circ} \mathrm{C}^{-1}$ para a região Amazônia e $\simeq-0,85 \mathrm{dBZ}{ }^{\circ} \mathrm{C}^{-1}$ para a região da Bacia do Prata.

As tempestades elétricas com FTA no 95ํㅜ percentil de ocorrência são encontradas sobre uma vasta região da $\mathrm{AS}$, com valores $\geq 52,76 \times 10^{-4}$ raios $\min ^{-1} \mathrm{~km}^{-2}$. Valores de FTA superiores a $84 \times 10^{-4}$ raios $\mathrm{min}^{-1} \mathrm{~km}^{-2}$ são encontrados ao Sul e Leste da Bacia Amazônica, parte central e Sudeste do Brasil, Sul do Peru, Bolívia, Paraguai, Oeste do Uruguai, Norte e centro da Argentina. No 99o percentil de FTA, os valores são $\geq 148,9310^{-4}$ raios $\min ^{-1} \mathrm{~km}^{-2}$ e estas tempestades elétricas ficam mais restritas às regiões de topografia elevada, principalmente entre o Pantanal Mato-grossense e o Planalto Central Brasileiro, entre as Bacias dos Rios Xingu, Araguaia e Tocantis, região do Planalto Meridional Brasileiro aonde está localizado os planaltos e chapadas da Bacia do Paraná e região Leste da Serra de Córdoba.

Os maiores valores do $95^{\circ}$ ( $\left(\geq 92,84\right.$ raios $\left.\min ^{-1}\right)$ e $99^{\circ}\left(\geq 272,28\right.$ raios min $\left.^{-1}\right)$ percentil do índice FT ficam situados na região Sul da América do Sul. 


\subsection{IMPLICAÇÕES PARA A ELETRIFICAÇÃO DAS NUVENS}

A altura em que a água super-resfriada se congela define a espessura da camada em que ocorre o processo de acreção na nuvem. Conforme a camada de acreção se estende em um caminho maior de temperatura, a eficiência de carregamento positivo e negativo do graupel e o granizo também aumentam devido a uma maior diversidade de processos de eletrificação: colisões entre gotas congeladas e super-resfriadas com graupel, cristais de gelo com graupel, cristal de gelo com cristais de gelo, agregados com cristais de gelo, etc.

Os resultados adquiridos pelos CFTDs mostram que o decréscimo de $Z_{c}$ com a diminuição da temperatura é mais pronunciado próximo do equador (Amazônia) do que no Sul da AS (Argentina), mostrando que apesar dos CFADs da porção tropical da AS possuírem níveis de contornos em altitude entre $1-2 \mathrm{~km}$ mais elevadas do que na região subtropical13, o caminho de temperatura que os hidrometeoros percorrem até congelarem é maior no sub-trópico sul-americano, causando aumento da probabilidade de carregamento, o que corrobora com resultados anteriores de Zipser et al. (2006), Rasmussen e Houze Jr. (2011), Cecil et al. (2005), que descrevem que as tempestades mais severas da América do Sul foram encontradas sobre o Planalto Argentino e Bacia do Prata.

Com o estudo da morfologia da precipitação 3D convertendo a dimensão de altitude $(\mathrm{km})$ para uma dimensão termodinâmica (temperatura), futuramente, poderão ser estimados os conteúdos de água líquida super-resfriada (SEKHON; SRIVASTAVA, 1971; HAGEN; YUTER, 2003) para determinados níveis de temperatura ao longo da camada de acreção, de modo a estimar a polaridade dos centros de cargas dominantes nas nuvens de tempestades elétricas a partir dos resultados de pesquisas de laboratório que mostraram que a polaridade do carregamento depende do conteúdo de água líquida e da temperatura (TAKAHASHI, 1978; SAUNDERS et al., 1999; SAUNDERS, 2008).

\footnotetext{
${ }^{13}$ Esse efeito deve ao fato da tropopausa ser mais alta na região tropical do que nos sub-trópicos.
} 


\section{REFERÊNCIAS}

ALBRECHT, R.; GOODMAN, S.; PETERSEN, W.; BUECHLER, D.; BRUNING, E.; BLAKESLEE, R.; CHRISTIAN, H. The 13 years of TRMM lightning imaging sensor: from individual flash characteristics to decadal tendencies. In: Proceedings of the XIV International Conference on Atmospheric Electricity. [S.l.: s.n.], 2011. p. $08-12$.

ALBRECHT, R. I. Comunicação Pessoal. São Paulo: [s.n.], 2010.

ALBRECHT, R. I.; MORALES, C. A.; DIAS, M. A. S. Electrification of precipitating systems over the amazon: Physical processes of thunderstorm development. Journal of Geophysical Research: Atmospheres (1984-2012), Wiley Online Library, v. 116, n. D8, 2011.

ALCÂNTARA, C. R. Um estudo da Relação entre o Jato de Baixos Níveis e as linhas de instabilidade na amazônia. Tese (Doutorado) - Universidade de São Paulo (USP). Instituto de Astronomia, Geofísica e Ciências Atmosféricas, 2010.

AUSTIN, P. M.; BEMIS, A. C. A quantitative study of the "bright band" in radar precipitation echoes. Journal of Meteorology, v. 7, n. 2, p. 145-151, 1950.

AWAKA, J.; IGUCHI, T.; KUMAGAI, H.; OKAMOTO, K. Rain type classification algorithm for TRMM precipitation radar. In: IEEE. Geoscience and Remote Sensing, 1997. IGARSS'97. Remote Sensing-A Scientific Vision for Sustainable Development., 1997 IEEE International. [S.l.], 1997. v. 4, p. 1633-1635.

BAKER, B.; BAKER, M. B.; JAYARATNE, E. R.; LATHAM, J.; SAUNDERS, C. P. R. The influence of diffusional growth rates on the charge transfer accompanying rebounding collisions between ice crystals and soft hailstones. Quarterly Journal of the Royal Meteorological Society, John Wiley \& Sons, Ltd, v. 113, n. 478, p. 1193-1215, 1987. ISSN 1477-870X.

BAKER, M.; DASH, J. Mechanism of charge transfer between colliding ice particles in thunderstorms. Journal of Geophysical Research: Atmospheres (1984-2012), Wiley Online Library, v. 99, n. D5, p. 10621-10626, 1994.

BATTAN, L. J. Radar observation of the atmosphere. [S.l.: s.n.], 1973.

BBC. Temporada de chuva põe em teste sistemas de prevenção no Brasil. 2011. Disponível em: <http://www.inpe.br/noticias/namidia/img/clip14122011_03.pdf $>$. Acesso em: 24 fev. 2015.

BIGG, E. The formation of atmospheric ice crystals by the freezing of droplets. Quarterly Journal of the Royal Meteorological Society, Wiley Online Library, v. 79 , n. 342 , p. $510-519,1953$. 
BOCCIPPIO, D. J.; KOSHAK, W. J.; BLAKESLEE, R. J. Performance assessment of the optical transient detector and lightning imaging sensor. part i: Predicted diurnal variability. Journal of Atmospheric and Oceanic Technology, v. 19, n. 9, p. 1318-1332, 2002.

BOCCIPPIO, D. J.; KOSHAK, W. J.; GOODMAN, S. J.; MACH, D. M. Science data validation plan for the lightning imaging sensor (lis). 1996.

BOMBARDI, R. J. Variabilidade do regime de monções da América do Sul: o clima presente e projeções para o século XXI. Dissertação (Mestrado) Universidade de São Paulo (USP). Instituto de Astronomia, Geofísica e Ciências Atmosféricas, 2008.

BROOKS, C. E. P. The distribution of thunderstorms over the globe. [S.l.]: Geophys. Memo. 3, 1925.

BROOKS, H. E.; LEE, J. W.; CRAVEN, J. P. The spatial distribution of severe thunderstorm and tornado environments from global reanalysis data. Atmospheric Research, Elsevier, v. 67, p. 73-94, 2003.

BÜRGESSER, R. E.; NICORA, M. G.; AVILA, E. E. Characterization of the lightning activity of "relámpago del catatumbo". Journal Of Atmospheric And Solar-Terrestrial Physics, Elsevier, v. 77, p. 241-247, 2012.

CAREY, L. D.; RUTLEDGE, S. A. Electrical and multiparameter radar observations of a severe hailstorm. Journal of Geophysical Research: Atmospheres (1984-2012), Wiley Online Library, v. 103, n. D12, p. 13979-14000, 1998.

CARVALHO, L. M.; JONES, C.; LIEBMANN, B. The south atlantic convergence zone: Intensity, form, persistence, and relationships with intraseasonal to interannual activity and extreme rainfall. Journal of Climate, v. 17, n. 1, p. 88-108, 2004.

CECIL, D.; GOODMAN, S.; BOCCIPPIO, D.; ZIPSER, E.; NESBITT, S. Three years of TRMM precipitation features. part i: Radar, radiometric, and lightning characteristics. Mon. Wea. Rev., v. 133, p. 543-566, 2005.

CECIL, D. J.; BUECHLER, D. E.; BLAKESLEE, R. J. Gridded lightning climatology from TRMM-LIS and OTD: Dataset description. Atmospheric Research, Elsevier, v. 135 , p. 404-414, 2014.

CHRISTIAN, H.; BLAKESLEE, R.; GOODMAN, S.; MACH, D. Algorithm theoretical basis document (ATBD) for the lightning imaging sensor (LIS). NASA TM, 2000.

CHRISTIAN, H. J.; BLAKESLEE, R. J.; BOCCIPPIO, D. J.; BOECK, W. L.; BUECHLER, D. E.; DRISCOLL, K. T.; GOODMAN, S. J.; HALL, J. M.; KOSHAK, W. J.; MACH, D. M. et al. Global frequency and distribution of lightning as observed from space by the optical transient detector. Journal of Geophysical Research: Atmospheres (1984-2012), Wiley Online Library, v. 108, n. D1, p. ACL-4, 2003.

CHRISTIAN, H. J.; RICHARD, J. B.; J., G. S. Lightning Imaging Sensor (LIS) for the Earth Observing System. Alabama, 1992. 193 p. NASA Technical Memorandum TM-4350. 
COHEN, J. C.; DIAS, M. A. S.; NOBRE, C. A. Environmental conditions associated with amazonian squall lines: A case study. Monthly Weather Review, v. 123, n. 11, p. 3163-3174, 1995.

CUSTÓDIO, M. d. S. Impacto da resolução dos modelos globais na América do Sul: climatologia, variabilidade e ciclo diurno. Tese (Doutorado) - Universidade de São Paulo (USP). Instituto de Astronomia, Geofísica e Ciências Atmosféricas, 2013.

DOLEZALEK, H. Discussion of the fundamental problem of atmospheric electricity. pure and applied geophysics, Springer, v. 100, n. 1, p. 8-43, 1972.

DOSWELL, C. A. Severe convective storms. [S.l.]: American Meteorological Society, 2001. Meteorological Monograph.

DURKEE, J. D.; MOTE, T. L. A climatology of warm-season mesoscale convective complexes in subtropical South America. International Journal of Climatology, Wiley Online Library, v. 30, n. 3, p. 418-431, 2009. ISSN 08998418.

FABRY, F.; ZAWADZKI, I. Long-Term Radar Observations of the Melting Layer of Precipitation and Their Interpretation. Journal of the Atmospheric Sciences, v. 52, n. 7, p. 838-851, 1995. ISSN 0022-4928.

FARADAY, M. Note on regelation. Proceedings of the Royal Society of London, The Royal Society, v. 10, p. 440-450, 1859.

FLETCHER, N. H. Surface structure of water and ice - ii. a revised model. Philosophical Magazine, v. 83, p. 1631-1643, 1968.

FOLHA. Raio causou apagão que atingiu 12 estados no sábado. 2012. Disponível em: <http://www1.folha.uol.com.br/mercado/2012/12/1202583-raio-causou-apagaoque-atingiu-12-estados-no-sabado.shtml>. Acesso em: 19 fev. 2015.

FOLHA. Ministro diz que apenas raios podem causar apagao no carnaval. 2015. Disponível em: <http://www1.folha.uol.com.br/mercado/2015/02/1589012-ministrodiz-que-apenas-raios-podem-causar-apagao-no-carnaval.shtml>. Acesso em: 19 fev. 2015.

G1. Brasil registra 181 apagões desde 2011, mostra levantamento. 2014a. Disponível em: <http://g1.globo.com/economia/noticia/2014/02/brasil-registra-181apagoes-desde-2011-diz-levantamento.html>, Acesso em: 19 fev. 2015.

G1. Tempestade no Tocantins pode ter causado apagão no país. 2014b. Disponível em: <http://g1.globo.com/to/tocantins/noticia/2014/02/tempestade-notocantins-pode-ter-causado-apagao-no-pais.html>. Acesso em: 19 fev. 2015.

GATLIN, P. N.; GOODMAN, S. J. A total lightning trending algorithm to identify severe thunderstorms. Journal of atmospheric and oceanic technology, v. 27, n. 1, p. 3-22, 2010 .

GOODMAN, S. J.; BUECHLER, D. E.; WRIGHT, P. D.; RUST, W. D. Lightning and precipitation history of a microburst-producing storm. Geophysical research letters, Wiley Online Library, v. 15, n. 11, p. 1185-1188, 1988. 
GRENET, G. Essai d'explication de la charge électrique des nuages d'orages. Ann. Geophys. 3, França, p. 306-307, 1947. Em inglês veja, Atmos. Res. 30 (1993), pp. 176-179.

GRIMM, A. M. The el niño impact on the summer monsoon in brazil: regional processes versus remote influences. Journal of Climate, v. 16, n. 2, p. 263-280, 2003.

HAGEN, M.; YUTER, S. E. Relations between radar reflectivity, liquid-water content, and rainfall rate during the map sop. Quarterly Journal of the Royal Meteorological Society, Wiley Online Library, v. 129, n. 588, p. 477-493, 2003.

HOUZE Jr., R. A. Cloud dynamics, 573 pp. Academic, San Diego, Calif, 1993.

IGUCHI, T.; KOZU, T.; MENEGHINI, R.; AWAKA, J.; OKAMOTO, K. Rain-profiling algorithm for the TRMM precipitation radar. Journal of Applied Meteorology, v. 39, n. 12, p. 2038-2052, 2000.

IGUCHI, T.; MENEGHINI, R. Intercomparison of single-frequency methods for retrieving a vertical rain profile from airborne or spaceborne radar data. Journal of Atmospheric and Oceanic Technology, v. 11, n. 6, p. 1507-1516, 1994.

INPE. A Maior catástrofe climática do Brasil sob a visão opracional do CPTEC/INPE. 2011. Disponível em: <http://plutao.sid.inpe.br/col/dpi.inpe.br/plutao/2011/11.23.16.17/doc/Pinheiro_A\%20maior.pdf $>$. Acesso em: 24 fev. 2015.

INPE, I. INPE avalia prejuízos causados por raios. 2007. Disponível em: $<$ http://www.inpe.br/noticias/noticia.php?Cod_Noticia=936>. Acesso em: 25 nov. 2014.

JAYARATNE, E.; SAUNDERS, C.; HALLETT, J. Laboratory studies of the charging of soft-hail during ice crystal interactions. Quarterly Journal of the Royal Meteorological Society, Wiley Online Library, v. 109, n. 461, p. 609-630, 1983.

JONAS, P.; MASON, B. Systematic charging of water droplets produced by break-up of liquid jets and filaments. Transactions of the Faraday Society, Royal Society of Chemistry, v. 64, p. 1971-1982, 1968.

JONES, C.; CARVALHO, L. M. V. Active and break phases in the South American monsoon system. Journal of Climate, v. 15, n. 8, p. 905-914, 2002.

KALNAY, E.; KANAMITSU, M.; KISTLER, R.; COLLINS, W.; DEAVEN, D.; GANDIN, L.; IREDELL, M.; SAHA, S.; WHITE, G.; WOOLLEN, J. et al. The ncep/ncar 40-year reanalysis project. Bulletin of the American meteorological Society, v. 77, n. 3, p. 437-471, 1996.

KANAMITSU, M.; EBISUZAKI, W.; WOOLLEN, J.; YANG, S.; HNILO, J.; FIORINO, M.; POTTER, G. L. Ncep-doe amip-ii reanalysis (r-2). Bull. Amer. Meteor. Soc., v. 83, p. 1631-1643, 2002. Doi:10.1175/BAMS-83-11-1631.

KOUSKY, V. E. Diurnal rainfall variation in northeast brazil. Monthly Weather Review, v. 108, n. 4, p. 488-498, 1980. 
KUMMEROW, C.; BARNES, W.; KOZU, T.; SHIUE, J.; SIMPSON, J. The tropical rainfall measuring mission (TRMM) sensor package. J. Atmos. Oceanic Technol., v. 15, p. $809-817,1998$.

LATHAM, J.; MASON, B. Electric charge transfer associated with temperature gradients in ice. Proceedings of the Royal Society of London. Series A. Mathematical and Physical Sciences, The Royal Society, v. 260, n. 1303, p. 523-536, 1961.

LAURENT, H.; MACHADO, L. A.; MORALES, C. A.; DURIEUX, L. Characteristics of the amazonian mesoscale convective systems observed from satellite and radar during the wetamc/lba experiment. Journal of Geophysical Research: Atmospheres (1984-2012), Wiley Online Library, v. 107, n. D20, p. LBA-21, 2002.

LEARY, C. A.; HOUZE Jr., R. A. The structure and evolution of convection in a tropical cloud cluster. Journal of the Atmospheric Sciences, v. 36, n. 3, p. 437-457, 1979.

LENARD, P. Über die elektrizität der wasserlälle. Annln Phys, v. 46, 1892.

MACGORMAN, D. R.; BURGESS, D. W.; MAZUR, V.; RUST, W. D.; TAYLOR, W. L.; JOHNSON, B. C. Lightning rates relative to tornadic storm evolution on 22 may 1981. Journal of the atmospheric sciences, v. 46, n. 2, p. 221-251, 1989.

MACGORMAN, D. R.; RUST, W. D. The electrical nature of storms. [S.l.]: Oxford University Press, 1998.

MACHADO, L.; ROSSOW, W.; GUEDES, R.; WALKER, A. Life cycle variations of mesoscale convective systems over the americas. Monthly Weather Review, v. 126, n. 6 , p. 1630-1654, 1998.

MADDOX, R. A. Mesoescale convective complexes. Bulletin American Meteorological Society, 1980.

MAPES, B. E.; HOUZE Jr., R. A. Cloud clusters and superclusters over the oceanic warm pool. Monthly Weather Review, v. 121, n. 5, p. 1398-1416, 1993.

MAREnGO, J. A.; LIEBMAnN, B.; GRIMM, A. M.; MISRA, V.; Silva Dias, P. L.; CAVAlCANTI, I. F. A.; CARVAlHO, L. M. V.; BERBERY, E. H.; AMBRIZZI, T.; VERA, C. S.; SAUlO, A. C.; NOGUES-PAEGLE, J.; ZIPSER, E.; SETH, A.; ALVES, L. M. Recent developments on the South American monsoon system. International Journal of Climatology, v. 32, n. 1, p. 1-21, 2012.

MARENGO, J. A.; SOARES, W. R.; SAULO, C.; NICOLINI, M. Climatology of the low-level jet east of the andes as derived from the ncep-ncar reanalyses: Characteristics and temporal variability. Journal of climate, v. 17, n. 12, p. 2261-2280, 2004.

MASON, B. A critical examination of theories of charge generation in thunderstorms. Tellus, Wiley Online Library, v. 5, n. 4, p. 446-460, 1953.

MASON, B. J. The Physics of Clouds. Londres: Oxford University Press, 1971. 671 p. Second edition. 
MATTHEWS, J.; MASON, B. Electrification produced by the rupture of large water drops in an electric field. Quarterly Journal of the Royal Meteorological Society, Wiley Online Library, v. 90, n. 385, p. 275-286, 1964.

MENEGHINI, R.; IGUCHI, T.; KOZU, T.; LIAO, L.; OKAMOTO, K.; JONES, J. A.; KWIATKOWSKI, J. Use of the surface reference technique for path attenuation estimates from the TRMM precipitation radar. Journal of Applied Meteorology, v. 39, n. 12 , p. 2053-2070, 2000.

MOHR, K. I.; ZIPSER, E. J. Mesoscale convective systems defined by their 85-ghz ice scattering signature: Size and intensity comparison over tropical oceans and continents. Monthly weather review, v. 124, n. 11, p. 2417-2437, 1996.

MORAleS, C. A. Comunicação Pessoal. São Paulo: [s.n.], 2010.

MORALES, C. A.; ANAGNOSTOU, E. N. Extending the capabilities of high-frequency rainfall estimation from geostationary-based satellite infrared via a network of long-range lightning observations. J. Hydrometeorology, v. 4, p. 141-159, 2003.

NASDA. TRMM Data Users Handbook. National Space Development Agency of Japan: [s.n.], 2001.

NATIONAL AERONAUTICS AND SPACE ADMINISTRATION. Goodbye to TRMM, First Rain Radar in Space. 2014. Disponível em: <http://pmm.nasa.gov/node/1229>. Acesso em: 27 jan. 2015.

NATIONAL AERONAUTICS AND SPACE ADMINISTRATION. TRMM Comes to an End after 17 Years. 2015. Disponível em: <http://pmm.nasa.gov/trmm/missionend $>$. Acesso em: 05 maio 2015.

NEALE, R.; SLINGO, J. The maritime continent and its role in the global climate: A gcm study. Journal of Climate, v. 16, n. 5, p. 834-848, 2003.

NESBITT, S. W.; ZIPSER, E. J. The diurnal cycle of rainfall and convective intensity according to three years of TRMM measurements. Journal of Climate, v. 16, n. 10, p. $1456-1475,2003$.

NESBITT, S. W.; ZIPSER, E. J.; CECIL, D. J. A Census of Precipitation Features in the Tropics Using TRMM: Radar, Ice Scattering, and Lightning Observations. Journal of Climate, v. 13, n. 23, p. 4087-4106, 2000. ISSN 08948755.

OGAWA, T. Handbook of atmospheric electrodynamics. In: VOLLAND, H. (Ed.). Ligthning Currents. [S.l.]: CRC Press, 1995. v. 1.

ORVILLE, R. E.; SPENCER, D. W. Global lightning flash frequency. Monthly Weather Review, v. 107, n. 7, p. 934-943, 1979.

PEREYRA, R. G.; AVIlA, E. E.; CASTellanO, N. E.; SAUNDERS, C. P. A laboratory study of graupel charging. Journal of Geophysical Research: Atmospheres (1984-2012), Wiley Online Library, v. 105, n. D16, p. 20803-20812, 2000 . 
PETERSEN, W. A.; NESBITT, S. W.; BLAKESLEE, R. J.; CIFELli, R.; HEIN, P.; RUTLEDGE, S. A. TRMM observations of intraseasonal variability in convective regimes over the amazon. Journal of Climate, v. 15, n. 11, p. 1278-1294, 2002.

PETERSEN, W. A.; RUTLEDGE, S. A. On the relationship between cloud-to-ground lightning and convective rainfall. Journal of Geophysical Research, v. 103, n. D12, p. 14025-14040, 1998.

PETERSEN, W. A.; RUTLEDGE, S. A. Regional variability in tropical convection: Observations from TRMM. Journal of Climate, v. 14, n. 17, p. 3566-3586, 2001.

PHILLIPS, B. Convected charge in thunderstorms. Monthly Weather Review, Citeseer, v. 95, n. 12, p. 863-870, 1967.

PINTO Jr., O. A arte da guerra contra os raios. [S.l.]: Oficina de Textos, 2005.

PROCON-SP. Ranking de Atendimentos - PROCON - Total de Atendimentos em 2014 ESTADUAL. 2014. Disponível em: <http://sistemas.procon.sp.gov.br$/$ rank_estadual/?m=rank_atend $>$. Acesso em: 19 fev. 2015.

RAMAGE, C. S. Role of a tropical "maritime continent" in the atmospheric circulation 1. Monthly Weather Review, v. 96, n. 6, p. 365-370, 1968.

RASMUSSEN, K. L.; HOUZE Jr., R. A. Orogenic convection in subtropical south america as seen by the TRMM satellite. Monthly Weather Review, v. 139, n. 8, p. 2399-2420, 2011. ISSN 00270644.

REBOITA, M.; GAN, M.; ROCHA, R. d.; AMBRIZZI, T. Regimes de precipitação na américa do sul: uma revisão bibliográfica. Revista Brasileira de Meteorologia, v. 25, n. 2, p. 185-204, 2010.

REYNOLDS, S.; BROOK, M.; GOURLEY, M. F. Thunderstorm charge separation. Journal of Meteorology, v. 14, n. 5, p. 426-436, 1957.

ROMATSCHKE, U.; HOUZE, R. A. Extreme Summer Convection in South America. Journal of Climate, AMER METEOROLOGICAL SOC, v. 23, n. 14, p. 3761-3791, 2010. ISSN 08948755.

RUST, W. D.; MARSHALL, T. C. On abandoning the thunderstorm tripole-charge paradigm. Journal of Geophysical Research: Atmospheres (1984-2012), Wiley Online Library, v. 101, n. D18, p. 23499-23504, 1996.

SAUNDERS, C. Charge separation mechanisms in clouds. Space Science Reviews, v. 137, p. 335-353, jun. 2008.

SAUNDERS, C.; AVIlA, E.; PECK, S.; CASTEllanO, N.; VARELA, G. A. A laboratory study of the effects of rime ice accretion and heating on charge transfer during ice crystal/graupel collisions. Atmospheric Research, v. 51, p. 99-117, mar. 1999.

SCHULTZ, C. J.; PETERSEN, W. A.; CAREY, L. D. Lightning and severe weather: A comparison between total and cloud-to-ground lightning trends. Weather and forecasting, v. 26, n. 5, p. 744-755, 2011. 
SEKHON, R. S.; SRIVASTAVA, R. Doppler radar observations of drop-size distributions in a thunderstorm. Journal of the Atmospheric Sciences, v. 28, n. 6, p. 983-994, 1971.

SHI, W.; HIGGINS, R. W.; YAROSH, E.; KOUSKY, V. E. The Annual Cycle and Variability of Precipitation in Brazil. 2009. Disponível em: <http://www.cpc.noaa.gov/products/outreach/research_papers/ncep_cpc_atlas/9>. Acesso em: 17 set. 2010.

SIMPSON, G. C. On the electricity of rain and its origin in thunderstorms.

Philosophical Transactions of the Royal Society of London. Series A, Containing Papers of a Mathematical or Physical Character, JSTOR, p. 379-413, 1909.

SIMPSON, J.; ADLER, R.; NORTH, G. A proposed tropical rainfall measuring mission (TRMM) satellite. J. Atmos. Oceanic Technol., v. 69, p. 278-295, 1988.

SOUlA, S.; CHAUZY, S.; CHONG, M.; COQUILLAT, S.; GEORGIS, J.; SEITY, Y.; TABARY, P. Surface precipitation electric current produced by convective rains during the mesoscale alpine program. Journal of Geophysical Research: Atmospheres (1984-2012), Wiley Online Library, v. 108, n. D13, 2003.

SPARROW, J. V. J.; NEY, E. Satellite observations of lightning. Science, v. 169, p. 860-862, 1970.

STOLZENBURG, M.; RUST, W. D.; MARSHALL, T. C. Electrical structure in thunderstorm convective regions. 3 . synthesis. Journal of Geographysical Research, v. 103, n. D12, p. 14097-14108, 1998. DOI: 10.1029/97JD03545.

TAKAHASHI, T. Rimming electrification as a charging generation mechanism in thunderstorms. J. Atmos. Sci., v. 35, p. 1536-1548, 1978.

TAKAHASHI, T.; MIYAWAKI, K. NOTES AND CORRESPONDENCE Reexamination of Riming Electrification in a Wind Tunnel. n. 1980, p. 1018-1025, 2002.

TURMAN, B. Analysis of lightning data from the dmsp satellite. Journal of Geophysical Research: Oceans (1978-2012), Wiley Online Library, v. 83, n. C10, p. 5019-5024, 1978.

VELASCO, I.; FRITSCH, J. M. Mesoscale convective complexes in the Americas. Journal of Geophysical Research, v. 92, n. D8, p. 9591, 1987. ISSN 0148-0227.

VILA, D. A.; MACHADO, L. A. T.; LAURENT, H.; VELASCO, I. Forecast and tracking the evolution of cloud clusters (fortracc) using satellite infrared imagery: Methodology and validation. Weather and Forecasting, v. 23, n. 2, p. 233-245, 2008.

VONNEGUT, B. How the external currents flowing to a thundercloud influence its electrification. In: COPERNICUS. Annales geophysicae. [S.l.], 1991. v. 9, n. 1, p. $34-36$.

VONNEGUT, B.; LATHAM, D. J.; MORE, C. B.; HUNYADY, S. J. An explanation for anomalous lightning from forest fire clouds. Journal of Geographysical Research, n. 100 , p. 5.037-5.050, mar. 1995. 
VONNEGUT, B.; MOORE, C.; SEMONIN, R.; BULlOCK, J.; STAGGS, D.; BRADLEY, W. Effect of atmospheric space charge on initial electrification of cumulus clouds. Journal of Geophysical Research, Wiley Online Library, v. 67, n. 10, p. 3909-3922, 1962.

VORPAHL, J. The frequency and intensity of lightning within 30 of the equator. Dissertação (Mestrado) — Masters thesis, University of Minnesota, 1967.

WAGNER, P.; TELFORD, J. Cloud dynamics and an electric charge separation mechanism in convective clouds. J. Rech. Atmos, v. 15, p. 97-120, 1981.

WHIPPLE, F. J. W. On the association of the diurnal variation of electric potential gradient in fine weather with the distribution of thunderstorms over the globe.

Quarterly Journal of the Royal Meteorological Society, Wiley Online Library, v. 55, n. 229, p. 1-18, 1929.

WIKIPEDIA. Enchentes e deslizamentos de terra no Rio de Janeiro em 2011. 2011. Disponível em: <http://pt.wikipedia.org/wiki/Enchentes_e_deslizamentos_de_terra_no_Rio_de_Janeiro_em_2011>. Acesso em: 24 fev. 2015.

WILliAMS, E.; BOLDI, B.; MATLIN, A.; WEBER, M.; HODANISH, S.; SHARP, D.; GOODMAN, S.; RAGHAVAN, R.; BUECHLER, D. The behavior of total lightning activity in severe florida thunderstorms. Atmospheric Research, Elsevier, v. 51, n. 3, p. 245-265, 1999.

WILLIAMS, E.; SÁTORI, G. Lightning, thermodynamic and hydrological comparison of the two tropical continental chimneys. Journal of atmospheric and solar-terrestrial physics, Elsevier, v. 66, n. 13, p. 1213-1231, 2004.

WILLIAMS, E. R. The tripole structure of thunderstorms. Journal of Geographysical Research, n. 94, p. 13.151-13.167, sep. 1989.

WILSON, C. A theory of thundercloud electricity. Proceedings of the Royal Society of London. Series A. Mathematical and Physical Sciences, The Royal Society, v. 236, n. 1206, p. 297-317, 1956.

YUTER, S. E.; HOUZE Jr., R. A. Three-dimensional kinematic and microphysical evolution of florida cumulonimbus. part ii: Frequency distribution of vertical velocity, reflectivity, and differential reflectivity. J. Appl. Meteor., v. 123, p. 1941-1963, 1995.

ZIPSER, E.; CECIL, D.; LIU, C.; NESBITT, S.; YORTY, D. Where are the most intense thunderstorms on earth? Bull. Amer. Meteor. Soc., v. 87, p. 1057-1071, 2006.

Ávila, E. E.; CASTEllanO, N. E.; SAUnderS, C. P. R.; BüRGESSER, R. E.; VARELA, G. G. A. Initial stages of the riming process on ice crystals. Geophysical Research Letters, v. 36, n. 9, p. n/a-n/a, 2009. ISSN 1944-8007. 


\section{ÍNDICE REMISSIVO}

Ciclo

anual, 56

diurno, 53

Diagrama de Contorno

de Frequência Cumulativa por Altitude - CCFAD, 50

de Frequência Cumulativa por Temperatura - CCFTD, 52

de Frequência por Altitude - CFAD, 50

de Frequência por Temperatura CFTD, 51

Distribuição geográfica de densidade de raios, 48

de raios por tempestades, 49

de tempestades, 49

Eletrificação das nuvens, 28
Estação das tempestades elétricas, 57

FT, 44

FTA, 44

O Satélite TRMM, 36

Processo de eletrificação indutivo, 30

não-indutivo, 31

Reanálises (r2) do NCEP-DOE, 40

Severidade regionalizada, 101

Tempestades elétricas, 41

Tempestades elétricas severas, 71

Teoria de

Eletrificação por Convecção, 28

Eletrificação por Precipitação, 30 